Nutritional interventions

to preserve skeletal muscle mass

Evelien Backx

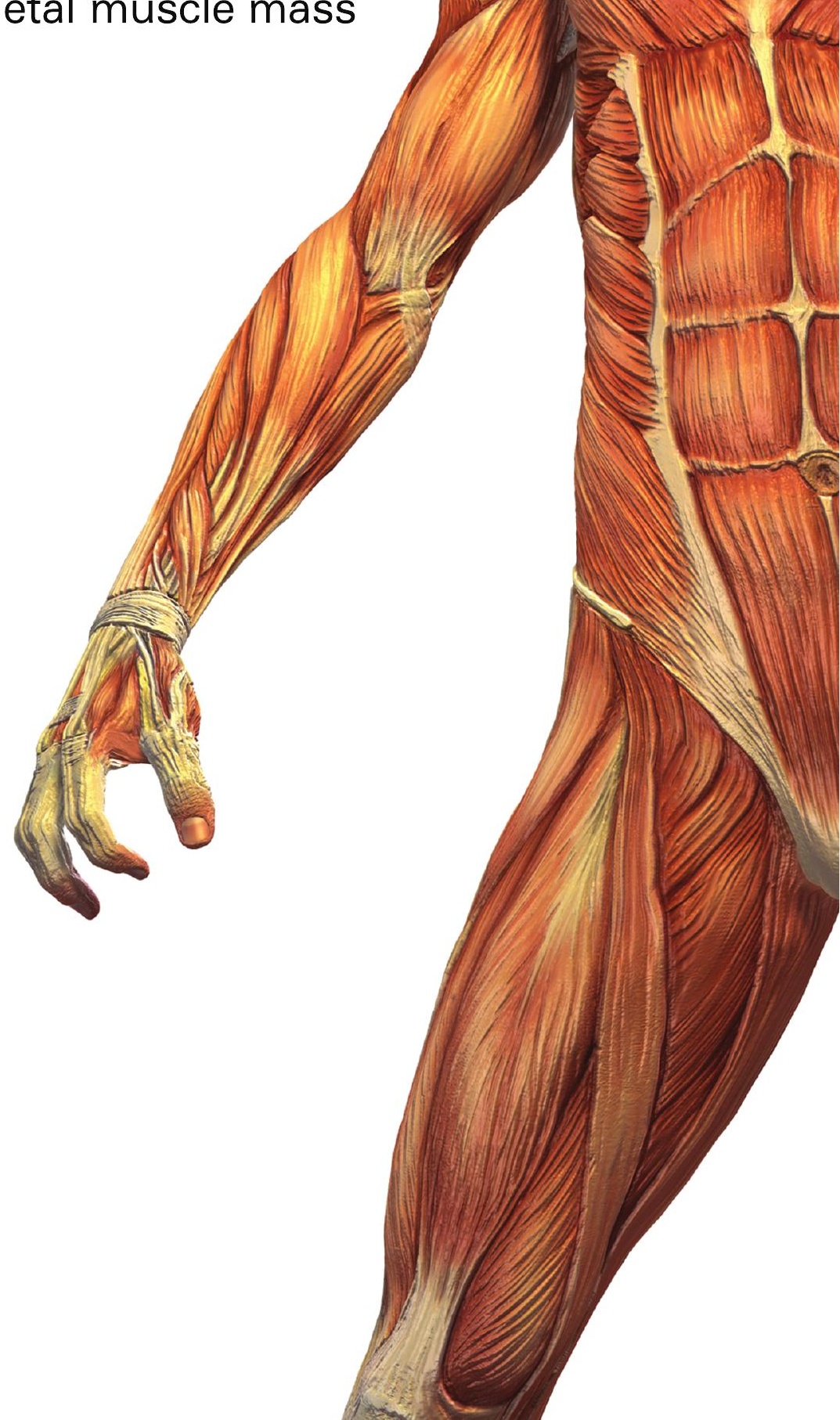


Nutritional interventions to preserve skeletal muscle mass 


\title{
Nutritional interventions to preserve skeletal muscle mass
}

\author{
Evelien M.P. Backx
}

\section{Thesis committee}

Promotors

Prof. Dr C.P.G.M. de Groot

Personal chair at the division of Human Nutrition

Wageningen University

Prof. Dr L.J.C. van Loon

Thesis

Professor of Physiology of Exercise

Maastricht University

Other members

Prof. Dr R.F. Witkamp, Wageningen University

Dr J.M. Steijns, FrieslandCampina, Wageningen

Prof. Dr W.H. Saris, Maastricht University

Dr N.M. de Roos, Wageningen University

This research was conducted under the auspices of the Graduate School VLAG (Advanced

studies in Food Technology, Agrobiotechnology, Nutrition and Health Sciences).

\author{
submitted in fulfilment of the requirements for the degree of doctor \\ at Wageningen University \\ by the authority of the Rector Magnificus \\ Prof. Dr A.P.J. Mol, \\ in the presence of the \\ Thesis Committee appointed by the Academic Board \\ to be defended in public \\ on Tuesday 6 December 2016 \\ at 4 p.m. in the Aula.
}




\section{Table of contents}

Chapter 1 General introduction

Chapter 2 Seasonal variation in vitamin D status in elite athletes: a longitudinal study

Chapter 3 The impact of 1-year vitamin D supplementation on vitamin $\mathrm{D}$ status in athletes: a dose-response study

Chapter $4 \quad$ Creatine loading does not preserve muscle mass or strength during leg immobilization in healthy, young males

Chapter 5

Leucine supplementation does not attenuate skeleta muscle loss during leg immobilization

Chapter 6 Nandrolone decanoate administration does not attenuate muscle atrophy during a short period of disuse

Chapter 7 Protein intake and lean body mass preservation during energy intake restriction in overweight older adults

Chapter $8 \quad$ General discussion

English summary

Nederlandse samenvatting

Dankwoord | Acknowledgements

List of publications

160 pages.

Overview of completed training activities 
Chapter 1

General introduction 


\section{Functions of muscle mass}

The main function of skeletal muscle is to maintain posture and allow movement of the human body. In accordance, muscle mass is a strong predictor for muscle strength, physical function and athletic performance. The muscle is a highly adaptive tissue that responds rapidly to anabolic stimuli, such as food intake and physical activity. Conversely, conditions of fasting and immobilization may cause rapid muscle loss. The loss of muscle mass results in a loss of muscle strength, physical function and performance. During the lifespan, muscle mass decreases progressively, which may lead to frailty and an increased risk of developing metabolic diseases later in life (1-3). Therefore, it is important to prevent or attenuate such loss of muscle mass. Acknowledging the capacity of skeletal muscle tissue to respond to anabolic stimuli, the two main strategies to preserve muscle mass are dietary protein intake and physical activity (4). In situations such as injury or illness, implementation of a physical activity intervention is not always possible. Therefore, there is a need for nutritional intervention strategies to attenuate the loss of muscle mass and strength. In this thesis, the effects of different nutritional intervention strategies to attenuate the loss of muscle mass are being evaluated in various settings and populations.

\section{Consequences of muscle loss}

Athletes

Along with its well-known health benefits, an inevitable part of participating in sports is the risk of injury. Knee injuries occur frequently in many sports, representing $14-33 \%$ of al injuries $(5,6)$. Rehabilitation of injury often requires an initial phase of complete immobilization of the joint, usually by a plaster cast or a brace (7). Depending on the severity of the injury, average recovery time ranges from 9-23 days, with approximately two-thirds of the injuries recovering within 7 days $(5,6)$. Such a short period of muscle disuse ( $\leq 7$ days) already leads to a substantial decline in muscle mass $(0.5-1.0 \%$ per day $(8,9)$, which is accompanied by a rapid loss of muscle strength (1-2\% per day) and a concomitant decrease in physical and athletic performance $(8,9)$. Furthermore, a decline in muscle mass and strength not only prolongs the time needed for an athlete to return to competition level, but also increases the recurrence risk for injuries (10-12). Unfortunately, the loss of muscle mass occurs at a much faster rate than the regain of muscle mass (13). Even after only 2 weeks of immobilization, a rehabilitation program of 4 weeks including 3 sessions of resistance-type exercise per week is needed to regain the muscle mass that was lost (13). When an athlete is unable to participate in such a progressive exercise-based rehabilitation program due to pain or other injury-related complications, the recovery may take even longer. It is therefore important to find strategies to prevent or attenuate the loss of muscle mass and strength during a period of disuse.
Olderadults

From the age of $~ 35$ years, muscle mass starts to decline progressively by $0.4-1.0 \%$ per year (1). The age-related loss of muscle mass and strength in otherwise healthy, older individuals is also referred to as sarcopenia. For older adults that already experience this age-related decline in muscle mass, a period of bed rest or immobilization due to disease or surgery leads to a more rapid decline in muscle mass and strength. The decline in muscle mass and strength can result in an increased risk of developing physical disabilities and in the inability to maintain daily functioning (14). Consequently, older adults have a higher risk of institutionalization and hospitalization and a decreased quality of life after being exposed to short periods of bed rest or immobilization.

The average hospital stay after surgery tends to be short ( $\sim 7$ days) for older patients (15) Such short periods of muscle disuse ( 5 days) have been shown to result in a loss of quadriceps cross-sectional area (CSA; reflecting muscle mass) of $1.5 \pm 0.7 \%$ in older men (16). Although 5 days of immobilization results in a greater, $3.5 \pm 0.5 \%$, muscle loss in young men (8), the relative decline in muscle strength is equivalent in both young and older people ( 8 16). This indicates that muscle loss in older people has an even greater impact on muscle strength and physical functioning when compared with younger individuals. Older individuals also have more difficulty regaining muscle mass after a period of disuse when compared to their younger counterparts. In older men, the loss of 5\% muscle mass after 14 days of immobilization is not regained within 4 weeks of rehabilitation including resistancetype exercise performed 3 times per week (13). Thus, most older men may not be able to fully regain muscle mass that is lost during a short period of muscle disuse. Therefore, successive short periods of muscle disuse throughout the lifespan can contribute substantially to the loss of muscle mass with aging (Figure 1).

Overweight individuals

In overweight and obese people, weight loss is generally encouraged to reduce the risk of developing chronic diseases. One of the most effective strategies to lose weight is energy intake restriction. However, during a period of energy intake restriction, the decline in body weight is accompanied by a substantial loss of muscle mass, ranging between 25 and $40 \%$ of the body weight lost $(18,19)$. Since muscle mass is a major contributor to the basal metabolic rate (20), the decline in muscle mass decreases energy expenditure, thereby hindering further weight loss and increasing the risk of weight regain $(21,22)$. In overweight older adults, excess fat mass can be accompanied by a relatively low muscle mass (23). In this condition, a loss of muscle mass during energy intake restriction may offset the benefits of body weight loss. Energy intake restriction in older individuals might therefore increase the risk of developing sarcopenia, leading to physical disabilities and decreased daily functioning (14). As such, it is important to prevent the loss of muscle mass during a period of energy intake restriction in older, overweight adults to maximize the physical and metabolic benefits of weight loss. 


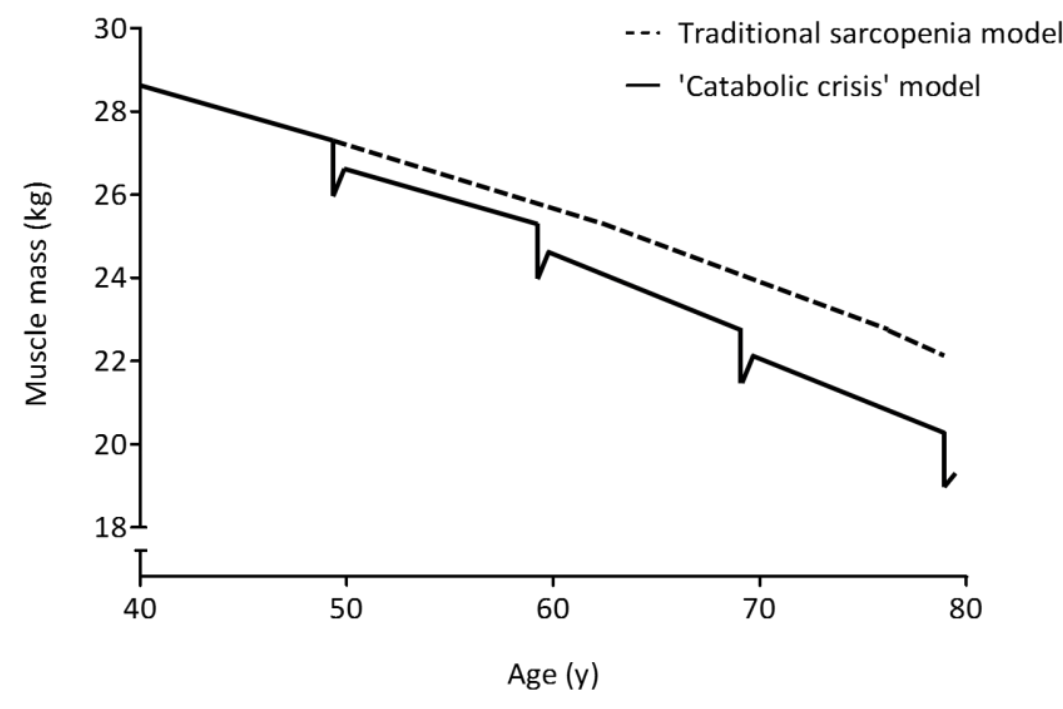

Figure 1. Proposed model of age-related muscle loss characterized by a progressive decline in muscle mass due to short successive episodes of muscle disuse. Adapted from English et al., 2010 (17)

\section{Regulation of muscle mass}

Skeletal muscle proteins are in a constant state of turnover, being continuously synthesized and broken down at a rate of $1-2 \%$ per day $(24,25)$. Muscle protein turnover is crucial for the maintenance of muscle protein quality and quantity (26). Skeletal muscle mass is maintained when muscle protein synthesis and muscle protein breakdown are in balance. Loss of muscle mass occurs during prolonged periods of decreased muscle protein synthesis rates, increased muscle protein breakdown rates, or a combination of both. To assess dynamic changes in muscle protein synthesis rates, intravenous infusions with stable isotope-labelled amino acids are often applied (27-31). Dynamic assessment of muscle protein breakdown is technically more challenging. Therefore, more static markers are often used, such as protein or mRNA expression of the ubiquitin ligases MAFbx and MuRF1, to represent a snapshot assessment of muscle protein breakdown $(8,32)$. Numerous factors influence muscle protein synthesis and breakdown rates, thereby regulating muscle mass (33). Among those factors, physical activity, exercise, disuse and nutrition are the most important.

\section{Physical activity and exercise}

Physical activity, especially resistance type exercise training, is one of the most effective interventions to increase muscle mass or attenuate the loss of muscle mass. A single session of resistance-type exercise increases both muscle protein synthesis and muscle protein breakdown rates, albeit the latter to a lesser extent (31). Intramuscular mRNA levels of
MAFbx, a ubiquitin ligase involved in proteolysis, have been shown to be elevated immediately following high intensity exercise, but decreased below basal levels after 24 and $72 \mathrm{~h}$ (34). This finding has been supported with the use of stable-isotope techniques, showing that muscle protein breakdown is elevated in the initial phase after exercise (up to 24h), but returned to baseline after $48 \mathrm{~h}$ (31). It has been speculated that the initial increase in muscle protein breakdown after exercise supports the muscle-remodeling processes (35). Muscle protein synthesis rates can be increased more than $100 \%$ within $3 \mathrm{~h}$ after an exercise session (31). The changes in muscle protein breakdown and muscle protein synthesis rates result in an increased muscle protein net balance that persists up to $48 \mathrm{~h}$ in young adults (31). In addition to the increased basal muscle protein net balance, exercise increases the anabolic response to food intake. Protein ingestion in close proximity to an exercise session results in $15-30 \%$ more amino acids being built into muscle protein (36-38). Therefore, physical activity represents a key factor in the regulation of muscle mass by increasing postabsorptive and postprandial muscle protein synthesis rates. Unfortunately, in many clinical situations, physical activity is temporarily not feasible or simply impossible.

\section{Muscle disuse}

A period of muscle inactivity (muscle disuse) results in a rapid decline in muscle mass $(8,9)$ The rate of muscle atrophy appears to be the highest during the initial period of immobilization (5-7 days), although a longer duration of muscle disuse results in a greater overall decrease in muscle mass (39). For example, by using a full-leg plaster cast, the reduction in muscle quadriceps CSA is shown to be $3.5 \pm 0.5 \%$ in the first 5 days in healthy young men, representing $0.7 \%$ per day. After 14 days, the same protocol results in a decline in quadriceps CSA of $8.4 \pm 2.8 \%$, representing $0.6 \%$ per day (40). Studies with longer durations show a wider range of muscle loss, $0.48-0.75 \%$ per day $(41,42)$. The wider range could be due to differences in study population, immobilization protocol or the diet of the subjects. Whereas studies with a longer duration (>2 weeks) of muscle disuse aim to represent chronic hospitalization and spaceflight, a shorter duration (<14 days) is more representative for injury and short periods of disease. The loss of muscle strength during disuse not only depends on the decline in muscle mass, but also on neural and metabolic changes $(43,44)$. The decline in muscle strength is usually $1-2 \%$ per day in the initial phase of disuse $(8,40)$ resulting in declines up to $50 \%$ after 4 weeks $(42)$.

The loss of muscle mass during disuse occurs after a prolonged period of a negative net protein balance. A period of muscle inactivity (muscle disuse) has been shown to decline basal rates of muscle protein synthesis by $25-50 \%$ in young, healthy individuals (45-51). Postprandial muscle protein synthesis rates in response to amino acid infusion or protein ingestion were also decreased by $30-70 \%(40,45,52)$. This reduced capacity to respond to anabolic stimuli, now coined anabolic resistance $(53,54)$, is likely a major contributor to the decline in muscle mass during a period of disuse. The dynamic assessment of muscle protein breakdown reveals no change during muscle disuse $(50,51)$, although other studies have reported an increase in mRNA expression of the ubiquitin ligases MuRF and MAFbx in the 
initial phase $(<10 \mathrm{~d})$ of disuse $(8,48)$. Given the magnitude of the decline in muscle protein synthesis following disuse, several studies indicate that muscle atrophy is almost entirely attributed to the decrease in muscle protein synthesis rates $(46,48,55,56)$. Thus, effective nutritional compounds to attenuate the loss of muscle mass during muscle disuse should focus on stimulating basal and postprandial muscle protein synthesis rates.

\section{Disuse models}

Two models are commonly used to study disuse-induced muscle atrophy, bed rest and limb immobilization. Although short-term, single-leg immobilization shows a similar decrease in muscle mass compared to bed rest (resp. $5.4 \pm 1.0$ vs $3.2 \pm 0.9 \%$ ) (57), the models mimic different real-life situations. The bed rest model offers a more relevant model from a clinical perspective as it represents a period of hospitalization and (some of) its implications. However, limb immobilization is a better suited model when focusing on sports injuries and ocal trauma. Moreover, limb immobilization represents a more controlled situation in which muscle disuse atrophy can be studied since it isolates the effect of local muscle disuse without interference from systemic factors.

\section{Nutrition}

It has been well established that nutrition is an important factor in the regulation of muscle mass $(58,59)$. In a postabsorptive phase, such as during overnight sleep, muscle protein breakdown rates exceed muscle protein synthesis rates resulting in a negative protein balance. Food intake stimulates muscle protein synthesis and inhibits muscle protein breakdown, thereby stimulating post-prandial muscle protein accretion (30). The postprandial muscle protein synthetic response to feeding is regulated on various levels, ranging from protein digestion and amino acid absorption, the post-prandial rise in circulating insulin and subsequent increase in microvascular recruitment, amino acid uptake in skeletal muscle tissue, intramuscular anabolic signaling and myofibrillar muscle protein synthesis and breakdown (60-62). One of the main driving factors for the postprandial stimulation of muscle protein synthesis is the postprandial rise in plasma amino acid availability (63). After ingesting a protein containing meal, approximately $50 \%$ of the dietary protein-derived amino acids become available in the circulation within $6 \mathrm{~h}(38,64)$. About $20 \%$ of the dietary protein derived amino acids released in the circulation are being used as precursors for de novo muscle protein synthesis (64). These amino acids have two main functions in the muscle; they stimulate muscle protein synthesis while providing the precursors for de novo muscle protein synthesis. Essential amino acids (EAA), and leucine in particular, have been shown to increase muscle protein synthesis rates more than $30-100 \%$ compared to the postabsorptive state (65-67). Thus, muscle mass is maintained through fluctuations in muscle protein synthesis and breakdown rates such that net muscle protein balance remains zero by the end of each day.

During a prolonged period of reduced energy intake, the loss of muscle mass results from negative net muscle protein balance. After 10 days of a decreased energy intake (-500 $\mathrm{kcal} / \mathrm{d}$ ), basal rates of muscle protein synthesis are reduced by $19 \%$ (68). In addition, the post-prandial rates of muscle protein synthesis in response to protein feeding decreases substantially (14-27\%) within the first weeks of an energy restricted diet (69-71). Thus, to support healthy weight loss, a dietary intervention should aim to maintain basal and postprandial muscle protein synthesis rates to attenuate the loss of muscle mass while energy intake is reduced.

\section{Nutritional interventions during situations of muscle atrophy}

It has often been speculated that nutritional strategies are able to prevent or attenuate the decline in muscle mass during situations of muscle atrophy $(55,72,73)$. During a period of energy intake restriction, an increase in the protein content of the diet has been suggested to preserve muscle mass (74-76). Whereas several intervention studies show that increasing protein intake during a period of energy intake restriction can alleviate the loss of muscle mass or increase the loss of fat mass $(69,74,77)$, other studies have failed to confirm these findings $(78,79)$. The discrepancy in the literature may be attributed to differences in the selected study population, the applied nutritional intervention and/or compliance of the subjects to the diet. To enhance the compliance to the diet, a strictly controlled intervention with nutrition provided and consumed under supervision has been shown to be effective (80-85)

An increased intake of protein or essential amino acids has also been suggested to reduce muscle loss during periods of disuse $(55,86)$. Until now, only one study showed that an increased intake of essential amino acids could preserve muscle mass during muscle disuse (87), whereas most studies did not confirm this finding $(16,88,89)$. Therefore, it is important to continue our search for other nutritional compounds that could preserve or attenuate the loss of muscle mass during muscle disuse. Although multiple nutritional compounds have been suggested to work in this setting, few of these compounds have been tested in humans in an in vivo muscle atrophy model. Leucine has been shown to be one of the most potent stimuli to induce muscle protein synthesis and decrease muscle protein breakdown (65-67), however, the effect of leucine supplementation on muscle mass preservation during limb immobilization has not been studied. Moreover, nutritiona compounds that are known to stimulate muscle mass gains in combination with resistancetype exercise training, like creatine, are suggested to be effective in attenuating the loss of muscle mass during disuse (55). While numerous studies have shown that vitamin D concentrations are associated with muscle mass and function in elderly and athletic populations (90-93), hardly any randomized controlled trials on the effect of vitamin D supplementation on muscle mass and function have been performed. It is surprising that despite frequent speculations, most of these compounds have not yet been tested in humans. Therefore, in this thesis, we studied the properties of several nutritional compounds to prevent or attenuate the loss of muscle mass. 


\section{Outline of this thesis}

The aim of this thesis is to evaluate the impact of nutritional interventions to prevent the loss of muscle mass. We performed a series of studies with some of the most promising nutritional compounds. For vitamin $\mathrm{D}$, we focused on nutritional status by assessing the prevalence of vitamin D deficiency and seasonal fluctuations in athletes (chapter 2). Continuing with that, we studied the effects of different vitamin D dosages on the serum vitamin D concentration in athletes (chapter 3 ). Thereafter, we applied limb immobilization to assess the effects of creatine (chapter 4), leucine (chapter 5), and nandrolone decanoate (chapter 6) administration on preserving muscle mass and strength. In chapter $\mathbf{7}$, we conducted a dietary intervention study to assess the effect of a high protein intake on the preservation of muscle mass during prolonged energy intake restriction. Finally, we discuss the main findings of the studies and provide general conclusions and directions for future research (chapter 8 ).

\section{References}

1. Mitchell WK, Williams J, Atherton P, Larvin M, Lund J, Narici M. Sarcopenia, dynapenia, and the impact of advancing age on human skeletal muscle size and strength; a quantitative review. Frontiers in physiology. 2012;3:260.

2. Koopman $\mathrm{R}$, Van Loon L. Aging, exercise, and muscle protein metabolism. Journal of applied physiolog (Bethesda, Md : 1985). 2009;106(6):2040-8.

3. Janssen I, Ross R. Linking age-related Changes in skeletal muscle mass and composition with metabolism and disease. The journal of nutrition, health \& aging. 2005;9(6):408-19.

Baumgartner RN, Waters DL, Gallagher D, Morley JE, Garry PJ. Predictors of skeletal muscle mass in elderly men and women. Mechanisms of ageing and development. 1999;107(2):123-36.

5. Tranaeus $\mathrm{U}$, Heintz $\mathrm{E}$, Johnson U, Forssblad M, Werner S. Injuries in Swedish floorball: a cost analysis. Scandinavian journal of medicine \& science in sports. 2016.

6. Swain MS, Lystad RP, Henschke N, Maher CG, Kamper S. Match injuries in amateur Rugby Union: prospective cohort study - FICS Biennial Symposium Second Prize Research Award. Chiropractic \& manual therapies. 2016;24:17.

7. Heijne A, Werner S. Early versus late start of open kinetic chain quadriceps exercises after AC reconstruction with patellar tendon or hamstring grafts: a prospective randomized outcome study. Kne surgery, sports traumatology, arthroscopy : official journal of the ESSKA. 2007;15(4):402-14.

8. Dirks ML, Wall BT, Snijders T, Ottenbros CL, Verdijk LB, van Loon L. Neuromuscular electrical stimulatio prevents muscle disuse atrophy during leg immobilization in humans. Acta physiologica (Oxford, England). 2014;210(3):628-41:

9. White MJ, Davies CT, Brooksby P. The effects of short-term voluntary immobilization on the contractile properties of the human triceps surae. Quarterly journal of experimental physiology (Cambridge, England). 1984;69(4):685-91.

10. Stevens JE, Walter GA, Okereke E, Scarborough MT, Esterhai IL, George SZ, et al. Muscle adaptations with immobilization and rehabilitation after ankle fracture. Medicine and science in sports and exercise. 2004;36(10):1695-701.

11. Vandenborne K, Elliott MA, Walter GA, Abdus S, Okereke E, Shaffer M, et al. Longitudinal study of skeleta muscle adaptations during immobilization and rehabilitation. Muscle Nerve. 1998;21(8):1006-12.

12. Dallinga JM, Benjaminse A, Lemmink KA. Which screening tools can predict injury to the lower extremities in team sports?: a systematic review. Sports medicine (Auckland, NZ). 2012;42(9):791-815.

13. Suetta C, Hvid LG, Justesen L, Christensen U, Neergaard K, Simonsen L, et al. Effects of aging on human skeletal muscle after immobilization and retraining. Journal of applied physiology (Bethesda, Md : 1985). 2009;107(4):1172-80

14. Covinsky KE, Palmer RM, Fortinsky RH, Counsell SR, Stewart AL, Kresevic D, et al. Loss of independence in activities of daily living in older adults hospitalized with medical illnesses: increased vulnerability with age. Journal of the American Geriatrics Society. 2003;51(4):451-8.

15. Wang D, Xu J, Zeng WN, Zhou K, Xie TH, Chen Z, et al. Closed Suction Drainage Is Not Associated with Faster Recovery after Total Knee Arthroplasty: A Prospective Randomized Controlled Study of 80 Patients. Orthopaedic surgery. 2016;8(2):226-33

16. Dirks ML, Wall BT, Nilwik R, Weerts DH, Verdijk LB, van Loon L. Skeletal muscle disuse atrophy is no attenuated by dietary protein supplementation in healthy older men. The Journal of nutrition. 2014;144(8):1196-203.

17. English KL, Paddon-Jones D. Protecting muscle mass and function in older adults during bed rest. Current opinion in clinical nutrition and metabolic care. 2010;13(1):34-9.

18. Villareal $\mathrm{DT}$, Apovian $\mathrm{CM}$, Kushner RF, Klein S. Obesity in older adults: technical review and position statement of the American Society for Nutrition and NAASO, The Obesity Society. The American journa of clinical nutrition. 2005;82(5):923-34.

19. Ballor DL, Katch VL, Becque MD, Marks CR. Resistance weight training during caloric restriction enhances lean body weight maintenance. The American journal of clinical nutrition. 1988;47(1):19-25.

20. Johnstone AM, Murison SD, Duncan IS, Rance KA, Speakman JR. Factors influencing variation in basa metabolic rate include fat-free mass, fat mass, age, and circulating thyroxine but not sex, circulating leptin or triiodothyronine. The American journal of clinical nutrition. 2005;82(5):941-8.

21. Stiegler $P$, Cunliffe A. The role of diet and exercise for the maintenance of fat-free mass and resting metabolic rate during weight loss. Sports medicine (Auckland, NZ). 2006;36(3):239-62.

22. Strychar $\mathrm{L}$. psychosocial, and dietary characteristics of overweight/obese postmenopausal women with a history of 
weight cycling: a MONET (Montreal Ottawa New Emerging Team) study. Journal of the American Dietetic 2009;109(4):718-24.

23. Parr EB, Coffey VG, Hawley JA. 'Sarcobesity': a metabolic conundrum. Maturitas. 2013;74(2):109-13.

24. Nair KS. Muscle protein turnover: methodological issues and the effect of aging. J Gerontol A Biol Sci Med Nair KS. Muscle protein turnover: methodological issues and the effect of aging. J Gerontol A Biol Sci Med
Sci. 1995;50 Spec No:107-12.

25. Koopmoteris metabolism. J Appl Physiol 09 Jan 8.

Dorrens in sports. 2003;13(1):26-33.

27. Paddon-Jones D, Sheffield-Moore M, Zhang XJ, Volpi E, Wolf SE, Aarsland A, et al. Amino acid ingestion improves muscle protein synthesis in the young and elderly. American journal of physiology Endocrinology and metabolism. 2004;286(3):E321-8.

28. Gorissen SH, Burd NA, Hamer HM, Gijsen AP, Groen BB, van Loon L. Carbohydrate coingestion delays dietary protein digestion and absorption but does not modulate postprandial muscle protein accretion. The Journal of clinical endocrinology and metabolism. 2014;99(6):2250-8.

29. Rennie MJ, Edwards RH, Halliday D, Matthews DE, Wolman SL, Millward DJ. Muscle protein synthesis measured by stable isotope techniques in man: the effects of feeding and fasting. Clin Sci (Lond). measured by stabi is

30. Moore DR, Tang JE, Burd NA, Rerecich T, Tarnopolsky MA, Phillips SM. Differential stimulation of myofibrillar and sarcoplasmic protein synthesis with protein ingestion at rest and after resistance exercise. The Journal of physiology. 2009;587(Pt 4):897-904.

31. Phillips SM, Tipton KD, Aarsland A, Wolf SE, Wolfe RR. Mixed muscle protein synthesis and breakdown after resistance exercise in humans. The American journal of physiology. 1997;273(1 Pt 1):E99-107.

32. Bodine SC, Latres E, Baumhueter S, Lai VK, Nunez L, Clarke BA, et al. Identification of ubiquitin ligases

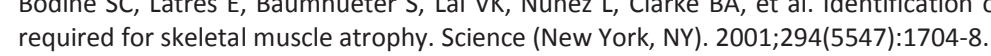

33. Atherton PJ, Smith K. Muscle protein synthesis in response to nutrition and exercise. The Journal of physiology. 2012;590(5):1049-57.

34. Deldicque L, Atherton P, Patel R, Theisen D, Nielens H, Rennie MJ, et al. Effects of resistance exercise with and without creatine supplementation on 8 (axpression and cell sigr Journal of applied physiology (Bethesda, Md: 1985). 2008;104(2):371-8.

35. Murton AJ, Greenhaff PL. Resistance exercise and the mechanisms of muscle mass regulation in humans: acute effects on muscle protein turnover and the gaps in our understanding of chronic resistance exercise training adaptation. The international journal of biochemistry \& cell biology. 2013;45(10):2209-14.

36. Holwerda AM, Kouw IW, Trommelen J, Halson SL, Wodzig WK, Verdijk LB, et al. Physical Activity Performed in the Evening Increases the Overnight Muscle Protein Synthetic Response to Presleep Protein Ingestion in Older Men. The Journal of nutrition. 2016.

37. Yang $Y$, Breen L, Burd NA, Hector AJ, Churchward-Venne TA, Josse AR, et al. Resistance exercise enhance myofibrillar protein synthesis with graded intakes of whey protein in older men. The British journal of nutrition. 2012;108(10):1780-8.

38. Pennings B, Koopman R, Beelen M, Senden JM, Saris WH, van Loon $L$. Exercising before protein intake allows for greater use of dietary protein-derived amino acids for de novo muscle protein synthesis in both young and elderly men. The American journal of clinical nutrition. 2011;93(2):322-31.

39. Wall BT, Dirks ML, Snijders T, Senden JM, Dolmans J, van Loon L. Substantial skeletal muscle loss occurs during only 5 days of disuse. Acta physiologica (Oxford, England). 2014;210(3):600-11.

40. Wall BT, Snijders T, Senden JM, Ottenbros CL, Gijsen AP, Verdijk LB, et al. Disuse impairs the muscle protein synthetic response to protein ingestion in healthy men. The Journal of clinical endocrinology and metabolism. 2013;98(12):4872-81.

41. de Boer MD, Selby A, Atherton P, Smith K, Seynnes OR, Maganaris CN, et al. The temporal responses of protein synthesis, gene expression and cell signalling in human quadriceps muscle and patellar tendon to disuse. The Journal of physiology. 2007;585(Pt 1):241-51.

42. Veldhuizen JW, Verstappen FT, Vroemen JP, Kuipers H, Greep JM. Functional and morphological adaptations following four weeks of knee immobilization. International journal of sports medicine. 1993;14(5):283-7.

43. Duchateau J, Hainaut K. Effects of immobilization on contractile properties, recruitment and firing rates of human motor units. The Journal of physiology. 1990;422:55-65.

44. van Loon L, Oosterlaar AM, Hartgens F, Hesselink MK, Snow RJ, Wagenmakers AJ. Effects of creatine loading and prolonged creatine supplementation on body composition, fuel selection, sprint and endurance performance in humans. Clin Sci (Lond). 2003;104(2):153-62.
45. Drummond MJ, Dickinson JM, Fry CS, Walker DK, Gundermann DM, Reidy PT, et al. Bed rest impairs skeletal muscle amino acid transporter expression, mTORC1 signaling, and protein synthesis in response to essential amino acids in older adults. American journal of physiology Endocrinology and metabolism. 2012;302(9):E1113-22.

46. Gibson JN, Halliday D, Morrison WL, Stoward PJ, Hornsby GA, Watt PW, et al. Decrease in human quadriceps muscle protein turnover consequent upon leg immobilization. Clin Sci (Lond). 1987;72(4):503quadil

47. Glover El, Phillips SM, Oates BR, Tang JE, Tarnopolsky MA, Selby A, et al. Immobilization induces anabolic resistance in human myofibrillar protein synthesis with low and high dose amino acid infusion. The Journal of physiology. 2008;586(Pt 24):6049-61.

48. de Boer MD, Selby A, Atherton P, Smith K, Seynnes OR, Maganaris CN, et al. The temporal responses of protein synthesis, gene expression and cell signalling in human quadriceps muscle and patellar tendon to disuse. The Journal of physiology. 2007;585(Pt 1):241-51.

49. Ferrando AA, Lane HW, Stuart CA, Davis-Street J, Wolfe RR. Prolonged bed rest decreases skeletal muscle and whole body protein synthesis. The American journal of physiology. 1996;270(4 Pt 1):E627-33.

50. Symons TB, Sheffield-Moore M, Chinkes DL, Ferrando AA, Paddon-Jones D. Artificial gravity maintain skeletal muscle protein synthesis during 21 days of simulated microgravity. Journal of applied physiology. 2009;107(1):34-8.

51. Paddon-Jones D, Sheffield-Moore M, Cree MG, Hewlings SJ, Aarsland A, Wolfe RR, et al. Atrophy and impaired muscle protein synthesis during prolonged inactivity and stress. The Journal of clinical endocrinology and metabolism. 2006;91(12):4836-41.

52. Glover EI, Phillips SM, Oates BR, Tang JE, Tarnopolsky MA, Selby A, et al. Immobilization induces anabolic resistance in human myofibrillar protein synthesis with low and high dose amino acid infusion. The Journal of physiology. 2008;586(Pt 24):6049-61.

53. Glover El, Phillips SM, Oates BR, Tang JE, Tarnopolsky MA, Selby A, et al. Immobilization induces anabolic resistance in human myofibrillar protein synthesis with low and high dose amino acid infusion. The Journal of physiology. 2008:586(24):6049-61.

54. Wall BT, Dirks ML, Snijders T, van Dijk JW, Fritsch M, Verdijk LB, et al. Short-term muscle disuse lowers myofibrillar protein synthesis rates and induces anabolic resistance to protein ingestion. American journal of physiology Endocrinology and metabolism. 2016;310(2):E137-47.

55. Wall BT, van Loon $\sqcup$. Nutritional strategies to attenuate muscle disuse atrophy. Nutrition reviews. 2013;71(4):195-208.

56. Phillips SM, McGlory C. CrossTalk proposal: The dominant mechanism causing disuse muscle atrophy is decreased protein synthesis. The Journal of physiology. 2014;592(24):5341-3.

57. Dirks ML, Backx EM, Wall BT, Verdijk LB, van Loon L. May bed rest cause greater muscle loss than limb immobilization? Acta physiologica (Oxford, England). 2016.

58. Koopman R, Saris WH, Wagenmakers AJ, van Loon $\mathrm{L}$. Nutritional interventions to promote post-exercise muscle protein synthesis. Sports medicine (Auckland, NZ). 2007;37(10):895-906.

59. Paddon-Jones D, Rasmussen BB. Dietary protein recommendations and the prevention of sarcopenia. Current opinion in clinical nutrition and metabolic care. 2009;12(1):86-90.

60. Cuthbertson D, Smith K, Babraj J, Leese G, Waddell T, Atherton P, et al. Anabolic signaling deficits underlie amino acid resistance of wasting aging muscle. FASEB journal : official publication of the Federation of American Societies for Experimental Biology. 2005;19(3):422-4.

61. Fry CS, Drummond MJ, Glynn EL, Dickinson JM, Gundermann DM, Timmerman KL, et al. Aging impairs contraction-induced human skeletal muscle mTORC1 signaling and protein synthesis. Skeletal muscle. 2011;1(1):11.

62. Volpi E, Ferrando AA, Yeckel CW, Tipton KD, Wolfe RR. Exogenous amino acids stimulate net muscle protein synthesis in the elderly. The Journal of clinical investigation. 1998;101(9):2000-7.

63. Volpi E, Kobayashi H, Sheffield-Moore M, Mittendorfer B, Wolfe RR. Essential amino acids are primarily responsible for the amino acid stimulation of muscle protein anabolism in healthy elderly adults. The American journal of clinical nutrition. 2003;78(2):250-8.

64. Groen BB, Horstman AM, Hamer HM, de Haan M, van Kranenburg J, Bierau J, et al. Post-Prandial Protein Handling: You Are What You Just Ate. PloS one. 2015;10(11):e0141582.

65. Wall BT, Hamer HM, de Lange A, Kiskini A, Groen BB, Senden JM, et al. Leucine co-ingestion improves post-prandial muscle protein accretion in elderly men. Clinical nutrition (Edinburgh, Scotland). 2013;32(3):412-9.

66. Katsanos CS, Kobayashi H, Sheffield-Moore M, Aarsland A, Wolfe RR. A high proportion of leucine is required for optimal stimulation of the rate of muscle protein synthesis by essential amino acids in the elderly. American journal of physiology Endocrinology and metabolism. 2006;291(2):E381-7. 
67. Rieu I, Balage M, Sornet C, Giraudet C, Pujos E, Grizard J, et al. Leucine supplementation improves muscle protein synthesis in elderly men independently of hyperaminoacidaemia. The Journal of physiology. protein synthesis in

68. Pasiakos SM, Vislocky LM, Carbone JW, Altieri N, Konopelski K, Freake HC, et al. Acute energy deprivation affects skeletal muscle protein synthesis and associated intracellular signaling proteins in physically active affects skeletal muscle protein synthesis and associa
adults. The Journal of nutrition. 2010;140(4):745-51.

69. Pasiakos SM, Cao JJ, Margolis LM, Sauter ER, Whigham LD, McClung JP, et al. Effects of high-protein diets on fat-free mass and muscle protein synthesis following weight loss: a randomized controlled trial. FASEB journal : official publication of the Federation of American Societies for Experimental Biology. 2013;27(9):3837-47.

70. Areta JL, Burke LM, Camera DM, West DW, Crawshay S, Moore DR, et al. Reduced resting skeletal muscle protein synthesis is rescued by resistance exercise and protein ingestion following short-term energy deficit. American journal of physiology Endocrinology and metabolism. 2014;306(8): E989-97.

71. Murphy CH, Churchward-Venne TA, Mitchell CJ, Kolar NM, Kassis A, Karagounis LG, et al. Hypoenergetic diet-induced reductions in myofibrillar protin synthesis are restored with resistance trainergetic diet.ing balanded rily

72. Magne H, Savary-Auzeloux I, Remond D, Dardevet D. Nutritional strategies to counteract muscle atrophy caused by disuse and to improve recovery. Nutrition research reviews. 2013;26(2):149-65.

73. Bajotto G, Shimomura Y. Determinants of disuse-induced skeletal muscle atrophy: exercise and nutrition countermeasures to prevent protein loss. Jutna of nutritional science and vitaminology 2006;52(4):23347.

74. Soenen S, Martens EA, Hochstenbach-Waelen A, Lemmens SG, Westerterp-Plantenga MS, Normal protein intake is required for body weight loss and weight maintenance, and elevated protein intake for addition preservation of restig
6. Westerterp-Plantenga MS, Nieuwenhuizen A, Tome D, Soenen S, Westerterp loss, and weight maintenance. Annual review of nutrition. 2009;29:21-41.

76. content and glycemic index for weight-loss maintenance. The New England journal 2010;363(22):2102-13.

77. Leidy HJ, Carnell NS, Mattes RD, Campbell WW. Higher protein intake preserves lean mass and satiety with weight loss in pre-obese and obese women. Obesity (Silver Spring, Md). 2007;15(2):421-9.

78. Parker B, Noakes M, Luscombe N, Clifton P. Effect of a high-protein, high-monounsaturated fat weight loss diet on glycemic control and lipid levels in type 2 diabetes. Diabetes care. 2002;25(3):425-30.

79. Mojtahedi MC, Thorpe MP, Karampinos DC, Johnson CL, Layman DK, Georgiadis JG, et al. The effects of a higher protein intake during energy restriction on changes in body composition and physical function in Jurnals of gerontology Series A, Biological sciences and medical sciences. 2011;66(11):1218-25.

80. Dansinger ML, Gleason JA, Griffith JL, Selker HP, Schaefer EJ. Comparison of the Atkins, Ornish, Weight Watchers, and Zone diets for weight loss and heart disease risk reduction: a randomized trial. JAMA : the journal of the American Medical Association. 2005;293(1):43-53.

81. McManus K, Antinoro L, Sacks F. A randomized controlled trial of a moderate-fat, low-energy diet compared with a low fat, low-energy diet for weight loss in overweight adults. International journal of obesity and related metabolic disorders : journal of the International Association for the Study of Obesity. 2001;25(10):1503-11.

82. Alhassan S, Kim S, Bersamin A, King AC, Gardner CD. Dietary adherence and weight loss success among overweight women: results from the A TO Z weight loss study. International journal of obesity (2005). 2008;32(6):985-91.

83. Stubbs RJ, O'Reilly LM, Whybrow S, Fuller Z, Johnstone AM, Livingstone MB, et al. Measuring the difference between actual and reported food intakes in the context of energy balance under laboratory conditions. The British journal of nutrition. 2014:1-12.

84. Black AE, Cole TJ. Biased over- or under-reporting is characteristic of individuals whether over time or by different assessment methods. Journal of the American Dietetic Association. 2001;101(1):70-80.

85. Astrup A, Geiker NR. Efficacy of higher protein diets for long-term weight control. How to assess quality of randomized controlled trials? Nutrition, metabolism, and cardiovascular diseases : NMCD. 2014;24(3):220-3.

86. Galvan E, Arentson-Lantz E, Lamon S, Paddon-Jones D. Protecting Skeletal Muscle with Protein and Amino Acid during Periods of Disuse. Nutrients. 2016;8(7).
87. Paddon-Jones D, Sheffield-Moore M, Urban RJ, Sanford AP, Aarsland A, Wolfe RR, et al. Essential amino acid and carbohydrate supplementation ameliorates muscle protein loss in humans during 28 days bedrest. The Journal of clinical endocrinology and metabolism. 2004;89(9):4351-8.

88. Ferrando AA, Paddon-Jones D, Hays NP, Kortebein P, Ronsen O, Williams RH, et aA supplementation to increase to increase nadgen

89. Trappe TA, Burd NA, Louis ES, Lee GA, Trappe SW. Influence of concurrent exercise or nutrition countermeasures on thigh and calf muscle size and function during 60 days of bed rest in women. Acta physiologica (Oxford, England). 2007:191(2):147-59.

90. Cristina C, Andra C, Mihai B, Catalina P. Short-term Administration of Alphacalcidol is Associated with More Significant Improven, Ca Muscular Peformance in Wortis to Native Vitamin D. Experimental and clincal endocrino 2 \& diabetes : official journal, German Society of Endocrinology [and] German Diabetes Association. 2016.

91. Grimaldi AS, Parker BA, Capizzi JA, Clarkson PM, Pescatello LS, White MC, et al. 25(OH) vitamin D is associated with greater muscle strength in healthy men and women. Medicine and science in sports and exercise. 2013;45(1):157-62.

92. Salminen M, Saaristo P, Salonoja M, Vaapio S, Vahlberg T, Lamberg-Allardt C, et al. Vitamin D status and physical function in older Finnish people: A one-year follow-up study. Archives of gerontology and geriatrics. 2015;61(3):419-24.

93. Tieland M Brouwer-Brolsma EM, Nienaber-Rousseau C, van Loon $L$, De Groot LC. Low vitamin D status is associad with reduced muscle mass andimpaired physcal performance in frail elderly people. European journal of clinical nutrition. 2013;67(10):1050-5. 


\section{Chapter 2}

Seasonal variation in vitamin D status in elite athletes:

a longitudinal study

Evelien M.P. Backx

Cindy van der Avoort

Michael Tieland

Kamiel Maase

Arie K. Kies

Luc J.C. van Loon

Lisette C.P.G.M. de Groot

Marco Mensink 


\section{Abstract}

Background: Studies monitoring vitamin D status in athletes are seldom conducted for a period of 12 months or longer, thereby lacking insight into seasonal fluctuations.

Objective: To identify seasonal changes in total 25 -hydroxyvitamin $\mathrm{D}(25(\mathrm{OH}) \mathrm{D})$ concentration throughout the year.

Methods: Fifty-two, mainly Caucasian athletes with a sufficient 25(OH)D concentration ( $>75 \mathrm{nmol} / \mathrm{L}$ ) in June were included in this study. Serum 25(OH)D concentration was measured every three months (June, September, December, March, June). Additionally, vitamin $\mathrm{D}$ intake and sun exposure were assessed by questionnaires at the same time points.

Results: Highest total 25(OH)D concentrations were found at the end of summer $(113 \pm 26$ $\mathrm{nmol} / \mathrm{L})$, whereas lowest concentrations were observed at the end of winter $(78 \pm 30$ $\mathrm{nmol} / \mathrm{L})$. Although all athletes had a sufficient $25(\mathrm{OH}) \mathrm{D}$ concentration at the start of the study, nearly $20 \%$ of the athletes were deficient $(<50 \mathrm{nmol} / \mathrm{L}$ ) in late winter.

Conclusion: A sufficient 25(OH)D concentration in summer does not guarantee a sufficient status in winter. Coaches and medical professionals should therefore monitor athletes' 25(OH)D concentration regularly in order to prevent vitamin $D$ deficiency.

\section{ntroduction}

A sufficient vitamin D status is important for an athlete's ability to train and perform, since vitamin $D$ deficiency has been linked to impaired skeletal muscle function, immune function and compromised is estimated to be between $40-60 \%(2,3)$. The reported prevalence depends on the concentrations of serum 25 -hydroxyvitamin $D(25(\mathrm{OH}) \mathrm{D})$ chosen to define vitamin $\mathrm{D}$ deficien$\mathrm{Cy}$, which ranges from 30-75 $\mathrm{nmol} / \mathrm{L}(1,4,5)$. It has been suggested, however, that optima 25(OH)D concentrations for exercise performance should be even higher $(75-125 \mathrm{nmol} / \mathrm{L})$ (6). As shown by recent studies, a low $25(\mathrm{OH}) \mathrm{D}$ concentrations is associated with reduced muscle strength (7) and muscle protein synthesis (8). Increasing the serum 25(OH)D concentration can improve sprint capacity and vertical jump performance (9), enhance muscular strength recovery following intense exercise (10) and decrease the risk of musculoskeletal injuries (11). Total 25(OH)D concentrations are mostly affected by sunlight exposure (12-15), vitamin $D$ intake $(12,14-16)$, body composition $(12,14)$, the capacity of the skin to synthesize vitamin $D(14,16)$ and latitude $(1,17)$. Athletes may differ in several of these factors compared to the general population. Namely, vitamin D intake might be higher due to a greater overall food intake. Athletes can also have a different level of sun exposure, depending on their sports. Furthermore, athletes typically have a lower percentage of fat mass, which is known to be involved in the storage of vitamin D (18). Finally, athletes have a higher amount of physical activity, which has been shown to have a positive association with $25(\mathrm{OH}) \mathrm{D}$ concentration (12).

The most important factor that influences total $25(\mathrm{OH}) \mathrm{D}$ concentration is the exposure to ultraviolet-B (UV-B) radiation. Therefore, 25(OH)D concentrations vary throughout the year and the time point at which vitamin $D$ concentrations are measured is decisive for whether an athlete is considered vitamin D deficient or not. Highest 25(OH)D concentrations are typically present at the end of summer (September for the northern hemisphere), while the lowest concentrations are typically measured at the end of winter (March). Most of the studies reporting 25(OH)D concentration in athletes have been cross sectional in nature or assessed 25(OH)D concentration over a maximum of six months (2, $3,19)$. These studies highlight vitamin $D$ deficiency, however, they do not directly evaluate seasonal changes in $25(\mathrm{OH}) \mathrm{D}$ concentration over the course of the year. Therefore, the aim of the present study was to identify seasonal changes in $25(\mathrm{OH}) \mathrm{D}$ concentration throughout the course of a year in elite athletes. Additionally, factors that are associated with a low $25(\mathrm{OH}) \mathrm{D}$ concentration, such as sunlight exposure and dietary vitamin $\mathrm{D}$ intake, were evaluated. 


\section{Methods}

Study population and design

In early summer, 100 healthy and injury free (sub) elite athletes had their total 25(OH)D concentration assessed. Athletes participated on a national or international level in sports supported by Netherlands Olympic Committee * Netherlands Sports Confederation (NOC*NSF) and were all living in the Netherlands at a latitude of $\sim 52^{\circ} \mathrm{N}$ and an altitude between -5 and $50 \mathrm{~m}$ above sea level.

Fifty-two athletes with a sufficient 25(OH)D concentration ( $>75 \mathrm{nmol} / \mathrm{L}$ ), were selected for follow-up. Of those 52 athletes, 22 were male and 30 were female athletes, with a mean age of $22 \pm 4$ years, a mean BMI of $23.0 \pm 1.9 \mathrm{~kg} / \mathrm{m}^{2}$, and an average number of trainings hours of $10 \pm 6$ per week. Seven athletes trained mainly outdoors (e.g. soccer, road cycling) and 45 indoors (e.g. judo, badminton, swimming). Of this group, 48 athletes had a white and 4 athletes had a darker skin tone. The 48 athletes with an insufficient $25(\mathrm{OH}) \mathrm{D}$ concentration were not different from the sufficient athletes based on vitamin $D$ intake, body weight, $\mathrm{BMI}$, age, sunlight exposure, sex and indoor/outdoor sports $(\mathrm{P}>0.05)$.

Total 25(OH)D concentration, dietary vitamin $\mathrm{D}$ intake and sun exposure were reassessed every three months: September $(n=45)$, December $(n=43)$, March $(n=35)$ and June $(n=35)$. Due to scheduling problems or illness, not all athletes were sampled at each occasion; 21 athletes completed all measurements.

This one-year longitudinal observational follow-up study is part of a larger project which assesses the effect of different vitamin $D$ dosages on 25(OH)D concentrations in athletes (20). The study was approved by the Medical Ethics Committee of Wageningen University (12/09). The design and aim of the study were registered in the NIH clinical trial database (ClinicalTrials.gov number: NCT02008201)

Total 25(OH)D concentration, vitamin D intake and sun exposure

Subjects were fasted for at least three hours before blood samples were collected. Serum total 25 hydroxy-vitamin D $(25(\mathrm{OH}) \mathrm{D})$ concentration was analyzed with a liquid chromatography-tandem mass spectrometry (LC-MS/MS) assay. Vitamin D deficiency was defined as $25(\mathrm{OH}) \mathrm{D}$ concentrations below $50 \mathrm{nmol} / \mathrm{L}$, vitamin $\mathrm{D}$ insufficiency was defined as 25(OH)D concentrations between $50-75 \mathrm{nmol} / \mathrm{L}$ and a concentration above $75 \mathrm{nmol} / \mathrm{L}$ was considered sufficient $(4,6)$. Dietary vitamin D intake was assessed using a validated 56 item food frequency questionnaire, specifically developed for measuring vitamin $D$ intake, including supplement use (21). Sun exposure was measured by a questionnaire that assessed the time spent outdoors likely representing exposure to sunlight. The questions pertained to time spent outdoors during the last 2 weeks to 3 months. The maximal score for all questions was 9 points with a lower score reflecting a lower exposure to sunlight. The self-reported sun exposure score could range from 0-108 and was used to rank athletes. In the winter months, points were only allocated when the athletes spent time at a sunny destination or used a tanning bed.
Statistics

Data represent mean $\pm S D$, or unstandardized $\beta$ coefficients with the $95 \%$ confidence intervals $(95 \% \mathrm{CI})$. Data were analyzed using SPSS version 22.0 (SPSS, IBM Corp., Armonk, NY, USA). Results were considered statistically significant at the 0.05 level. Independent $t$-tests were used to assess differences between the insufficient and sufficient athletes and between male and female athletes at baseline. Linear mixed models analysis was used to assess the fluctuations throughout the year with $25(\mathrm{OH}) \mathrm{D}$ concentration as dependent variable. Subjects were added to the model as a random factor and time as a fixed factor. The best fitting covariance matrix was assessed using the Restricted Maximum Likelihood (REML) and tested with the Chi-square distribution. The first order autoregressive covariance matrix $(A R(1))$ was found to be the best fitted covariance matrix. Other factors were included based on a significant contribution to the outcome in the linear mixed model, as tested by the Satterthwaite test. The following fixed factors were tested: Vitamin D intake, sex, age, indoor/outdoor athletes, and exposure to sunlight. BMI and skin colour were included as covariates. Interactions with time are only included if they contributed significantly to the model, as tested by the Satterthwaite test. For 25(OH)D concentration, only sunlight exposure, sex and the interactions sunlight exposure*time and sex*time contributed significantly to the statistical model and are therefore included to test changes in 25(OH)D concentration over the year.

\section{Results}

Seasonal variation

As expected, 25(OH)D concentrations varied significantly throughout the year (see Figure 2.1 and Table 2.1). The highest concentrations were found at the end of the summer season (September, $113 \pm 26 \mathrm{nmol} / \mathrm{L}$ ), whereas the lowest 25(OH)D concentrations were observed at the end of the winter season (March, $78 \pm 30 \mathrm{nmol} / \mathrm{L} ; 36 \%$ decrease). Although all athletes had a sufficient 25(OH)D concentration at the start of the observational period, $2 \%(n=1)$ had an insufficient 25(OH)D concentration ( $<75 \mathrm{nmol} / \mathrm{L}$ ) in September, $23 \%$ $(n=10)$ in December, $46 \%(n=16)$ in March and 6\% $(n=2)$ in June the following year. In March, 18\% ( $\mathrm{n}=6$ athletes) even had a 25(OH)D concentration below $50 \mathrm{nmol} / \mathrm{L}$ ('deficient'). Of the 21 athletes who had their 25(OH)D concentration assessed at all time points, 9 athletes had 25(OH)D concentrations below $75 \mathrm{nmol} / \mathrm{L}$ in March. Of those 9 athletes, 8 athletes improved their 25(OH)D concentration up to $75 \mathrm{nmol} / \mathrm{L}$ or above in June. Highest sun exposure scores were achieved in September (71 \pm 4 points). Lowest scores were observed in December and March ( $14 \pm 5$ points). Self-reported sun exposure scores changed significantly over time $(P<0.01)$. The overall mean intake of dietary vitamin $D$ was $4.8 \pm 3.4 \mu \mathrm{g} /$ day and did not change over time $(P=0.054)$. 


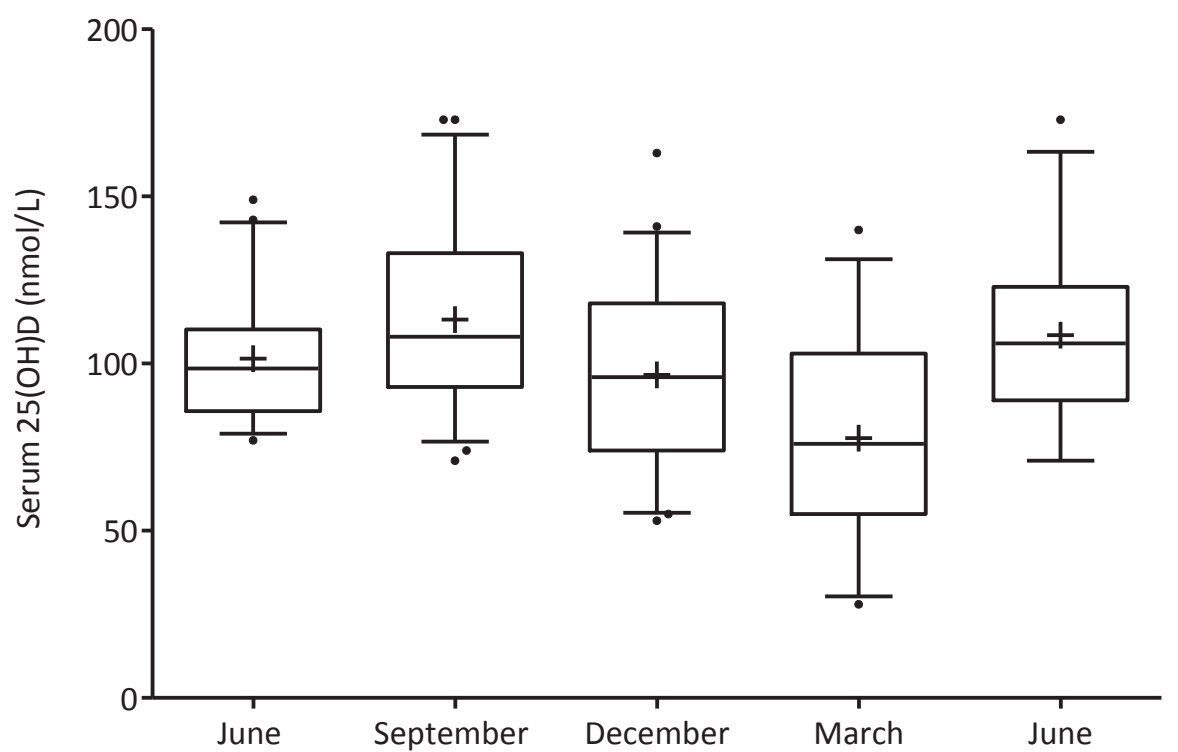

Figure 2.1. Seasonal changes in serum $25(\mathrm{OH}) \mathrm{D}$ in $\mathrm{nmol} / \mathrm{L}$. Data represent median $\pm 5-95$ percentile, ' + ' represents the mean. Serum $25(\mathrm{OH}) \mathrm{D}$ concentration varies over time as analyzed by linear mixed models.

Table 2.1. Serum 25 -hydroxyvitamin $D$, dietary vitamin $D$ intake and sun exposure scores over time

\begin{tabular}{llllll}
\hline & June & September & December & March & June \\
\hline $\begin{array}{l}\text { Serum 25(OH)D } \\
\text { (nmol/L) }\end{array}$ & $100 \pm 16$ & $113 \pm 26$ & $97 \pm 26$ & $78 \pm 30$ & $108 \pm 26$ \\
$\begin{array}{l}\text { Vitamin D intake } \\
\text { ( } \mathrm{Mg} / \text { day) }\end{array}$ & $4.1 \pm 2.2$ & $3.8 \pm 2.3$ & $3.1 \pm 1.4$ & $3.6 \pm 1.8$ & $3.6 \pm 1.8$ \\
$\begin{array}{l}\text { Sun exposure score } \\
\text { (AU) }\end{array}$ & $64 \pm 12$ & $71 \pm 10$ & $14 \pm 5$ & $14 \pm 5$ & $67 \pm 11$ \\
\hline $\begin{array}{l}\mathrm{A} \text { ) } \\
\text { Data represent mean }+ \text { SD }\end{array}$ & & & & &
\end{tabular}

Factors associated with low $25(\mathrm{OH}) \mathrm{D}$ concentration

At baseline, male and female athletes did not show a different 25(OH)D concentration $(P=0.73)$. However, male and female athletes showed a different change in 25(OH)D concentration over time (Sex*Time interaction $\mathrm{P}<0.01$ ). In September, $25(\mathrm{OH}) \mathrm{D}$ concentration was $32 \mathrm{nmol} / \mathrm{L}(95 \% \mathrm{Cl}, 14$ to $49 \mathrm{nmol} / \mathrm{L})$ higher in female athletes compared to male athletes $(\mathrm{P}<0.01)$. In December, female athletes showed a 25(OH)D concentration of 22 $\mathrm{nmol} / \mathrm{L}(95 \% \mathrm{Cl}, 6$ to $38 \mathrm{nmol} / \mathrm{L})$ higher compared to males and in March the difference was $39 \mathrm{nmol} / \mathrm{L}(95 \% \mathrm{Cl}, 20$ to $58 \mathrm{nmol} / \mathrm{L}$ ) (all P<0.01). In June 2013, there was no difference between female and male athletes $(\beta 13 \mathrm{nmol} / \mathrm{L} ; 95 \% \mathrm{Cl},-16$ to $40 \mathrm{nmol} / \mathrm{L} ; \mathrm{P}=0.38$ ). The self-reported exposure to sunlight also showed a significant interaction with time
$(P=0.03)$. The change in $25(\mathrm{OH}) \mathrm{D}$ concentration was partly explained by the difference in sunlight exposure between December and March.

Sun light and UV index in the Netherlands

Retrospectively, the number of sun hours in the Netherlands was assessed by using information from the Dutch Meteorological Institute (KNMI). The average numbers of sun hours in the 3-month period before each measurement were as follows: 181 sun hours in June, 205 in September, 73 in December, 89 in March, and 185 hours in June 2013. In the Netherlands, the UV index is lower than 0.5 in winter months and maximal 7 in summer months (22). Endogenous vitamin D can only be synthesized between March and November $(23,24)$.

\section{Discussio}

The present study demonstrates that 25(OH)D concentrations in athletes show seasonal variation, with the lowest concentrations in late winter, confirming earlier observations in athletes (19) and in the general population (25). The largest difference of $36 \%$ lower concentrations in March compared to September is somewhat smaller than the $\sim 50 \%$ reductions observed in professional soccer players playing in the English Premier League (19) and in British adults (25). The difference in seasonal variation might be explained by our selection of athletes with a sufficient vitamin $D$ status at baseline, these athletes show possibly a higher $25(\mathrm{OH}) \mathrm{D}$ concentration throughout the whole year compared to a randomly selected group of athletes.

Though all athletes in the follow-up part had a sufficient total 25(OH)D concentration at the start of the study, we found $18 \%$ of the athletes to be deficient in late winter. According to the literature, an insufficient dietary vitamin D intake, larger body (or fat) mass, poor sunlight exposure, dark skin colour and participation in indoor activities could be riskfactors for a low 25(OH)D concentration in winter (26). However, in our small sample size only sunlight exposure and sex affected 25(OH)D concentration over time. Male athletes showed a larger decrease in 25(OH)D in winter compared to female athletes, whereas female athletes showed a higher $25(\mathrm{OH}) \mathrm{D}$ concentration late summer. It is important to note that the current study population consisted mainly of Dutch athletes with a white skin colour and that the seasonal variation might be different in athletes with a darker skin colour.

Interestingly, a sufficient 25(OH)D concentration in summer does not guarantee a sufficient status in winter. Coaches and medical professionals should therefore monitor athletes' $25(\mathrm{OH}) \mathrm{D}$ concentration regularly in order to prevent vitamin $\mathrm{D}$ deficiency.

\section{Acknowledgement}

The authors thank all the students and Lucy Okma for assisting during the tests. The authors thank Bas Engel for statistical advice. 


\section{References}

1. von Hurst PR, Beck KL. Vitamin D and skeletal muscle function in athletes. Current opinion in clinica nutrition and metabolic care. 2014;17(6):539-45.

2. Close GL, Leckey J, Patterson M, Bradley W, Owens DJ, Fraser WD, et al. The effects of vitamin D(3) supplementation on serum total $25[\mathrm{OH}] \mathrm{D}$ concentration and physical performance: a randomised doseresponse study. British journal of sports medicine. 2013;47(11):692-6.

3. Allison RJ, Close GL, Farooq A, Riding NR, Salah O, Hamilton B, et al. Severely vitamin D-deficient athletes present smaller hearts than sufficient athletes. European journal of preventive cardiology. 2014.

Holick MF, Binkley NC, Bischoff-Ferrari HA, Gordon CM, Hanley DA, Heaney RP, et al. Evaluation treatment, and prevention of vitamin D deficiency: an Endocrine Society clinical practice guideline. The Journal of clinical endocrinology and metabolism. 2011;96(7):1911-30.

5. IOM. Dietary Reference Intakes for Calcium and Vitamin D. Washington, DC: National Academy Press, 2010.

6. Girgis CM, Clifton-Bligh RJ, Turner N, Lau SL, Gunton JE. Effects of vitamin D in skeletal muscle: falls, strength, athletic performance and insulin sensitivity. Clinical endocrinology. 2014;80(2):169-81.

Mowe M, Haug E, Bohmer T. Low serum calcidiol concentration in older adults with reduced muscular function. Journal of the American Geriatrics Society. 1999;47(2):220-6.

8. Salles J, Chanet A, Giraudet C, Patrac V, Pierre P, Jourdan M, et al. 1,25(OH)2-vitamin D3 enhances the stimulating effect of leucine and insulin on protein synthesis rate through Akt/PKB and mTOR mediated pathways in murine C2C12 skeletal myotubes. Molecular nutrition \& food research. 2013;57(12):213746.

9. Close GL, Russell J, Cobley JN, Owens DJ, Wilson G, Gregson W, et al. Assessment of vitamin D concentration in non-supplemented professional athletes and healthy adults during the winter month in the UK: implications for skeletal muscle function. Journal of sports sciences. 2013;31(4):344-53.

10. Barker T, Schneider ED, Dixon BM, Henriksen VT, Weaver LK. Supplemental vitamin D enhances the recovery in peak isometric force shorty after intense exercise. Nutrition \& metabolism. 2013;10(1):69. Wyon MA, Koutedakis $Y$, Wolman $R$, Nevill AM, Allen $N$. The influence of winter vitamin $D$ supplementation on muscle function and injury occurrence in elite ballet dancers: a controlled study. Journal of science and medicine in sport/Sports Medicine Australia. 2014,17(1):8-12.

12. Valtuena J, Gonzalez-Gross M, Huybrechts I, Breidenassel C, Ferrari M, Mouratidou T, et al. Factors adolescents: the HELENA study. Journal of nutrition science and vitaminology. 2013;59(3):161-71

13. Mavroeidi A, O'Neill F, Lee PA, Darling AL, Fraser WD, Berry JL, et al. Seasonal 25-hydroxyvitamin D changes in British postmenopausal women at 57 degrees $\mathrm{N}$ and 51 degrees $\mathrm{N}$ : a longitudinal study. The Journal of steroid biochemistry and molecular biology. 2010;121(1-2):459-61

14. Greene-Finestone LS, Berger C, de Groh M, Hanley DA, Hidiroglou N, Sarafin K, et al. 25-Hydroxyvitam $D$ in Canadian adults: biological, environmental, and behavioral correlates. Osteoporosis international : journal established as result of cooperation between the European Foun National Osteoporosis Foundation of the USA. 2011;22(5):1389-99.

15. Brouwer-Brolsma EM, Vaes AM, van der Zwaluw NL, van Wijngaarden JP, Swart KM, Ham AC, et al. Relative importance of summer sun exposure, vitamin $D$ intake, and genes to vitamin $D$ status in Dutc older adults: The B-PROOF study. The Journal of steroid biochemistry and molecular biology. 2015

16. Gozdzik A, Barta JL, Wu H, Wagner D, Cole DE, Vieth R, et al. Low wintertime vitamin D levels in a sample of healthy young adults of diverse ancestry living in the Toronto area: associations with vitamin $D$ intake and skin pigmentation. BMC public health. 2008;8:336.

17. Engelsen O, Brustad M, Aksnes L, Lund E. Daily duration of vitamin D synthesis in human skin with relation to latitude, total ozone, altitude, ground cover, aerosols and cloud thickness. Photochemistry and photobiology. 2005;81(6):1287-90.

8. Blum M, Dolnikowski G, Seyoum E, Harris SS, Booth SL, Peterson J, et al. Vitamin D(3) in fat tissue.

19. Morton JP, I labal Z, Drust B, Burgess D, Close GL, Brukner PD. Seasonal variation in vitamin D status in professional soccer players of the English Premier League. Applied physiology, nutrition, and metabolism ologie appliquee, nutrition et metabolisme. 2012;37(4):798-802.

20. Backx EM, Tieland M, Maase K, Kies AK, Mensink M, van Loon $\sqcup$, et al. The impact of 1-ver vitamin D supplementation on vitamin D status in athletes: a dose-response study. European journal of clinical nutrition. 2016.

21. Siebelink E, Geelen A, de Vries JH. Self-reported energy intake by FFQ compared with actual energy intake to maintain body weight in 516 adults. The British journal of nutrition. 2011:106(2):274-81. den Outer PN, Slaper, H., Tax, R. B. UV radiation in the Netherlands: Assessing long-term variability (D)

Webt AR. Who, what where and when-influences on cutaneous vitamin D synthesis. Progress in 作

Cenaluatie van de voedingsnormen voor vitamine D. Den Haag: Gezondheidsraad, 2012 Contract No.: ISBN 978-90-5549-931-1

in dietary and lifestyle predictors. The American journal of clinical nutrition. 2007/85(3):860-8.

, (B) (DEGS1). BMC public health. 2015;15:641. 


\section{Chapter 3}

The impact of 1-year vitamin D supplementation on vitamin D

status in athletes: a dose-response study

Evelien M.P. Backx

Michael Tieland

Kamiel Maase

Arie K. Kies

Marco Mensink

Luc J.C. van Loon

Lisette C.P.G.M. de Groot 


\section{Abstract}

Objective: To assess the prevalence of vitamin $D$ deficiency in Dutch athletes and to define the required dosage of vitamin $D_{3}$ supplementation to prevent vitamin $D$ deficiency over the course of a year.

Methods: Blood samples were collected from 128 highly trained athletes to assess total 25(OH)D concentration. Of these 128 athletes, 54 male and 48 female athletes (18-32 y) were included in a randomized, double blind, dose-response study. Athletes with either a deficient $(<50 \mathrm{nmol} / \mathrm{L}$ ) or insufficient $(50-75 \mathrm{nmol} / \mathrm{L}) 25(\mathrm{OH}) \mathrm{D}$ concentration were randomly assigned to take 400, 1100 or 2200 IU vitamin D3 per day orally for one year. Athletes who had a total 25(OH)D concentration above $75 \mathrm{nmol} / \mathrm{L}$ at baseline continued with the study protocol without receiving vitamin D supplements. Serum total 25(OH)D concentration was assessed every 3 months as well as dietary vitamin D intake and sunlight exposure.

Results: Nearly $70 \%$ of all athletes showed an insufficient $(50-75 \mathrm{nmol} / \mathrm{L}$ ) or deficient ( $<50$ $\mathrm{nmol} / \mathrm{L}$ ) 25(OH)D concentration at baseline. After 12 months, serum 25(OH)D concentration had increased more in the $2200 \mathrm{IU} / \mathrm{d}$ group $(+50 \pm 27 \mathrm{nmol} / \mathrm{L})$ than the sufficient group receiving no supplements $(+4 \pm 17 \mathrm{nmol} / \mathrm{L} ; \mathrm{P}<0.01)$ and the $1100 \mathrm{IU} / \mathrm{d}$ group $(+25 \pm 23 \mathrm{nmol} / \mathrm{L}$; $\mathrm{P}<0.05)$. Supplementation with $2200 \mathrm{IU} / \mathrm{d}$ vitamin $\mathrm{D}$ resulted in a sufficient $25(\mathrm{OH}) \mathrm{D}$ concentration in $80 \%$ of the athletes after 12 months.

Conclusions: Vitamin D deficiency is highly prevalent in athletes. Athletes with a deficient or insufficient 25(OH)D concentration can achieve a sufficient 25(OH)D concentration within 3 months by taking $2200 \mathrm{IU} / \mathrm{d}$.

\section{Introduction}

Vitamin $D$ inadequacy is traditionally defined as a serum total 25 -hydroxyvitamin $D$ $(25(\mathrm{OH}) \mathrm{D})$ concentrations below $50 \mathrm{nmol} / \mathrm{L}$ based upon studies concerning bone health and calcium metabolism (1). Using this definition, only $40-60 \%$ of the athletes have adequate total 25(OH)D concentrations (2-4). More recent studies show that low total 25(OH)D concentrations are also associated with reduced muscle strength (5) and muscle protein synthesis (6), which may impact athletic performance. So far, a limited number of studies have investigated the effect of vitamin D supplementation on athletic performance (7-9). These studies demonstrate that increasing serum total 25(OH)D concentration improves sprint capacity and vertical jump performance (7), enhances muscular strength recovery following intense exercise (8) as well as decreases the risk of musculoskeletal injuries (9). However, these studies tend to have a small sample size and did not control for covariates like physical activity which might explain the positive effects that are found.

Data from both observational and intervention studies demonstrate improvements in athletic performance when serum total 25(OH)D concentrations are above $75 \mathrm{nmol} / \mathrm{L}(7$ 11). However, it is important to note that not all studies have confirmed this finding $(3,12)$ and more well-controlled studies are needed to assess the optimal 25(OH)D concentrations specifically for athletic performance. An effective and commonly used strategy to increase serum total 25(OH)D concentrations is supplementation with vitamin $D_{3}(13)$. Although a number of dose-response studies have been performed, most have investigated older, nonathletic populations (14-16). The results from these studies cannot be directly translated to athletes considering differences in dietary vitamin D intake (17-19), body composition (20, $21)$, sunlight exposure $(17,19)$ and the age-related capacity of the skin to produce vitamin $D$ (22). Moreover, to improve a low total 25(OH)D concentration at the end of the winter and to maintain a sufficient $25(\mathrm{OH}) \mathrm{D}$ concentration throughout the year, studies need to focus on assessing total 25(OH)D concentration during all seasons. Therefore, the current study was conducted to 1$)$ assess the prevalence of vitamin $D$ deficiency $(<50 \mathrm{nmol} / L)$ in a group of highly trained athletes and 2) identify the dose of vitamin $D_{3}$ supplementation required to achieve and maintain a total $25(\mathrm{OH}) \mathrm{D}$ concentration $>75 \mathrm{nmol} / \mathrm{L}$ throughout the course of a year.

\section{Methods}

Subjects

A total of 128 highly trained athletes were recruited through contacts with their coaches, trainers and/or medical doctors. All athletes participated on a national or international level in sports supported by Netherlands Olympic Committee * Netherlands Sports Confederation (NOC*NSF) and were all living in the Netherlands at a latitude of $\sim 52^{\circ} \mathrm{N}$. Athletes were excluded if they had chronic diseases that could influence total 25(OH)D concentrations and/or the response to vitamin D supplementation. Athletes were also 
excluded if they used vitamin D supplements and participants were not allowed to start taking supplements during the study. Athletes that used a sun bed or travelled to foreign countries were not excluded but this information was monitored by questions in the sunlight questionnaire. At baseline, athletes were asked to fill in a training log with the amount of training hours per day for one week.

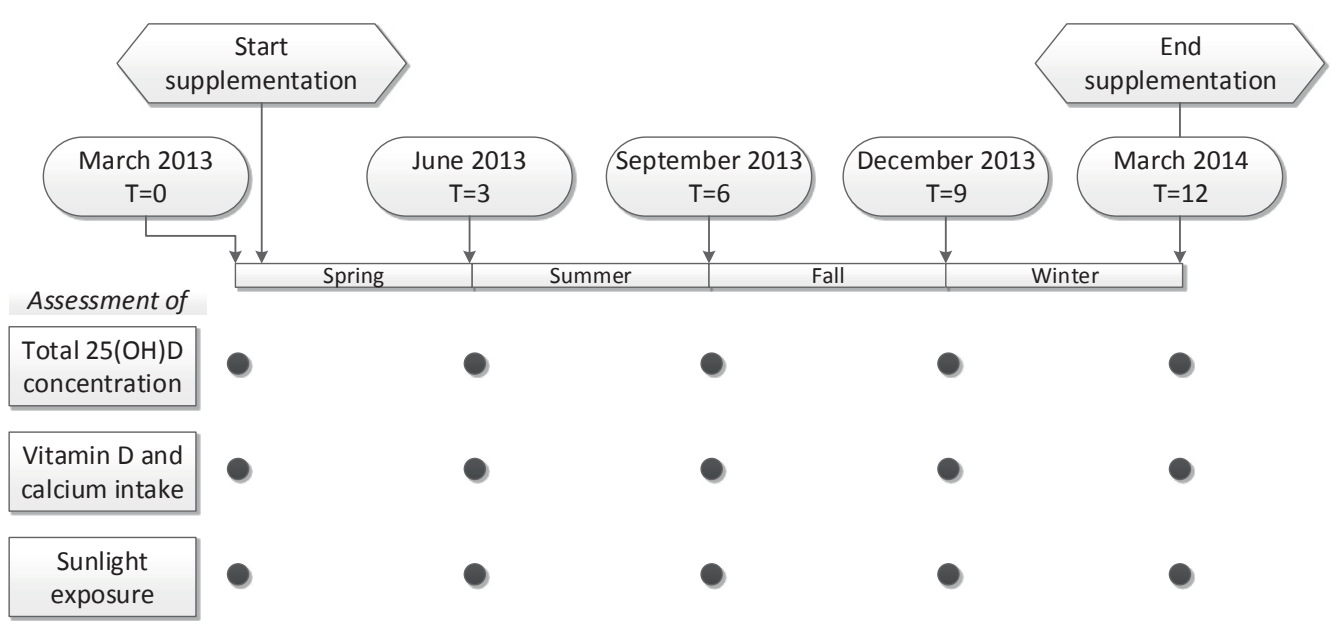

Figure 3.1: Overview of the study design

\section{Design and intervention}

The present study consisted of two parts. The first part was a cross-sectional observation of total $25(\mathrm{OH}) \mathrm{D}$ concentration at the end of the winter to assess the prevalence of vitamin $\mathrm{D}$ deficiency in athletes. The second part comprised a dose-response study to compare the effect of 3 dosages of vitamin D supplements on total 25(OH)D concentrations in a selection of athletes who participated in the first part.

After providing written informed consent, 58 male and 70 female athletes had their serum total $25(\mathrm{OH}) \mathrm{D}$ concentration assessed, while concurrently recording vitamin $\mathrm{D}$ and calcium intake, sun exposure, and general well-being (baseline measurement). Baseline measurements were assessed at the end of the winter season (March until April 2013), since the winter months are known to impose the highest risk of vitamin D deficiency due to the lack of sun exposure (23). From this group, 102 athletes were included in a randomized, double-blind, dose-response study for 12 months. Serum 25(OH)D, vitamin D and calcium intake and sun exposure were reassessed every 3 months (Figure 3.1). Selected athletes were stratified based on their baseline total $25(\mathrm{OH}) \mathrm{D}$ concentration as having a deficient $(<50 \mathrm{nmol} / \mathrm{L})$, insufficient $(50-75 \mathrm{nmol} / \mathrm{L})$ or sufficient $(>75 \mathrm{nmol} / \mathrm{L})$ total $25(\mathrm{OH}) \mathrm{D}$ concentration. Those athletes with a deficient $(n=43)$ and insufficient $(n=46)$ total 25(OH)D concentration were randomized to take $400(n=31), 1100(n=29)$ or 2200 IU $(n=29)$ vitamin $D_{3}$ (cholecalciferol) per day for one year (Table 3.1). The sufficient group $(n=13)$ continued with the study protocol without receiving vitamin $\mathrm{D}$ supplements. For subjects whose total $25(\mathrm{OH}) \mathrm{D}$ concentration reached $125 \mathrm{nmol} / \mathrm{L}$ or higher (as measured during the 3-monthly assessment), the dose was adjusted to a maintenance dose of $400 \mathrm{IU} / \mathrm{d}$ to prevent possible harmful effects (1). The study was approved by the Medical Ethics Committee of Wageningen University (12/09). The design and aim of the study were registered in the NIH clinical trial database (ClinicalTrials.gov number: NCT02008201).

\section{Supplements}

Vitamin D supplements (400, 1100 or 2200 IU) were taken on a daily basis together with a meal to enhance absorption (24). Vitamin $\mathrm{D}_{3}$ was provided by DSM Biotechnology Cente (Delft, The Netherlands) in capsulated form. Capsules were administered in a double-blind manner and provided in blisters. Supplements were tested by independent laboratories for the correct dosage and to guarantee the absence of contamination with prohibited substances. The HFL Sport Science lab guaranteed the absence of contamination with prohibited substances. The dosages were measured by TNO Triskelion BV by the following method: Samples are saponified using a $1.5 \mathrm{~mol} / \mathrm{l}$ potassium hydroxide ethanolic solution. The mixture is extracted using diisopropyl ether. The extract is partly evaporated and redissolved in methanol. After sterol precipitation and solid phase extraction, the eluate is further purified by fractionation with straight phase chromatography. Finally, the resulting extract is analyzed by reversed phase chromatography with diode array detection, quantifying at $265 \mathrm{~nm}$. Subjects were asked to fill in a calendar to monitor compliance to the supplement intake. Also, subjects were asked to hand in all supplement packages. For statistical analysis, all subjects were included. The calendar and supplement count data was used to explain deviating results of individual subjects. Overall, 4 subjects in the $2200 \mathrm{IU} / \mathrm{d}$ group displayed deviating $25(\mathrm{OH}) \mathrm{D}$ concentrations. For these subjects, the calendar and supplement count helped to explain the data.

Table 3.1: Block randomization of vitamin D supplementation

\begin{tabular}{|c|c|c|}
\hline Vitamin D status & $\begin{array}{c}\text { Total } 25(\mathrm{OH}) \mathrm{D} \\
\text { concentration }(\mathrm{nmol} / \mathrm{L})\end{array}$ & Supplementation \\
\hline Deficient & $<50 \mathrm{nmol} / \mathrm{L}$ & $\begin{array}{ll}\text { 1. } & 400 \mathrm{IU} / \text { day } \\
\text { 2. } & 1100 \mathrm{IU} / \text { day } \\
\text { 3. } & 2200 \mathrm{IU} / \text { day }\end{array}$ \\
\hline Insufficient & $50-75 \mathrm{nmol} / \mathrm{L}$ & $\begin{array}{ll}\text { 1. } & 400 \mathrm{IU} / \text { day } \\
\text { 2. } & 1100 \mathrm{IU} / \text { day } \\
\text { 3. } & 2200 \mathrm{IU} / \text { day }\end{array}$ \\
\hline Sufficient & $>75 \mathrm{nmol} / \mathrm{L}$ & No supplements \\
\hline
\end{tabular}


Subjects were fasted for at least 3 hours before blood samples were collected by venipuncture to assess serum total 25(OH)D concentration. After collection, blood tubes (SST ${ }^{\mathrm{TM}}$ Tube with Silica Clot Activator) were stored for at least 30 minutes in a dark box to allow clotting, after which they were centrifuged for 10 minutes at $1550 \mathrm{G}$. Serum was separated and stored at $-80^{\circ} \mathrm{C}$ until analysis. Serum $25(\mathrm{OH}) \mathrm{D}$ concentrations were analysed with a liquid chromatography-tandem mass spectrometry (LC-MS/MS) assay (Online SPE) at the VU Medical Centre, Amsterdam. The VU Medical Centre participates in the United Kingdom National External Quality Assessment Schemes (UK NEQAS) and the Dutch society for quality control in medical laboratories (SKML). The intra-assay and inter-assay CV's (Coefficients of Variability) of this lab were $5-9 \%$ and $7-9 \%$ respectively.

Safety

To prevent possible harmful effects of the vitamin D supplements, athletes in the 2200 and $1100 \mathrm{IU} / \mathrm{d}$ group who reached total 25(OH)D concentrations higher than $125 \mathrm{nmol} / \mathrm{L}$ switched to a maintenance dose of $400 \mathrm{IU} / \mathrm{d}$. This occurred in 31 athletes. In only 5 of them total $25(\mathrm{OH}) \mathrm{D}$ concentrations dropped below $75 \mathrm{nmol} / \mathrm{L}$ (lowest value $47 \mathrm{nmol} / \mathrm{L}$ ) at the end of the winter $(T=12)$.

Vitamin D and sun exposure questionnaire

Vitamin $D$ and calcium intake were calculated from a validated 56 -item food frequency questionnaire (25). Sun exposure was measured by a questionnaire that assessed the time spent outdoors likely representing exposure to sunlight. The questions pertained to time spent outdoors during the last 2 weeks to 3 months. The self-reported sun exposure score could range from 0-108 and was used to rank athletes. Scores obtained at T0, T9 and T12 were recoded to 0 to accommodate for the absence of cutaneous synthesis of vitamin $D$ during the winter months. Body weight and height were also assessed by a questionnaire, $\mathrm{BMI}$ was calculated as body weight in $\mathrm{kg} /(\text { height in } \mathrm{m})^{2}$.

\section{Statistics}

A sample size calculation was performed prior to the start of the study using GPower (26) To detect a significant difference in serum 25(OH)D in response to the lowest and middle doses of vitamin $D$ supplementation with an 1-beta of $>0.80$ and an alpha of $<0.05$, at least 10 participants per group were required (27). Considering a drop-out rate of $30 \%, 15$ participants per group were needed. To include a group of 90 subjects with a deficient or insufficient total $25(\mathrm{OH}) \mathrm{D}$ concentration, we estimated that 120-140 athletes should be included at baseline (28)

Data are presented as means \pm standard deviations (SD). Intention to treat analysis was applied, meaning that all subjects were included also in case they missed one or more measurements. Baseline characteristics and total 25(OH)D concentrations were normally distributed as evaluated by plotting a histogram and the skewness and kurtosis values (al between -1.0 and +1.0 ). To check whether there were baseline differences between the groups, a one-way ANOVA was used in combination with a Bonferroni post-hoc test to assess differences between specific dosage groups. Linear mixed models analysis in combination with a Bonferroni post-hoc test was applied to assess differences between groups over time. Supplement dose, time and supplement dose*time were entered as fixed factors. Random factors were included based on a significant contribution to the outcome in the linear mixed model. The following random factors were tested: Vitamin D intake, gender, age, skin colour, indoor/outdoor athletes, baseline 25(OH)D, exposure to sunlight and BMI. Only baseline 25(OH)D and exposure to sunlight were significant. Firstly, linear mixed models was applied with only exposure to sunlight as random factor to compare mean total 25(OH)D concentrations between groups (Table 3.3A). Secondly, exposure to sunlight and baseline total 25(OH)D concentrations were included as random factors to compare changes over time (Table 3.3B). Data were analysed using SPSS version 21 (SPSS Inc Chicago, IL) and effects were considered statistically significant at $\mathrm{P}<0.05$.

\section{Results}

Baseline characteristics

The total group of 128 subjects had a mean age of $22 \pm 3$ years and a mean BMI of $22 \pm 2$ $\mathrm{kg} / \mathrm{m}^{2}$ (Table 3.2). Athletes trained on average $9 \pm 4$ hours per week. Most athletes had a light skin colour $(n=112)$ and only 16 athletes had a darker skin colour. Athletes competed in different sport disciplines, classified as mainly training outdoors (total $n=94$ ): field hockey $(n=61)$, athletics $(n=15)$, soccer $(n=12)$, rowing $(n=4)$, cycling $(n=1)$, bobsleighing $(n=1)$, or indoors (total $n=34)$ : volleyball $(n=26)$, synchronized swimming $(n=5)$ and judo $(n=3)$.

On average, baseline characteristics of the athletes participating in the dose-response study did not differ from those of the total group, nor did the three supplemental groups differ from each other, except for gender distribution. The sufficient group included only female indoor athletes (Table 3.2)

During the dose-response study, 12 participants withdrew after T0, another 13 after T3, and 7 participants withdrew after T6. A total of 40 athletes completed all measurements, of which 11 subjects in the $400 \mathrm{IU} / \mathrm{d}, 7$ in the $1100 \mathrm{lU} / \mathrm{d}, 12$ in the $2200 \mathrm{lU} / \mathrm{d}$ group and 10 in the sufficient group; see Figure $\mathbf{3 . 2}$ for participant flow. 
Table 3.2: Baseline characteristics

\begin{tabular}{llllll}
\hline & $\begin{array}{l}\text { Total } \\
(\boldsymbol{n}=\mathbf{1 2 8})\end{array}$ & $\begin{array}{l}\mathbf{4 0 0} \mathrm{IU} / \mathbf{d} \\
(\boldsymbol{n}=\mathbf{3 1})\end{array}$ & $\begin{array}{l}\mathbf{1} \mathbf{1 0 0} \mathrm{IU} / \mathrm{d} \\
(\boldsymbol{n}=\mathbf{2 9})\end{array}$ & $\begin{array}{l}\mathbf{2} \mathbf{2 0 0} \mathrm{IU} / \mathrm{d} \\
(\boldsymbol{n}=\mathbf{2 9})\end{array}$ & $\begin{array}{l}\text { Sufficient } \\
(\boldsymbol{n}=\mathbf{1 3})\end{array}$ \\
\hline Age (y) & $22 \pm 3$ & $21 \pm 3$ & $22 \pm 3$ & $21 \pm 3$ & $23 \pm 4$ \\
Gender (M/F) & $58 / 70$ & $18 / 13$ & $18 / 11$ & $18 / 11$ & $0 / 13$ \\
Body weight (kg) & $70 \pm 8.8$ & $71 \pm 10$ & $73 \pm 10$ & $70 \pm 7$ & $74 \pm 6$ \\
Height (m) & $1.78 \pm 0.09$ & $1.80 \pm 0.09$ & $1.79 \pm 0.09$ & $1.77 \pm 0.09$ & $1.81 \pm 0.06$ \\
BMI (kg/m $)$ & $22 \pm 2$ & $22 \pm 2$ & $22 \pm 2$ & $22 \pm 2$ & $23 \pm 2$ \\
$\begin{array}{l}\text { Indoor/Outdoor } \\
\text { ( } \boldsymbol{n} \text { ) }\end{array}$ & $34 / 94$ & $6 / 25$ & $6 / 23$ & $2 / 27$ & $13 / 0$ \\
$\begin{array}{l}\text { Trainingshours } \\
\text { per week (h:min) }\end{array}$ & $8: 53 \pm 3: 39$ & $7: 26 \pm 2: 42$ & $8: 08 \pm 2: 37$ & $7: 51 \pm 2: 38$ & $7: 51 \pm 2: 38$ \\
$\begin{array}{l}\text { Self-reported } \\
\text { sunlight exposure }\end{array}$ & $13.0 \pm 6.3$ & $12.1 \pm 5.8$ & $13.6 \pm 7.2$ & $13.7 \pm 6.4$ & $12.0 \pm 5.9$ \\
(scores 1-108) & & & & & \\
$\begin{array}{l}\text { Skin colour (light } \\
\text { vs darker) }\end{array}$ & $112 / 16$ & $27 / 4$ & $24 / 5$ & $25 / 4$ & $12 / 1$ \\
\hline
\end{tabular}

Data represent means $\pm S D$. The sufficient group included only female and indoor athletes and showed a higher average training load. Furthermore, no differences between groups were found by one-way ANOVA. BMI: Body Mass Index.

Baseline serum 25(OH)D

Baseline mean total 25(OH)D concentration was $64 \pm 26 \mathrm{nmol} / \mathrm{L}$ in all athletes and $64 \pm 21$ $\mathrm{nmol} / \mathrm{L}$ in the athletes who completed all measurements $(n=40)$. Of the total group, 43 athletes had a deficient ( $<50 \mathrm{nmol} / \mathrm{L}$ ), 46 athletes had an insufficient $(50-75 \mathrm{nmol} / \mathrm{L}$ ) and 39 athletes had a sufficient ( $>75 \mathrm{nmol} / \mathrm{L}$ ) baseline total $25(\mathrm{OH}) \mathrm{D}$ concentration. This means that $70 \%$ of all athletes showed an insufficient or deficient total $25(\mathrm{OH}) \mathrm{D}$ concentration at baseline (the end of the winter season). A higher percentage of male athletes were vitamin $D$ deficient or insufficient as compared to female athletes (average 25(OH)D for men and women $46 \pm 19$ and $78 \pm 21 \mathrm{nmol} / \mathrm{L}$ respectively; $\mathrm{P}<0.01$ ).

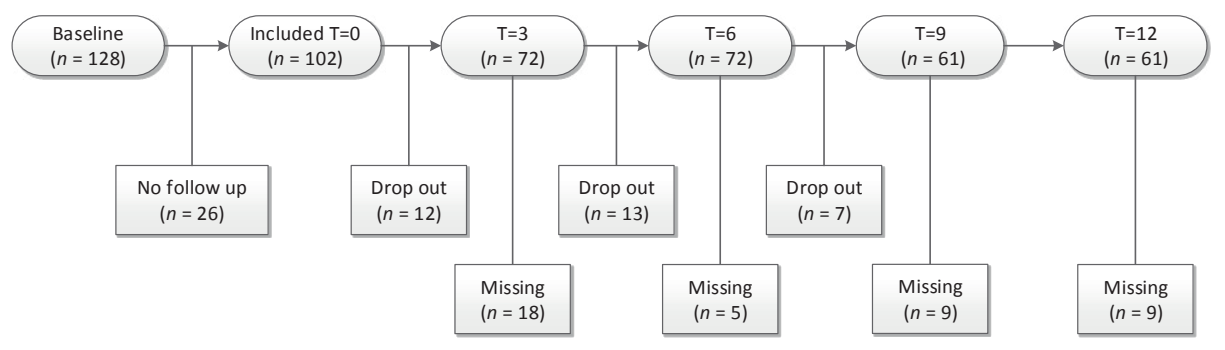

Figure 3.2: Participant flow chart

\section{Serum 25(OH)D over time}

Overall, the three vitamin $D$ dosage groups showed different effects over time (time*treatment interaction $\mathrm{P}<0.01$ ) as can be seen in Table $\mathbf{3 . 3}$.

At 3 months, serum total $25(\mathrm{OH}) \mathrm{D}$ concentration was $80 \pm 17$ for the $400 \mathrm{IU} / \mathrm{d}$ group, $79 \pm 18$ $\mathrm{nmol} / \mathrm{L}$ in the $1100 \mathrm{IU} / \mathrm{d}$ group, $94 \pm 19 \mathrm{nmol} / \mathrm{L}$ in the $2200 \mathrm{IU} / \mathrm{d}$ group and $100 \pm 22 \mathrm{nmol} / \mathrm{L}$ for the sufficient group. The increases from baseline were not different between supplementation groups $(P>0.05)$. However, all three supplemental groups increased total 25(OH)D concentration more compared to the sufficient group ( $P=0.049$ for the $400 \mathrm{IU} / \mathrm{d}$ group, $P=0.01$ for the $1100 \mathrm{IU} / \mathrm{d}$ group and $\mathrm{P}<0.01$ for the $2200 \mathrm{IU} / \mathrm{d}$ group). In the 2200 $\mathrm{IU} / \mathrm{d}$ group, a sufficient total $25(\mathrm{OH}) \mathrm{D}$ concentration was achieved in $85 \%$ of the athletes within 3 months. A sufficient total $25(\mathrm{OH}) \mathrm{D}$ concentration was achieved in $50 \%$ and $57 \%$ of the athletes within the first 3 months in the $1100 \mathrm{lU} / \mathrm{d}$ and $400 \mathrm{lU} / \mathrm{d}$ group, respectively.

At 6 months, in late summer, peak total 25(OH)D concentrations were achieved in all four groups. The $2200 \mathrm{IU} / \mathrm{d}$ group showed the highest mean of $144 \pm 33 \mathrm{nmol} / \mathrm{L}$, which was significantly different from the $400(\mathrm{P}<0.01)$ and $1100(\mathrm{P}=0.03) \mathrm{IU} / \mathrm{d}$ groups. The sufficient group had a mean total $25(\mathrm{OH}) \mathrm{D}$ concentration of $129 \pm 32 \mathrm{nmol} / \mathrm{L}$, the $400 \mathrm{IU} / \mathrm{d}$ group had a mean total $25(\mathrm{OH}) \mathrm{D}$ concentration of $111 \pm 31 \mathrm{nmol} / \mathrm{L}$, and the $1100 \mathrm{IU} / \mathrm{d}$ group had a mean total 25(OH)D concentration of $119 \pm 27 \mathrm{nmol} / \mathrm{L}$. In the 1100 and $2200 \mathrm{IU} / \mathrm{d}$ and in the sufficient group, all athletes had total $25(\mathrm{OH}) \mathrm{D}$ concentrations above $75 \mathrm{nmol} / \mathrm{L}$. In the $400 \mathrm{IU} / \mathrm{d}$ group, $86 \%$ of the athletes achieved a sufficient total $25(\mathrm{OH}) \mathrm{D}$ concentration.

At 12 months, all groups that received vitamin D supplements had higher total $25(\mathrm{OH}) \mathrm{D}$ concentrations as compared to baseline $(P<0.01)$. The difference was more pronounced in the $2200 \mathrm{IU} / \mathrm{d}$ group $(+50 \pm 27 \mathrm{nmol} / \mathrm{L})$ than in both the sufficient group $(+4 \pm 17 \mathrm{nmol} / \mathrm{L}$ $\mathrm{P}<0.01)$ or the $1100 \mathrm{IU} / \mathrm{d}$ group $(+25 \pm 23 \mathrm{nmol} / \mathrm{L} ; \mathrm{P}=0.049)$, while the difference tended to be higher compared to the $400 \mathrm{IU} / \mathrm{d}$ group $(+28 \pm 24 \mathrm{nmol} / \mathrm{L} ; \mathrm{P}=0.06)$. The $2200 \mathrm{IU} / \mathrm{d}$ group had a total $25(\mathrm{OH}) \mathrm{D}$ concentration of $100 \pm 27 \mathrm{nmol} / \mathrm{L}$, the $1100 \mathrm{had} 76 \pm 29 \mathrm{nmol} / \mathrm{L}$, the 400 $\mathrm{IU} / \mathrm{d}$ group had $81 \pm 26 \mathrm{nmol} / \mathrm{L}$ and the sufficient group had a total $25(\mathrm{OH}) \mathrm{D}$ concentration of $96 \pm 22 \mathrm{nmol} / \mathrm{L}$. After 12 months of supplementation, $80 \%$ of the athletes in the $2200 \mathrm{lU} / \mathrm{d}$ group achieved a sufficient total 25(OH)D concentration. In the $1100 \mathrm{IU} / \mathrm{d}$ group, only $43 \%$ of the athletes achieved a sufficient total $25(\mathrm{OH}) \mathrm{D}$ concentration, whereas in the $400 \mathrm{lU} / \mathrm{d}$ group, this percentage was $63 \%$.

\section{Vitamin D intake}

The average baseline dietary vitamin $D$ intake was $4.2 \pm 2.6 \mathrm{mcg}$ per day (i.e. $168 \pm 104 \mathrm{IU} / \mathrm{d}$ ). Dietary vitamin $D$ intake did not affect total $25(\mathrm{OH}) \mathrm{D}$ concentration $(\mathrm{P}=1.00)$. Dietary vitamin $D$ intake did not significantly change over time $(P=0.28)$. 
Table 3.3: Total 25(OH)D concentrations in athletes receiving 400; 1100 or $2200 \mathrm{IU}$ vitamin $\mathrm{D}_{3}$ per day

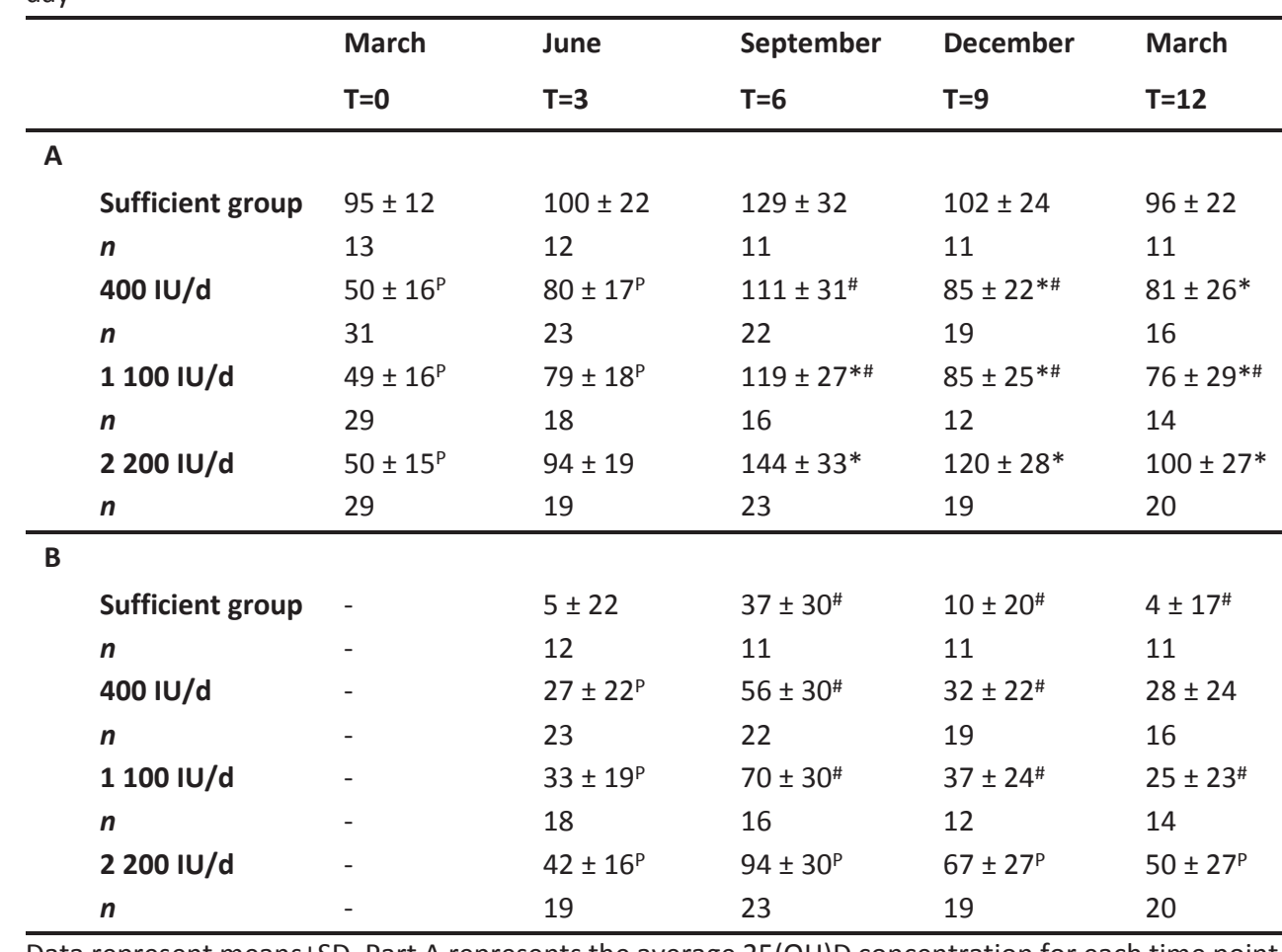

Data represent means $\$ S D$. Part A represents the average $25(\mathrm{OH}) \mathrm{D}$ concentration for Linear mixed models was applied to compare mean $25(\mathrm{OH}) \mathrm{D}$ levels between groups. Part $\mathrm{B}$ represents the change in $25(\mathrm{OH}) \mathrm{D}$ concentrations from baseline $(\mathrm{T}=0)$. Changes over time are analyzed by Linear mixed models with correction for baseline 25(OH)D concentrations. *Significantly different from T0, "Significantly different from $2200 \mathrm{IU} / \mathrm{d}$ at the same time point, PSignificantly different from the sufficient group at the same time point.

Sun exposure

Self-reported sun exposure scores varied from 0 points in winter till 84 points in summer ( $T=6$ months). Scores only varied at 3 months between groups: the $400 \mathrm{IU} / \mathrm{d}$ group showed a higher score compared to the $1100 \mathrm{IU} / \mathrm{d}$ group ( $56 \pm 10$ vs $48 \pm 8$ points; $\mathrm{P}=0.02$ ) and compared to the sufficient group ( $45 \pm 7$ points; $P<0.01$ ), but not to the $2.220 \mathrm{IU} / \mathrm{d}$ group

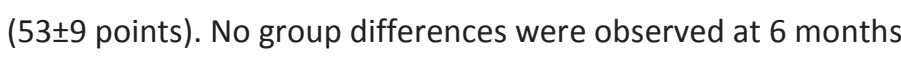

\section{Discussion}

The aims of the current study were firstly to assess the prevalence of vitamin $D$ deficiency in highly trained athletes, and secondly to identify the dosage of vitamin $D_{3}$ supplementation required to achieve and maintain a sufficient total 25(OH)D concentration throughout the year. We observed that only $30 \%$ of the highly-trained Dutch athletes had a sufficient total 25(OH)D concentration $(>75 \mathrm{nmol} / \mathrm{L})$ at the end of the winter. A considerable $34 \%$ of the athletes showed a deficient total $25(\mathrm{OH}) \mathrm{D}$ concentration $(<50$ $\mathrm{nmol} / \mathrm{L}$ ) and $30 \%$ of the athletes were vitamin $D$ insufficient $(50-75 \mathrm{nmol} / \mathrm{L})$. This observation is in line with other studies showing a prevalence of vitamin $D$ deficiency ranging from $40-60 \%(2-4)$ and sufficient total $25(\mathrm{OH}) \mathrm{D}$ concentrations in $\sim 44 \%$ of the athletes (28-30). Supplementing athletes with $2200 \mathrm{lU} / \mathrm{d}$ was the most effective dosage to achieve and maintain a sufficient total 25(OH)D concentration throughout the year.

The current study defined vitamin D deficiency as serum total $25(\mathrm{OH}) \mathrm{D}$ concentrations below $50 \mathrm{nmol} / \mathrm{L}$, based upon data considering bone health and calcium metabolism (1). Many other studies use the same definition $(2,30,31)$, while other researchers consider total $25(\mathrm{OH}) \mathrm{D}$ concentrations below 25 or $30 \mathrm{nmol} / \mathrm{L}$ as vitamin $D$ deficiency $(4,13)$. If the current study would have interpreted the data according to the latter definition, only $6 \%$ of the athletes would be vitamin $D$ deficient at baseline. The classification of vitamin $D$ sufficiency is also under debate (28). We chose to define total 25(OH)D concentrations above $75 \mathrm{nmol} / \mathrm{L}$ as sufficient since these values are commonly used in athletic populations $(2,29,32)$ and are considered to have a positive effect on training ability and sports performance (7-9). Using this cut-off, $70 \%$ of the athletes had an insufficient total $25(\mathrm{OH}) \mathrm{D}$ concentration.

Cashman and colleagues calculated that $\sim 400 \mathrm{IU} / \mathrm{d}$ of vitamin D would result in only $50 \%$ of the population reaching $25(\mathrm{OH}) \mathrm{D}$ concentrations of $>50 \mathrm{nmol} / \mathrm{L}$. According to their study, dosages of at least $800 \mathrm{IU} / \mathrm{d}$ were needed to ensure that $50 \%$ of the population would maintain $>80 \mathrm{nmol} / \mathrm{L} 25(\mathrm{OH}) \mathrm{D}$, and $97.5 \%$ of the adult population would maintain total $25(\mathrm{OH}) \mathrm{D}$ concentrations of $>50 \mathrm{nmol} / \mathrm{L}$ during winter $(15,33,34)$. Thus, vitamin $\mathrm{D}$ intakes that are described to maintain adequate total $25(\mathrm{OH}) \mathrm{D}$ concentrations, may not suffice to correct a low status $(15,33,34)$. In the present study, all vitamin D dosages $(400 ; 1100$; 2 $200 \mathrm{IU} / \mathrm{d}$ ) increased total $25(\mathrm{OH}) \mathrm{D}$ concentrations from baseline to 12 months. Supplements containing $2200 \mathrm{IU} / \mathrm{d}$ were shown to be the most effective in preventing vitamin D deficiency throughout the year, resulting in $85 \%$ of the athletes achieving a sufficient total 25(OH)D concentrations after 3 months and 80\% maintaining a sufficient total 25(OH)D concentration after 12 months. If the current study would have used a total $25(\mathrm{OH}) \mathrm{D}$ concentration below $50 \mathrm{nmol} / \mathrm{L}$ for selecting the dosage to achieve and maintain sufficient 25(OH)D levels, a dosage of $400 \mathrm{IU} / \mathrm{d}$ would be enough for all athletes to increase a low $25(\mathrm{OH}) \mathrm{D}$ concentration to $>50 \mathrm{nmol} / \mathrm{L}$ within 3 months. After 12 months, $89 \%$ of the athletes in the $400 \mathrm{IU} / \mathrm{d}$ group was able to increase 25(OH)D concentration above 50 $\mathrm{nmol} / \mathrm{L}$, in the $1100 \mathrm{IU} / \mathrm{d}$ group, this was $79 \%$ and in the $2200 \mathrm{IU} / \mathrm{d}$ group, this was $100 \%$. The results of the current dose-response study show that in 4 athletes randomized to take supplements with $2200 \mathrm{IU} / \mathrm{d}$, total 25(OH)D concentrations dropped or remained below 75 $\mathrm{nmol} / \mathrm{L}$ at 12 months (ranging from $43-73 \mathrm{nmol} / \mathrm{L}$ ). Of those 4 athletes, 2 athletes had their supplemental dose reset to $400 \mathrm{IU} / \mathrm{d}$ after reaching a total $25(\mathrm{OH}) \mathrm{D}$ concentration above $125 \mathrm{nmol} / \mathrm{L}$. The 2 other athletes showed poor compliance by taking less than $75 \%$ of the provided supplements. Therefore, we presume that daily intake of $2200 \mathrm{IU} / \mathrm{d}$ would be high enough for all athletes to reach and maintain a sufficient total 25(OH)D concentration 
during the course of a year. In all subjects receiving $400 \mathrm{IU} / \mathrm{d}$ from 6 months onwards, only $10 \%$ dropped their total $25(\mathrm{OH}) \mathrm{D}$ concentration under $75 \mathrm{nmol} / \mathrm{L}$ at 12 months. This shows that supplementation with $400 \mathrm{IU} / \mathrm{d}$ is adequate to maintain a sufficient total $25(\mathrm{OH}) \mathrm{D}$ concentration once serum total 25(OH)D concentrations rise above $125 \mathrm{nmol} / \mathrm{L}$. Therefore, it is unnecessary to take a high dose of $2200 \mathrm{lU} / \mathrm{d}$ throughout the whole year.

Exceedingly high total 25(OH)D concentrations are considered as detrimental to health $(35$ $36)$. Upon starting the study, literature suggested that the safe upper limit of $25(\mathrm{OH}) \mathrm{D}$ was $125 \mathrm{nmol} / \mathrm{L}$ (1). To keep total 25(OH)D concentrations under this upper limit, subjects with total 25(OH)D concentrations above $125 \mathrm{nmol} / \mathrm{L}$ had their dosage adjusted to a maintenance dose of $400 \mathrm{IU} / \mathrm{d}$. Currently, total 25(OH)D concentrations up to 220-250 $\mathrm{nmol} / \mathrm{L}$ are generally considered as safe $(13,37)$. If the current study had used an upper level of $250 \mathrm{nmol} / \mathrm{L}$ instead of $125 \mathrm{nmol} / \mathrm{L}$, more athletes would have taken 2200 or 1100 $\mathrm{U} / \mathrm{d}$ during the entire intervention period. As a consequence, the percentage of athletes with a sufficient total 25(OH)D concentration after 12 months would likely have been higher in the 1100 and $2200 \mathrm{IU} / \mathrm{d}$ groups. Along with increasing the safe upper level of 25(OH)D, the upper daily intake level was also newly set to $4,000 \mathrm{IU} / \mathrm{d}$ (38). However, the present study supports that long-term use of such high amounts is not necessary to achieve and maintain total 25(OH)D concentrations above $75 \mathrm{nmol} / \mathrm{L}$ in healthy young athletes.

The current dose-response study was conducted in a group of 102 young, highly-trained, healthy male and female athletes. This study population is an underrepresented group in current dose-response studies as most studies are done in older populations (14-16). However, the lifestyle and characteristics of athletes inhibit the direct translation from other study populations as age might affect sun exposure behavior and/or the ability of the skin to produce vitamin $D(39)$. Despite the higher dietary vitamin $D$ intake compared to the average Dutch population $(3.2 \pm 2.2 \mathrm{mcg} / \mathrm{d})(40)$, athletes are at high risk of vitamin D deficiency in the winter as shown in the current study. This vitamin $D$ deficiency might hinder optimal sports performance. Therefore, it is important to measure total 25(OH)D concentration in athletes at the end of the winter and recommend athletes with a low total $25(\mathrm{OH}) \mathrm{D}$ concentration to take vitamin D supplements.

One of the strengths of the current dose-response study is the large sample size of 102 male and female athletes. Elite athletes are generally hard to reach as research participants and are therefore an underrepresented group in current literature. The number of elite athletes in the current study exceeds most of the previous dose-response studies. In addition, the follow-up period of 12 months allowed us to assess the effect of supplements throughout all seasons. However, the large group of athletes and the long follow-up period resulted in a relatively high number of drop-outs and missing values (Figure 3.2). Another strength of the current dose-response study is the inclusion of the self-reported sunlight exposure. Although an objective measure of sunlight exposure (for example a dosimeter) would possibly show a more precise estimate of the UVB-exposure, we were able to assess factor as sun bed use, time spent outside and clothing habits. The development of a standardized sunlight questionnaire or the use of a dosimeter would be valuable for studies focusing on vitamin D intake and/or total 25(OH)D concentrations. Also, data on the effect of vitamin D supplements on athletic performance and general agreement on the definitions for vitamin $D$ deficiency, insufficiency and sufficiency, would be valuable for future studies.

In conclusion, vitamin $\mathrm{D}$ deficiency is highly prevalent among Dutch elite athletes. Athletes with a deficient or insufficient total $25(\mathrm{OH}) \mathrm{D}$ concentration can achieve a sufficient tota 25(OH)D concentration within 3 months by taking $2200 \mathrm{IU} / \mathrm{d}$. After reaching a high total $25(\mathrm{OH}) \mathrm{D}$ concentration (> $125 \mathrm{nmol} / \mathrm{L}$ ), vitamin $\mathrm{D}$ supplementation of $400 \mathrm{lU} / \mathrm{d}$ is adequate to maintain a sufficient total $25(\mathrm{OH}) \mathrm{D}$ concentration.

Acknowledgement

The authors thank all the students and Lucy Okma for assisting during the tests. 


\section{References}

Ross AC, Manson JE, Abrams SA, Aloia JF, Brannon PM, Clinton SK, et al. The 2011 report on dietary reference intakes for calcium and vitamin $D$ from the Institute of Medicine: what clinicians need to know. The Journal of clinical endocrinology and metabolism. 2011;96(1):53-8.

2. Allison RJ, Close GL, Farooq A, Riding NR, Salah O, Hamilton B, et al. Severely vitamin D-deficient athletes present smaller hearts than sufficient athletes. European journal of preventive cardiology. 2014.

3. Close GL, Leckey J, Patterson M, Bradley W, Owens DJ, Fraser WD, et al. The effects of vitamin D(3) supplementation on serum total $25[\mathrm{OH}] \mathrm{D}$ concentration and physical performance: a randomised doseresponse study. British journal of sports medicine. 2013;47(11):692-6.

4. Ducher G, Kukuljan S, Hill B, Garnham AP, Nowson CA, Kimlin MG, et al. Vitamin D status and musculoskeletal health in adolescent male ballet dancers a pilot study. Journal of dance medicine \& science : official publication of the International Association for Dance Medicine \& Science. 2011;15(3):99107.

5. Mowe M, Haug E, Bohmer T. Low serum calcidiol concentration in older adults with reduced muscular function. Journal of the American Geriatrics Society. 1999:47(2):220-6.

6. Salles J, Chanet A, Giraudet C, Patrac V, Pierre P, Jourdan M, et al. 1,25(OH)2-vitamin D3 enhances the stimulating effect of leucine and insulin on protein synthesis ret. stimulating effect Close GL, Russell d, Coby IN, Owens DJ, Wilson G, Gretson W et al. Asssment of vitamin D

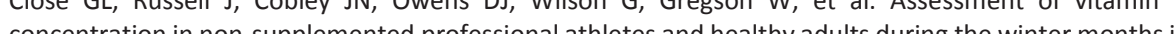
the UK implications for skeleta muscle function. Jounal of sports sciences. 2013;31(4):344-53. 8. Barker T, Schneider ED, Dixon BM, Henriksen VT, Weaver LK. Supplemental vitamin D enhances the

Wyon MA, Koutedakis $Y$, Wolman R, Nevill AM, Allen N. The influence of winter vitamin supplementation on muscle function and injury occurrence in elite ballet dancers: a controlled study. Journal of science and medicine in sport / Sports Medicine Australia. 2014;17(1):8-12

10. Holick MF. Vitamin D status: measurement, interpretation, and clinical application. Annals of epidemiology. 2009:19(2):73-8.

11. Wyon MA, Wolman R, Nevill AM, Cloak R, Metsios GS, Gould D, et al. Acute Effects of Vitamin D3 Supplementation on Muscle Strength in Judoka Athletes: A Randomized Placebo-Controlled Double Blind Trial Clinical journal of sport medicine official journal of the Canation Academy of Sport Medicine 2015.

Dubnov-Raz G, Livne N, Raz R, Cohen AH, Constantini NW, Vitamin D Supplementation and Physical Cons 2015;25(4):317-25.
2

13. Gezondheidsraad. Evaluation of dietary reference values for vitamin D. The Hague Health Council of the Netherlands, 2012.

14. Gallagher JC, Sai A, Templin T, 2nd, Smith L. Dose response to vitamin D supplementation in postmenopausal women: a randomized trial. Annals of internal medicine. 2012;156(6):425-37.

15. Cashman KD, Wallace JM, Horigan G, Hill TR, Barnes MS, Lucey AJ, et al. Estimation of the dietary requirement for vitamin $D$ in free-living adults $>=64$ y of age. The American journal of clinical nutrition. 2009;89(5):1366-74.

16. Heaney RP, Davies KM, Chen TC, Holick MF, Barger-Lux MJ. Human serum 25-hydroxycholecalcifero response to extended oral dosing with cholecalciferol. The American journal of clinical nutrition. 2003;77(1):204-10

17. Halliday TM, Peterson NJ, Thomas JJ, Kleppinger K, Hollis BW, Larson-Meyer DE. Vitamin D status relative to diet, lifestyle, injury, and illness in college athletes. Medicine and science in sports and exercise. 2011;43(2):335-43.

18. Clark M, Reed DB, Crouse SF, Armstrong RB. Pre- and post-season dietary intake, body composition, and performance indices of NCAA division I female soccer players. International journal of sport nutrition and exercise metabolism. 2003;13(3):303-19.

19. Brouwer-Brolsma EM, Vaes AM, van der Zwaluw NL, van Wijngaarden JP, Swart KM, Ham AC, et a. Relative importance of summer sun exposure, vitamin $D$ intake, and genes to vitamin $D$ status in Dutch older adults: The B-PROOF study. The Journal of steroid biochemistry and molecular biology. 2015.

20. Fitzgerald JS, Peterson BJ, Wilson PB, Rhodes GS, Ingraham SJ. Vitamin D status is associated with adiposity in male ice hockey players. Medicine and science in sports and exercise. 2015;47(3):655-61.

21. Blum M, Dolnikowski G, Seyoum E, Harris SS, Booth SL, Peterson J, et al. Vitamin D(3) in fat tissue Endocrine. 2008:33(1):90-4.
22. Holick MF, Matsuoka LY, Wortsman J. Age, vitamin D, and solar ultraviolet. Lancet. 1989;2(8671):1104-5.

23. Mavroeidi A, ONeill F, Lee PA, Darling AL, Fraser WD, Berry JL, et al. Seasonal 25-hydroxyvitamin $D$ changes in British postmenopausal women at 57 degrees $\mathrm{N}$ and 51 degrees $\mathrm{N}$ : a longitudinal study. The Journal of steroid biochemistry and molecular biology. 2010;121(1-2):459-61.

24. Dawson-Hughes B, Harris SS, Palermo NJ, Ceglia L, Rasmussen H. Meal conditions affect the absorption of supplemental vitamin D3 but not the plasma 25-hydroxyvitamin D response to supplementation. Journa of bone and mineral research : the official journal of the American Society for Bone and Mineral Research. 2013;28(8):1778-83

25. Siebelink E, Geelen A, de Vries JH. Self-reported energy intake by FFQ compared with actual energy intake to maintain body weight in 516 adults. The British journal of nutrition. 2011;106(2):274-81.

26. Faul F, Erdfelder E, Lang AG, Buchner A. G*Power 3: a flexible statistical power analysis program for the social, behavioral, and biomedical sciences. Behavior research methods. 2007;39(2):175-91.

27. Cashman KD, Seamans KM, Lucey AJ, Stocklin E, Weber P, Kiely M, et al. Relative effectiveness of oral 25 hydroxyvitamin D3 and vitamin D3 in raising wintertime serum 25-hydroxyvitamin D in older adults. The American journal of clinical nutrition. 2012;95(6):1350-6.

28. Farrokhyar F, Tabasinejad R, Dao D, Peterson D, Ayeni OR, Hadioonzadeh R, et al. Prevalence of Vitami $D$ Inadequacy in Athletes: A Systematic-Review and Meta-Analysis. Sports medicine (Auckland, NZ). 2014. Constantini NW, Arieli R, Chodick G, Dubnov-Raz G. High prevalence of vitamin D insufficiency in athletes and dancers. Clinical journal of sport medicine : official journal of the Canadian Academy of Sport Medicine. 2010;20(5):368-71

30. Hamilton B, Grantham J, Racinais S, Chalabi H. Vitamin D deficiency is endemic in Middle Eastern sportsmen. Public health nutrition. 2010;13(10):1528-34.

31. Bescos Garcia R, Rodriguez Guisado FA. Low levels of vitamin D in professional basketball players after wintertime: relationship with dietary intake of vitamin $D$ and calcium. Nutricion hospitalaria. 2011;26(5):945-51

32. Galan F, Ribas J, Sanchez-Martinez PM, Calero T, Sanchez AB, Munoz A. Serum 25-hydroxyvitamin D in early autumn to ensure vitamin $D$ sufficiency in mid-winter in professional football players. Clinica nutrition (Edinburgh, Scotland). 2012,31(1).132-6.

33. Cashman KD, Fitzgerald AP, Kiely M, Seamans KM. A systematic review and meta-regression analysis of the vitamin $D$ intake-serum 25 -hydroxyvitamin D relationship to inform European recommendations. The British journal of nutrition. 2011,106(11):1638-48.

34. Cashman KD, Hill TR, Lucey AJ, Taylor N, Seamans KM, Muldowney S, et al. Estimation of the dietary requirement for vitamin $D$ in healthy adults. The American journal of clinical nutrition. 2008;88(6):153542.

35. Melamed ML, Michos ED, Post W, Astor B. 25-hydroxyvitamin D levels and the risk of mortality in the general population. Archives of internal medicine. 2008;168(15):1629-37.

36. Durup D, Jorgensen HL, Christensen J, Schwarz P, Heegaard AM, Lind B. A reverse J-shaped association of all-cause mortality with serum 25 -hydroxyvitamin $D$ in general practice: the CopD study. The Journal of clinical endocrinology and metabolism. 2012;97(8):2644-52.

37. Vieth R. Vitamin D supplementation, 25-hydroxyvitamin D concentrations, and safety. The American journal of clinical nutrition. 1999;69(5):842-56.

38. EFSA Panel on Dietetic Products NaAN. Scientific Opinion on the Tolerable Upper Intake Level of vitamin D EFSA Journal 2012;10(7):2813-2858: 2012

39. MacLaughlin J, Holick MF. Aging decreases the capacity of human skin to produce vitamin D3. The Journa of clinical investigation. 1985;76(4):1536-8.

40. KFAM Hulshof MO, CTM van Rossum, EJM Buurma-Rethans, HAM Brants, JJMM Drijvers, D ter Doest Resultaten van de Voedselconsumptiepeiling 2003 Zeist: 2003. 


\section{Chapter 4}

Creatine loading does not preserve muscle mass or strength during leg immobilization in healthy, young males

Evelien M.P. Backx Roland Hangelbroek

Tim Snijders

Marie-Louise Verscheijden

Lex B. Verdijk

Lisette C.P.G.M. de Groot

Luc J.C. van Loon 
Background A short period of leg immobilization leads to rapid loss of muscle mass and strength. Creatine supplementation has been shown to increase lean body mass in active individuals and can be used to augment gains in muscle mass and strength during prolonged resistance type exercise training.

Objective To investigate whether creatine loading can attenuate the loss of muscle mass and strength during short-term leg immobilization.

Methods Thirty healthy, young men (aged $23 \pm 1 \mathrm{y} ; \mathrm{BMI} 23.3 \pm 0.5 \mathrm{~kg} \cdot \mathrm{m}^{-2}$ ) were randomly assigned to either a creatine (CR) or a placebo group (PLA). Subjects received placebo or creatine supplements $(20 \mathrm{~g} / \mathrm{d})$ for 5 days before one leg was immobilized by means of a fullleg cast for 7 days. Muscle biopsies were taken before creatine loading, prior to and immediately after leg immobilization and after 7 days of subsequent recovery. Quadriceps cross-sectional area (CT scan) and leg muscle strength (1-RM knee extension) were assessed before and immediately after immobilization and after one week of recovery. Data were analyzed using repeated measures ANOVA. Data is represented consistently as mean \pm SEM. Results Quadriceps muscle cross sectional area had declined by $465 \pm 59$ and $425 \pm 69 \mathrm{~mm}^{2}$ $(P<0.01)$ in the $C R$ and PLA group, respectively, with no differences between groups $(P=0.76)$. Leg muscle strength decreased from $56 \pm 4$ to $53 \pm 4 \mathrm{~kg}$ in the $C R$ and from $59 \pm 3$ to $53 \pm 3 \mathrm{~kg}$ in the PLA group, with no differences between groups $P=0.20)$. Muscle fiber size did not change significantly over time in either group $(P>0.05)$. When non-responders to creatine loading were excluded $(n=6)$, responders $(n=8$; total creatine content increasing from 70 to $106 \mathrm{mmol} \cdot \mathrm{kg}^{-1}$ ) showed similar findings with no signs of preservation of muscle mass or strength during immobilization. During the subsequent recovery phase, no differences in muscle mass or strength were found between the two groups $(P>0.05)$.

Conclusion Creatine supplementation prior to and during leg immobilization does not prevent or attenuate the loss of muscle mass or strength during short term muscle disuse.

\section{Introduction}

Recovery from injury or illness often requires a period of inactivity. Even short periods of disuse lead to a substantial loss of skeletal muscle mass and strength $(1,2)$. The loss of muscle mass and strength is associated with a longer recovery period and with a higher risk of injury reoccurrence $(3,4)$. Moreover, periods of disuse result in reduced insulin sensitivity $(5,6)$, a decline in basal metabolic rate (7) and an increase in body fat mass (8). These factors impair physical functioning and decline metabolic health, causing even more health concerns. Therefore, strategies are warranted to prevent the loss of muscle mass and/or strength during short periods of disuse due to injury or hospitalization.

During the nineties, creatine supplements became a popular ergogenic aid for athletes. Creatine monohydrate supplementation can increase the phosphocreatine/creatine ratio in skeletal muscle tissue, thereby increasing the capacity for rapid ATP resynthesis during repeated high-intensity exercise tasks (9-11). In accordance, creatine supplementation was shown to effectively augment athletic performance during various exercise tasks characterized by repeated, high intensity exercise and has since become common practice among many athletes (12-14) . Besides increasing high-intensity exercise performance, creatine supplementation has also been reported to increase muscle mass and strength in the presence as well as in the absence of prolonged resistance type exercise training $(9,15$, 16). The increase in lean mass following creatine supplementation has, at least partly, been attributed to water retention in muscle tissue $(11,17)$. The greater osmotic pressure following the increase in creatine content has been suggested to result in muscle cel swelling, which is considered a key stimulus for cell growth $(11,18)$.

Consequently, it has been hypothesized that creatine loading prior to immobilization may help to prevent muscle loss during a short period of disuse (19). So far, only two studie have assessed the clinical benefits of creatine supplementation during immobilization to prevent or attenuate disuse atrophy $(20,21)$. Whereas creatine supplementation attenuated muscle loss during a 1-wk arm immobilization (20), no effect was observed during a 2-wk leg immobilization period (21). Since both studies did not include a creatine loading phase to allow an increase in muscle creatine content before immobilization (20, 21 ), it remains to be determined whether creatine loading prior to (leg) immobilization can preserve muscle mass and strength in humans.

We hypothesized that creatine loading prevents or attenuates the loss of muscle mass and strength during one week of leg immobilization. To test our hypothesis, we selected 30 young males to participate in a study in which they were subjected to 7 days of single-leg immobilization. Subjects received either placebo or creatine supplements from 5 days prior to immobilization until the end of the study. To assess the effect of creatine loading, muscle biopsies were taken at baseline and after 5 days of creatine loading $(20 \mathrm{~g} / \mathrm{d})$. Before and after 7 days of immobilization as well as after 7 days of subsequent recovery, we assessed muscle mass and strength. In addition, muscle biopsies were taken to assess muscle fiber characteristics. 
Methods

\section{Subjects}

After screening, thirty healthy, young men (age: $23 \pm 1 \mathrm{y}$; body mass index: $23.3 \pm 0.5 \mathrm{~kg} \cdot \mathrm{m}^{-2}$ ) were included in the study. Exclusion criteria included a (family) history of thrombosis, any back/leg/knee/shoulder complaints which could interfere with the use of crutches, and any co-morbidities interacting with mobility or muscle metabolism of the lower limbs (e.g. arthritis, spasticity/rigidity, all neurological disorders and paralysis). None of the subjects reported to have performed progressive resistance type exercise training, used creatine supplements, anti-coagulants, corticosteroids, growth hormone, testosterone, immunosuppressants or exogenous insulin over the previous 6 months. During the screening, subjects gave written informed consent after they were fully informed about the nature and possible risks of the experimental procedures. The study was approved by the Medical Ethics Committee of the Maastricht University Medical Centre+ and performed in accordance with the Declaration of Helsinki.

\section{Experimental design}

The present study was a double-blind, placebo-controlled intervention trial with 30 subjects randomly allocated into either the placebo (PLA; $n=15)$ or the creatine (CR; $n=15$ ) supplemented group (Figure 4.1). All subjects reported to the laboratory following an overnight fast on 4 occasions. Standardized meals (2.9 MJ; providing 51 energy percent (En\%) as carbohydrate, $32 \mathrm{En \%}$ as fat, and $17 \mathrm{En} \%$ as protein) were consumed the evening prior to all 4 test days. On the first test visit (baseline), body weight was assessed after which a muscle biopsy sample was taken from the vastus lateralis muscle. Subjects started with the creatine or placebo supplements directly after the baseline test. Five days after the baseline test, the subjects came in for the pre-immobilization test. During the preimmobilization test, a second muscle biopsy was taken to assess the effect of creatine loading on muscle creatine content and a baseline assessment of muscle mass (CT scan upper legs) and knee extension strength (one-repetition maximum (1-RM)) were conducted. Two days after the pre-immobilization test, one leg was immobilized by means of a full leg cast for 7 subsequent days. On the day of the cast removal and after 7 days of recovery, another muscle biopsy was taken and muscle mass and strength assessments were repeated.

\section{Measurements}

Body weight was measured with a digital balance with an accuracy of $0.1 \mathrm{~kg}$ (SECA GmbH, Hamburg, Germany). Muscle biopsies were taken from the middle region of the vastus lateralis muscle under local anaesthesia, $\sim 15 \mathrm{~cm}$ above the patella and $\sim 3 \mathrm{~cm}$ below entry through the fascia, using the percutaneous needle biopsy technique (22). All biopsies were taken from the leg that was subsequently immobilized. Muscle samples were dissected carefully and freed from any visible non-muscle material and were immediately frozen in liquid nitrogen (biochemical analyses), or in liquid-nitrogen cooled isopentane (histochemical analyses). Subsequently, muscle samples were stored at $-80^{\circ} \mathrm{C}$ until further analysis.

Muscle mass was assessed with a single slice CT-scan (Philips Brilliance 64, Philips Medical Systems, Best, the Netherlands) to assess cross-sectional area (CSA) of the quadriceps muscle. The scanning characteristics were as follows: $120 \mathrm{kV}, 300 \mathrm{~mA}$, rotation time of 0.75 $\mathrm{s}$, and a field of view of $500 \mathrm{~mm}$. With subjects lying supine with their legs extended and feet secured, a $3 \mathrm{~mm}$ thick axial image was taken $15 \mathrm{~cm}$ proximal to the top of the patella. The precise scan position was marked with semi-permanent ink for the duration of the intervention period to ensure accurate repeated measurements. For analysis, muscle area of the legs was selected between -29 to 150 Hounsfield units (23), after which the quadriceps muscle was selected by manual tracing using ImageJ software (version 1.49p, National Institute of Health, Maryland, USA) (24-26). As a measure of muscle strength, maximal leg strength was assessed by 1-RM (5) for each leg individually on a knee extension machine (Technogym, Rotterdam, The Netherlands), as described in more detail previously (27). In short, during the screening visit, subjects started with a warm-up on a cycle ergometer. After demonstration of the lifting technique, a familiarization trial was performed to ensure proper execution of the exercise protocol. The maximum amount of repetitions measured for a certain load was used to estimate the 1-RM: 1-RM 1/4 load/(1.02787 $0.0278^{*}$ reps) (28). This estimate was used during the following visits to determine the initial load for the actual 1-RM test. During the actual 1-RM test, the load was set at $~ 90 \%$ of the estimated 1-RM and was increased by $2.5-5.0 \%$ after each successful lift until failure.

\begin{tabular}{|c|c|c|}
\hline $\begin{array}{c}\text { Loading } \\
(20 \mathrm{~g} / \mathrm{d})\end{array}$ & \multicolumn{2}{|c|}{ Maintenance } \\
\hline $5 \mathrm{~g} / \mathrm{d}$ \\
\hline $5 \mathrm{~d}$ & $7 \mathrm{~d}$ immobilization & $7 \mathrm{~d}$ recovery \\
\hline
\end{tabular}

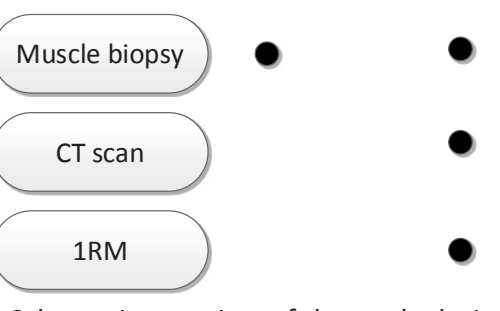

Figure 4.1: Schematic overview of the study design

Supplements

The PLA group received a placebo supplement consisting of $7.5 \mathrm{~g}$ maltodextrin (AVEBE, Veendam, The Netherlands) and $7.5 \mathrm{~g}$ of dextrose monohydrate (AVEBE). The CR group received the same supplement with the addition of $5 \mathrm{~g}$ creatine monohydrate (Creapure AlzChem, Trostberg, Germany). The creatine supplements could not be distinguished from the placebo supplement with respect to colour, taste, smell or appearance. All subjects 
were instructed to dissolve the supplement in lukewarm tap water prior to ingestion. During the first 5 days of creatine loading, subjects consumed 4 supplements per day (providing a total of $20 \mathrm{~g}$ creatine per day for the CR group) at breakfast, lunch, dinner and immediately prior to going to bed (approximately $5 \mathrm{~h}$ intervals between supplements). Thereafter subjects continued with one supplement per day as a maintenance dose (containing 5 creatine per day for the CR group) during the subsequent immobilization and recovery period. The applied creatine supplementation protocol was designed according to the guidelines on creatine supplementation set by the American College of Sports Medicine (29).

Limb immobilization

Two days after the pre-immobilization test, subjects attended the Casting Room at Maastricht University Medical Centre at 08.00 am to have a full leg cast fitted to induce knee immobilization. The leg to be immobilized was randomized and counter-balanced between left and right. The circular leg cast extended from $10 \mathrm{~cm}$ above the ankle to approximately $25 \mathrm{~cm}$ above the patella. The knee was casted at a $30^{\circ}$ angle of flexion to prevent subjects from being able to perform any weight bearing activities on the casted limb. Subjects were provided with crutches for proper ambulation. Throughout the immobilization period, subjects were instructed to perform a series of daily simple ankle exercises (i.e. plantar and dorsal flexion, and circular movements of the entire foot) to keep the calf muscle pump activated in the immobilized leg, thereby minimizing the risk of developing deep vein thrombosis. Prior to the start of the third test visit, subjects visited the Casting Room to have the cast removed. Following cast removal, subjects were transported by wheelchair to prevent any weight bearing on the immobilized leg until the muscle biopsy sample was collected.

Diet and physical activity

Subjects were asked to maintain habitual dietary intake during the entire intervention period. To check for any deviations, the participants completed dietary intake records, including food sources, estimation of the portion size using household measures and the timing of intake. Dietary intake records were completed before and during the immobilization period on 2 weekdays and 1 weekend day. DieetInzicht software (7), based on the Dutch food composition table (NEVO table) 2011, was used to analyze dietary intake records. Alcohol intake was allowed until $48 \mathrm{~h}$ before every test visit. Subjects refrained from any heavy physical exercise during the entire intervention period. Therefore, a 3-day activity journal was completed by the participants on the same days as the dietary intake records

Muscle total creatine analysis

ne fraction of the muscle sample (approximately $50 \mathrm{mg}$ wet tissue) was freeze-dried and pulverized. Muscle creatine and phosphocreatine content were analyzed as described by
Harris et al. (30). After adding perchloric acid (250 $\mu \mathrm{L}$ PCA 1M), muscle samples (10 mg dry muscle) were centrifuged, $\mathrm{KHCO} 3(105 \mu \mathrm{L}, 2 \mathrm{M})$ was added to neutralize samples, after which samples were centrifuged again. Supernatants were used for spectrophotometric determination of creatine and phosphocreatine content on the Cobas Fara (Roche, Switzerland). The biochemically determined metabolite concentrations for each muscle sample were expressed as millimoles per kilogram dry weight.

Histochemical analysis

Part of each muscle biopsy sample was frozen in liquid nitrogen cooled isopentane. These samples were cut into $5-\mu \mathrm{m}$ thick cryosections using a cryostat at $-20^{\circ} \mathrm{C}$. Muscle biopsies were stained for muscle fiber typing and used to assess muscle fiber type composition and type I and II muscle fiber size as described in detail previously (31). In short, slides were incubated with primary antibodies directed against myosin heavy chain (MHC)-I (A4.840, dilution 1:25; Developmental Studies Hybridoma Bank, lowa City, IA, USA) and laminin (polyclonal rabbit antilaminin, dilution 1:50; Sigma, Zwijndrecht, the Netherlands). Goat anti-mouse IgM AlexaFluor555 and goat anti-rabbit IgG AlexaFluor647 were applied as secondary antibodies (dilution 1:500 and 1:400; Molecular Probes, Invitrogen, Breda, the Netherlands). Images were captured with a fluorescent microscope and analyzed for muscle cross-sectional area and fiber type distribution using ImageJ software.

\section{Statistics}

All data are expressed as means \pm SEM. The sample size was based upon a power calculation with an expected difference in the loss of quadriceps CSA of $40 \%$ between the PLA and CR group (respectively 5 vs $3 \%$ loss of quadriceps CSA) (32). With a power of $80 \%$ and a significance level $(\alpha)$ of 0.05 , at least 13 participants are required per group. Thirty subjects were included to allow for drop-outs.

An independent t-test was used to assess differences in baseline characteristics between subjects in the PLA and CR group. Our main objective focused on the differences between the PLA and CR group during immobilization. A two-way repeated measures ANOVA with time (pre-immobilization vs post-immobilization) as within-subjects factor, and treatment (CR and PLA group) as between-subjects factors was used to compare changes in quadriceps CSA, muscle strength and muscle fiber characteristics during immobilization. Thereafter, a two-way repeated measures ANOVA was conducted with time (post-immobilization vs postrecovery) as within-subjects factor to test the differences between the PLA and CR groups during the recovery week. A third repeated measures ANOVA with all 3 time points (preimmobilization, post-immobilization and post-recovery) was conducted to test whether the PLA and CR group responded differently throughout the whole study period. For muscle fiber characteristics, a second within-subjects factor was added (type I vs type II fibers). The effects of the creatine loading phase on muscle free creatine, phosphocreatine and total creatine, as well as body weight were tested using a two-way repeated measures 
ANOVA with time (all time points; and baseline vs pre-immobilization separately) as withinsubjects factor and treatment (CR and PLA group) as between-subjects factors.

In case of a significant time $x$ treatment interaction, paired t-tests were performed in the CR and PLA groups separately, with Bonferroni correction when appropriate (i.e. more than 2 time points). Data were analyzed using SPSS version 21 (SPSS, IBM Corp., Armonk, NY, USA). Results were considered statistically significant in case $\mathrm{P}<0.05$.

Results

Subjects

Baseline subjects' characteristics did not differ between the PLA and CR groups (quadricep CSA $7712 \pm 324$ and $8194 \pm 263 \mathrm{~mm}^{2} ; \mathrm{P}=0.26$, and leg muscle strength $56 \pm 4$ and $59 \pm 3 \mathrm{~kg}$; $\mathrm{P}=0.47$ respectively) (Table 4.1). Three subjects withdrew prior to immobilization due to time constraints. From the 30 participants, 27 completed the study (PLA: $n=13 ; C R: n=14$ ).

Table 4.1: Subjects' baseline characteristics

\begin{tabular}{lll}
\hline & Placebo group $(\boldsymbol{n}=\mathbf{1 3})$ & Creatine group $(\boldsymbol{n}=\mathbf{1 4})$ \\
\hline Age (years) & $23 \pm 1$ & $23 \pm 1$ \\
Body weight $(\mathbf{k g})$ & $73 \pm 3$ & $75 \pm 2$ \\
Height $(\mathrm{m})$ & $1.76 \pm 0.03$ & $1.81 \pm 0.02$ \\
BMI $\left(\mathbf{k g} \cdot \mathbf{m}^{-2}\right)$ & $23.5 \pm 0.9$ & $23.0 \pm 0.5$ \\
1RM (kg) & $55 \pm 4$ & $59 \pm 3$ \\
Quadriceps CSA $\left(\mathbf{m m}^{2}\right)$ & $7712 \pm 324$ & $8194 \pm 263$
\end{tabular}

Data are expressed as the means \pm SEM. No differences are found between groups ( $P>0.05)$. BMI: body mass index $\left(\mathrm{kg} \cdot \mathrm{m}^{-2}\right)$, CSA: cross-sectional area.

\section{Creatine loading}

Muscle tissue free creatine, phosphocreatine, and total creatine content are displayed in Table 4.2. At baseline, total muscle creatine content averaged $89 \pm 5 \mathrm{mmol} \cdot \mathrm{kg}$ of dry muscle ${ }^{-1}$ $\left(\mathrm{mmol} \cdot \mathrm{kg}^{-1}\right)$, with no differences between the PLA and CR group $\left(88 \pm 4\right.$ vs $90 \pm 9 \mathrm{mmol} \cdot \mathrm{kg}^{-1}$, respectively; $\mathrm{P}=0.68)$. Despite similar baseline values, an overall treatment effect was observed when all time points were included in the analysis, showing that muscle creatine content was greater in the CR vs PLA group $(P=0.03)$. When focusing on the loading phase, a significant main effect of time $(P=0.049)$ was observed, showing an increase in total creatine content. Although the time $x$ group interaction did not reach statistical significance $(P=0.066)$, this increase in total muscle creatine content appeared to be driven by an increase in the CR group (from $90 \pm 9$ to $107 \pm 4 \mathrm{mmol} \cdot \mathrm{kg}^{-1}$ following 5 days of loading), with no apparent changes in muscle total creatine contents in the PLA group (from $88 \pm 4$ to $90 \pm 3$ $\left.\mathrm{mmol} \cdot \mathrm{kg}^{-1}\right)$. In accordance, a significant time $\mathrm{x}$ treatment interaction was observed for muscle free creatine content $(P=0.011)$, with post-hoc analyses showing a significant increase in the $C R$ group $(P<0.001)$ with no changes over time in the PLA group (Table 4.2). In the CR group ( $n=14), 6$ subjects did not show an increase in total muscle creatine content exceeding $10 \mathrm{mmol}$ creatine $\cdot \mathrm{kg}^{-1}$ and could, therefore, be considered non-responders to creatine loading (10). In agreement with previous findings $(10,33)$, these non-responders showed higher baseline muscle creatine contents when compared to most responders $\left(121 \pm 8\right.$ vs $\left.70 \pm 9 \mathrm{mmol} \cdot \mathrm{kg}^{-1} ; \mathrm{P}<0.01\right)$. The individual responses to creatine loading are presented in Figure 4.2. In the responders to creatine loading, we observed a significant increase in total creatine content in muscle from $70 \pm 9$ to $106 \pm 6 \mathrm{mmol} \cdot \mathrm{kg}^{-1}(P<0.01)$.

During the loading phase, body weight increased more in the CR compared to the PLA group (time $x$ treatment interaction $P=0.02$ ). Body weight increased from $73.7 \pm 2.2$ to $74.4 \pm 2.3 \mathrm{~kg}$ the $C R$ group $(P=0.01)$, with no changes observed in the PLA group $(71.2 \pm 2.8$ to $71.4 \pm 2.8 \mathrm{~kg}$ $P=0.39$ ). Within the $C R$ group, greater increases in body weight were observed in the responders to creatine loading compared with the non-responders $(P=0.03)$. Individual changes in body weight in the responders and non-responders in the creatine group are presented in Figure 4.3.

Table 4.2: Muscle creatine content

\begin{tabular}{lllllllll}
\hline & \multicolumn{3}{c}{ Placebo group ( $n=13)$} & \multicolumn{4}{c}{ Creatine group (n=13) } \\
\hline & Baseline & $\begin{array}{l}\text { Pre- } \\
\text { immobili }\end{array}$ & $\begin{array}{l}\text { Post- } \\
\text { immobili }\end{array}$ & Recovery & Baseline & $\begin{array}{l}\text { Pre- } \\
\text { immobili }\end{array}$ & $\begin{array}{l}\text { Post- } \\
\text { immobili }\end{array}$ & Recovery \\
& & zation & zation & & & $\begin{array}{l}\text { zation } \\
\text { zation }\end{array}$ & \\
Free Cr & $40 \pm 2$ & $44 \pm 4$ & $48 \pm 4$ & $40 \pm 3$ & $34 \pm 1$ & $48 \pm 4^{\#}$ & $53 \pm 3^{\#}$ & $52 \pm 3^{\#}$ \\
CrP & $48 \pm 4$ & $45 \pm 4$ & $40 \pm 4$ & $55 \pm 5$ & $55 \pm 10$ & $59 \pm 6$ & $45 \pm 5$ & $52 \pm 5$ \\
Total Cr & $88 \pm 4$ & $90 \pm 3$ & $87 \pm 3$ & $95 \pm 4$ & $90 \pm 9^{*}$ & $107 \pm 4^{*}$ & $98 \pm 6^{*}$ & $104 \pm 4^{*}$
\end{tabular}

Data are expressed as the means \pm SEM. Free $\mathrm{Cr}$ (Creatine), CrP (creatine phosphate), and total $\mathrm{Cr}$ content are expressed in $\mathrm{mmol} \cdot \mathrm{kg}$ of dry muscle ${ }^{-1}$. Independent t-tests showed no differences between treatments at baseline. Repeated measures ANOVA (time $x$ treatment) showed: "Significant time $x$ treatment interaction $(\mathrm{P}=0.01)$ for Free $\mathrm{Cr}$; Bonferroni corrected post-hoc showed a significant increase compared with baseline in the creatine group only (all $\mathrm{P} \leq 0.01)$. *Significant treatment effect $(\mathrm{P}=0.03)$ for Total $\mathrm{Cr}$. 


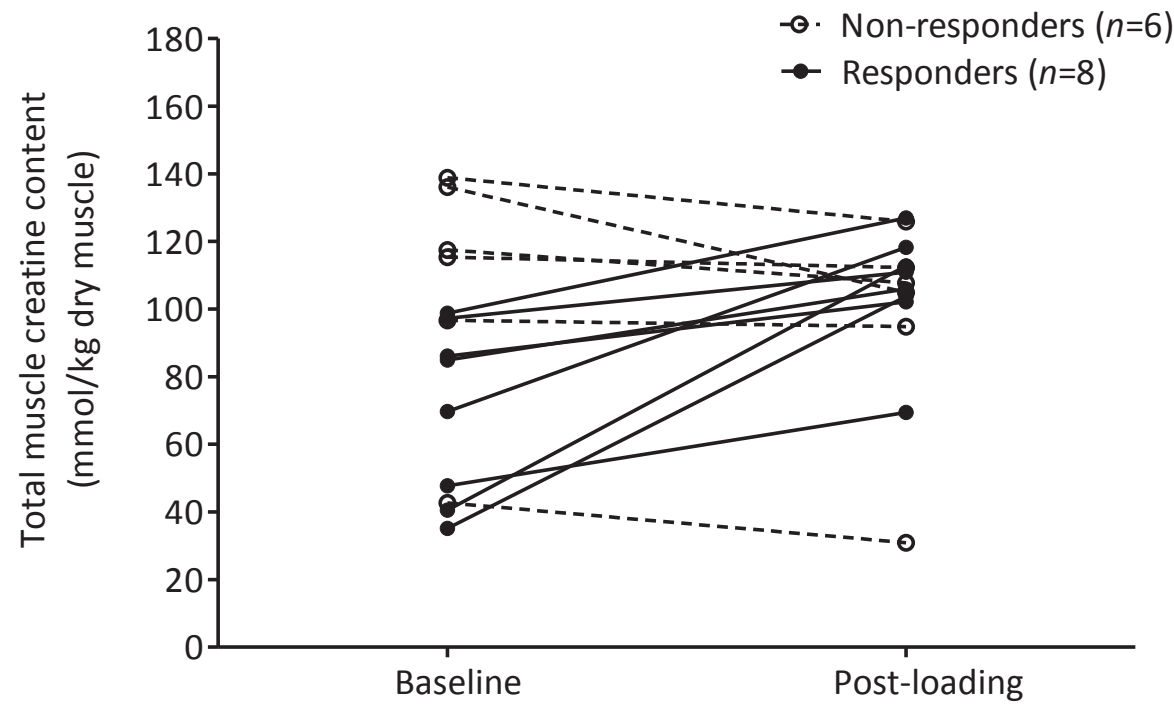

Figure 4.2: Individual changes in total muscle creatine at baseline and after 5 days of creatine loading in the CR group. The responders to creatine supplementation $(n=8)$ were defined as subjects who showed an increase in total muscle creatine exceeding $10 \mathrm{mmol} \cdot \mathrm{kg}^{-1}(10)$. The non-responders $(n=6)$ were defined as those subjects that showed no increase in muscle total creatine content or an increase less than $10 \mathrm{mmol}$ creatine $\cdot \mathrm{kg}^{-1}(10)$.

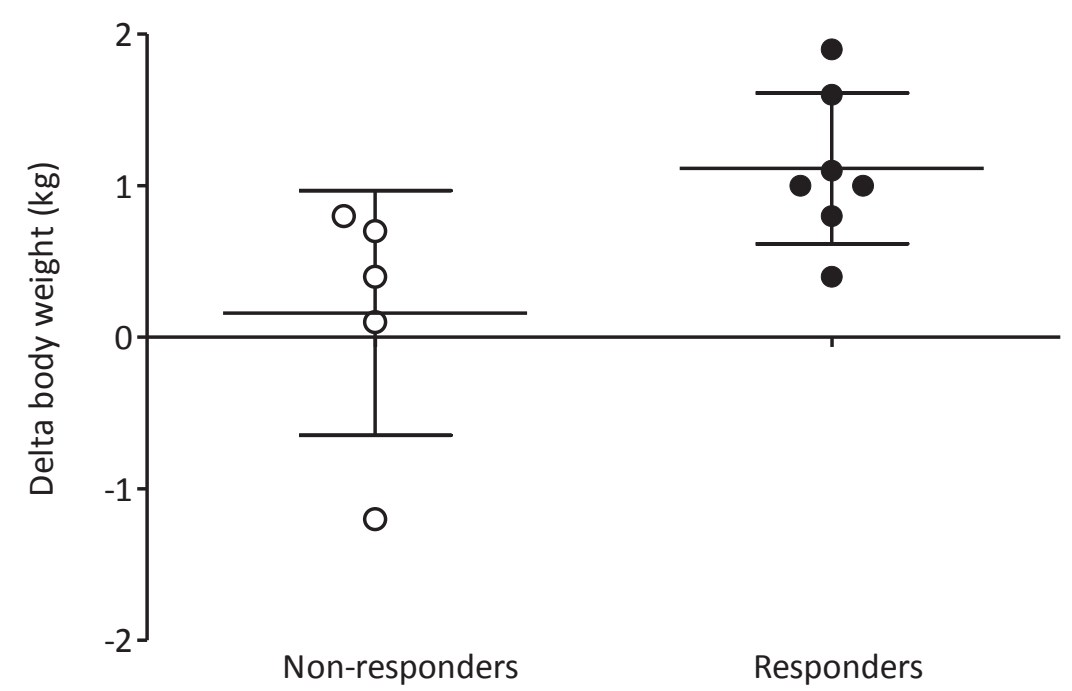

Figure 4.3: Individual changes in body weight in the responders and non-responders following 5 days of creatine loading. Body weight changes are calculated as post-loading minus baseline values.

\section{Muscle mass}

Leg immobilization resulted in a significant decline in muscle cross-sectional area of the quadriceps muscle $(\mathrm{P}<0.01)$ with no differences between groups (Figure 4.4; time $x$ treatment interaction $P=0.76$ ). Quadriceps CSA decreased by $5.5 \pm 0.8 \%$ (from $7712 \pm 324$ to $7287 \pm 305 \mathrm{~mm}^{2}$ ) in the PLA group. In the CR group, quadriceps CSA decreased by $5.6 \pm 0.8 \%$ (from $8194 \pm 263$ to $7729 \pm 245 \mathrm{~mm}^{2}$ ). During the subsequent recovery phase, quadriceps CSA increased by $2.0 \pm 0.6$ and $1.1 \pm 0.7 \%$ in the PLA and CR group respectively $(P<0.01)$, with no differences between groups (time $x$ treatment interaction $P=0.52$ ).

In agreement with the changes in quadriceps CSA, the CSA of the whole thigh muscle decreased during immobilization in both the PLA (3.6 $\pm 0.7 \%)$ and CR $(3.7 \pm 0.6 \%)$ groups, with no differences between groups $(P=0.76)$. During the recovery week, whole thigh muscle CSA of the total group increased by $1.2 \pm 0.4 \%(P<0.01)$, with no differences between groups (time $x$ treatment interaction $\mathrm{P}=0.52$ ).

In the non-immobilized leg, quadriceps muscle CSA did not change differently in the PLA or CR group during immobilization (respectively $-8 \pm 33$ and $41 \pm 48 \mathrm{~mm}^{2}$; time $x$ treatment interaction $\mathrm{P}=0.41$ ) or subsequent recovery (respectively $+62 \pm 44$ and $+94 \pm 47 \mathrm{~mm}^{2}$; time $\mathrm{x}$ treatment interaction $\mathrm{P}=0.63$ ). The responders to creatine loading showed a similar change in quadriceps muscle CSA compared to the non-responders to creatine loading during immobilization (respectively $-446 \pm 88$ and $-489 \pm 79 \mathrm{~mm}^{2}$ ) or recovery (respectively $+85 \pm 41$ and $+106 \pm 122 \mathrm{~mm}^{2}$ ).

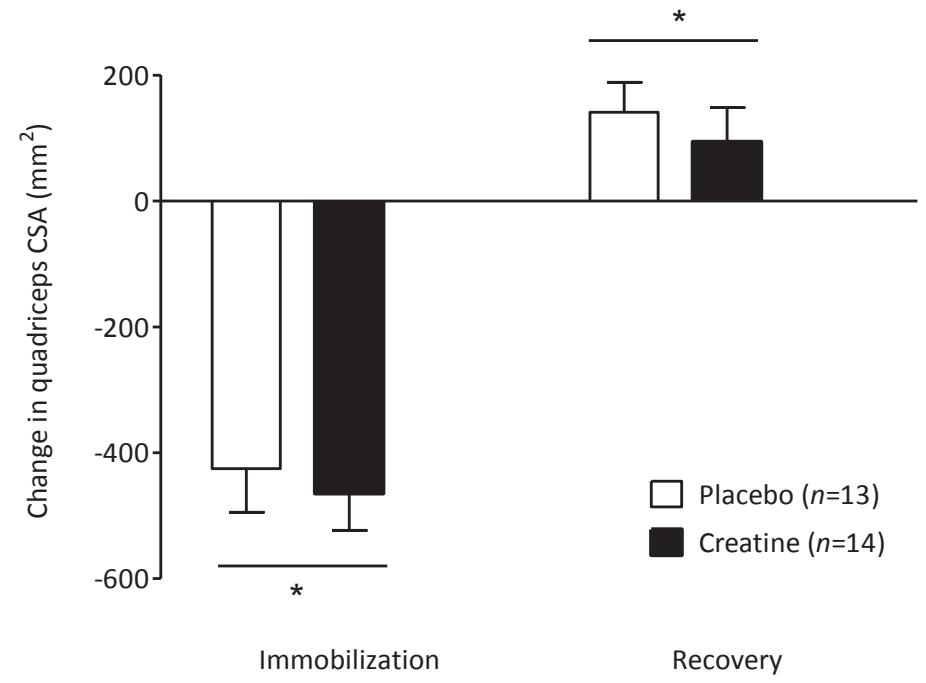

Figure 4.4: Changes in cross-sectional area (CSA) of the quadriceps muscle in the Creatine and Placebo group following 7 days of one-legged knee immobilization and 7 days of subsequent recovery. Data were analyzed by two-way repeated measures ANOVA with time as within-subjects factor, and treatment (CR and PLA group) as between-subjects factors. Data are expressed as means \pm SEM Immobilization resulted in a significant decline in quadriceps CSA in both groups $(*)$, with no differences between groups. Quadriceps CSA increased during the recovery week $(*)$, with no differences between groups. 


\section{Knee extension strength}

One repetition maximum (1-RM) decreased significantly during leg immobilization $(P<0.01)$ with no differences between groups (Figure 4.5; time $x$ treatment interaction $P=0.20$ ). 1 RM decreased by $5.6 \pm 2.2 \%$ (from $56 \pm 4$ to $53 \pm 4 \mathrm{~kg}$ ) in the PLA group. In the CR group, 1-RM decreased by $9.2 \pm 3.1 \%$ (from $59 \pm 3$ to $53 \pm 3 \mathrm{~kg}$ ). During the subsequent recovery week, 1 RM did not increase in either group and no differences were found between the two groups (time $\mathrm{x}$ treatment interaction $\mathrm{P}=0.32$ ). The responders and non-responders to creatine loading showed a similar change in 1-RM during immobilization (respectively $-5 \pm 3$ and $-8 \pm 2$ $\mathrm{kg}$ ) and recovery (respectively $+1 \pm 2$ and $+3 \pm 1 \mathrm{~kg}$ )

$1-R M$ in the non-immobilized leg increased during the immobilization period by $3.0 \pm 1.5 \%$ (from $61 \pm 2$ to $63 \pm 2 \mathrm{~kg} ; \mathrm{P}=0.03$ ), with no differences between the PLA and CR group (time $x$ treatment interaction $\mathrm{P}=0.90)$. 1-RM in the non-immobilized leg did not change during the subsequent recovery week $(P=0.57)$.

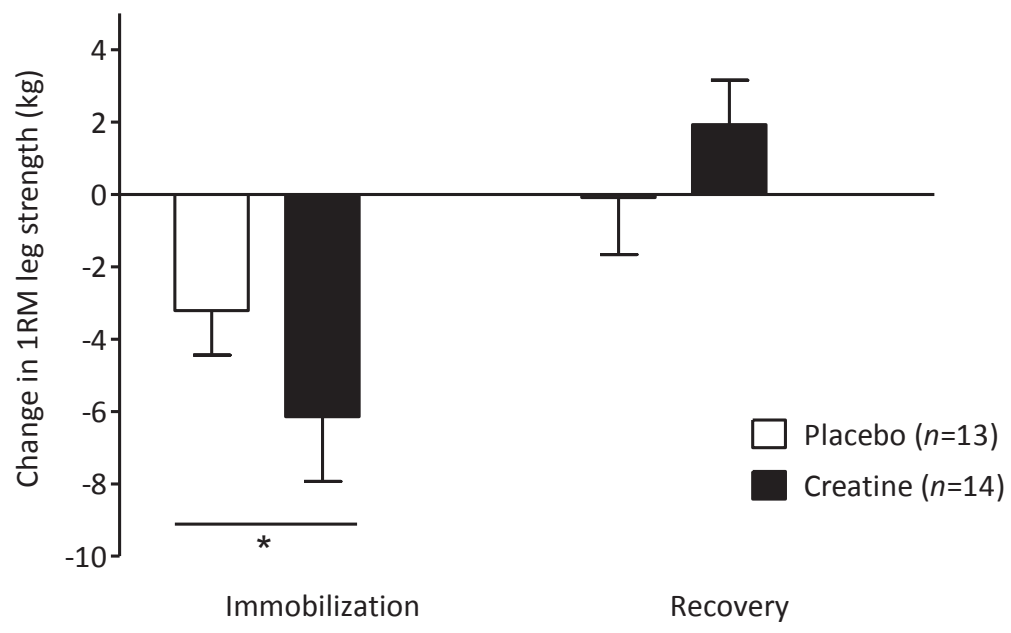

Figure 4.5: Changes in the one-repetition maximum (1-RM) leg muscle strength in the Creatine and Placebo group, following 7 days of one-legged knee immobilization and 7 days of subsequent recovery. Data were analyzed by two-way repeated measures ANOVA with time as within-subjects factor, and treatment (CR and PLA group) as between-subjects factors. Data are expressed as means \pm SEM. Immobilization resulted in a significant decline in muscle strength in both groups $\left({ }^{*}\right.$, with no differences between groups. Muscle strength did not change during the recovery week, with no differences between groups.

\section{Muscle fiber characteristics}

Muscle fiber characteristics are presented in Table 4.3. At baseline, type I and II muscle fiber size averaged $6458 \pm 334$ and $7263 \pm 375 \mu \mathrm{m}^{2}$, respectively $(P=0.01)$, with no differences between groups. No significant changes in type I or II muscle fiber size were observed following leg immobilization or during subsequent recovery. The proportion of type I and type II muscle fibers was $39 \pm 3$ and $61 \pm 3 \%$, respectively, before the loading period. No changes in muscle fiber type composition were observed over time or between groups. No differences were observed in fiber size between responders and non-responders to creatine loading, and no changes were observed over time in either group.

Diet and physical activity

Baseline daily energy intake was $8.2 \pm 0.4 \mathrm{MJ}$ per day, with no differences between groups

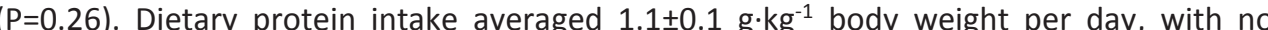
differences between groups $(P=0.61)$. Neither daily energy nor protein intake changed significantly during the subsequent immobilization and recovery period.

\section{Discussion}

The present study shows that 7 days of one-legged knee immobilization results in substantial decrease in muscle mass and strength in healthy, young men. Creatine loading prior to immobilisation and creatine supplementation during immobilisation did not attenuate the loss of muscle mass or strength during immobilization. In addition, creatine supplementation failed to accelerate muscle mass or strength regain during one week of subsequent recovery.

Short-term disuse leads to substantial losses in muscle mass and strength. The current study demonstrates that merely 7 days of disuse leads to $5.5 \pm 0.5 \%$ loss of muscle mass (Figure 44.), representing $0.8 \%$ loss of muscle mass per day. This muscle loss is in line with earlie work $(1,32,34)$ and underlines the impact that even short periods of disuse can have. Besides the loss of muscle mass, muscle strength declined by $7.6 \pm 2.0 \%$ (Figure 4.5). Similar declines in muscle strength (1-2 \% per day) have been reported previously by our laboratory as well as others $(1,32,34)$. The loss of muscle mass and strength during disuse is associated with a longer recovery period, a higher risk of injury reoccurrence, and a decline in metabolic health (3-6). Hence, short-term disuse atrophy is of high clinical relevance and effective strategies are needed to preserve muscle mass and strength during short periods of disuse or bed rest due to injury or hospitalization (35).

We hypothesized that creatine loading prior to disuse, thereby increasing muscle creatine content, attenuates the loss of muscle mass and strength. Therefore, the creatine group consumed $20 \mathrm{~g}$ creatine per day during the 5 day loading phase, which allowed total creatine content in muscle to increase by $19 \%$. This loading and maintenance supplementation scheme has previously been shown to increase muscle free creatine and creatine phosphate $(9,11)$ and is in accordance with the guidelines of the American College of Sports Medicine (29). In the present study, 8 subjects showed an increase in total creatine content of more than $20 \%$. In the creatine supplemented group, 6 subjects did not show a substantial increase in muscle creatine content (Figure 4.2). These subjects, not showing differences in muscle creatine content exceeding $10 \mathrm{mmol} \cdot \mathrm{kg}^{-1}$, were defined as nonresponders (10). It has been well established that $15-30 \%$ of the people who take creatine supplements do not experience increases in total muscle creatine contents $(9,10,33)$ 
Such non-responders to creatine supplementation typically show high(er) baseline muscle creatine contents, potentially preventing further increases in muscle creatine content $(9$, $10,33)$.In agreement, our non-responders showed substantially greater baseline creatine contents when compared to the responders (108 \pm 14 vs $70 \pm 9 \mathrm{mmol} \cdot \mathrm{kg}^{-1}$ respectively; $P=0.04)$. We also observed an increase in body weight in the responders to creatine supplementation ranging from $0.4-1.9 \mathrm{~kg}$, which is in line with previous studies $(9,10,29)$. The increase in body weight with creatine loading has been found to result from water retention due to the increased cellular osmolarity $(11,17)$ or from the increase in fat free mass $(9,15,16)$. The fact that the individuals with an increase in muscle total creatine content also show an increase in body weight supports the fact that these subjects are responders to creatine supplementation. Despite the effective creatine loading, the greater muscle creatine contents did not result in the preservation of muscle mass or strength during 7 days of single-leg immobilization. When only the responders to creatine supplementation were included in the analyses, similar findings were observed. In addition to the changes in muscle quadriceps cross-sectional area, we also assessed potential disuse atrophy on a muscle fiber level in the vastus lateralis muscle. Average type I and type II muscle fibers cross-sectional areas showed no net changes following immobilization in both the placebo and creatine group (Table 4.3). The absence of a detectable decline in muscle fiber size following short-term immobilization has been reported previously (2) and is attributed to the substantial inter- and intra-subject variation in muscle fiber sizes (36). Of course, the vastus lateralis muscle does not per se represent the entire quadriceps muscle. Furthermore, a muscle biopsy sample taken from the mid region of the vastus lateralis does not necessarily represent the entire muscle. Therefore, we can only assume that the presented data extend to all upper and/or lower leg muscle.

Though the current study focused on the impact of creatine loading on the decline in muscle mass and strength during immobilization, we also assessed changes in muscle mass and leg strength during the acute stages of recovery from disuse. After one week of recovery, we observed a $1.5 \pm 0.5 \%$ regain in skeletal muscle mass. Although significant, this increase in muscle mass represents only $26 \%$ of the muscle mass that was lost during the 7 day immobilization period. Thus, to regain all muscle mass after a period disuse, much more time will be required for rehabilitation than the duration of the disuse period itself. Interestingly, no detectable regain in leg strength was observed after the first week of recovery. Creatine supplementation did not affect muscle mass or leg strength regain. Previously, Hespel et al. showed greater muscle regain following a period of disuse when creatine was supplemented during a more prolonged period of rehabilitation, which included a 10 week resistance type exercise training program (21). Clearly, though we show that creatine supplementation does not preserve muscle mass during disuse or support muscle regain during the acute stages of recovery form disuse, it may still be of benefit to support muscle mass and strength regains during more prolonged, active rehabilitation. We hypothesised that creatine loading prior to and during immobilisation would prevent or attenuate muscle loss during a short period of immobilisation. The increase in muscle 
creatine content following creatine loading creates an osmotic potential that forces water in the muscle, causing muscle cells to swell (18). Increases in cell volume and the impact on cell volume homeostasis have been associated with muscle anabolism (18). Despite the successful creatine loading prior to the immobilization period, the greater muscle creatine content did not prevent or attenuate the decline in muscle mass or strength that is typically observed during short term disuse. Therefore, in spite of frequent speculation on the clinical advantage of creatine supplementation during disuse, we have to remove creatine from the list of potential nutritional or pharmaceutical compounds that may help to prevent disuse atrophy. Of course, creatine supplementation can still provide an ergogenic advantage in anaerobic energy provision required during exhaustive, intermittent type exercise. As such, creatine supplementation may be used during clinical rehabilitation to augment the skeletal muscle adaptive response to prolonged resistance type exercise training. However, it should be noted that muscle loss during disuse occurs at a rate that is several-fold greater than muscle (re)gain during resistance type exercise training. Therefore, it is imperative that we continue our endeavor to identify nutritional or pharmaceutical compounds that may prevent or attenuated disuse atrophy (35).

In conclusion, creatine supplementation prior to and during leg immobilization does not prevent or attenuate the loss of muscle mass or strength during short term muscle disuse in humans.

\section{References}

1. Suetta C, Hvid LG, Justesen L, Christensen U, Neergaard K, Simonsen L, et al. Effects of aging on human skeletal muscle after immobilization and retraining. Journal of applied physiology (Bethesda, $M d$ : 1985). 2009;107(4):1172-80.

2. Wall BT, Dirks ML, Snijders T, Senden JM, Dolmans J, van Loon $\sqcup$. Substantial skeletal muscle loss occurs during only 5 days of disuse. Acta physiologica (Oxford, England). 2014;210(3):600-11.

3. Stevens JE, Walter GA, Okereke E, Scarborough MT, Esterhai IL, George SZ, et at Muscle adaptations with . 2004;36(10):1695-701.

4. Vandenborne K, Elliott MA, Walter GA, Abdus S, Okereke E, Shaffer M, et al. Longitudinal study of skeleta muscle adaptations during immobilization and rehabilitation. Muscle \& nerve. 1998;21(8):1006-12.

5. Stuart CA, Shangraw RE, Prince MJ, Peters EI, Wolfe RR. Bed-rest-induced insulin resistance occurs primarily in muscle. Metabolism: clinical and experimental. 1988;37(8):802-6.

6. Gunther O, Frenzel R. [Effect of prolonged physical inactivity on carbohydrate tolerance]. Zeitschrift fur die gesamte innere Medizin und ihre Grenzgebiete. 1969:24(22):814-7.

Tzankoff SP, Norris AH. Effect of muscle mass decrease on age-related BMR changes. J Appl Physiol Respir Environ Exerc Physiol. 1977;43(6):1001-6.

8. Ferrando AA, Lane HW, Stuart CA, Davis-Street J, Wolfe RR. Prolonged bed rest decreases skeletal muscle and whole body protein synthesis. The American journal of physiology. 1996;270(4 Pt 1):E627-33.

9. van Loon L, Oosterlaar AM, Hartgens F, Hesselink MK, Snow RJ, Wagenmakers AJ. Effects of creatine loading and prolonged creatine supplementation on body composition, fuel selection, sprint and endurance performance in humans. Clin Sci (Lond). 2003;104(2):153-62.

10. Greenhaff PL, Bodin K, Soderlund K, Hultman E. Effect of oral creatine supplementation on skeletal muscle phosphocreatine resynthesis. The American journal of physiology. 1994;266(5 Pt 1):E725-30.

11. Hultman E, Soderlund K, Timmons JA, Cederblad G, Greenhaff PL. Muscle creatine loading in men. Journa of applied physiology (Bethesda, Md : 1985). 1996;81(1):232-7.

12. Balsom PD, Soderlund K, Sjodin B, Ekblom B. Skeletal muscle metabolism during short duration highintensity exercise: influence of creatine supplementation. Acta physiologica Scandinavica. 1995;154(3):303-10.

13. Greenhaff PL, Casey A, Short AH, Harris R, Soderlund K, Hultman E. Influence of oral creatine supplementation of muscle torque during repeated bouts of maximal voluntary exercise in man. Clinical science (London, England : 1979). 1993;84(5):565-71.

14. Branch JD. Effect of creatine supplementation on body composition and performance: a meta-analysis. International journal of sport nutrition and exercise metabolism. 2003;13(2):198-226.

15. Mihic S, MacDonald JR, McKenzie S, Tarnopolsky MA. Acute creatine loading increases fat-free mass, but does not affect blood pressure, plasma creatinine, or CK activity in men and women. Medicine and science in sports and exercise. 2000;32(2):291-6.

16. Becque MD, Lochmann JD, Melrose DR. Effects of oral creatine supplementation on muscular strength and body composition. Medicine and science in sports and exercise. 2000;32(3):654-8.

17. Deminice R, Rosa FT, Pfrimer K, Ferrioli E, Jordao AA, Freitas E. Creatine Supplementation Increases Tota Body Water in Soccer Players: a Deuterium Oxide Dilution Study. International journal of sports medicine. 2016;37(2):149-53.

18. Lang F, Busch GL, Ritter M, Volkl H, Waldegger S, Gulbins E, et al. Functional significance of cell volume regulatory mechanisms. Physiological reviews. 1998;78(1):247-306.

19. Wall BT, Morton JP, van Loon L. Strategies to maintain skeletal muscle mass in the injured athlete nutritional considerations and exercise mimetics. European journal of sport science. 2015;15(1):53-62.

Johnston AP, Burke DG, MacNeil LG, Candow DG. Effect of creatine supplementation during cast-induced immobilization on the preservation of muscle mass, strength, and endurance. Journal of strength and conditioning research / National Strength \& Conditioning Association. 2009;23(1):116-20.

21. Hespel P, Op't Eijnde B, Van Leemputte M, Urso B, Greenhaff PL, Labarque V, et al. Oral creatine supplementation facilitates the rehabilitation of disuse atrophy and alters the expression of muscle myogenic factors in humans. The Journal of physiology. 2001;536(Pt 2):625-33.

22. Bergstrom J. Percutaneous needle biopsy of skeletal muscle in physiological and clinical research. Scandinavian journal of clinical and laboratory investigation. 1975;35(7):609-16.

23. Frayn K, Maycock P. Skeletal muscle triacylglycerol in the rat: methods for sampling and measurement, and studies of biological variability. J Lipid Res. 1980;21(1):139-44. 
24. Folch J, Lees M, Sloane Stanley G. A simple method for the isolation and purification of total lipides from animal tissues. J Biol Chem. 1957;226(1):497-509.

25. Goodpaster BH, Kelley DE, Thaete $L$, He J, Ross R. Skeletal muscle attenuation determined by computed tomography is associated with skeletal muscle lipid content. J Appl Physiol. 2000;89(1):104-10.

Strandberg S, Wretling ML, Wredmark T, Shalabi A. Reliability of computed tomography measurements in asso

27. Verdijk LB, van Loon L, Meijer K, Savelberg HH. One-repetition maximum strength test represents a valid

28. Mayhew JL, Prinster IL, Ware IS, Zimmer DL, Arabas JR, Bemben MG Muscular 271 59 . 68.

predict bench press strength in men of different training levels. The Journal of sports medicions to predict bench

29. Terjung RL, Clarkson P, Eichner ER, Greenhaff PL, Hespel PJ, Israel RG, et al. American College of Sports Medicine roundtable. The physiological and health effects of oral creatine supplementation. Medicine .

30. Harris RC, Hultman E, Nordesjo LO. Glycogen, glycolytic intermediates and high-energy phosphates determined in biopsy samples of musculus quadriceps femoris of man at rest. Methods and variance of values. Scandinavian journal of clinical and laboratory investigation. 1974;33(2):109-20.

31. Verdijk LB, Koopman R, Schaart G, Meijer K, Savelberg HH, van Loon L. Satellite cell content is specifically reduced in type II skeletal muscle fibers in the elderly. American journal of physiology Endocrinology and metabolism. 2007;292(1):E151-7.

32. Dirks ML, Wall BT, Snijders T, Ottenbros CL, Verdijk LB, van Loon L. Neuromuscular electrical stimulation prevents muscle disuse atrophy during leg immobilization in humans. Acta physiologica (Oxford, England). 2014;210(3):628-41. Syrotuik DG, Bell GJ. Acute cretine mon Conditionin Association $2004 ; 18(3) 610-7$ 2004;18(3):610-7.

34. Wall BT, Sniiders T, Senden JM, Ottenbros CL, Gijsen AP, Verdijk LB, et al. Disuse impairs the muscle protein synthetic response to protein ingestion in healthy men. The Journal of clinical endocrinology and metabolism. 2013;98(12):4872-81.

W. Wall $B T$, van Loon $\mathrm{L}$. Nutritional strategies to attenuate muscle disuse atrophy. Nutrition reviews.

muscle mass with, Leenders M, Groen BB, van Kranenburg J, Verdijk LB, et al. The decline in skeleta gerontology. 2013;48(5):492-8. 


\section{Chapter 5}

Leucine supplementation does not attenuate skeletal muscle

loss during leg immobilization

Evelien M.P. Backx

Astrid M. Horstman Gabriel N. Marzuca Nassr Janneau van Kranenburg Joey S. Smeets

Cas J. Fuchs

Anniek Janssen Lisette C.P.G.M. de Groot Luc J.C. van Loon 
Background: Short successive periods of reduced physical activity occur throughout life and contribute substantially to the loss of skeletal muscle mass with aging. Muscle mass maintenance during short periods of disuse is required to prevent functional decline and maintain metabolic health

Objective: To assess whether daily leucine supplementation during a short period of disuse can attenuate subsequent muscle loss in vivo in humans.

Methods: Thirty healthy ( $22 \pm 1$ y) young males were subjected to 7 days of one-legged knee immobilization by means of a full leg cast with (LEU, $n=15$ ) or without (CON, $n=15$ ) daily leucine supplementation ( $2.5 \mathrm{~g}$ leucine 3 times daily). Prior to and immediately after immobilization, quadriceps muscle cross-sectional area (CT) and leg strength (1-RM) were assessed. Furthermore, muscle biopsies were taken in both groups before and after immobilization to assess changes in type I and type II muscle fiber CSA

Results: Quadriceps muscle cross sectional area (CSA) declined in the CON and LEU group $(\mathrm{P}<0.01)$, with no differences between the two group (respectively from 7603 \pm 301 to $7156 \pm 279 \mathrm{~mm}^{2}$ vs $7643 \pm 317$ to $7164 \pm 328 \mathrm{~mm}^{2} ; \mathrm{P}=0.77$ ). Leg muscle strength decreased from $56 \pm 4$ to $53 \pm 4 \mathrm{~kg}$ in the CON group ( $P=0.03$ ) and from $63 \pm 3$ to $55 \pm 2 \mathrm{~kg}$ in the LEU group $(P<0.01)$, with no differences between groups $(P=0.052)$. Type I and II muscle fiber size did not change significantly over time and no differences are found between groups $(P>0.05)$. Conclusion: Fortification of the three main meals with free leucine $(7.5 \mathrm{~g} / \mathrm{d})$ does not attenuate the loss of muscle mass or strength during a short period of leg immobilization.

\section{Introduction}

Aging is associated with progressive loss of skeletal muscle mass and strength. This loss of muscle mass and strength leads to a decline in functional capacity and predisposes to the development of chronic metabolic diseases [1]. Though the mechanisms responsible for age-related muscle mass loss remain to be elucidated, it is clear that an inadequate protein intake and reduced level of physical activity play a key role [2]. Recently, it has been suggested that age-related muscle loss may be largely attributed to the muscle loss that occurs during short successive periods of muscle disuse throughout the lifespan [3-5] Merely a few days of immobilization [6-10] or bedrest [11-13] can already result in substantial muscle and strength loss in older individuals. Furthermore, it has been reported that older individuals have a reduced capacity to regain skeletal muscle mass that was lost during a period of disuse [14]. As a consequence, our group and others have started to look for strategies to prevent or attenuate muscle loss during such short periods of muscle disuse to support healthy aging.

Muscle mass is regulated by the fluctuations in muscle protein synthesis and breakdown rates $[15,16]$. The loss of muscle mass during a period of disuse has been attributed to decline in both basal muscle protein synthesis [11, 17-21] and a blunted muscle protein synthetic response to protein ingestion [21-24]. Furthermore, a rapid increase in muscle protein breakdown rate has been suggested to occur during the early stages of muscle disuse [2, 25-27]. Protein ingestion forms a key anabolic stimulus with a rapid increase in muscle protein synthesis rates and an inhibition of proteolysis following the postprandial rise in plasma amino acid concentrations. It has been well established that the postprandial increase in muscle protein synthesis is attributed to the rise in plasma essential amino acids concentrations $[28,29]$, with the rise in circulating leucine being of particular relevance [3035]. Leucine administration has been shown to stimulate muscle protein synthesis by direct or indirect activation of many key regulatory proteins in the mTOR pathway [36-39] Furthermore, leucine has been shown to have strong anti-proteolytic properties [40], either directly or via its insulinotropic properties [41, 42]. We hypothesize that providing additional free leucine with each main meal may compensate for anabolic resistance and, as such, prevent or attenuate muscle mass loss during a short period of immobilization. In the present study, we subjected 30 healthy, young men to 7 days of one-legged knee mmobilization. One group $(n=15)$ was supplemented with $2.5 \mathrm{~g}$ of leucine three times daily during immobilization $(7.5 \mathrm{~g} / \mathrm{d}$ in total), whereas the other group $(n=15)$ ingested a contro supplement. Skeletal muscle mass and function were assessed before and after immobilization, and muscle biopsies were collected to assess changes in muscle fiber size. 


\section{Methods}

Subjects

Thirty young $\left(18-35\right.$ y) healthy males $\left(18.5<\mathrm{BMI}<30 \mathrm{~kg} / \mathrm{m}^{-2}\right)$ participated in this randomized controlled trial. Participants' characteristics are presented in Table 5.1. All subjects were screened and excluded in case one or more of the following criteria were met: a history of thromboembolic events, smoker, currently participating in progressive resistance type exercise training, back/leg/knee/shoulder complaints that could interfere with the use of crutches, systematic use of corticosteroids, anabolic steroids, growth hormone, testosterone, immunosuppressants, insulin, or blood glucose lowering medication, pre-existing renal disease or potential risk for renal dysfunction (diabetes, hypertension, reduced glomerular filtration rate), liver disease, heart failure or migraines. All participants were informed about the purpose of the study, the experimental procedures, and all its possible risks prior to providing written consent to participate. This study was approved by the Medical Ethics Committee from the Academic Hospital Maastricht and Maastricht University (MUMC+). The procedures followed were in accordance with the ethical standards of the responsible institutional or regional committee on human experimentation or in accordance with the Declaration of Helsinki of 1975 as revised in 1983.

Experimental outline

After inclusion into the study, subjects were allocated to either the control (CON, $n=15$ ) or the leucine (LEU, $n=15$ ) supplemented group. Both groups were subjected to 7 days of muscle disuse induced by means of a full leg cast. The immobilized leg was randomly allocated and counter-balanced between left and right. Two days prior to casting and directly after cast removal, a series of measurements were performed. Single-slice computed tomography (CT) scans were performed at the mid-thigh of both legs. In addition, a single muscle biopsy from the immobilized leg and a venous blood sample were collected. Leg extension strength was assessed (1 repetition maximum) for both legs separately.

\section{Pretesting/screening}

Body weight and height were measured using a digital balance and a stadiometer to calculate BMI. A medical questionnaire was filled in to assess whether subjects met the inclusion criteria. Subsequently, a familiarization session on the leg extension machine (Technogym, Rotterdam, the Netherlands) was performed as described previously [43, 44].

\section{Measurements}

Subjects participated in two identical experimental test days, before and immediately after the immobilization period. Two days prior to the immobilization period, subjects arrived at the laboratory at $08.00 \mathrm{am}$ after an overnight fast, and body weight was measured with a digital balance with an accuracy of $0.1 \mathrm{~kg}$ (SECA GmbH, Hamburg, Germany). Thereafter, a single-slice CT scan (Philips Brilliance 64; Philips Medical Systems, Best, the Netherlands) was performed to assess quadriceps muscle and whole thigh muscle cross-sectional area (CSA) in both legs. The scanning characteristics were as follows: $120 \mathrm{kV}, 300 \mathrm{~mA}$, rotation time of $0.75 \mathrm{~s}$ and a field of view of $500 \mathrm{~mm}$. With subjects lying supine with their legs extended and feet secured, a 3-mm thick axial image was taken $15 \mathrm{~cm}$ proximal to the top of the patella. The precise scan position was marked with semi-permanent ink for the 7 days of immobilization to ensure accurate repeat measurements at the second test day. Muscle area of the thigh was selected between -29 and 150 Hounsfield units, after which the quadriceps muscle was selected by manual tracing using ImageJ software (version 1.46d National Institute of Health, Bethesda, MD, USA) [45]. Subsequently, a blood sample was taken from the antecubital vein by venipucture. After collection, EDTA-containing blood tubes were immediately centrifuged at $1000 \mathrm{Xg}$ for 10 minutes at $4{ }^{\circ} \mathrm{C}$. Aliquots of plasma were frozen in liquid nitrogen and stored at $-80^{\circ} \mathrm{C}$ until analysis.

Thereafter, a muscle biopsy was collected from the leg that was subsequently immobilized by using the percutaneous needle biopsy technique [46]. Muscle biopsy samples were obtained from the middle region of the vastus lateralis, $\sim 1-3 \mathrm{~cm}$ below the level that the CT scan was performed, and $\sim 3 \mathrm{~cm}$ below entry through the fascia,. Any visible non-muscle tissue was removed immediately, after which the biopsy sample was embedded in TissueTec (Sakura Finetek, Zoeterwoude, the Netherlands) before being frozen in liquid nitrogencooled isopentane.. Muscle samples were subsequently stored at $-80{ }^{\circ} \mathrm{C}$ until further analyses.

After consuming breakfast, subject's single-leg one repetition maximum (1-RM) was assessed on a leg extension machine. The estimations obtained during the screening visit were used to determine 1-RM [44]. Finally, subjects were instructed on, and familiarized with, the use of crutches.

On the second test day, post-immobilization, the cast was removed before the measurements described above (CT scan, muscle biopsy, blood draw and 1-RM leg strength) were performed.

Limb immobilization protocol

Two days after the first test day, subjects reported at 8 am at the Casting Room at Maastricht University Medical Centre, to have a full leg cast fitted. The casting procedure has been described previously $[43,47]$. In short, the circular leg cast extended from $10 \mathrm{~cm}$ above the ankle to $\sim 25 \mathrm{~cm}$ above the patella. The knee was casted at a $30^{\circ}$ angle of flexion to prevent subjects performing any weight bearing activities with the casted leg. Subjects were provided with crutches for proper ambulation. All subjects were instructed to perform a series of simple ankle exercises (i.e. plantar and dorsal flexion, and circular movements of the entire foot) to keep the calf muscle pump activated in the immobilized leg, thereby minimizing the risk of developing deep vein thrombosis. After 7 days of immobilization and prior to the start of the second test day, subjects visited the Casting Room to have the cas removed. Immediately after the cast-removal, subjects were taken by wheelchair to the 
laboratory to prevent any weight bearing activities prior to the CT scan and muscle biopsy collection.

Leucine supplementation

Subjects in the LEU group were supplemented with free crystalline leucine (BUFA, Uitgeest, The Netherlands) for 1 week, starting at the first day of immobilization. The leucine was provided in capsules $(0.5 \mathrm{~g}$ free leucine per capsule). The supplementation protocol consisted of $7.5 \mathrm{~g}$ leucine per day; i.e. $2.5 \mathrm{~g}$ with each main meal (breakfast, lunch, and dinner), thus three times per day 5 capsules during the immobilization week.

Dietary intake and physical activity records

On the evening prior to both test days, subjects received a standardized meal containing 2.9 MJ providing 51 energy\% (En\%) as carbohydrate, $32 \mathrm{En} \%$ as fat and $17 \mathrm{En} \%$ as protein. Subjects were asked to maintain their habitual food intake during the study and to refrain from consuming alcohol in the $48 \mathrm{~h}$ leading up to a test day. All volunteers refrained from any sort of heavy physical exercise from $48 \mathrm{~h}$ before the first test until the end of the study.

Blood analyses

Plasma leucine concentration was determined by GC-MS (Agilent 7890A GC/5975C; MSD, Little Falls, DE). Specifically, the internal standard of $\left[\mathrm{U}_{-13}{ }^{13} \mathrm{C}_{6}\right]$-Leucine was added to the samples. Plasma was deproteinized on ice with dry 5-sulfosalicylic acid. Leucine was purified using cation exchange AG 50W-X8 resin (mesh size: 100-200, ionic form: hydrogen (Bio-Rad Laboratories, Hercules, CA)) columns and converted to its tert-butyl dimethylsilyl (TBDMS) derivative before analysis by GC-MS. The leucine concentration was determined using electron impact ionization by monitoring ions at mass/charge $(\mathrm{m} / \mathrm{z}) 302$ and 308 for unlabeled and $\left[\mathrm{U}-{ }^{13} \mathrm{C}_{6}\right]$-Leucine, respectively. Standard regression curves were applied from a series of known standard concentration values against the measured values to assess the linearity of the mass spectrometer.

\section{Muscle analyses}

Frozen muscle biopsies were cut into 5 - $\mu \mathrm{m}$-thick cryosections using a cryostat at $-20^{\circ} \mathrm{C}$, and thaw mounted on uncoated pre-cleaned glass slides. Samples from pre- and postimmobilization were mounted together on the same glass slide. Care was taken to properly align the samples for cross-sectional fiber analyses. Muscle biopsies were stained for muscle fiber typing (FT). First antibodies were directed against laminin (polyclonal rabbit antilaminin, dilution 1:50; Sigma, Zwijndrecht, the Netherlands) and myosin heavy chain (MHC)-I (A4.840, dilution 1:25; Developmental Studies Hybridoma Bank, lowa City, IA, USA) Appropriate secondary antibodies were applied: goat anti-rabbit IgG AlexaFluor647 and goat antimouse IgM AlexaFluor555 (dilution 1:400 and 1:500, respectively; Molecular Probes, Invitrogen, Breda, the Netherlands). All primary and secondary antibodies were diluted in $0.1 \%$ bovine serum albumin (BSA) in $0.1 \%$ Tween-phosphate-buffered saline
(PBS). All incubations took place at room temperature Staining procedures are described before [48].

Images were visualized and automatically captured at 109 magnification with a fluorescent microscope equipped with an automatic stage (IX81 motorized inverted microscope Olympus, Hamburg, Germany) EXi Aqua CCD camera (Q Imaging, Surrey, Canada). Micromanager 1.4 software was used for image acquisition [49]. Quantitative analyses were carried out using Image J software package (version $1.45 \mathrm{~d}$, National Institute of Health; [45]). All image recordings and analyses were performed by an investigator blinded to subject coding. Mean muscle fiber size was calculated for the type I and type II muscle fibers separately. To assess fiber circularity, form factors were calculated by using the following formula: $(4 \pi \cdot \mathrm{CSA}) /(\text { perimeter })^{2}$. Fiber circularity did not change over time or between groups. Mean numbers of $274 \pm 25$ and $306 \pm 28$ fibers were analyzed in pre- and postimmobilization samples, respectively.

Statistics

All data are expressed as mean \pm SEM. Baseline values between groups were compared by means of an independent samples t-test. Pre- versus post-immobilization data were analyzed using Repeated Measures ANOVA with treatment (CON vs LEU) as betweensubjects factor and time (pre- vs post-immobilization) as within-subjects factor. Fiber type (type I vs type II) was added to the test as a within-subjects factor when performing the statistical analyses for the muscle data. A $P$-value of $<0.05$ was used to determine significance. All data were analyzed using SPSS version 22.0 ( SPSS, IBM Corp., Armonk, NY, USA).

Results

Subjects and dietary intake

Subjects' characteristics are provided in Table 5.1. The mean age of the subjects was $22 \pm 1$ y with an average BMI of $23.1 \pm 0.5 \mathrm{~kg} \cdot \mathrm{m}^{-2}$. Baseline subjects' characteristics did not differ between the CON and LEU groups (quadriceps CSA $7603 \pm 301$ and $7643 \pm 317 \mathrm{~mm}^{2}(P=0.93)$, and leg muscle strength $56 \pm 4$ and $63 \pm 3 \mathrm{~kg}(\mathrm{P}=0.16)$, respectively). Three subjects withdrew prior to immobilization due to time constraints. From the 30 participants, 27 completed the study (CON: $n=13$; LEU: $n=14$ ).

Muscle mass and strength

Quadriceps muscle cross-sectional area (CSA) is displayed in Figure 5.1. At baseline, no differences were observed in quadriceps or muscle CSA between groups $(P=0.93)$. Seven days of immobilization caused significant muscle atrophy of the quadriceps (time effect, $P<0.01$; from $7603 \pm 301$ to $7156 \pm 279 \mathrm{~mm}^{2}$ vs $7643 \pm 317$ to $7164 \pm 328 \mathrm{~mm}^{2}$ in the CON and LEU group, respectively). No differences were observed between the CON and LEU group 
(interaction effect $P=0.77$ ). Leg muscle strength data are presented in Figure 5.2. Maximal leg strength had decreased during immobilization from $56 \pm 4 \mathrm{~kg}$ to $53 \pm 4 \mathrm{~kg}$ in the CON group $(P=0.03)$ and from $63 \pm 3 \mathrm{~kg}$ to $55 \pm 2 \mathrm{~kg})$ in the LEU group $(P<0.01)$. No significant differences were observed between the CON and LEU group (interaction effect; $\mathrm{P}=0.052$ ).

Table 5.1: Subjects' characteristics

\begin{tabular}{lll}
\hline & Leucine & Placebo \\
\hline Age $(\mathbf{y})$ & $21 \pm 1$ & $22 \pm 1$ \\
Body mass $(\mathrm{kg})$ & $73.5 \pm 1.9$ & $73.4 \pm 2.8$ \\
Height $(\mathrm{m})$ & $1.80 \pm 0.02$ & $1.77 \pm 0.02$ \\
BMI $\left(\mathbf{k g} \cdot \mathrm{m}^{-2}\right)$ & $22.7 \pm 0.6$ & $23.5 \pm 0.8$ \\
Leg strength $(\mathbf{k g})$ & $63 \pm 3$ & $56 \pm 4$ \\
Whole-thigh CSA $\left(\mathrm{mm}^{2}\right)$ & $14417 \pm 537$ & $14204 \pm 469$ \\
Quadriceps CSA $\left(\mathrm{mm}^{2}\right)$ & $7691 \pm 299$ & $7603 \pm 301$ \\
\hline
\end{tabular}

Data are expressed as the means \pm SEM. Baseline characteristics are not different between groups.

\section{Plasma analyses}

Post-absorptive plasma leucine concentrations did not change in the LEU $(154 \pm 5$ and $160 \pm 4$ $\mu \mathrm{mol} \cdot \mathrm{L}^{-1}$ before and after supplementation respectively; $\left.\mathrm{P}=0.34\right)$ and in the CON group $\left(156 \pm 5\right.$ and $150 \pm 6 \mu \mathrm{mol} \cdot \mathrm{L}^{-1}$ before and after supplementation respectively; $\mathrm{P}=0.23$ ). No differences in post-absorptive plasma leucine concentrations were observed between the CON and LEU group $(\mathrm{P}=0.13)$

\section{Muscle fiber characteristics}

Muscle fiber characteristics are displayed in Table 5.2. At baseline, no differences between groups were observed for any of the variables. No measurable decline in muscle fiber CSA was observed following 7 days of immobilization ( $P \geq 0.05$ ). Muscle fiber type distribution (in $\%$ and $\%$ area) did not change during $7 \mathrm{~d}$ of immobilization ( $P \geq 0.05)$ and no differences were observed between groups $(P \geq 0.05)$. Muscle fiber CSA and fiber type distribution (in \% and $\%$ area) were different between type I and type II muscle fibers on all time points $(P \leq 0.01)$.
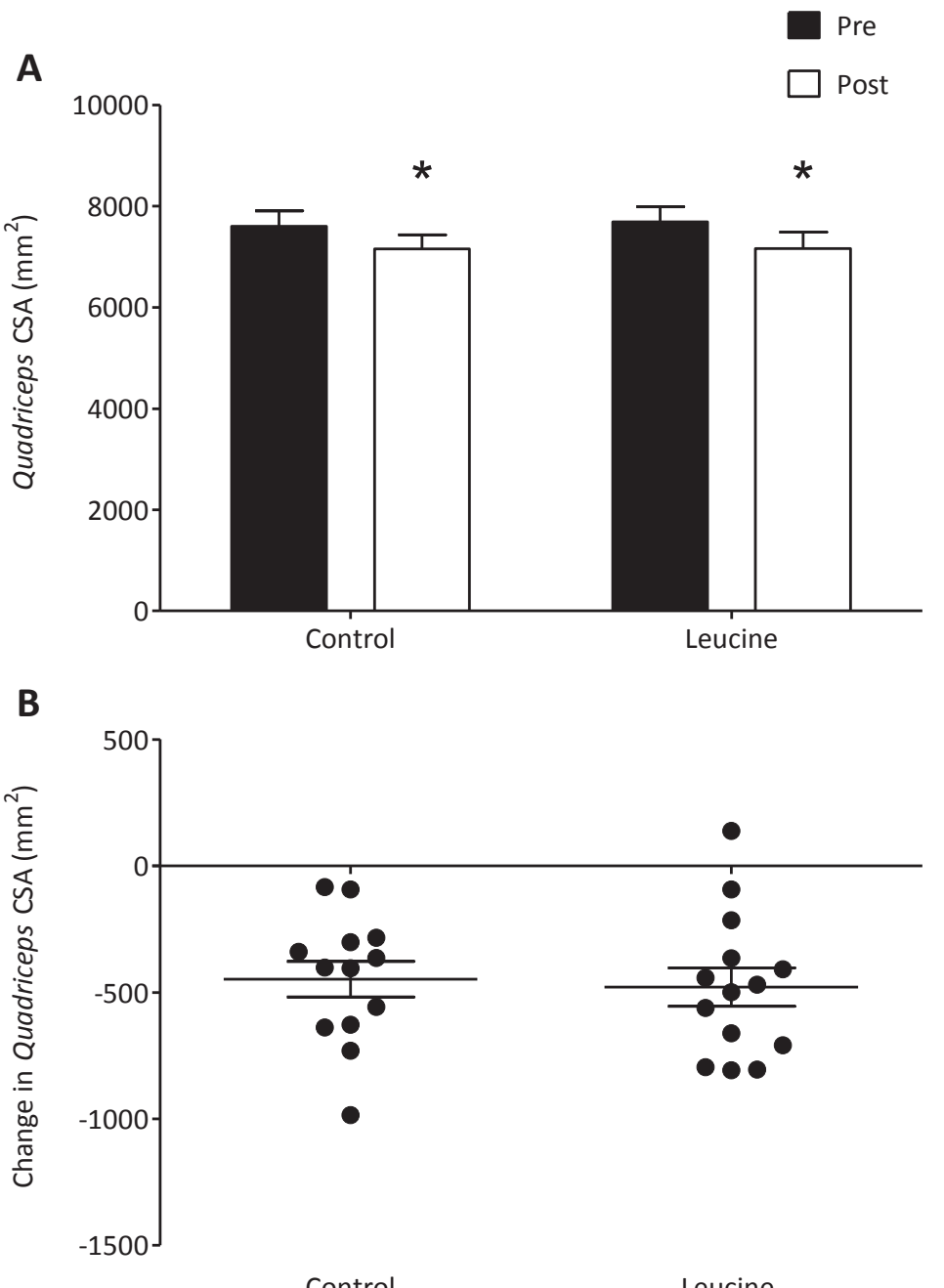

Control

Leucine

Figure 5.1A: Cross-sectional area (CSA) of the quadriceps muscle in the Control and Leucine group before and after 7 days of one-legged knee immobilization. Figure 5.1B: Individual changes in quadriceps CSA following 7 days of one-legged knee immobilization. Data were analyzed using repeated measures ANOVA. Data are expressed as means \pm SEM. Immobilization resulted in a significant decline in quadriceps CSA in both groups $\left({ }^{*}\right)$, with no differences between groups. 


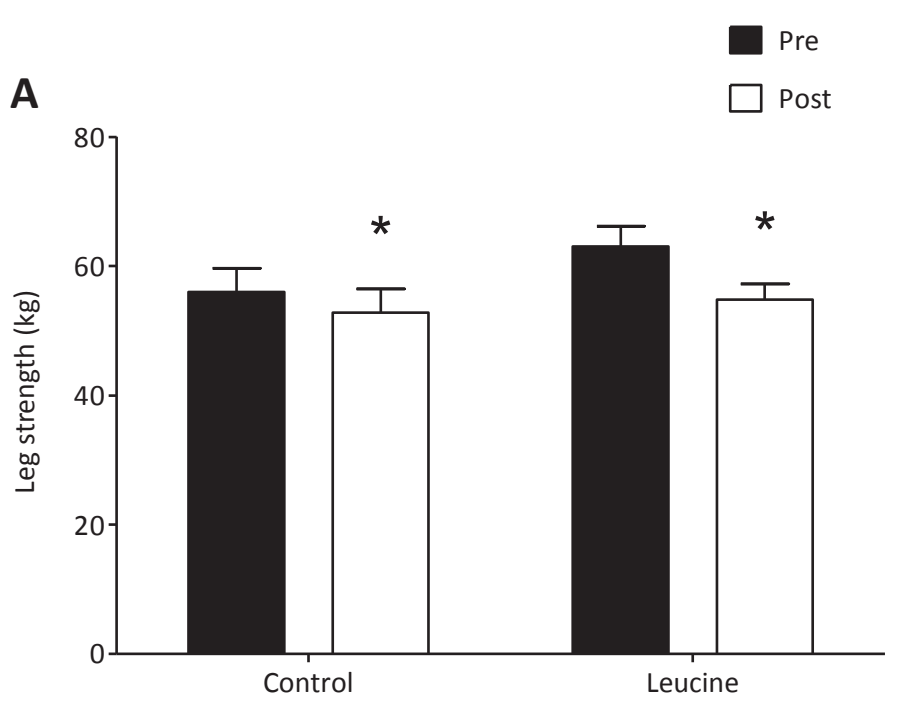

B

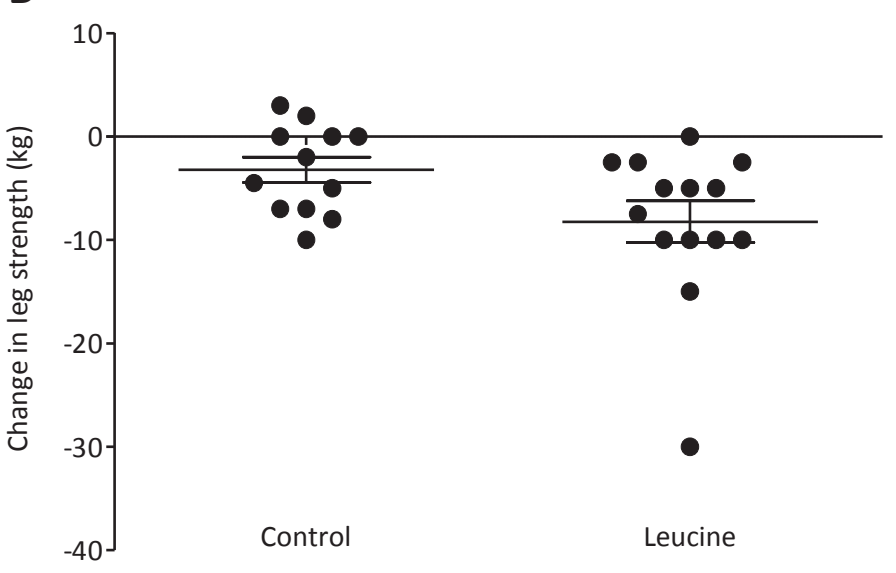

Figure 5.2A: One-repetition maximum (1-RM) leg muscle strength in the Control and Leucine group before and after 7 days of one-legged knee immobilization. Figure 5.2B: Individual changes in 1-RM leg muscle strength following 7 days of one-legged knee immobilization. Data were analyzed using repeated measures ANOVA. Data are expressed as means \pm SEM. Immobilization resulted in a significant decline in muscle strength in both groups $\left({ }^{*}\right)$, with no differences between groups.
Table 5.2: Muscle fiber characteristics in the control and leucine group

\begin{tabular}{l|l|llll}
\hline \multicolumn{2}{l|}{} & \multicolumn{2}{c}{ Control group ( $\boldsymbol{n = 1 3 )}$} & \multicolumn{2}{c}{ Leucine group $(\boldsymbol{n}=\mathbf{1 1})$} \\
\hline & $\begin{array}{l}\text { Fiber } \\
\text { type }\end{array}$ & $\begin{array}{l}\text { Pre- } \\
\text { immobilization }\end{array}$ & $\begin{array}{l}\text { Post- } \\
\text { immobilization }\end{array}$ & $\begin{array}{l}\text { Pre- } \\
\text { immobilization }\end{array}$ & $\begin{array}{l}\text { Post- } \\
\text { immobilization }\end{array}$ \\
\hline Muscle fiber & I & $6105 \pm 588$ & $6857 \pm 571$ & $5781 \pm 354$ & $6196 \pm 415$ \\
CSA $\left(\boldsymbol{\mu m ^ { 2 }}\right.$ ) & II* & $7420 \pm 741$ & $7954 \pm 614$ & $6033 \pm 482$ & $6589 \pm 509$ \\
Fiber type & I & $39 \pm 4$ & $35 \pm 3$ & $39 \pm 5$ & $41 \pm 5$ \\
distribution (\%) & II* & $61 \pm 4$ & $65 \pm 3$ & $61 \pm 5$ & $59 \pm 5$ \\
Fiber type & I & $35 \pm 4$ & $32 \pm 3$ & $38 \pm 4$ & $40 \pm 5$ \\
distribution & II* & $65 \pm 4$ & $68 \pm 3$ & $62 \pm 4$ & $60 \pm 5$ \\
(\% area) & & & & & \\
\hline
\end{tabular}

Values are means \pm SEMs. CSA, cross-sectional area. No differences over time were found between the Control and Leucine group. *Muscle fiber CSA and fiber type distribution (in \% and \% area) were different between type I and type II muscle fibers on all time points

\section{Discussion}

In the present study, we show that fortification of the main meals with free leucine did not attenuate muscle disuse atrophy or muscle strength during 7 days of leg immobilization in healthy adults.

The skeletal muscle loss experienced during short successive periods of muscle disuse (e.g. following injury or during recovery from illness) has been hypothesized to be partly responsible for the loss of muscle mass throughout the lifespan [4, 5, 47]. Most periods of forced muscle disuse are of relative short duration, lasting less than one week $[4,50]$. Whereas ample studies have shown that long-term disuse leads to considerable muscle loss $[18,51-53]$, only a limited number of short-term disuse studies have been performed [ 43 54]. In the current study, we show that as little as 7 days of muscle disuse leads to considerable loss of muscle mass. We observed a $6 \%$ decline in muscle cross-sectional area of the upper leg (Figure 5.1), which was accompanied by a $9 \%$ decline in leg strength (Figure 5.2) in healthy males. These findings are in line with previous work from our group [4, 10, $43,47]$ as well as others [55] and underline the impact of even a short period of muscle disuse. Disuse atrophy is accompanied by numerous negative health consequences such as reduced functional capacity, increased risk of post-surgery complications and comorbidities, and less successful rehabilitation upon hospital discharge [20, 56-59]. Clearly, effective strategies are needed to prevent or attenuate muscle mass and strength loss during such short periods of muscle disuse in both health and disease.

The loss of muscle mass during a period of disuse has been, at least partly, attributed to a decline in the muscle protein synthetic response to meal ingestion, now coined anabolic resistance $[60,61]$. Increasing protein intake $[62]$ or co-ingesting free leucine $[63,64]$ has previously been shown to increase the postprandial muscle protein synthetic response to protein ingestion, implying that free leucine supplementation or food fortification with leucine may represent effective strategies to compensate for anabolic resistance and, as 
such, may be used to attenuate muscle mass loss [65]. Therefore, we hypothesized that free leucine supplementation with each main meal $(3 * 2.5 \mathrm{~g}$ per day) would compensate for anabolic resistance and attenuate muscle loss during 7 days of muscle disuse. However muscle loss did not differ between the leucine and control groups $(-479 \pm 75$ and $-447 \pm 7$ $\mathrm{mm}^{2}$, respectively; $\left.\mathrm{P}=0.77\right)$. In line with the loss of muscle mass, muscle strength loss did not differ between groups $(-8.2 \pm 2.0$ and $-3.2 \pm 1.2 \mathrm{~kg}$, respectively; $\mathrm{P}=0.52)$

A recent study from English et al. assessed the effects of leucine supplementation during 2 weeks of bedrest in young individuals [66]. Their study seemed to support our hypothesis as leucine supplementation ( $4.4 \mathrm{~g}$ leucine per meal, $13.2 \mathrm{~g}$ per day) attenuated lean mas loss following 7 days of bedrest $(-1.5 \pm 0.3$ and $-0.8 \pm 0.3 \mathrm{~kg}$ lean mass loss in the control and leucine group, respectively). However, this attenuated loss of lean mass was no longer evident following 2 weeks of bedrest $(-1.5 \pm 0.3$ and $-1.0 \pm 0.3 \mathrm{~kg}$ lean mass loss, respectively) Our data show no benefits of leucine in either preserving muscle mass or strength following one week of limb immobilization. Whether the apparent discrepancy between our data and those by English et al. is attributed to the disuse model used (limb immobilization vs bedrest) or the amount of leucine provided (7.5 vs $13.2 \mathrm{~g}$ per day) remains unclear. Nonetheless, our work is in line with previous work in our group as we have been unable to detect net changes in muscle mass, strength, or glucose homeostasis following 3 and 6 months of leucine supplementation in healthy individuals [67] and type 2 diabetes patients [68], respectively. In the latter publication, we hypothesised that free leucine supplementation may be more relevant under more clinically compromised conditions where muscle atrophy is apparent. However, based upon the present data we can only conclude that under well-fed conditions, local anabolic resistance due to limb immobilization [24] is not compensated for by free leucine co-ingestion. We need to stress that in our study, healthy subjects were fed in energy balance, with a dietary protein intake of $1.1 \pm 0.1 \mathrm{~g}$ protein $\cdot \mathrm{kg}^{-1}$ body weight per day being well in excess of the Recommended Dietary Allowance (RDA) [69]. As dietary protein intake does not meet the RDA in a large proportion of institutionalized older people or more clinically comprised individuals admitted to hospital [70], these results may not necessarily represent the impact of leucine supplementation on preserving skeletal muscle mass during disuse under malnourished conditions.

In conclusion, free leucine ingestion with each main meal ( $3 * 2.5 \mathrm{~g}$ leucine per day) does not attenuate the loss of leg muscle mass and leg strength during a short period of limb immobilization in healthy, young males.

\section{References}

Evans, W.J., What is sarcopenia? J Gerontol A Biol Sci Med Sci, 1995. 50 Spec No: p. 5-8.

phy. Nutr Rev, 2013 71(4): p. 195-208.

Paddon-Jones, D., et al., Protein and healthy aging. Am J Clin Nutr, 2015

Wall, B.T., M.L. Dirks, and L.J. van Loon, Skeletal muscle atrophy during short-term disuse: implications for age-related sarcopenia. Ageing Res Rev, 2013. 12(4): p. 898-906.

En lish, $K$ L and D. Paddon-Jones, Protecting muscle mass and function in older adults during bed rest. Curr Opin Clin Nutr Metab Care, 2010. 13(1): p. 34-9.

Hvid, L., et al., Effects of aging on muscle mechanical function and muscle fiber morphology during shortterm immobilization and subsequent retraining. J Appl Physiol (1985), 2010. 109(6): p. 1628-34.

Hvid, L.G., et al., Aging impairs the recovery in mechanical muscle function following 4 days of disuse. Exp Gerontol, 2014. 52: p. 1-8.

Urso, M.L., P.M. Clarkson, and T.B. Price, Immobilization effects in young and older adults. Eur J App Physiol, 2006. 96(5): p. 564-71.

Hvid, L.G., et al., Four days of muscle disuse impairs single fiber contractile function in young and old healthy men. Exp Gerontol, 2013. 48(2): p. 154-61.

Dirks, M.L., et al., Skeletal muscle disuse atrophy is not attenuated by dietary protein supplementation in healthy older men. J Nutr, 2014. 144(8): p. 1196-203.

Kortebein, P., et al., Effect of 10 days of bed rest on skeletal muscle in healthy older adults. JAMA, 2007. 297(16): p. 1772-4.

Drummond, M.J., et al., Short-term bed rest increases TLR4 and IL-6 expression in skeletal muscle of older adults. Am J Physiol Regul Integr Comp Physiol, 2013. 305(3): p. R216-23.

Deutz, N.E., et al., Effect of beta-hydroxy-beta-methylbutyrate (HMB) on lean body mass during 10 days of bed rest in older adults. Clin Nutr, 2013. 32(5): p. 704-12.

Suetta, C., et al., Ageing is associated with diminished muscle re-growth and myogenic precursor cell expansion early after immobility-induced atrophy in human skeletal muscle. J Physiol, 2013. 591(Pt 15): p. 3789-804

15. Cuthbertson, D., et al., Anabolic signaling deficits underlie amino acid resistance of wasting, aging muscle. FASEB J, 2005. 19(3): p. 422-4.

Kumar, V., et al., Age-related differences in the dose-response relationship of muscle protein synthesis to resistance exercise in young and old men. J Physiol, 2009. 587(Pt 1): p. 211-7.

de Boer, M.D., et al., The temporal responses of protein synthesis, gene expression and cell signalling in human quadriceps muscle and patellar tendon to disuse. J Physiol, 2007. 585(Pt 1): p. 241-51.

Ferrando, A.A., et al., Prolonged bed rest decreases skeletal muscle and whole body protein synthesis. Am J Physiol, 1996. 270(4 Pt 1): p. E627-33.

Ferrando, A.A., et al., Resistance exercise maintains skeletal muscle protein synthesis during bed rest. Appl Physiol (1985), 1997. 82(3): p. 807-10.

Gibson, J.N., et al., Decrease in human quadriceps muscle protein turnover consequent upon leg immobilization. Clin Sci (Lond), 1987. 72(4): p. 503-9.

Glover, E.l., et al., Immobilization induces anabolic resistance in human myofibrillar protein synthesis with low and high dose amino acid infusion. J Physiol, 2008. 586(Pt 24): p. 6049-61.

Biolo, G., et al., Short-term bed rest impairs amino acid-induced protein anabolism in humans. J Physio , 2004. 558(Pt 2): p. 381-8.

Biolo, G., et al., Sensitivity of whole body protein synthesis to amino acid administration during shortterm bed rest. J Gravit Physiol, 2002. 9(1): p. P197-8.

Wall, B.T., et al., Disuse impairs the muscle protein synthetic response to protein ingestion in healthy men. J Clin Endocrinol Metab, 2013. 98(12): p. 4872-81.

Abadi, A., et al., Limb immobilization induces a coordinate down-regulation of mitochondrial and other metabolic pathways in men and women. PLoS One, 2009. 4(8): p. e6518.

Glover, E.I., et al., Little change in markers of protein breakdown and oxidative stress in humans in immobilization-induced skeletal muscle atrophy. Appl Physiol Nutr Metab, 2010. 35(2): p. 125-33. Gustafsson, T., et al., Effects of 3 days unloading on molecular regulators of muscle size in humans. Appl Physiol (1985), 2010. 109(3): p. 721-7.

Tipton, K.D., et al., Nonessential : phe acids are not necessary to stimulate net muscle protein synthesis in healthy volunteers. J Nutr Biochem, 1999. 10(2): p. 89-95. 
Volpi, E., et al., Essential amino acids are primarily responsible for the amino acid stimulation of muscle Anabolism in healthy elderly adults. Am I Clin Nutr, 2003. 78(2): p. 250-8. A

. rats in the absence of increases in 4E-BP1 or S6K1 phosphorylation. Diabetes, 2002. 51(4): $\mathrm{P}$. $928-36$. Dardevet, D., et al., Postprandial stimulation of muscle protein synthesis in old rats can be restored by a leucine-supplemented meal. J Nutr, 2002. 132(1): p. 95-100. ino acids in regulating protein metabolism in vivo. Am J Physiol, 1992. 262(6 Pt 1): p. E925-35.

34. postexercise muscle protein synthesis in vivo in male

35.

I. et al, Leucine supplementation improves muscle protein synthesis in elderly men independently of hyperaminoacidaemia. J Physiol, 2006. 575(Pt 1): p. 305-15.

36. Ham, D.J., et al., Leucine as a treatment for muscle wasting: a critical review. Clin Nutr, 2014. 33(6): p. 937-45.

37. Anthony, J.C., et al., Orally administered leucine stimulates protein synthesis in skeletal muscle of postabsorptive rats in association with increased elF4F formation. J Nutr, 2000. 130(2): p. 139-45.

38. Anthony, J.C., et al., Leucine stimulates translation initiation in skeletal muscle of postabsorptive rats via a rapamycin-sensitive pathway. J Nutr, 2000. 130(10): p. 2413-9.

Kimball, S.R. and LS. Jefferson, Signaling pathways and molecular mechanisms through which branched-chain amino acids mediate translational control of protein synthesis. I Nutr, 2006. Suppl): p. 227S-31S.

40. Magne, $\mathrm{H}$., et al., Nutritional strategies to counteract muscle atrophy caused by disuse and to improve recovery. Nutr Res Rev, 2013. 26(2): p. 149-65.

41. van Loon, L.J., Leucine as a pharmaconutrient in health and disease. Curr Opin Clin Nutr Metab Care, 2012. 15(1): p. 71-7.

Leenders, $M$. and $L$, van Loon Leucine as a pharmaconutrient to prevent and treat sarcopenia and type 2 diabetes. Nutr Rev, 2011. 69(11): p. 675-89.

43. Dirks, M.L., et al., Neuromuscular electrical stimulation prevents muscle disuse atrophy during leg immobilization in humans. Acta Physiol (Oxf), 2014. 210(3): p. 628-41.

Verdijk, L.B., et al One-repetition maximum strength test represents a valid means to assess leg strength in vivo in humans. J Sports Sci, 2009. 27(1): p. 59-68.

Strandberg, S., et al., Reliability of computed tomography measurements in assessment of thigh muscle cross-sectional area and attenuation. BMC Med Imaging, 2010. 10: p. 18.

Bergstrom, J., Percutaneous needle biopsy of skeletal muscle in physiological and clinical research. Scand I Clin Lab Invest, 1975. 35(7): p. 609-16.

Wall, B.T., et al, Substantial skeletal muscle loss occurs during only 5 days of disuse. Acta Physiol (Oxf), 2014. 210(3): p. 600-11.

Verdijk, L.B., et al., Satellite cell content is specifically reduced in type II skeletal muscle fibers in the elderly. Am J Physiol Endocrinol Metab, 2007. 292(1): p. E151-7.

49. Edelstein, A., et al., Computer control of microscopes using microManager. Curr Protoc Mol Biol, 2010. Chapter 14: p. Unit14 20

Fisher, S.R., et al., Early ambulation and length of stay in older adults hospitalized for acute illness. Arch Intern Med, 2010. 170(21): p. 1942-3.

Trappe, T.A., et al., Influence of concurrent exercise or nutrition countermeasures on thigh and calf mus.

52. Brooks, N., et al., Resistance training and timed essential amino acids protect against the loss of muscle mass and strength during 28 days of bed rest and energy deficit. J Appl Physiol (1985), 2008. 105(1): p. 241-8.

53. Rejc, E., et al., Maximal explosive power of the lower limbs before and after 35 days of bed rest under different diet energy intake. Eur J Appl Physiol, 2015. 115(2): p. 429-36.

Drummond, M.J., et al., Bed rest impairs skeletal muscle amino acid transporter expression, mTORC1 signaling, and protein synthesis in response to essential amino acids in older adults. Am J Physio Endocrinol Metab, 2012. 302(9): p. E1113-22.

55. Suetta, C., et al., Aging affects the transcriptional regulation of human skeletal muscle disuse atrophy. PLoS One, 2012. 7(12): p. e51238.
Christensen, T., T. Bendix, and H. Kehlet, Fatigue and cardiorespiratory function following abdominal surgery. Br J Surg, 1982. 69(7): p. 417-9.

the effect of immobilization on metabolic and physiological functions of normal men. Bull N Y Acad Med, 1948. 24(6): p. 364-75

Stuart, C.A., et al., Bed-rest-induced insulin resistance occurs primarily in muscle. Metabolism, 1988. 37(8): p. 802-6.

Haruna, Y., et al., Decremental reset in basal metabolism during 20-days bed rest. Acta Physiol Scand Suppl, 1994. 616: p. 43-9.

Glover, E.l., et al., Immobilization induces anabolic resistance in human myofibrillar protein synthesis with low and high dose amino acid infusion. J Physiol, 2008. 586(24): p. 6049-61.

Wall, B.T., et al., Short-term muscle disuse lowers myofibrillar protein synthesis rates and induces anabolic resistance to protein ingestion. Am J Physiol Endocrinol Metab, 2016. 310(2): p. E137-47.

Pennings, B., et al., Amino acid absorption and subsequent muscle protein accretion following graded intakes of whey protein in elderly men. Am J Physiol Endocrinol Metab, 2012. 302(8): p. E992-9.

Wall, B.T., et al., Leucine co-ingestion improves post-prandial muscle protein accretion in elderly men. Clin Nutr, 2013. 32(3): p. 412-9.

(a) adults consuming the RDA for protein. Clin Nutr, 2012. 31(4): p. 512-9. athlete: nutritional considerations and exercise mimetics. Eur J Sport Sci, 2015. 15(1): p. 53-62.

English, K.L., et al., Leucine partially protects muscle mass and function during bed rest in middle-aged adults. Am J Clin Nutr, 2016. 103(2): p. 465-73.

Verhoeven, $\mathrm{S}$, et al., Long-term leucine supplementation does not increase muscle mass or strength in healthy elderly men. Am J Clin Nutr, 2009. 89(5): p. 1468-75.

Leenders, M., et al., Prolonged leucine supplementation does not augment muscle mass or affect glycemic control in elderly type 2 diabetic men. J Nutr, 2011. 141(6): p. 1070-6.

Panel, E.N. Scientific Opinion on Dietary Reference Values for protein. EFSA Journal, 2012. 10(2):2557. Tieland, $\mathrm{M}$, et al. Dietary protein intake in community-dwelling, frail, and institutionalized elderly people: scope for improvement. Eur J Nutr, 2012. 51(2): p. 173-9. 


\section{Chapter 6}

Nandrolone decanoate administration does not attenuate muscle atrophy during a short period of disuse

Astrid M. Horstman*

Evelien M.P. Backx* Janneau van Kranenburg

Douwe de Boer

John Dolmans Lisette C.P.G.M. de Groot

Luc J.C. van Loon

*These authors contributed equally to this work 
Background: A few days of bed rest or immobilization following injury, disease, or surgery can lead to considerable loss of skeletal muscle mass and strength. It has been speculated that such short, successive periods of muscle disuse may be largely responsible for the agerelated loss of muscle mass throughout the lifespan.

Objective: To assess whether a single intramuscular injection of nandrolone decanoate prior to immobilization can attenuate subsequent muscle loss in healthy men.

Methods: Thirty healthy $(22 \pm 1 y)$ men were subjected to $7 \mathrm{~d}$ of one-legged knee immobilization by means of a full leg cast with (NAD, $n=15)$ or without (CON, $n=13$ ) an intramuscular nandrolone decanoate injection (200 mg). Prior to and immediately after immobilization, quadriceps muscle cross-sectional area (CT) and leg strength (1-RM) were assessed. Furthermore, muscle biopsies were taken in both groups before and after immobilization to assess changes in type I and type II muscle fiber CSA.

Results: Quadriceps muscle cross-sectional area (CSA) decreased during immobilization in both CON and NAD (Time $P<0.01$ ) with no difference between the groups $(-6 \pm 1 \%$ in both groups, Time $\mathrm{x}$ Treatment $P=0.95)$. 1-RM significantly declined in both groups $(-7 \pm 3 \%$ and $6 \pm 2 \%$, resp, Time $P<0.01$ ), with no difference between the groups (Time $\times$ Treatment $P=0.55$ ). Muscle fiber size and distribution did not change over time and no differences were observed between groups $(\mathrm{P}>0.05)$.

Conclusion: This is the first study to report that nandrolone decanoate administration does not preserve skeletal muscle mass and strength during a short period of leg immobilization in vivo in humans.

\section{Introduction}

Muscle disuse, such as forced upon following injury or during illness can lead to substantia loss of skeletal muscle mass and strength and has numerous negative side effects. Most periods of muscle disuse tend to be short, lasting less than 7 days $(1,2)$. Recently, it has been shown that even a few days of muscle disuse can lead to a substantial decline in muscle mass and strength (3). It has been speculated that such short successive periods of bed rest or immobilization can contribute largely to the loss of muscle mass throughout the lifespan $(1,4)$. Obviously, effective strategies are required to prevent or attenuate muscle loss during short periods of muscle disuse (5).

Skeletal muscle disuse is accompanied by a decline in basal muscle protein synthesis rates, an increase in protein breakdown, and the development of anabolic resistance to feeding $(1,6)$. The anabolic steroid nandrolone, with nandrolone decanoate as one of its esters (7$10)$ has been shown to increase protein synthesis and decrease proteolysis in mice $(11,12$. Prolonged nandrolone decanoate administration (ranging from 25-600 mg for a period between 1-6 months) has been shown to increase fat free mass, muscle cross-sectional area and/or strength in several pathological conditions in vivo in humans (13-23). Based on these findings it could be speculated that nandrolone decanoate administration may represent an effective adjuvant pharmaceutical strategy to prevent or attenuate disuse atrophy.

We hypothesize that intramuscular administration of a single dose of nandrolone decanoate attenuates muscle mass and strength loss during short-term leg immobilization. To test this hypothesis, we selected 30 healthy, young males who were subjected to 7 days of onelegged knee immobilization. One group $(n=15)$ received a single intramuscular nandrolone decanoate injection $(200 \mathrm{mg}$ ) at the start of the immobilization period, whereas the othe group ( $n=15)$ acted as controls. Skeletal muscle mass and function were assessed before and after immobilization.

\section{Methods}

Subjects

Thirty young (18-35 $\mathrm{y}$ ) healthy males $\left(18.5<\mathrm{BMI}<30 \mathrm{~kg} / \mathrm{m}^{2}\right)$ participated in this experiment. Participants' characteristics are presented in Table 6.1. All subjects were screened and excluded in case one or more of the following criteria were met: a history of thromboembolic events, smoker, history of participating in regular resistance type exercise training, back/leg/knee/shoulder complaints that could interfere with the use of crutches, systematic use of corticosteroids, anabolic steroids, growth hormone, testosterone, immunosuppressants, insulin, or blood glucose lowering medication, pre-existing renal disease or potential risk for renal dysfunction (diabetes, hypertension, reduced glomerula filtration rate), liver disease, heart failure or migraines. All participants were informed about the purpose of the study, the experimental procedures, and all its possible risks prior to providing written consent to participate. This study was approved by the Medical Ethics 
Committee from the Academic Hospital Maastricht and Maastricht University (MUMC+) The procedures followed were in accordance with the ethical standards of the responsible institutional or regional committee on human experimentation or in accordance with the Declaration of Helsinki of 1975 as revised in 1983.

\section{Experimental outline}

After inclusion into the study, subjects were allocated to either the control (CON, $n=15$ ) or the nandrolone decanoate (NAD, $n=15$ ) group. Both groups were subjected to $7 \mathrm{~d}$ of muscle disuse induced by way of a full leg cast. The immobilized leg was randomly allocated and counter-balanced between left and right. Two days prior to casting and directly after cast removal, a series of measurements were performed. Single-slice computed tomography (CT) scans were performed at the mid-thigh of both legs to assess muscle mass. After that a single muscle biopsy was taken from the immobilized leg to assess changes in muscle fibe size and distribution, a venous blood sample was collected to assess changes in serum testosterone and nandrolone, and knee extension strength (1 repetition maximum; 1-RM) was assessed for both legs separately.

\section{Pretesting/screening}

Body weight, height, blood pressure and heart rate were measured. Subsequently, a familiarization session was performed on the leg extension machine (Technogym, Rotterdam, the Netherlands) to estimate the subjects' single-leg one repetition maximum (1-RM) as described previously $(24,25)$.

Muscle mass, biopsies and strength

Subjects participated in two identical experimental test days, before and immediately after the immobilization period. Two days prior to the immobilization period, subjects arrived at the laboratory after an overnight fast. Body weight was measured with a digital balance with an accuracy of $0.1 \mathrm{~kg}$ (SECA GmbH, Hamburg, Germany). Thereafter, a single-slice CT scan (Philips Brilliance 64; Philips Medical Systems, Best, the Netherlands) was performed to assess quadriceps muscle and whole upper leg muscle anatomical cross-sectional area (CSA) in both legs. The scanning characteristics were as follows: $120 \mathrm{kV}, 300 \mathrm{~mA}$, rotation time of $0.75 \mathrm{~s}$ and a field of view of $500 \mathrm{~mm}$. With subjects lying supine with their legs extended and feet secured, a 3-mm thick axial image was taken $15 \mathrm{~cm}$ proximal to the top of the patella. The precise scan position was marked with semi-permanent ink for the $7 \mathrm{~d}$ of immobilization to ensure accurate repeated measurements at the second test day. Muscle area of the leg was selected between -29 and 150 Hounsfield units, after which the quadriceps muscle was selected by manual tracing using ImageJ software (version 1.46d National Institute of Health, Bethesda, MD, USA) (26).

Subsequently, a blood sample was collected from the antecubital vein by venipuncture in SST containing tubes (SST ${ }^{\mathrm{TM}}$ Tube with Silica Clot Activator). After 30 min clotting time, blood tubes were centrifuged at $1550 \mathrm{Xg}$ for 15 minutes at $21^{\circ} \mathrm{C}$. Aliquots of serum were frozen in liquid nitrogen and stored at $-80^{\circ} \mathrm{C}$ until analysis.

Thereafter, a muscle biopsy was collected from the vastus lateralis muscle of the les identified as the leg to become immobilized (or the previously immobilized leg in the case of the second visit). Muscle biopsy samples were obtained from the middle region of the vastus lateralis, $\sim 1-3 \mathrm{~cm}$ below the level that the $\mathrm{CT}$ scan was performed, and $\sim 3 \mathrm{~cm}$ below entry through the fascia, by using the percutaneous needle biopsy technique (27). Any visible non-muscle tissue was removed immediately, after which the biopsy sample was embedded in Tissue-Tec (Sakura Finetek, Zoeterwoude, the Netherlands) before being frozen in liquid nitrogen-cooled isopentane. Muscle samples were subsequently stored at $80^{\circ} \mathrm{C}$ until further analyses. Thereafter, subject's single-leg one repetition maximum (1-RM) was assessed. The estimations obtained during the screening visit were used to determine 1-RM (25). Finally, subjects were instructed on, and familiarized with, the use of crutches. On the second test day, post-immobilization, the cast was removed before the measurements described above (CT scan, muscle biopsy, blood draw and 1-RM leg strength) were performed again

\section{Limb immobilization protocol}

Two days after the first test day, subjects reported at 8 am at the Casting Room at Maastricht University Medical Centre, to have a full leg cast fitted. The casting procedure has been described previously $(3,24)$. In short, the circular leg cast extended from the ankle to $\sim 25 \mathrm{~cm}$ above the patella. The knee was casted at a $30^{\circ}$ angle of flexion to prevent subjects performing any weight bearing activities with the casted leg. Subjects were provided with crutches for proper ambulation. All subjects were instructed to perform series of simple ankle exercises (i.e. plantar and dorsal flexion, and circular movements of the entire foot) to keep the calf muscle activated in the immobilized leg, thereby minimizing the risk of developing deep vein thrombosis. After $7 \mathrm{~d}$ of immobilization and prior to the start of the second test day, subjects visited the Casting Room again to have the cast removed. Thereafter, subjects were taken by wheelchair to conduct the CT scan and the muscle biopsies before any weight bearing exercise was performed.

Nandrolone decanoate injection

Subjects in the NAD group were administered $200 \mathrm{mg}$ nandrolon-17 $\beta$-decanoaat (DecaDurabolin) by intramuscular injection in the $M$. gluteus maximus just before casting.

\section{Diet and activity}

On the evening prior to both test days, subjects received a standardized meal containing $2.9 \mathrm{MJ}$ providing 51 energy\% (En\%) as carbohydrate, $32 \mathrm{En} \%$ as fat and $17 \mathrm{En} \%$ as protein Subjects were asked to maintain their habitual food intake during the study and to refrain from consuming alcohol in the $48 \mathrm{~h}$ leading up to a test day. All volunteers refrained from any sort of heavy physical exercise from $48 \mathrm{~h}$ before the first test until the end of the study. 


\section{Blood analyses}

Nandrolone was measured by Liquid Chromatography/Tandem Mass Spectrometry (LC/MS/MS) using a diethyl ether liquid/liquid extraction preparation step to isolate the non-conjugated steroid fraction. CV of quality control (CV) samples was $<10 \%$

Total testosterone was measured by electrochemiluminescence immunoassay (ECLIA) (Roche Diagnostics GmbH, Sandhofer Strasse 116, D-68305 Mannheim) using the COBAS 8000 modular system. CV of QC samples were $<20 \%$.

Muscle analyses

Frozen muscle biopsies were cut into 5 - $\mu \mathrm{m}$-thick cryosections using a cryostat at $-20^{\circ} \mathrm{C}$, and thaw mounted on uncoated pre-cleaned glass slides. Samples from pre- and postimmobilization were mounted together on the same glass slide. Care was taken to properly align the samples for cross-sectional fiber analyses. Muscle biopsies were stained for muscle fiber typing (FT). First antibodies were directed against laminin (polyclonal rabbit antilaminin, dilution 1:50; Sigma, Zwijndrecht, the Netherlands) and myosin heavy chain (MHC)-I (A4.840, dilution 1:25; Developmental Studies Hybridoma Bank, lowa City, IA, USA) Appropriate secondary antibodies were applied: goat anti-rabbit IgG AlexaFluor647 and goat antimouse IgM AlexaFluor555 (dilution 1:400 and 1:500, respectively; Molecular Probes, Invitrogen, Breda, the Netherlands). All primary and secondary antibodies were diluted in $0.1 \%$ bovine serum albumin (BSA) in $0.1 \%$ Tween-phosphate-buffered saline (PBS). All incubations took place at room temperature, unless otherwise stated. Staining procedures were as follows.

After fixation ( $5 \mathrm{~min}$ acetone), slides were air-dried and incubated at room temperature for 30 min with $3 \%$ BSA in $0.1 \%$ Tween-PBS. Slides were then washed (5 min PBS). Thereafter primary antibodies against laminin and MHC-I were applied for $45 \mathrm{~min}$. Slides were then washed and incubated with the appropriate secondary antibodies. After a final washin step, slides were mounted with cover glasses using Mowiol (Calbiochem, Amsterdam, the Netherlands). Images were visualized and automatically captured at 109 magnification with a fluorescent microscope equipped with an automatic stage (IX81 motorized inverted microscope; Olympus, Hamburg, Germany) EXi Aqua CCD camera (Q Imaging, Surrey, Canada).

Micromanager 1.4 software was used for image acquisition (28). Quantitative analyses were carried out using Image J software package (version 1.45d, National Institute of Health (26)). All image recordings and analyses were performed by an investigator blinded to subject coding. Mean muscle fiber size was calculated for the type I and type II muscle fibers separately. To assess fiber circularity, form factors were calculated by using the following formula: $(4 \pi \cdot \mathrm{CSA}) /(\text { perimeter) })^{2}$. Fiber circularity did not change over time or between groups. Mean numbers of $115 \pm 12$ and $175 \pm 16$ fibers were analyzed in pre- and postimmobilization samples, respectively.
Statistics

All data are expressed as mean \pm SEM. Baseline values between groups were compared by means of an independent samples t-test. Pre- versus post-immobilization data were analyzed using Repeated Measures ANOVA with treatment (CON vs NAD) as betweensubjects factor and time (pre- vs post-immobilization) as within-subjects factor. A $P$-value of $<0.05$ was used to determine significance. All data were analyzed using SPSS version 22.0 (SPSS, IBM Corp., Armonk, NY, USA).

Results

Subjects and dietary intake

Subjects' characteristics are provided in Table 6.1. No differences were observed for age height, weight, BMI, whole thigh and quadriceps CSA and strength between the contro (CON) and nandrolone decanoate (NAD) groups. Two subjects from CON withdrew prior to immobilization due to time constraints.

Table 6.1: Subjects' characteristics

\begin{tabular}{lll}
\hline & $\begin{array}{l}\text { Control } \\
(\boldsymbol{n}=13)\end{array}$ & $\begin{array}{l}\text { Nandrolone } \\
(\boldsymbol{n}=15)\end{array}$ \\
\hline Age $(\mathbf{y})$ & $22 \pm 1$ & $22 \pm 1$ \\
Body mass $(\mathrm{kg})$ & $73.4 \pm 2.8$ & $70.1 \pm 2.6$ \\
Height $(\mathrm{m})$ & $1.77 \pm 0.02$ & $1.72 \pm 0.02$ \\
BMI $\left(\mathrm{kg} / \mathrm{m}^{2}\right)$ & $23.5 \pm 0.8$ & $22.8 \pm 0.6$ \\
Leg strength $(\mathrm{kg})$ & $56 \pm 4$ & $64 \pm 3$ \\
Whole-thigh CSA $\left(\mathrm{mm}^{2}\right)$ & $14204 \pm 469$ & $14471 \pm 386$ \\
Quadriceps CSA $\left(\mathrm{mm}^{2}\right)$ & $7603 \pm 301$ & $7805 \pm 221$ \\
\hline
\end{tabular}

Values are means \pm SEM. Abbreviations: BMI, Body Mass Index; CSA, Cross-sectional area. No differences were observed between groups $(P>0.05)$

\section{Muscle mass and strength}

Quadriceps muscle cross-sectional area (CSA) is displayed in Figure 6.1. At baseline, no differences were observed in quadriceps muscle CSA between groups $(P=0.59)$. Seven days of immobilization caused a significant decline in muscle mass of the quadriceps (from $7603 \pm 301$ to $7156 \pm 279 \mathrm{~mm}^{2}$ vs from $7805 \pm 221$ to $7352 \pm 202 \mathrm{~mm}^{2}$ in the CON and NAD group, respectively (Time $\mathrm{P}<0.01)$ ) with a similar loss in CON $(5.8 \pm 0.8 \%)$ and NAD $(5.8 \pm 0.7 \%$; $P>0.05)$. Leg muscle strength data are presented in Figure 6.2. Maximal leg muscle strength had decreased following immobilization from $56 \pm 4 \mathrm{~kg}$ to $53 \pm 4 \mathrm{~kg}(5.6 \pm 2.2 \%)$ and from $64 \pm 3$ $\mathrm{kg}$ to $60 \pm 3 \mathrm{~kg}(6.9 \pm 2.6 \%)$ in the CON and NAD group, respectively (Time, $P<0.01$ ), with no differences between groups (Time $\times$ Treatment $P=0.55$ ). 


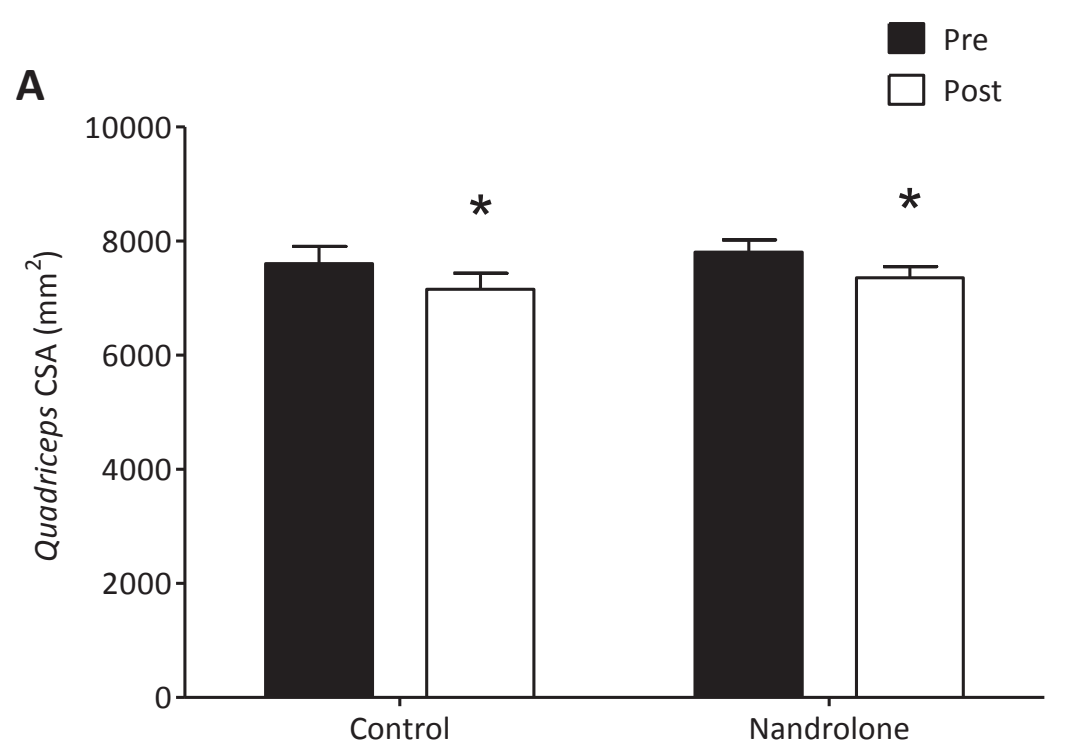

B

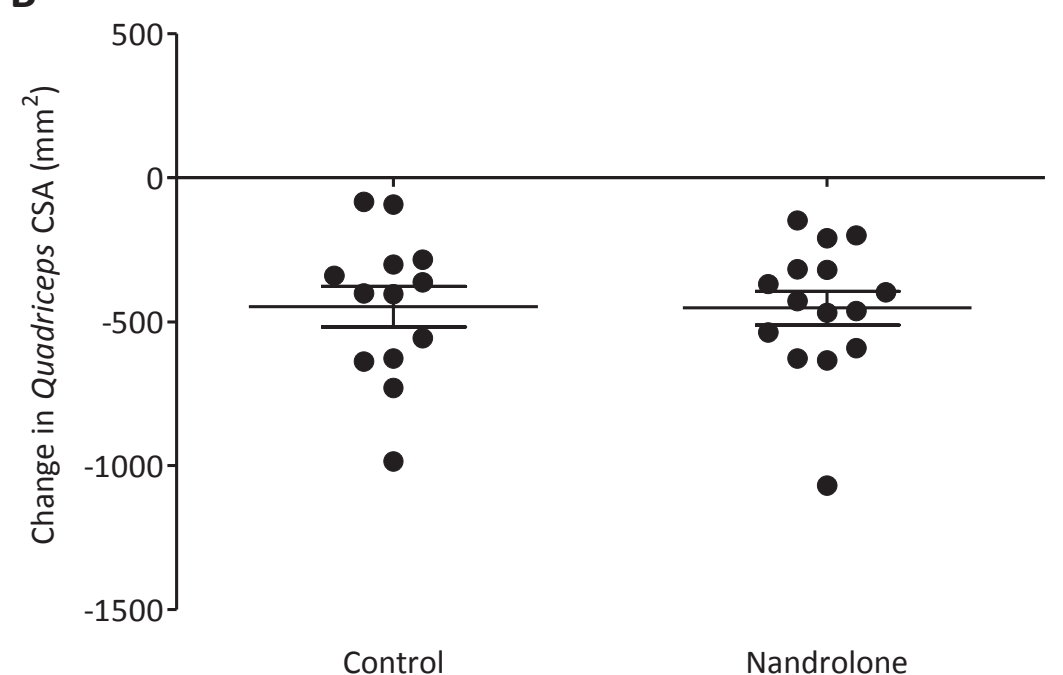

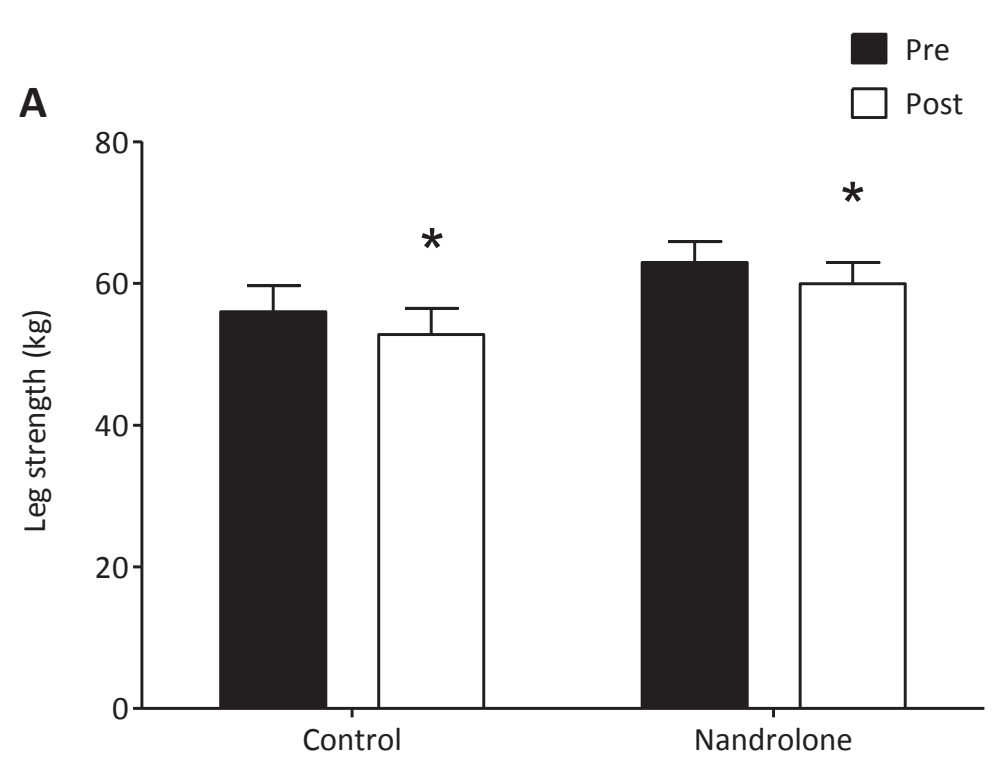

B

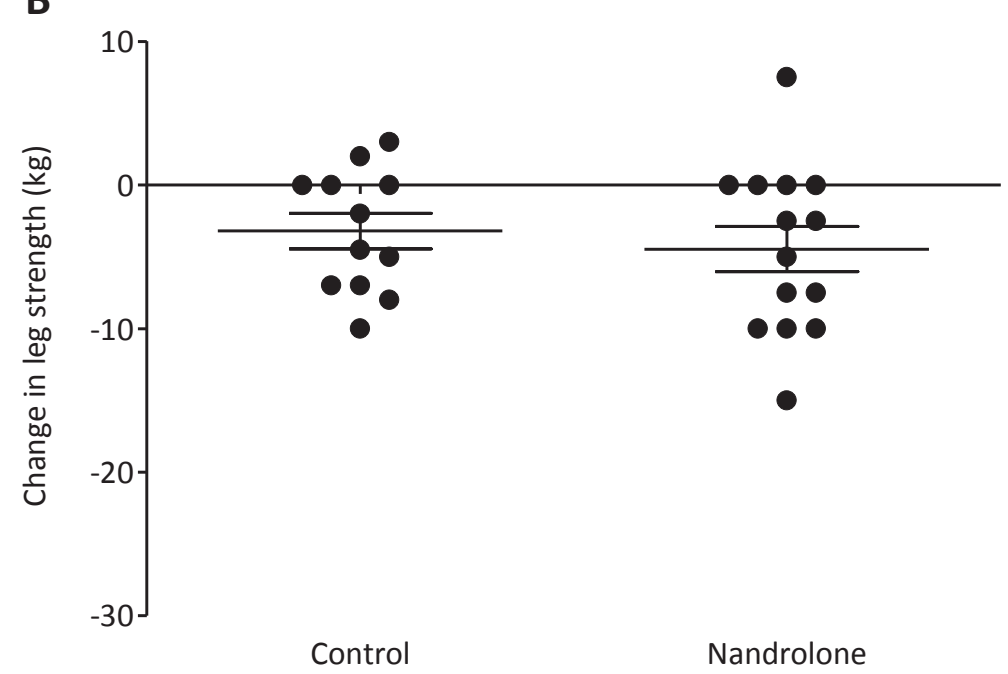

Figure 6.2A: One-repetition maximum (1-RM) leg muscle strength in the Control and Nandrolone group before and after 7 days of one-legged knee immobilization. Figure 2B: Individual changes in $1-$ RM leg muscle strength following 7 days of one-legged knee immobilization. Data were analyzed using repeated measures ANOVA. Data are expressed as means \pm SEM. Immobilization resulted in a significant decline in muscle strength in both groups $\left({ }^{*}\right)$, with no differences between groups. 


\section{Blood analyses}

Serum NAD concentrations significantly increased in the NAD group $(0.04 \pm 0.002$ and $13.83 \pm 0.98 \mathrm{nmol} / \mathrm{L})$ compared with the CON group $(0.04 \pm 0.003$ and $0.04 \pm 0.01 \mathrm{nmol} / \mathrm{L})$, preand post-immobilization, respectively (Time $\mathrm{x}$ Treatment $P<0.01$ ). Serum testosterone concentrations increased more in the NAD group (from $22.75 \pm 1.85$ to $42.87 \pm 2.22 \mathrm{nmol} / \mathrm{L}$ ) than the CON group (from $21.82 \pm 1.46$ to $21.09 \pm 1.43 \mathrm{nmol} / \mathrm{L}$ ), pre and post immobilization, respectively (Time $\mathrm{x}$ Treatment $P<0.01$ ).

Muscle fiber characteristics

Muscle fiber characteristics are displayed in Table 6.2. At baseline, no differences between groups were observed for any of the variables. No measurable changes in muscle fiber CSA or distribution were observed following immobilization $(P>0.05)$. No differences over time were observed between groups $(P>0.05)$.

Table 6.2: Muscle fiber characteristics of healthy young men before (pre) and after (post) $7 \mathrm{~d}$ of leg immobilization in the control and nandrolone group

\begin{tabular}{llllll}
\hline & \multicolumn{2}{c}{ Control } & \multicolumn{2}{c}{ Nandrolone } \\
\cline { 2 - 6 } & $\begin{array}{l}\text { Fiber } \\
\text { type }\end{array}$ & Pre & Post & Pre & Post \\
\cline { 2 - 6 } Muscle fiber CSA & I & $6034 \pm 501$ & $6620 \pm 508$ & $6014 \pm 283$ & $6188 \pm 253$ \\
$\left(\mu\right.$ m $\left.^{2}\right)$ & II & $7202 \pm 640$ & $7540 \pm 587$ & $6587 \pm 512$ & $6594 \pm 311$ \\
$\%$ Fiber & I & $38 \pm 4$ & $33 \pm 3$ & $40 \pm 3$ & $40 \pm 4$ \\
& II & $62 \pm 4$ & $67 \pm 3$ & $60 \pm 3$ & $60 \pm 4$ \\
\% Fiber (area) & I & $46 \pm 1$ & $47 \pm 1$ & $48 \pm 1$ & $48 \pm 1$ \\
& II & $54 \pm 1$ & $53 \pm 1$ & $52 \pm 1$ & $52 \pm 1$ \\
Nuclei (n/fiber) & I & $3.6 \pm 0.3$ & $3.7 \pm 0.2$ & $4.4 \pm 0.4$ & $4.5 \pm 0.2$ \\
& II & $4.2 \pm 0.4$ & $4.0 \pm 0.2$ & $4.5 \pm 0.5$ & $4.7 \pm 0.3$ \\
Myonuclear & I & $1697 \pm 87$ & $1786 \pm 88$ & $1484 \pm 108$ & $1401 \pm 69$ \\
domain ( $\left.\mu m^{2}\right)$ & II & $1764 \pm 89$ & $1883 \pm 101$ & $1562 \pm 114$ & $1454 \pm 68$ \\
SC (n/fiber) & I & $0.128 \pm 0.016$ & $0.103 \pm 0.012$ & $0.056 \pm 0.011$ & $0.057 \pm 0.008$ \\
& II & $0.083 \pm 0.011$ & $0.081 \pm 0.008$ & $0.047 \pm 0.008$ & $0.055 \pm 0.010$ \\
\hline Data represent & means \pm SEM. Abbreviations: CSA, Cross-sectional area, SC, & Satellite Cell. No \\
interaction- or time
\end{tabular}

interaction- or time effect was found in any of the variables $(P>0.05)$.

\section{Discussion}

In the present study, we demonstrated that nandrolone decanoate administration does not attenuate muscle disuse atrophy during 7 days of leg immobilization in healthy adults. Also, nandrolone decanoate administration did not prevent the decline in muscle strength during this short period of disuse.

A period of prolonged muscle disuse or successive short episodes of muscle disuse reduce skeletal muscle mass and strength and cause numerous negative health outcomes (29-33)
As a consequence, it has been proposed that such short successive periods of muscle disuse due to injury or disease may be largely responsible for the loss of muscle mass throughout the lifespan $(1,4)$. In the present study, we report that merely $7 \mathrm{~d}$ of muscle disuse leads to substantial loss of muscle mass (6\%; Fig. $2 \mathrm{~A}$ ), which translates to $260 \mathrm{~g}$ lean muscle from a single leg. The $6 \%$ decline in quadriceps cross-sectional area was accompanied by a similar (6\%) decline in leg strength (Fig. $3 \mathrm{~A}$ ) in healthy males. These observations are in line with recent data from our group $(3,34)$ as well as others $(35)$ reporting similar declines in both muscle mass and strength in both young and older individuals. These data are of important clinical relevance as hospitalization following acute illness or injury is generally accompanied by an average hospital stay of one week (2). The loss of muscle mass and strength during such short (successive) periods of muscle disuse impairs functional capacity, increases the risk of developing chronic metabolic disease, and hinders the subsequent rehabilitation upon discharge (36). Clearly, effective interventional strategies need to be developed to prevent or attenuate muscle mass and strength loss during short periods of muscle disuse due to injury, disease and/or surgery.

Prolonged anabolic steroid administration (ranging from 25-600 mg during 1-6 months of intervention) has previously been shown to increase fat free mass, muscle cross-sectional area and/or strength in several pathological conditions (13-23) and in athletes (37). In the present study, we administered one single intramuscular dose $(200 \mathrm{mg})$ of nandrolone at the day of immobilization. The injection was well received and no major adverse events were reported following nandrolone administration during the subsequent immobilization period. In our study, nandrolone decanoate administration did not attenuate muscle or strength loss.

In the present study, we chose to provide nandrolone on the day of immobilization as opposed to several days or weeks prior to bed rest or immobilization, as it presents a practical and clinically relevant strategy for more clinically compromised patients bein hospitalized following both acute injury as well as scheduled surgery. As demonstrated in previous work, a single injection of nandrolone shows a peak in serum concentrations 72 hours after intramuscular injection, with the half-life of 7-12 days (7). As a consequence, we believe that the treatment strategy applied in the present study should be effective to increase circulating steroid levels during the entire 7 days immobilization protocol. Indeed, after 7 days of immobilization, serum testosterone levels were still significantly increased compared to pre-immobilization

In conclusion, administration of a single bolus of nandrolone decanoate prior to a shor period of disuse does not attenuate muscle atrophy nor does it preserve muscle strength. 


\section{References}

1. Wall BT, Dirks ML, van Loon $\mathrm{L}$. Skeletal muscle atrophy during short-term disuse: implications for agerelated sarcopenia. Ageing research reviews. 2013;12(4):898-906.

2. Fisher SR, KuO YF, Graham JE, Ottenbacher KJ, Ostir GV. Early ambulation and length of stay in older adults hospitalized for acute illness. Archives of internal medicine. 2010;170(21):1942-3.

Wall BT, Dirks ML, Snijders T, Senden JM, Dolmans J, van Loon L. Substantial skeletal muscle loss occurs during only 5 days of disuse. Acta physiologica (Oxford, England). 2014;210(3):600-11.

English KL, Paddon-Jones D. Protecting muscle mass and function in older adults during bed rest. Current opinion in clinical nutrition and metabolic care. 2010;13(1):34-9.

5. Adams GR, Caiozzo VJ, Baldwin KM. Skeletal muscle unweighting: spaceflight and ground-based models. J Appl Physiol (1985). 2003;95(6):2185-201.

Wall BT, van Loon L. Nutritional strategies to attenuate muscle disuse atrophy. Nutrition reviews. 2013;71(4):195-208.

7. Bagchus WM, Smeets JM, Verheul HA, De Jager-Van Der Veen SM, Port A, Geurts TB. Pharmacokinetic evaluation of three different intramuscular doses of nandrolone decanoate: analysis of serum and urine samples in healthy men. J Clin Endocrinol Metab. 2005;90(5):2624-30.

8. Belkien L, Schurmeyer T, Hano R, Gunnarsson PO, Nieschlag E. Pharmacokinetics of 19-nortestosteron

9. Minto CF, Howe C, Wishart S, Conway AJ, Handelsman DJ. Pharmacokinetics and pharmacodynamics of nandrolone esters in oil vehicle: effects of ester, injection site and injection volume. J Pharmacol Exp Ther. 1997;281(1):93-102.

10. Wijnand HP, Bosch AM, Donker CW. Pharmacokinetic parameters of nandrolone (19-nortestosterone) after intramuscular administration of nandrolone decanoate (Deca-Durabolin) to healthy volunteers. Acta Endocrinol Suppl (Copenh). 1985,271.19-30.

11. Qin W, Pan J, Wu Y, Bauman WA, Cardozo C. Protection against dexamethasone-induced muscle atrophy is related to modulation by testosterone of FOXO1 and PGC-1alpha. Biochemical and biophysical research communications. 2010;403(3-4):473-8.

12. White JP, Gao S, Puppa MJ, Sato S, Welle SL, Carson JA. Testosterone regulation of Akt/mTORC1/FoxO3 signaling in skeletal muscle. Molecular and cellular endocrinology. 2013;365(2):174-86.

13. Batterham MJ, Garsia R. A comparison of megestrol acetate, nandrolone decanoate and dietary counselling for HIV associated weight loss. Int $J$ Androl, 2001,24(4):232-40.

4. Creutzberg EC, Wouters EF, Mostert R, Pluymers RJ, Schols AM. A role for anabolic steroids in the rehabilitation of patients with COPD? A double-blind, placebo-controlled, randomized trial. Chest. 2003;124(5):1733-42

15. Gold J, High HA, Li Y, Michelmore H, Bodsworth NJ, Finlayson R, et al. Safety and efficacy of nandrolon decanoate for treatment of wasting in patients with HIV infection. AIDS. 1996;10(7):745-52.

16. Hassager C, Riis BJ, Podenphant J, Christiansen C. Nandrolone decanoate treatment of post-menopausa osteoporosis for 2 years and effects of withdrawal. Maturitas. 1989;11(4):305-17.

17. Hohmann E, Tetsworth K, Hohmann S, Bryant AL. Anabolic steroids after total knee arthroplasty. A double blinded prospective pilot study. J Orthop Surg Res. 2010;5:93.

18. Johansen KL, Mulligan K, Schambelan M. Anabolic effects of nandrolone decanoate in patients receivin dialysis: a randomized controlled trial. JAMA : the journal of the American Medical Association. 1999;281(14):1275-81.

19. Sattler FR, Jaque SV, Schroeder ET, Olson C, Dube MP, Martinez C, et al. Effects of pharmacological doses of nandrolone decanoate and progressive resistance training in immunodeficient patients infected with human immunodeficiency virus. The Journal of clinical endocrinology and metabolism. 1999;84(4):126876.

20. Schols AM, Soeters PB, Mostert R, Pluymers RJ, Wouters EF. Physiologic effects of nutritional support and anabolic steroids in patients with chronic obstructive pulmonary disease. A placebo-controlled randomized trial. Am J Respir Crit Cre Med. 1955;1152(4Pt 1).1268-74.

mass and strength but not muscle quality: results from two studies. American journal of physiology Endocrinology and metabolism. 2003;285(1):E16-24

22. Storer TW, Woodhouse $L$, Sattler F, Singh AB, Schroeder ET, Beck K, et al. A randomized, placebocontrolled trial of nandrolone decanoate in human immunodeficiency virus-infected men with mild to moderate weight loss with recombinant human growth hormone as active reference treatment. The Journal of clinical endocrinology and metabolism. 2005:90(8):4474-82.
23. Velema MS, Kwa BH, de Ronde W. Should androgenic anabolic steroids be considered in the treatment regime of selected chronic obstructive pulmonary disease patients? Current opinion in pulmonary medicine. 2012:18(2):118-24.

24. Dirks ML, Wall BT, Snijders T, Ottenbros CL, Verdijk LB, van Loon L. Neuromuscular electrical stimulation prevents muscle disuse atrophy during leg immobilization in humans. Acta physiologica (Oxford, England). 2014;210(3):628-41.

25. Verdijk LB, van Loon L Meijer $\mathrm{K}$ Savelberg $\mathrm{HH}$. One-repetition maximum strength test represents a valid means to assess leg strength in vivo in humans. J Sports Sci. 2009;27(1):59-68.

26. Strandberg S, Wretling ML, Wredmark T Shalabi A. Reliability of computed tomography measurements in assessment of thigh muscle cross-sectional area and attenution. BMC Med Imasin 2010;10:18.

27. Berstrom J. Percutaneous needle biopsy of skeletal muscle in physiological and clinical research. Scand J Clin

Edelstein A, Amodaj N, Hoover K, Vale R, Stuurman N. Computer control of microscopes using Chapter 14:Unit14 20

29. Deitrick JE. The Cfect of immobilization on metabolic and physiological functions of normal men. BullN Acad Med. 1948:24(6):364-75.

30. Gibson IN Halliday D, Morrison WL, Stoward PJ, Hornsby GA Watt PW, et al. Decrease in human 9 . Haruna Y, Suzuki Y, Kawakubo K, Yanagibori R, Gunji A. Decr

Stuart CA, Shangraw RE, Prince MJ, Peters EJ, Wolfe RR. Bed-rest-induced insulin resistance occurs primarily in muscle. Metabolism. 1988;37(8):802-6.

3. Tzankoff SP, Norris AH. Effect of muscle mass decrease on age-related BMR changes. J Appl Physiol Respir Environ Exerc Physiol. 1977:43(6):1001-6.

34. Dirks ML, Wall BT, Nilwik R, Weerts DH, Verdijk $L B$, van Loon $L$ Skeletal muscle disuse atrophy is not 2014;144(8):1196-203.

35. Suetta C, Frandsen U, Jensen L, Jensen MM, Jespersen JG, Hvid LG, et al. Aging affects the transcription regulation of human skeletal muscle disuse atrophy. PLoS One. 2012;7(12):e51238.

36. Christensen T, Bendix T, Kehlet H. Fatigue and cardiorespiratory function following abdominal surgery - Br I Surg. 1982;69(7):417-9.

37. Bhasin S, Storer TW, Berman N, Callegari C, Clevenger B, Phillips J, et al. The effects of supraphysiologic , 1996;335(1):1-7. 


\section{Chapter 7}

Protein intake and lean body mass preservation during energy

intake restriction in overweight older adults

Evelien M.P. Backx Michael Tieland

Karin J. Borgonjen-van den Berg

Pauline R. Claessen

Luc J.C. van Loon Lisette C.P.G.M. de Groot 


\section{Abstract}

Background Dietary induced weight loss is generally accompanied by a decline in skeleta muscle mass. The loss of muscle mass leads to a decline in muscle strength and impairs physical performance. A high dietary protein intake has been suggested to allow muscle mass preservation during energy intake restriction.

Objective To investigate the impact of increasing dietary protein intake on lean body mass, strength and physical performance during 12 weeks of energy intake restriction in overweight older adults.

Design Sixty-one overweight and obese men and women ( $63 \pm 5 \mathrm{y})$ were randomly assigned to either a high protein diet (HP; $1.7 \mathrm{~g} / \mathrm{kg} / \mathrm{d} ; n=31)$ or normal protein diet (NP; $0.9 \mathrm{~g} / \mathrm{kg} / \mathrm{d}$ $n=30$ ) during a 12 week $25 \%$ energy intake restriction. During this controlled dietary intervention, $90 \%$ of the diet was provided by the university. At baseline and after the intervention, body weight, lean body mass (DXA), leg strength (1-RM), physical performance (SPPB, $400 \mathrm{~m}$ ) and habitual physical activity (actigraph) were assessed.

Results Body weight declined in both groups with no differences between the HP and NP groups $(-8.9 \pm 2.9 \mathrm{~kg}$ vs $-9.1 \pm 3.4 \mathrm{~kg}$, respectively; $\mathrm{P}=0.584)$. Lean body mass declined by $1.8 \pm 2.2$ and $2.1 \pm 1.4 \mathrm{~kg}$, respectively, with no significant differences between groups $(P=0.213)$. Leg strength had decreased during the intervention by $8.8 \pm 14.0$ and $8.9 \pm 12.8 \mathrm{~kg}$ with no differences between groups $(P=0.689)$. Physical performance as measured by 400 $m$ walking speed improved in both groups, with no differences between groups $(P=0.219)$. Conclusion Increasing protein intake above habitual intake levels $(0.9 \mathrm{~g} / \mathrm{kg} / \mathrm{d})$ does not preserve lean body mass or muscle strength during prolonged energy intake restriction in overweight older adults.

\section{Introduction}

Muscle mass and strength are main predictors of physical function and health status in older adults. During a period of energy intake restriction, the decline in body weight is accompanied by a significant loss of muscle mass and strength $(1,2)$. This decline in muscle mass and strength may even offset the metabolic benefits of the reduction of excess body fat. Novel strategies to preserve muscle mass during energy intake restriction are warranted.

It has been well established that nutrition is an important factor in regulating muscle mass maintenance $(3,4)$. Dietary protein intake stimulates muscle protein synthesis and allows post-prandial muscle protein accretion (5). It has been suggested that increasing the protein content of the diet might be an effective interventional strategy to preserve muscle mass during prolonged energy intake restriction, thereby maintaining strength and physical performance. Whereas several intervention studies show that increasing protein intake during a period of energy intake restriction can alleviate the loss of lean body mass (LBM) or increase the loss of fat mass (FM) (6-8), other studies have failed to confirm these findings $(9,10)$. The discrepancy in the literature may be attributed to differences in the selected study population, the applied nutritional intervention and/or compliance and adherence of the subjects to the diet.

Most of the previous work investigating the impact of different protein intakes on LBM preservation during energy intake restriction have been conducted in young to middle-aged adults $(7,8,11-16)$. However, the results of these studies may not be translated to the older population due to differences in muscle mass and the prevalence of anabolic resistance (17-

19). Another explanation for the discrepancy in the literature is the protein content of the applied intervention diets. Previous studies have compared the impact of a wide variety of protein intakes on LBM preservation during prolonged energy intake restriction, ranging from $0.6-0.8$ versus $1.1-2.4 \mathrm{~g}$ protein per $\mathrm{kg}$ body weight per day $(8,9,20,21)$ Furthermore, the compliance and adherence to a dietary intervention requires careful attention, with nutrition being provided and consumed under strict supervision $(22,23)$. In the present study, we investigate the impact of an increase in dietary protein intake on the preservation of muscle mass during prolonged energy intake restriction in overweight, older adults. Maintenance of habitual protein intake $(0.9-1.0 \mathrm{~g} / \mathrm{kg} / \mathrm{d})$ has previously been shown to be required for muscle mass preservation $(24,25)$. Therefore, we assess the impact of energy intake restriction on LBM preservation with protein intakes being set at 1.7 versus $0.9 \mathrm{~g} / \mathrm{kg} / \mathrm{d}$. We hypothesize that a high protein intake can preserve LBM during energy intake restriction in overweight, older adults. To ensure proper compliance and adherence to the intervention diet, a strictly controlled dietary intervention is performed. 


\section{Methods}

Subjects

In total, 61 overweight and obese men $(n=36)$ and women $(n=25)$ were included in the study Supplemental Figure 7.1). All subjects were aged between 55 and $70 \mathrm{y}$, with a BMI between 27 and $40 \mathrm{~kg} / \mathrm{m}^{2}$ and a waist circumference of $\geq 102 \mathrm{~cm}$ for men and $\geq 88 \mathrm{~cm}$ for women (26). Subjects were excluded if they suffered from renal insufficiency (MDRD eGFR > $60 \mathrm{~mL} / \mathrm{min} / 1.73 \mathrm{~m}^{2}$ ) (27), type 1 or type 2 diabetes (fasting glucose levels $\geq 7 \mathrm{mmol} / \mathrm{L}$ ) (28), cancer, COPD, allergy to milk products or underwent a gastric bypass. Subjects were also excluded if they had severe loss of appetite, participated in a weight loss or heavy resistance-type exercise program 3 months before the intervention, or if they used supplements or drugs known to interfere with energy balance. Women could only participate if they were postmenopausal (last period one year previous to study start) Written informed consent was obtained from all the subjects.

Design

The study is a randomized, fully controlled dietary intervention trial of 12 weeks. In total, 76 subjects were screened for current medical status, medical history, BMI, waist circumference, fasting glucose and renal insufficiency. In addition, the 1 repetition maximum (1-RM) was estimated during the screening as a familiarization session. Subjects were randomly allocated to either the high protein group or the normal protein group. Randomization was carried out with permuted blocks, stratified by gender and BMI. After randomization, the following measurements were performed: Body composition, the Short Physical Performance Battery (SPPB), handgrip strength, $400 \mathrm{~m}$ walk test, leg strength (1RM leg press and leg extension), blood pressure, body weight and habitual physical activity. Subsequently, the subjects enrolled in the dietary intervention period that lasted for 13 weeks, consisting of one run-in week and 12 weeks of intervention. The subjects were not aware of the exact aim of the study to limit any possible effect on the outcome measures. The study is in accordance with the ethical standards with the Helsinki Declaration of 1975 as revised in 1983 and approved by the Medical Ethical Committee of Wageningen University. The design and aim of the study was registered in the NIH clinical trial database (ClinicalTrials.gov number: NCT01915030).

\section{Dietary intervention}

One week after baseline measurements, subjects started with the run-in week. During the run-in week, subjects consumed $100 \%$ of their habitual energy intake (protein 14 Energy\% (En\%), fat $31 \mathrm{En \% ,} \mathrm{carbohydrate} 51 \mathrm{En \%})$. Habitual energy intake was calculated from validated 177-item food frequency questionnaire (29) and estimated by the Schofield formula in combination with a standard PAL (physical activity level) of 1.6 (30). Menus were designed for 10 levels of energy intake, ranging from 7-16 MJ/d. Procedures during the runin week were the same as during the intervention to familiarize the subjects with the intervention procedures and to standardize dietary conditions among groups. Moreover, if subjects lost or gained body weight during the run-in week, energy intake was adjusted to attain an adequate estimation of the habitual energy intake for the rest of the intervention. Directly after the run-in week, subjects enrolled in the dietary intervention.

The intervention diets were isocaloric compared to each other and energy intake restricted by $25 \%$ from baseline energy intake. Ninety percent of the diet was provided by the university and $10 \%$ was chosen by the subjects from a restricted list. Food products were weighed for each subject individually. The high protein (HP) diet contained $1.7 \mathrm{~g}$ protein $/ \mathrm{kg} / \mathrm{d}$ and the normal protein (NP) diet contained $0.9 \mathrm{~g} / \mathrm{kg} / \mathrm{d}$. Protein was replaced by carbohydrates in the NP group, the fat content was equal in both diets. Subjects consumed a supplement twice a day, containing either $20 \mathrm{~g}$ protein for the HP group (50\% whey, $40 \%$ casein, $10 \%$ soy) or $25 \mathrm{~g}$ carbohydrate for the NP group. The intervention diets were designed and calculated by experienced research dieticians using the Dutch food composition table (31). On weekdays, subjects came to the university to consume their hot meal (during afternoon or evening). The rest of the diet (breakfast, bread meal, snacks and beverages) and all meals for Saturdays and Sundays were provided in take-home packages, together with the meal planning. Subjects were carefully instructed how to prepare the hot meals for the weekend. Protein intake was evenly divided over the day with on average $34 \pm 4 \mathrm{~g}$ (ranging from $25-41 \mathrm{~g}$ ) protein per meal in the HP group and $16 \pm 1 \mathrm{~g}$ (ranging from 15-18 g) protein per meal in the NP group. A sample daily meal plan and an overview of the macronutrient distribution are provided in the supplemental material. To cover the remaining $10 \%$ of daily energy intake, subjects were obliged to choose foods that were low in fat and protein content (max $0.6 \mathrm{~g}$ protein per portion) from a list with allowed food products. They recorded these foods in a diary in which they also noted any deviations from the study protocol, illnesses and use of drugs.

Dietary analysis

To analyze the amount of energy and macronutrients in the diet as provided by the university, one complete diet for each group was collected throughout the intervention. The collected duplicates were stored at $-20^{\circ} \mathrm{C}$ until analysis. After the study, all duplicate meals were pooled, homogenized and analyzed. Total energy, fat, protein, dry matter, ash, and fiber were analyzed and available carbohydrates were calculated. The nutrien composition of the remaining $10 \%$ of energy intake was calculated from the food dairies.

Compliance

Compliance was assured via daily contact (weekdays) with the investigators and dieticians. Dieticians supervised during meal time to ensure that the complete meal was consumed. Food diaries were discussed once per 2 weeks to ensure that the remaining $10 \%$ of energy intake was properly consumed. Body weight was measured twice a week on a digita balance with indoor clothing, without shoes and with empty pockets. If body weight 
changed more than two kilogram within the first weeks of the intervention, energy intake was adjusted.

\section{Body composition}

Fasted body weight was measured at baseline and at the end of the study to the neares $0.1 \mathrm{~kg}$ using a digital balance (Seca, Bascule MT, USA) with indoor clothing, without shoes and with empty pockets. Waist circumference was measured between the lower rib margin and the iliac crest, accurate to $0.5 \mathrm{~cm}$, using a non-stretchable tape. Height was measured to the nearest $0.1 \mathrm{~cm}$ using a microtoise. Total LBM (primary outcome), appendicular LBM and FM was determined using dual energy X-ray absorptiometry (DXA, model DPX-L, Luna Radiation Corp, Madison WI, software version 1.31)

\section{Muscle strength}

Maximum leg strength was assessed by 1-RM strength tests on leg press and leg extension machines (Technogym, Rotterdam, The Netherlands). During a first familiarization session during the screening, the proper lifting technique was demonstrated and practiced, after which maximum strength was estimated using the multiple repetitions testing procedure for leg press and leg extension. Handgrip strength of the dominant hand was measured using a hydraulic hand dynamometer (Jamar, Jackson, MI). Three consecutive measures of handgrip strength were recorded to the nearest $0.5 \mathrm{~kg}$ with subjects sitting in an upward position and the arm in a 90-degree angle. The maximum strength effort was reported.

Physical performance

Physical performance was assessed by two different tests, the Short Physical Performance Battery (SPPB) and a $400 \mathrm{~m}$ walk test. The SPPB consists of three components: balance, gait speed and chair rise ability. Scores of 0 to 4 were based on categories of performance in the balance test, on the time necessary to complete the walk, and on the time needed to perform the chair rise test. A summary performance score of 0 to 12 was calculated by summing the scores of the tests. The $400 \mathrm{~m}$ walk test assessed the time it takes to walk 400 $m$. Directly after finishing the test, subjects had to score the rate of perceived exertion (RPE) from 6 to 200 points.

\section{Physical activity}

Subjects were asked to maintain their habitual physical activity level during the intervention. Physical activity was measured in counts per min (CPM) using a small-sized triaxial accelerometer (Actigraph GT3X Actigraph LLC, Pensacola FL, USA), worn on the waist. Subjects wore the actigraph during wakefulness for 7 consecutive days and were instructed not to wear them while bathing or swimming. The actigraph method enables a reliable and objective assessment of daily physical activity (32-34). Activity counts were assessed at 1-min intervals. Data were included if subjects wore the actigraph for minimum of 5 days and at least $10 \mathrm{~h}$ per day.
Blood pressure

Blood pressure was measured in the morning after 10 min of rest with an Omron HEM-907 (Omron Healthcare, Lake Forest, IL, USA) device. At baseline and end, four measurements were done, with an interval of $2 \mathrm{~min}$, of which the first measurement was discarded. The mean value of the three subsequent measurements for systolic and diastolic blood pressure was taken

Statistics

The sample size was based upon a power calculation with an expected difference in lean body mass of $1.4 \pm 1.6 \mathrm{~kg}$ between the HP and NP group(35). With a power of $80 \%$ and significance level $(\alpha)$ of 0.05 , at least 23 participants are required per group. Sixty-one subjects were included to allow for drop-outs.

Data are presented as means \pm standard deviations (SD). To check if there were baseline differences between the groups, an independent sampled t-test was used. A paired t-test was used to locate if parameters changed over time. After checking the assumptions, Analysis of Covariance (ANCOVA) was applied to assess the differences between groups over time with diet group as independent variable, end parameters as dependent variable and BMI, gender and baseline parameters as covariates. Data were analyzed using SPSS version 21 (SPSS Incl Chicago, IL). Results were considered statistically significant at the 0.05 level.

\section{Results}

Subjects

An overview of the subjects' baseline characteristics is presented in Table 7.1. A total of 61 subjects participated in the intervention with a mean age of $63 \pm 4.8 \mathrm{y}$ and $\mathrm{BMI}$ of $31.2 \pm 3.0$ $\mathrm{kg} / \mathrm{m}^{2}$. One person in the high protein group withdrew during the run-in week, because of the time constraints of the intervention (Supplemental material Figure 7.1). No significant differences were observed in baseline values between groups.

Dietary intake

The actual composition of the intervention diets based on chemical analysis of the duplicate meals, food diaries and supplements is presented in Table 7.2. The HP diet group consumed on average $7.93 \mathrm{MJ} / \mathrm{d}$ with $27 \mathrm{En} \%$ from fat, $35 \mathrm{En} \%$ from carbohydrates and $34 \mathrm{En} \%$ from protein (1.69 g protein $/ \mathrm{kg} /$ day). The NP diet group consumed on average $7.80 \mathrm{MJ} / \mathrm{d}$ with 24 En\% from fat, $51 \mathrm{En} \%$ from carbohydrate and $19 \mathrm{En} \%$ from protein $(0.92 \mathrm{~g}$ protein/kg/d). Habitual dietary protein intake measured by the FFQ was $1.1 \pm 0.4 \mathrm{~g} / \mathrm{kg} / \mathrm{d}$. 
Table 7.1 Baseline subjects' characteristics.

\begin{tabular}{lll}
\hline & High protein group & Normal protein group \\
& $\boldsymbol{n}=\mathbf{3 1}$ & $\boldsymbol{n}=\mathbf{3 0}$ \\
\hline Male/Female $(\boldsymbol{n})$ & $18 / 13$ & $18 / 12$ \\
Age $(\mathbf{y})$ & $63 \pm 4.8$ & $62 \pm 4.8$ \\
Body weight $(\mathbf{k g})$ & $92.8 \pm 11.0$ & $90.5 \pm 10.0$ \\
BMI $\left(\mathbf{k g} / \mathbf{m}^{2}\right)$ & $31.3 \pm 3.0$ & $31.0 \pm 2.9$ \\
Lean body mass $(\mathbf{k g})$ & $54.8 \pm 12.2$ & $54.5 \pm 9.3$ \\
Fat mass (\%) & $37.7 \pm 8.4$ & $36.1 \pm 8.0$ \\
Fat mass $(\mathbf{k g})$ & $34.4 \pm 7.2$ & $32.5 \pm 8.2$ \\
Waist circumference (cm) & $108 \pm 8.4$ & $107 \pm 6.6$ \\
Fasting glucose (mmol/L) & $5.7 \pm 0.5$ & $5.8 \pm 0.5$ \\
\hline
\end{tabular}

Data represented as meanstSD. No baseline differences between groups are observed with an independent sampled t-test. BMI: Body Mass Index.

Table 7.2 Diet composition

\begin{tabular}{|c|c|c|c|c|}
\hline & \multicolumn{2}{|c|}{ High protein group } & \multicolumn{2}{|c|}{ Normal protein group } \\
\hline & $n=31$ & & $n=30$ & \\
\hline & $(g / d)$ & (En\%) & $(g / d)$ & (En\%) \\
\hline Energy (MJ/d) & 7.93 & 100 & 7.80 & 100 \\
\hline Energy (kcal/d) & 1894 & 100 & 1863 & 100 \\
\hline Total fat & 57 & 27 & 51 & 24 \\
\hline Total carbohydrate & 170 & 35 & 236 & 51 \\
\hline Total protein & 157 & 34 & 84 & 19 \\
\hline Protein (in g/kg/d) & 1.69 & 34 & 0.92 & 19 \\
\hline Fiber $(g / d)$ & 21.3 & 2 & 33.9 & 4 \\
\hline Alcohol (g/d) & 7.7 & 3 & 7.1 & 3 \\
\hline
\end{tabular}

Body composition

Body weight declined over time for both groups (HP: $92.8 \pm 11.0$ to $83.9 \pm 10.1 \mathrm{~kg}$; $\mathrm{P}<0.01$; NP: $90.5 \pm 10.0$ to $81.5 \pm 9.7 \mathrm{~kg} ; \mathrm{P}<0.01)$. However, no significant differences in weight loss were detected between the diet groups $(P=0.584)$. Waist circumference declined from $108 \pm 8$ to $97 \pm 7 \mathrm{~cm}(P<0.01)$ in the HP group and from $107 \pm 7$ to $97 \pm 7 \mathrm{~cm}$ in the NP group $(P<0.01)$ with no significant differences observed between groups $(P=0.921)$. Similarly, $B M$ decreased in both groups; from $31.3 \pm 3.0$ to $27.5 \pm 5.8 \mathrm{~kg} / \mathrm{m}^{2}(\mathrm{P}<0.01)$ in the HP group and from $31.0 \pm 2.9$ to $27.9 \pm 3.1 \mathrm{~kg} / \mathrm{m}^{2}(\mathrm{P}<0.01)$ in the NP group. No significant difference between the diet groups was found $(P=0.395)$. LBM also changed, as it declined over time in both the HP group (from $54.8 \pm 12.2$ to $53.1 \pm 11.4 \mathrm{~kg}$; $\mathrm{P}<0.01$ ) and in the NP group (from $54.5 \pm 9.3$ to $52.4 \pm 9.1 \mathrm{~kg} ; \mathrm{P}<0.01$ ), without a significant difference between the two groups $(P=0.213)$. In both groups, appendicular LBM decreased; from $23.8 \pm 5.5$ to $23.1 \pm 5.4 \mathrm{~kg}$ and from $23.8 \pm 4.8$ to $22.8 \pm 4.6 \mathrm{~kg}$ in the HP and NP group respectively $(P<0.01)$, without a significant difference between the two diet groups $(\mathrm{P}=0.122)$. Changes in body composition are presented in Figure $\mathbf{7 . 1}$ and Figure 7.2.

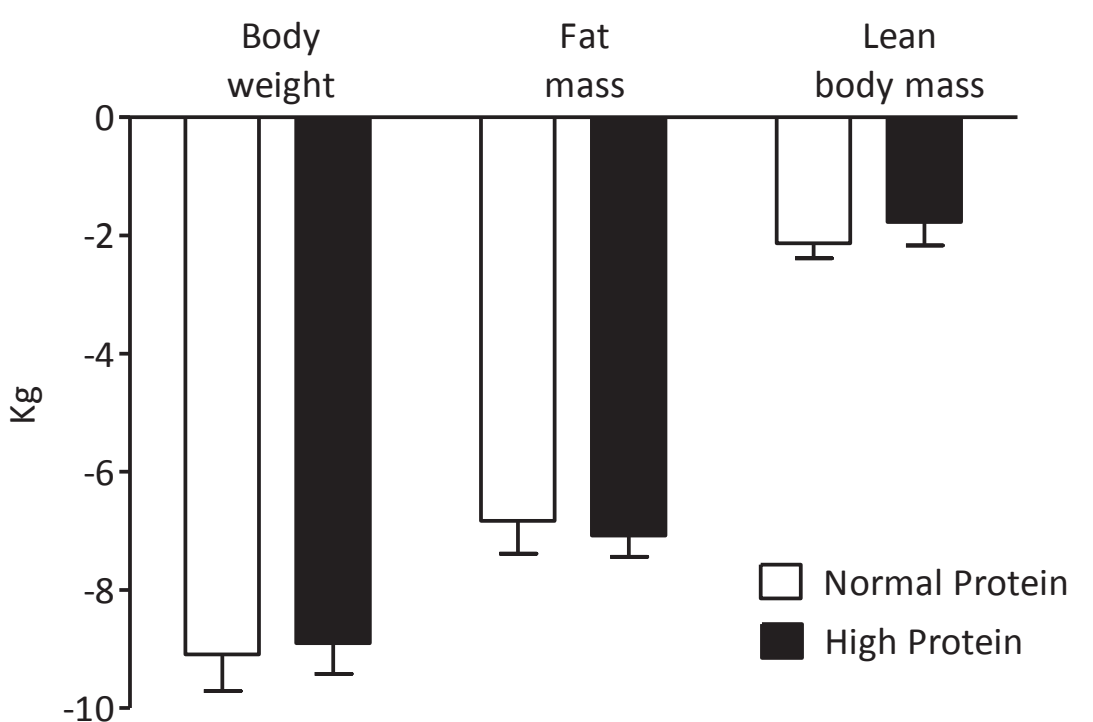

Figure 7.1 Body composition changes after 12 weeks in the normal protein and high protein group. Paired t-tests showed that body weight, fat mass and lean body mass all changed over time. No differences are found between groups, as indicated by an ANCOVA. No differences in loss of lean body mass are found between men and women $(P=0.50)$ and between overweight and obese subjects $(P=0.52)$. Data are represented as mean $\pm S D$.

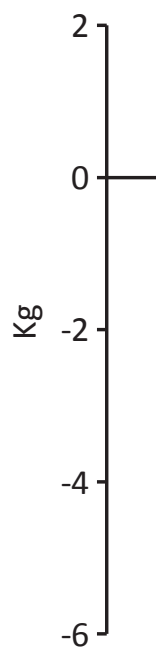

Figure 7.2 Individual changes in appendicular lean body mass following 12 weeks of energy intake restriction with or without an increase in protein intake. Appendicular lean body mass changed over time, indicated by a paired t-test. ANCOVA testing showed no significant differences between groups. Data are represented as mean \pm SD. 


\section{Muscle strength}

Leg strength declined over time in both groups, without a significant difference between the groups (for leg press $\mathrm{P}=0.689$; for leg extension $\mathrm{P}=0.296$ ). In accordance, handgrip strength declined over time in the HP group $(P=0.013)$, but not in the NP group $(P=0.215)$ with no significant differences observed between groups $(P=0.210)$. Strength and physical performance data are presented in Table 7.3.

\section{Physical performance}

The total scores of the SPPB did not change over time (11.5 \pm 0.7 to $11.6 \pm 0.5$ points; $\mathrm{P}=0.132$ ) and no significant differences were observed between groups $(P=0.483)$. The $400 \mathrm{~m}$ walking velocity increased from $1.45 \pm 0.19$ to $1.49 \pm 0.21 \mathrm{~ms}^{-1}(\mathrm{P}<0.01)$ without a difference between the two groups $(P=0.219)$. Strength and physical performance data are presented in Table 7.3.

Table 7.3 Muscle strength and physical performance before and after intervention

\begin{tabular}{|c|c|c|c|c|c|c|c|c|}
\hline & \multicolumn{4}{|c|}{ High protein group } & \multicolumn{4}{|c|}{ Normal protein group } \\
\hline & $n$ & Baseline & End & $\Delta$ & $n$ & Baseline & End & $\Delta$ \\
\hline 1-RM Leg & 28 & $152 \pm 44$ & $143 \pm 39$ & $-9 \pm 14^{*}$ & 25 & $157 \pm 33$ & $148 \pm 30$ & $-9 \pm 13^{*}$ \\
\hline Press (kg) & & & & & & & & \\
\hline $\begin{array}{l}\text { 1-RM Leg } \\
\text { Extension (kg) }\end{array}$ & 27 & $93 \pm 31$ & $91 \pm 29$ & $-2 \pm 8$ & 26 & $98 \pm 25$ & $94 \pm 25$ & $-4 \pm 4 *$ \\
\hline $\begin{array}{l}\text { Handgrip } \\
\text { strength (kg) }\end{array}$ & 30 & $40 \pm 11$ & $37 \pm 9$ & $-3 \pm 6^{*}$ & 30 & $41 \pm 10$ & $40 \pm 11$ & $-1 \pm 5$ \\
\hline SPPB (score) & 30 & $11.6 \pm 0.7$ & $11.7 \pm 0.5$ & $0.1 \pm 0.7$ & 30 & $11.4 \pm 0.9$ & $11.6 \pm 0.6$ & $0.1 \pm 0.7$ \\
\hline $\begin{array}{l}400 \mathrm{~m} \text { walk } \\
(\mathrm{m} / \mathrm{s})\end{array}$ & 30 & $1.46 \pm 0.19$ & $1.50 \pm 0.20$ & $0.05 \pm 0.09 *$ & 29 & $1.45 \pm 0.19$ & $1.47 \pm 0.22$ & $0.02 \pm 0.08$ \\
\hline
\end{tabular}

Data represented as means \pm SD. Data with * represent significant differences over time $(P<0.01)$, indicate with a paired t-test. ANCOVA testing showed no significant differences between groups. 1-RM: 1 repetition maximum, SPPB: Short Physical Performance Battery

Physical activity

Habitual physical activity did not change over time in the HP group ( $\mathrm{P}=0.748$; baseline value $916 \pm 203 \mathrm{CPM}$ ) or the NP ( $P=0.176$; baseline value $825 \pm 258 \mathrm{CPM})$. No significant differences in habitual physical activity were observed between groups $(P=0.685)$.

Blood pressure

Systolic blood pressure decreased over time from $139 \pm 18$ to $132 \pm 15 \mathrm{mmHg}(\mathrm{P}<0.01)$ in both groups. Diastolic blood pressure decreased from $82 \pm 9$ to $77 \pm 8 \mathrm{mmHg}(\mathrm{P}<0.01)$ in both groups. No significant differences between groups were observed for systolic $(P=0.279)$ and diastolic $(\mathrm{P}=0.170)$ blood pressure.
Discussion

In the present study we observed a nearly $10 \mathrm{~kg}$ reduction in body weight following 12 weeks of $25 \%$ energy intake restriction in overweight, older adults. The reduction in body mass was accompanied by a $2 \mathrm{~kg}$ decline in lean body mass and as much as a $10 \%$ decline in leg strength. Increasing dietary protein intake from 0.9 to $1.7 \mathrm{~g} / \mathrm{kg} / \mathrm{d}$ during the intervention did not preserve lean body mass nor did it prevent the decline in muscle strength associated with prolonged energy intake restriction.

Twelve weeks of energy intake restriction (25\%) successfully reduced body weight by $9.0 \pm 3.1 \mathrm{~kg}$ in this group overweight older adults $(P<0.01$; Figure 7.1). These results are in line with previous work showing that 12 weeks of $20-33 \%$ energy intake reduction induced $7-10 \mathrm{~kg}$ decline in body weight in overweight and obese adults $(6,12,20,36)$. The loss of body weight in the present study was attributed to a decline in both fat mass $(7.0 \pm 2.5 \mathrm{~kg})$ and lean body mass $(2.0 \pm 1.8 \mathrm{~kg} ; \mathrm{P}<0.01$; Figure 7.1$)$. The changes in lean body mass were correlated with the changes in appendicular lean body mass $(R=0.697 ; P<0.01)$, the latter ranging from as much -3.8 to $+1.9 \mathrm{~kg}$ (Figure 7.2). The overall decline in lean body mass was accompanied by a concomitant $-8.9 \pm 13.3 \mathrm{~kg}$ decline in leg strength $(-42$ to $+16 \mathrm{~kg} ; \mathrm{P}<0.01)$. Despite the reduction in leg strength, physical performance assessed with the $400 \mathrm{~m}$ walking speed test showed a significant improvement following dietary intervention (Table 7.3). This was at least partly attributed to the decline in fat mass $(R=-0.243 ; P=0.06)$. The SPPB score did not change over time, probably because the high baseline scores that limit the range for improvement (average score $11.5 \pm 0.7$ of 12 points maximum). Energy intake restriction improved blood pressure, BMI and waist circumference in both groups.

Despite the benefits of prolonged energy intake restriction to reduce body fat mass and improve metabolic function, the loss of skeletal muscle mass and strength is particularly undesirable in an older population prone to sarcopenia (37). Therefore, effective dietary strategies should be developed to preserve muscle mass during a period of energy intake restriction. During a period of energy intake restriction, muscle protein synthesis rates usually decrease (8), which would lead to the loss of lean body mass. However, this decline in muscle protein synthesis rates can be attenuated by the intake of $27 \mathrm{~g}$ whey protein (38) Increasing the protein content of the diet might therefore be an effective strategy to preserve muscle mass during prolonged energy intake restriction, thereby preserving strength and physical performance. This is confirmed by previous work showing that a high protein diet can preserve lean body mass during prolonged energy intake restriction (6-8, $11,12)$. In the present study we tested our hypothesis that a higher protein intake preserves lean body mass during prolonged energy intake restriction in overweight, older adults. We compared the impact of a higher protein diet (1.7 g protein $/ \mathrm{kg} / \mathrm{d} ; 34 \mathrm{En} \%$ protein) with a normal protein diet ( $0.9 \mathrm{~g}$ protein $/ \mathrm{kg} / \mathrm{d} ; 19 \mathrm{En} \%$ protein) on lean body mass, muscle strength and physical performance (Table 7.2). Despite substantial declines in lean body mass in both the normal and high protein groups $(2.1 \pm 1.4$ and $1.8 \pm 2.2 \mathrm{~kg}$, respectively), we observed no differences between groups $(P=0.213$; Figure 7.2). These findings are in contrast with some 
$(6-8)$ but certainly not all $(9,10)$ studies. The apparent discrepancy may be attributed to differences in the level of dietary control $(7-9,11-16,18,20)$, the protein content in the diets $(15,16,18)$, the duration of the intervention period $(7,8,11,39)$, the level of physical activity $(10,13,35)$ or the specific population that is studied $(7-9,11-16,20)$.

Through our strict dietary control, whereby we provided all subjects with $90 \%$ of their prescribed energy intake, the influence of possible confounders is limited. Dietary compliance was assured by daily contact (on weekdays) with the investigators and dieticians and body weight measurements performed twice weekly. No subject failed to consume the supplement more than twice during the entire intervention period as reported in the food intake diaries. Moreover, the results confirm the high level of compliance of the subjects in both groups showing a $10 \%$ reduction in body weight with a concomitant decrease in waist circumference of $10.3 \pm 4.3 \mathrm{~cm}$. In addition, by collecting duplicate meals, we were also able to analyze the actual macronutrient composition of the diets, thereby knowing the exact protein content of diets consumed in both intervention groups. Furthermore, people generally reduce overall energy intake when the level of dietary protein is increased (40), due to the satiating effect of protein (41). By providing the subjects with nearly their entire diet in the current study, energy intake remained equal in both intervention groups (7.66 $\mathrm{MJ} / \mathrm{d}$ in the high protein group, $7.38 \mathrm{MJ} / \mathrm{d}$ in the normal protein group). Consequently, the normal protein and high protein diet groups lost exactly the same amount of body weight $(-9.1 \pm 3.4$ and $8.9 \pm 2.9 \mathrm{~kg}$, respectively). In addition, it is well known that underreporting of energy intake is common in dietary interventions $(23,42)$. Overweight subjects typically underestimate energy (and macronutrient) intake, which can make data interpretation difficult (43). The results of the current study cannot be influenced by underreporting because intake of energy and macronutrients does not rely on food intake diaries, but is based on macronutrient analyses of the diet as provided by the university.

The current study aimed to investigate the additional effect of a high protein diet over a normal protein diet containing $0.9 \mathrm{~g} / \mathrm{kg} / \mathrm{d}$, the latter representing habitual protein intake $(24,25)$. Several previous studies consider intakes of $1.1 \mathrm{~g} / \mathrm{kg} / \mathrm{d}$ as a high protein diet $(9,20$ $44)$, and intakes of $0.8 \mathrm{~g} / \mathrm{kg} / \mathrm{d}$ or lower as normal to low protein diets $(7,8,14,16,20)$. The present study demonstrates $20 \%$ loss of lean body mass expressed as a proportion of total weight lost in the high protein group - an effect also observed in the comparable literature $(6,12)$. Surprisingly, we demonstrate that the normal protein group experienced a lowe percentage of lean body mass loss ( $23 \%$ of total weight lost) compared with the results of the aforementioned studies showing a $35 \%$ loss of lean body mass with similar protein intakes of $18 \%(6,13)$. Thus, comparing our data with the literature suggests that maintaining habitual protein intake may be more important than increasing protein intake beyond habitual protein intake levels as a means to preserve lean body mass during energy intake restriction. It is hereby important that protein intake during energy intake restriction is expressed in En\% as well as in $\mathrm{g} / \mathrm{kg} / \mathrm{d}$. When energy intake is reduced and protein intake is expressed only in En\%, protein intake might falsely be defined as normal while absolute protein intake is decreased.
The protein intake in the current study was on average $34 \mathrm{~g}$ per meal and evenly distributed throughout the day, which is in accordance to the current guidelines for elderly $(45,46)$. Specifically during energy restriction, an evenly distributed protein intake with lower protein amounts per meal appears to be more effective or as good as a skewed protein intake pattern in preserving muscle protein synthesis rates or lean body mass $(47,48)$ Details about the food products and macronutrient distribution are provided in Supplemental Tables 7.1-7.3. The current study had an intervention period of 12 weeks and is therefore in line with previous work that showed a positive effect of a high protein diet on lean body mass $(6,12,13)$. A recent meta-analysis (18) concluded that an intervention period of 12 weeks or longer is required to show any measurable intervention effect on lean body mass preservation. Thus, the current study is most likely of sufficient duration to be able to detect any possible differences between diets.

The present study only focuses on the effect of a dietary intervention on lean body mass. However, concurrent changes in physical activity level may interact with the impact of dietary intervention. To account for individual variability in physical activity levels, the physical activity status of each subject was measured before and at the end of the intervention period. The measurements indicate that habitual physical activity levels did not change over time in either group. Therefore, we can safely assume that changes in physical activity levels did not impact the outcome of the present study. Studies that included exercise as a co-intervention generally show a greater effect of a higher protein intake diet on lean body mass preservation, which has been confirmed by an RCT and systematic review $(10,21,35,49,50)$.

The study population of the current work are older men and women (55-70 y) whereas most previous work has been performed in young to middle-aged adults $(7,8,11-16)$. Although weight loss shows clear health benefits for overweight and obese adults, recent studies indicate that weight loss is not beneficial per se in an older population (51). A key determinant of healthy weight loss in the elderly is the amount of fat and not lean mass loss (51). The present study confirms that weight loss causes a substantial decline in muscle mass and strength. Therefore, interventions that limit the loss of muscle mass and strength during weight loss are of particular clinical relevance for the older adults (37).

Our observations imply that it is important to maintain a sufficient amount of protein intake during weight loss. Thus, decreases in energy intake should be derived mainly from decreases in carbohydrates and fat intake. Future studies could aim to optimize protein distribution throughout the day. However, current literature shows that total preservation of lean body mass is not possible with only a dietary intervention. The combination of exercise and energy intake restriction is generally more effective in preserving lean body mass $(35,52)$.

In conclusion, increasing dietary protein intake above habitual intake levels does not preserve lean body mass or muscle strength during prolonged energy intake restriction in overweight older adults. 
Acknowledgements We gratefully thank the dedication and cooperation of the participants of the study. Likewise, we acknowledge the help of all dieticians and students involved in the practical work.

\section{References}

1. Villareal DT, Apovian CM, Kushner RF, Klein S. Obesity in older adults: technical review and position of clinical nutrition. 2005:82(5):923-34.

2. Ballor DL Katch VL, Becque MD, Marks CR. Resistance weight training during caloric restriction enhances lean body weight maintenance. The American journal of clinical nutrition. 1988;47(1):19-25.

3. Koopman R, Saris WH, Wagenmakers AJ, van Loon $\sqcup$. Nutritional interventions to promote post-exercise muscle protein synthesis. Sports medicine (Auckland, NZ). 2007;37(10):895-906.

4. Paddon-Jones D, Rasmussen BB. Dietary protein recommendations and the prevention of sarcopenia. Current opinion in clinical nutrition and metabolic care. 2009;12(1):86-90

Moore DR, Tang JE, Burd NA, Rerecich T, Tarnopolsky MA, Phillips SM. Differential stimulation of myofibrillar and sarcoplasmic protein synthesis with protein ingestion at rest and after resistance exercise. The Journal of physiology. 2009;587(Pt 4):897-904.

6. Leidy HJ, Carnell NS, Mattes RD, Campbell WW. Higher protein intake preserves lean mass and satiety with weight loss in pre-obese and obese women. Obesity (Silver Spring, Md). 2007;15(2):421-9.

Soenen S, Martens EA, Hochstenbach-Waelen A, Lemmens SG, Westerterp-Plantenga MS. Normal protein intake is required for body weight loss and weight maintenance, and elevated protein intake for additiona 6 present

8. Pasiakos SM, Cao JJ, Margolis LM, Sauter ER, Whigham LD, McClung JP, et al. Effects of high-protein diets on fat-free mass and muscle protein synthesis following weight loss: a randomized controlled trial. FASEB 2013;27(9):3837-47.

9. Parker B, Noakes M, Luscombe N, Clifton P. Effect of a high-protein, high-monounsaturated fat weight loss diet on glycemic control and lipid levels in type 2 diabetes. Diabetes care. 2002;25(3):425-30.

10. Mojtahedi MC, Thorpe MP, Karampinos DC, Johnson CL, Layman DK, Georgiadis JG, et al. The effects of a higher protein intake during energy restriction on changes in body composition and physical function in older women. The journals of gerontology Series A, Biological sciences and medical sciences. 2011;66(11):1218-25

11. Piatti PM, Monti F, Fermo I, Baruffaldi L, Nasser R, Santambrogio G, et al. Hypocaloric high-protein diet improves glucose oxidation and spares lean body mass: comparison to hypocaloric high-carbohydrate diet. Metabolism: clinical and experimental. 1994;43(12):1481-7.

12. Farnsworth E, Luscombe ND, Noakes M, Wittert G, Argyiou E, Clifton PM. Effect of a high-protein, energyrestricted diet on body composition, glycemic control, and lipid concentrations in overweight and obese hyperinsulinemic men and women. The American journal of clinical nutrition. 2003;78(1):31-9.

13. Layman DK, Evans E, Baum JI, Seyler J, Erickson DJ, Boileau RA. Dietary protein and exercise have additive effects on body composition during weight loss in adult women. The Journal of nutrition. 2005;135(8):1903-10

14. Evans EM, Mojtahedi MC, Thorpe MP, Valentine RJ, Kris-Etherton PM, Layman DK. Effects of protein intake and gender on body composition changes: a randomized clinical weight loss trial. Nutrition \& metabolism. 2012;9(1):55.

15. Griffin HJ, Cheng HL, O'Connor HT, Rooney KB, Petocz P, Steinbeck KS. Higher protein diet for weight management in young overweight women: a 12-month randomized controlled trial. Diabetes, obesity \& metabolism. 2013;15(6):572-5.

16. Noakes M, Keogh JB, Foster PR, Clifton PM. Effect of an energy-restricted, high-protein, low-fat die relative to a conventional high-carbohydrate, low-fat diet on weight loss, body composition, nutritiona status, and markers of cardiovascular health in obese women. The American journal of clinical nutrition. 2005;81(6):1298-306.

17. Janssen I, Ross R. Linking age-related changes in skeletal muscle mass and composition with metabolism and disease. The journal of nutrition, health \& aging. 2005;9(6):408-19.

18. Wycherley TP, Moran L, Clifton PM, Noakes M, Brinkworth GD. Effects of energy-restricted high-protein, low-fat compared with standard-protein, low-fat diets: a meta-analysis of randomized controlled trials. The American journal of clinical nutrition. 2012;96(6):1281-98.

19. Breen L, Phillips SM. Skeletal muscle protein metabolism in the elderly: Interventions to counteract the 'anabolic resistance' of ageing. Nutrition \& metabolism. 2011;8:68. 
20. Wycherley TP, Noakes M, Clifton PM, Cleanthous X, Keogh JB, Brinkworth GD. A high-protein diet with resistance exercise training improves weight loss and body composition in overweight and obese patients with type 2 diabetes. Diabetes care. 2010;33(5):969-76.

21. Villareal D.T. C, S., Parimi, N., Sinacore, D.R., Hilton, T., Armamento-Villareal, R., Nicola Napoli, N., Qualls, C., Krupa Shah, K. Weight Loss, Exercise, or Both and Physical Function in Obese Older Adults. The New .

22. Alhassan S, Kim S, Bersamin A, King AC, Gardner CD. Dietary adherence and weight loss success amon overweight women: results from the A TO Z weight loss study. International journal of obesity (2005). 2008;32(6):985-91

23. Stubbs RJ, O'Reilly LM, Whybrow S, Fuller Z, Johnstone AM, Livingstone MB, et al. Measuring the

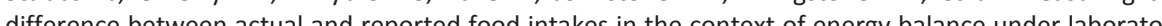
conditions. The British journal of nutrition. 2014:111, 2032-3043.

24. Houston DK, Nicklas BJ, Ding J, Harris TB, Tylavsky FA, Newman AB, et al. Dietary protein intake is associated with lean mass change in older, community-dwelling adults: the Health, Aging, and Body Composition (Health ABC) Study. The American journal of clinical nutrition. 2008:87(1):150-5.

25. Tieland $\mathrm{M}$, Borgonjen-Van den Berg KJ, van Loon $\mathrm{L}$, de Groot LC. Dietary protein intake in communitydwelling frail and institutionatized eld van loope: 2012;51(2):173-9.

26. World Health Organization. Waist Circumference and Waist-Hip Ratio. World Health Organization. Geneva, Switserland: 2011.

27. Levey AS, Eckardt KU, Tsukamoto Y, Levin A, Coresh J, Rossert J, et al. Definition and classification of chronic kidney disease: a position statement from Kidney Disease: Improving Global Outcomes (KDIGO). Kidney international. 2005:67(6):2089-100.

28. World Health Organization. Definition and diagnosis of diabetes mellitus and intermediate hyperglycemia: report of a WHO/IDF consultation World Health Organization. Geneva, Switserland 2011

29. Siebelink E, Geelen A, de Vries JH. Self-reported energy intake by FFQ compared with actual energy intake to maintain body weight in 516 adults. The British journal of nutrition. 2011;106(2):274-81.

30. Schofield WN. Predicting basal metabolic rate, new standards and review of previous work. Human nutrition Clinical nutrition. 1985:39 Suppl 1:5-41.

31. RIVM. NEVO tabel. RIVM: Bilthoven2011.

32. Corder K, Ekelund U, Steele RM, Wareham NJ, Brage S. Assessment of physical activity in youth. Journa of applied physiology (Bethesda, Md : 1985). 2008;105(3):977-87.

33. Reilly JJ, Penpraze V, Hislop J, Davies G, Grant S, Paton JY. Objective measurement of physical activity and sedentary behaviour: review with new data. Archives of disease in childhood. 2008;93(7):614-9.

34. De Vries SI, Van Hirtum HW, Bakker I, Hopman-Rock M, Hirasing RA, Van Mechelen W. Validity and reproducibility of motion sensors in youth: a systematic update. Medicine and science in sports and exercise. 2009;41(4):818-27.

35. Josse AR, Atkinson SA, Tarnopolsky MA, Phillips SM. Increased consumption of dairy foods and protein during diet- and exercise-induced weight loss promotes fat mass loss and lean mass gain in overweight and obese premenopausal women. The Journal of nutrition. 2011;141(9):1626-34.

36. Belobrajdic DP, Frystyk J, Jeyaratnaganthan N, Espelund U, Flyvbjerg A, Clifton PM, et al. Moderate energy restriction-induced weight loss affects circulating IGF levels independent of dietary composition. European journal of endocrinology / European Federation of Endocrine Societies. 2010;162(6):1075-82. Wall BT, Cermak NM, van Loon L. Dietary protein considerations to support active aging. Sports medicine (Auckland, NZ). 2014;44 Suppl 2:185-94

38. Hector AJ, Marcotte GR, Churchward-Venne TA, Murphy CH, Breen L, von Allmen M, et al. Whey protein supplementation preserves postprandial myofibrillar protein synthesis during short-term energy restriction in overweight and obese adults. The Journal of nutrition. 2015;145(2):246-52.

39. Coker RH, Miller S, Schutzler S, Deutz N, Wolfe RR. Whey protein and essential amino acids promote the reduction of adipose tissue and increased muscle protein synthesis during caloric restriction-induced weight loss in elderly, obese individuals. Nutrition journal. 2012;11:105.

40. Shab-Bidar S, Bours S, Geusens PP, Kessels AG, van den Bergh JP. Serum 25(OH)D response to vitamin D3 supplementation: a meta-regression analysis. Nutrition (Burbank, Los Angeles County, Calif). 2014;30(9):975-85.

41. Dawson-Hughes B, Dallal GE, Krall EA, Harris S, Sokoll L, Falconer G. Effect of vitamin D supplementation on wintertime and overall bone loss in healthy postmenopausal women. Annals of internal medicine. 1991;115(7):505-12.

42. Black AE, Cole TJ. Biased over- or under-reporting is characteristic of individuals whether over time or by different assessment methods. Journal of the American Dietetic Association. 2001;101(1):70-80.
43. Shaneshin M, Jessri M, Rashidkhani B. Validity of energy intake reports in relation to dietary patterns. Journal of health, population, and nutrition. 2014;32(1):36-45

44. Clifton PM, Keogh JB, Noakes M. Long-term effects of a high-protein weight-loss diet. The American journal of clinical nutrition. 2008;87(1):23-9.

45. Bauer J, Biolo G, Cederholm T, Cesari M, Cruz-Jentoft AJ, Morley JE, et al. Evidence-based recommendations for optimal dietary protein intake in older people: a position paper from the PROT-AGE Study Group. Journal of the American Medical Directors Association. 2013:14(8):542-59.

46. Pennings B, Groen B, de Lange A, Gijsen AP, Zorenc AH, Senden JM, et al. Amino acid absorption and Pubse journal of physiology Endocrinology and metabolism. 2012;302(8):E992-9.

47. Murphy CH, Churchward-Venne TA, Mitchell CJ, Kolar NM, Kassis A, Karagounis LG, et al. Hypoenergetic dietinduced reductions in myofibrillar protein synthesis are restored with resistance training and

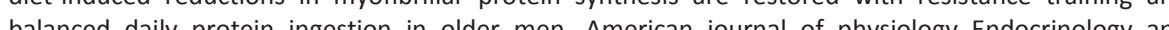
metabolism. 2015:308(9):E734-43.

48. Adechian S, Balage M, Remond D, Migne C, Quignard-Boulange A, Marset-Baglieri A, et al. Protein feeding pattern, casein feeding or milk-soluble protein feeding did not chane the evolution of body composition during a short-term weight loss progam. American journal of physiolegy Endocrinology and metabolism. during a short-term weig

49. Weinheimer EM, Sands LP, Campbell WW. A systematic review of the separate and combined effects of energy restriction and exercise on fat-free mass in middle-aged and older adults: implications for sarcopenic obesity. Nutrition reviews. 2010;68(7):375-88.

50. Verreijen AM, Verlaan $S$, Engberink MF, Swinkels $S$, de Vogel-van den Bosch J, Weijs PJ. A high whey protein- leucine-, and vitamin D-enriched supplement preserves muscle mass during intentional weight loss in obese older adults: a double-blind randomized controlled trial. The American journal of clinica nutrition. 2015;101(2):279-86.

51. Miller SL, Wolfe RR. The danger of weight loss in the elderly. The journal of nutrition, health \& aging. 2008;12(7):487-91.

52. Chomentowski P, Dube JJ, Amati F, Stefanovic-Racic M, Zhu S, Toledo FG, et al. Moderate exercise attenuates the loss of skeletal muscle mass that 0 ccurs with intentional caloric restriction-induced weight loss in older, overweight to obese adults. The journals of gerontology Series A, Biological sciences and medical sciences. 2009;64(5):575-80. 


\section{Supplemental Figure 7.1 Flow chart of the recruitment of subjects}

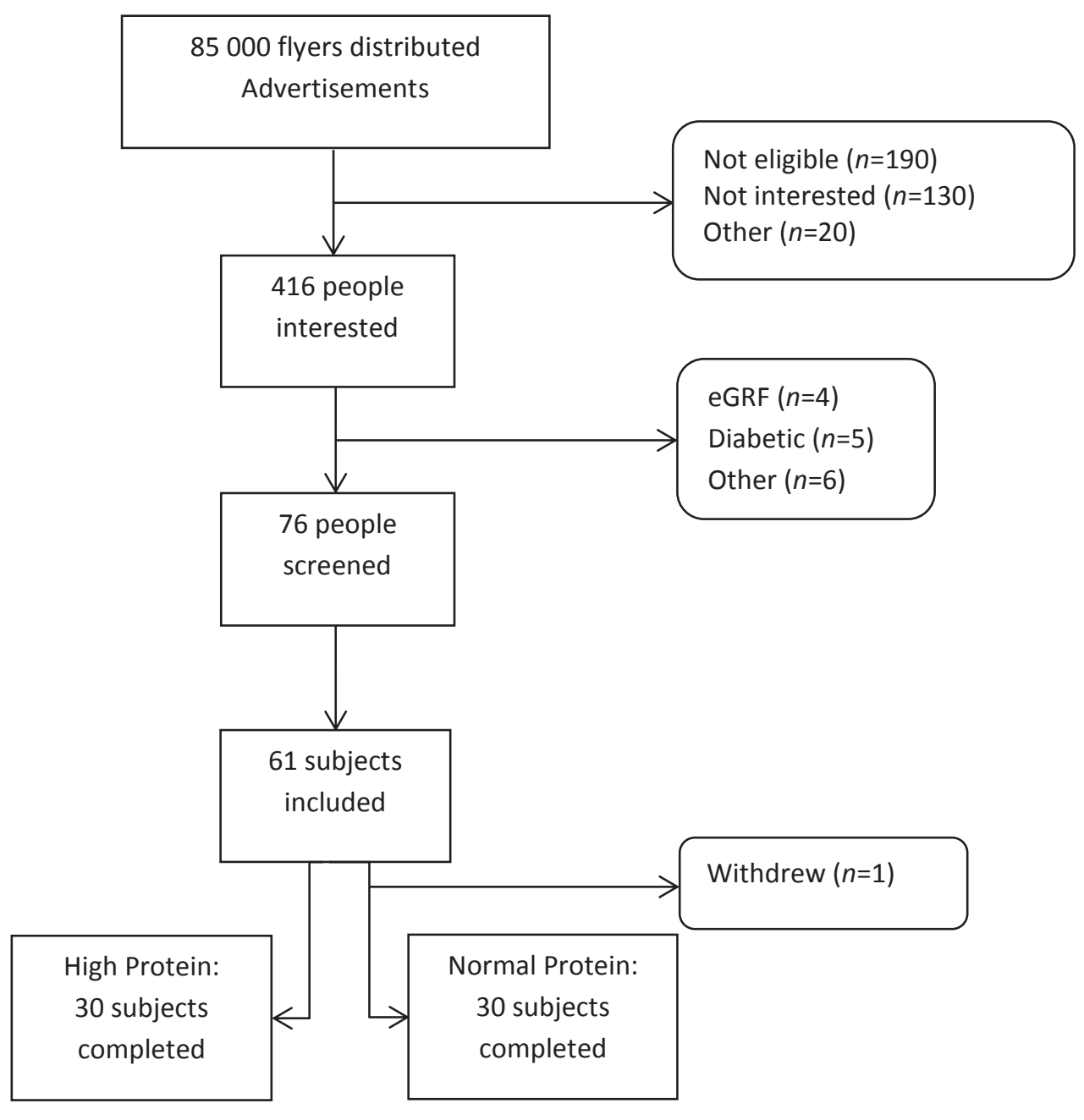

Supplemental Table 7.1: Example of a daily meal plan*

\begin{tabular}{|c|c|c|c|c|c|}
\hline & \multirow[b]{2}{*}{ Food product } & \multicolumn{2}{|c|}{ High Protein diet } & \multicolumn{2}{|c|}{ Normal Protein diet } \\
\hline & & $\begin{array}{l}\text { Food } \\
\text { product (g) }\end{array}$ & $\begin{array}{l}\text { Protein } \\
\text { amount (g) }\end{array}$ & $\begin{array}{l}\text { Food } \\
\text { product (g) }\end{array}$ & $\begin{array}{l}\text { Protein } \\
\text { amount (g) }\end{array}$ \\
\hline \multirow[t]{6}{*}{ Breakfast } & Bread & 105 & & 70 & \\
\hline & Cheese & 32 & & 16 & \\
\hline & Meat & 17 & & - & \\
\hline & Sweet topping & - & & 16 & \\
\hline & Milk & 160 & & 141 & \\
\hline & & & 33 & & 17 \\
\hline \multirow{4}{*}{ Snack } & Cheese & 60 & & 16 & \\
\hline & Supplement & 20 & & 25 & \\
\hline & Bread & - & & 35 & \\
\hline & & & 35 & & 9 \\
\hline \multirow[t]{6}{*}{ Lunch } & Bread & 70 & & 70 & \\
\hline & Cheese & 16 & & - & \\
\hline & Meat & 34 & & 17 & \\
\hline & Cream cheese & - & & 17 & \\
\hline & Dessert & 179 & & 130 & \\
\hline & & & 32 & & 16 \\
\hline Snack & Dessert & - & & 130 & 14 \\
\hline \multirow[t]{7}{*}{ Dinner } & Rice & 129 & & 85 & \\
\hline & Meat & 80 & & 70 & \\
\hline & Sauce & 45 & & 45 & \\
\hline & Cooked vegetables & 150 & & 150 & \\
\hline & $\begin{array}{l}\text { Uncooked } \\
\text { vegetables }\end{array}$ & 100 & & 100 & \\
\hline & Dressing & 15 & & 12 & \\
\hline & & & 35 & & 17 \\
\hline \multirow[t]{3}{*}{ Snack } & Supplement & 20 & & 25 & \\
\hline & Dessert & - & & 75 & \\
\hline & & & 20 & & 7 \\
\hline \multirow{3}{*}{$\begin{array}{l}\text { Subjects } \\
\text { decision of time } \\
\text { to consume }\end{array}$} & Low-fat margarine & 20 & & 25 & \\
\hline & Fruit (portion) & 1 & & 2 & \\
\hline & Egg (per week) & 3 & & - & \\
\hline \multirow[t]{2}{*}{ Other** } & $\begin{array}{l}\text { Points from list with } \\
\text { allowed food } \\
\text { products }\end{array}$ & 20 & - & 20 & - \\
\hline & & & 4 & & 3 \\
\hline
\end{tabular}


Supplemental Table 7.2: Macronutrients per meal in the Normal Protein group*

\begin{tabular}{llllllll}
\hline & Breakfast & Snack & Lunch & Snack & Dinner & Snack & Other** \\
\hline Energy (kJ) & 1417 & 972 & 1227 & 305 & 1546 & 678 & 1666 \\
Energy (kcal) & 339 & 232 & 293 & 73 & 369 & 162 & 398 \\
Total fat (g) & 10 & 5 & 8 & 1 & 16 & 4 & 9 \\
Total & 41 & 37 & 33 & 4 & 35 & 25 & 59 \\
carbohydrates (g) & & & & & & & \\
Total protein (g) & 17 & 9 & 16 & 14 & 17 & 7 & 3 \\
Fiber (g/d) & 7 & 3 & 8 & 0 & 10 & 0 & 0 \\
Alcohol (g/d) & 0 & 0 & 0 & 0 & 0 & 0 & 7
\end{tabular}

*Based on a subject with a body weight of $90 \mathrm{~kg}$ and an energy intake of $8 \mathrm{MJ} / \mathrm{d}(1911 \mathrm{kcal} / \mathrm{d})$ during the intervention. ${ }^{* *}$ 'Other' consists of the $10 \%$ of energy that the subjects could choose themselves from a restricted list, timing of those products was chosen by the subjects.

Supplemental Table 7.3: Macronutrients per meal in the High Protein group*

\begin{tabular}{llllllll}
\hline & Breakfast & Snack & Lunch & Snack & Dinner & Snack & Other** \\
\hline Energy (kJ) & 1938 & 955 & 1477 & 1911 & 417 & 1427 \\
Energy (kcal) & 463 & 228 & 353 & 457 & 100 & 341 \\
Total fat (g) & 16 & 9 & 9 & 15 & 0 & 10 \\
Total & 42 & 5 & 32 & 41 & 4 & 43 \\
carbohydrates (g) & & & & & & \\
Total protein (g) & 33 & 35 & 32 & 35 & 20 & 4 \\
Fiber (g/d) & 6 & 0 & 5 & 7 & 0 & 2 \\
Alcohol (g/d) & 0 & 0 & 0 & 0 & 0 & 8 \\
\hline
\end{tabular}

*Based on a subject with a body weight of $90 \mathrm{~kg}$ and an energy intake of $8 \mathrm{MJ} / \mathrm{d}(1911 \mathrm{kcal} / \mathrm{d})$ during the intervention. ${ }^{* *}$ OOther' consists of the $10 \%$ of energy that the subjects could choose themselves from a restricted list, timing of those products was chosen by the subjects. 


\section{Chapter 8}

General discussion 
Muscle mass is the main predictor for muscle strength and physical function. For athletes, it is important to maintain muscle mass during a period of disuse, since the loss of muscle is associated with decreased muscle strength, decreased physical performance and a longer recovery period $(1,2)$. In the older and more clinically compromised populations, the consequences of muscle disuse can substantially impact metabolic health (3-5), physical functioning (6), quality of life (7) and mortality rates $(8,9)$. In this thesis, we evaluated nutritional interventions to support muscle mass maintenance. Although an adequate serum vitamin $D$ concentration is considered important for maintenance of muscle mass and function, we uncovered that a high percentage of Dutch athletes have a low vitamin D status (chapter $\mathbf{2}$ and $\mathbf{3}$ ). During a period of muscle disuse, supplementing creatine (chapter 4) or leucine (chapter 5) did not prevent or attenuate the loss of muscle mass and strength, neither did a single injection of an anabolic steroid (nandrolone decanoate) (chapter 6). During a period of weight loss in older, overweight subjects, simply increasing protein intake did not attenuate the loss of muscle mass and function (chapter 7).

\section{Vitamin D}

The effect of vitamin D intake on bone health is well-described (10), however, the effect of vitamin $\mathrm{D}$ on muscle mass and function has only recently received attention from the scientific community. Cross-sectional studies have shown that vitamin D status (commonly assessed as serum 25-hydroxyvitamin D (25(OH)D) concentration) is positively correlated with skeletal muscle mass and function (11-13). Prospective studies have indicated that, in the older population, serum $25(\mathrm{OH}) \mathrm{D}$ concentrations below 25 or $50 \mathrm{nmol} / \mathrm{L}$ are associated with an increased fall risk (14), muscle weakness (15), and a greater muscle mass loss (15, 16) when compared to serum concentrations above $50 \mathrm{nmol} / \mathrm{L}$. Yet, the limited evidence from intervention trials show only small or no positive effects of vitamin $D$ supplementation on the preservation of muscle strength in older adults (17-19).

Although optimal muscle function is essential for athletes, they are currently an underrepresented group in vitamin D research (11-16). Until now, only a limited number of studies have focused specifically on the effect of vitamin $D$ supplementation on exercise performance in athletes (20-24). A daily vitamin D dosage of $5000 \mathrm{IU} / \mathrm{d}$ for 8 weeks improved 10 meter sprint time and vertical jump performance compared to the placebo group (20). In a separate study, provision of $2000 \mathrm{lU} / \mathrm{d}$ vitamin D for 4 months increased isometric muscular strength by $19 \%$ and vertical jump height by $7 \%$ in ballet dancers (21) The same study also reported that the vitamin $D$ supplemented group suffered fewer injuries than the athletes in the control group (21). Another recent study assessed the effects of $4000 \mathrm{IU} / \mathrm{d}$ vitamin D for 6 weeks and showed a $14 \%$ improvement in functional recovery from eccentric exercise at $48 \mathrm{~h}$ and 7 days post-exercise compared to a placebo group (22). Important to note, these studies tend to have a small sample size $(n=10-24)$ and other studies failed to find an effect of vitamin D supplementation on athletic performance
$(23,24)$. Although more studies are needed to firmly establish the effect of vitamin $D$ supplementation on muscle mass and function, previous work suggests that an adequate serum vitamin $D$ concentration can enhance muscle mass and function in athletes. Individuals with baseline serum $25(\mathrm{OH}) \mathrm{D}$ concentrations below $<50 \mathrm{nmol} / \mathrm{L}$ show greater benefits of vitamin $D$ supplementation on muscle mass and function compared to individuals with higher vitamin D concentrations at baseline $(25,26)$. Our study showed that a considerable $34 \%$ of the athletes had deficient $(<50 \mathrm{nmol} / \mathrm{L}) 25(\mathrm{OH}) \mathrm{D}$ concentrations at the end of the winter (chapter 3). Only $30 \%$ of the highly-trained Dutch athletes had a sufficient $(>75 \mathrm{nmol} / \mathrm{L}$ ) total serum $25(\mathrm{OH}) \mathrm{D}$ concentration and the other $36 \%$ of the athletes were vitamin $D$ insufficient $(50-75 \mathrm{nmol} / \mathrm{L}$ ) (chapter 3$)$. We also showed that $25(\mathrm{OH}) \mathrm{D}$ concentrations fluctuate throughout the year, with $36 \%$ lower concentrations in March compared to September (chapter 2). Thus, athletes with a sufficient 25(OH)D concentration in summer, still have a high risk $(20 \%)$ of being deficient $(<50 \mathrm{nmol} / \mathrm{L})$ in late winter (chapter 2). Given the considerable number of deficient athletes and the seasonal fluctuations in 25(OH)D concentrations, it is important to assess an athlete's $25(\mathrm{OH}) \mathrm{D}$ concentration on a regular basis.

The interpretation of our results clearly depends on the definition of vitamin $D$ deficiency. We defined vitamin D deficiency as serum total $25(\mathrm{OH}) \mathrm{D}$ concentrations below $50 \mathrm{nmol} / \mathrm{L}$, as traditionally used for bone health and calcium metabolism (27). However, at this point, the $25(\mathrm{OH}) \mathrm{D}$ concentration that optimally supports training ability and sports performance is still under debate (28). Whereas some researchers suggest that 25(OH)D concentrations above $50 \mathrm{nmol} / \mathrm{L}$ do not have additional benefits, others consider 25(OH)D concentrations above $125 \mathrm{nmol} / \mathrm{L}$ to be optimal for musculoskeletal health and function (29). The lack of consensus among researchers can be partly explained by differences in outcome (bone health vs sports performance) and partly by the limited number of randomized controlled trials linking $25(\mathrm{OH}) \mathrm{D}$ concentrations with functional performance measures $(20,21,30$, 31). Most of the work on vitamin $D$ supplementation shows positive findings of vitamin $D$ supplements when $25(\mathrm{OH}) \mathrm{D}$ concentrations are increased from $<50 \mathrm{nmol} / \mathrm{L}$ to $>75 \mathrm{nmol} / \mathrm{L}$ $(20,22,32)$. Therefore, we chose to define total serum $25(\mathrm{OH}) \mathrm{D}$ concentrations above 75 $\mathrm{nmol} / \mathrm{L}$ as sufficient.

By defining 25(OH)D concentrations above $75 \mathrm{nmol} / \mathrm{L}$ as sufficient, $70 \%$ of the athletes in our study had an insufficient or deficient serum 25(OH)D concentration at the end of the winter season (chapter 3). Supplementing with $2200 \mathrm{IU}(55 \mu \mathrm{g} / \mathrm{d})$ vitamin D per day was effective to achieve and maintain a sufficient serum 25(OH)D concentration throughout the entire year (chapter 3). However, a daily dosage of $2200 \mathrm{IU} / \mathrm{d}$ is much higher than the current guidelines of the Netherlands Health Council (33) and the Institute of Medicine (IOM) (27). The Netherlands Health Council recommends only $400 \mathrm{IU} / \mathrm{d}$ and the Institute of Medicine (IOM) recommends $600 \mathrm{IU} / \mathrm{d}$ for individuals with minimum or no sunlight exposure $(27,33)$. Individuals with sufficient sunlight exposure are advised to take supplements in a lower dosage or no supplements at all. The difference between our data and current guidelines is mainly attributable to the difference in target level. Current 
recommendations are set to maintain $25(\mathrm{OH}) \mathrm{D}$ concentrations at $30-50 \mathrm{nmol} / \mathrm{L}(27,33)$ whereas our target was to increase $25(\mathrm{OH}) \mathrm{D}$ concentrations above $75 \mathrm{nmol} / \mathrm{L}$. Our data are therefore more in line with the Endocrine Society (34) and the International Osteoporosis Foundation (35), both stating that a vitamin D intake up to $2000 \mathrm{lU} / \mathrm{d}$ is needed to increase 25(OH)D concentrations above $75 \mathrm{nmol} / \mathrm{L}$.

Although our work did not focus on the effect of an improved 25(OH)D concentration on muscle hypertrophy or atrophy, previous work suggests a potential role of vitamin D on regulating muscle mass. Currently, only in vitro and in vivo studies using rodents have shown an effect of vitamin $D$ on muscle atrophy. More specifically, myocytes treated with the active form of vitamin $\mathrm{D}, 1,25(\mathrm{OH})_{2} \mathrm{D}$, demonstrates inhibited expression of MAFbx and MuRF1, thereby potentially slowing the rate of muscle protein breakdown $(36,37)$ Although some of these findings have already been confirmed in vivo in animals (36, 38-40), no human studies are performed to assess the effects of vitamin D supplementation on muscle mass preservation. Interestingly, a study in older women with limited mobility and a serum 25(OH)D concentration below $60 \mathrm{nmol} / \mathrm{L}$ at baseline, increased muscle fiber size by a substantial $10 \%$ in 4 months while receiving vitamin $D$ supplementation (4000 IU/d) (41) These pilot data suggest that vitamin $D$ supplementation can have anabolic effects, even in the absence of an exercise intervention. Thus, vitamin D supplementation may also help to attenuate disuse-induced muscle atrophy. Until now, we propose that athletes should aim to prevent vitamin $D$ deficiency throughout the year to allow optimal muscle mass and function. More studies are needed to provide evidence for the effect of vitamin $D$ supplementation on muscle mass and function during muscle maintenance and during muscle atrophic-conditions. Also, since $25(\mathrm{OH}) \mathrm{D}$ concentrations are positively associated with the rehabilitation after surgery $(42,43)$, the effects of vitamin $D$ supplementation after a period of injury or disuse remains to be established.

\section{Creatine, leucine and nandrolone}

Unlike for vitamin $D$, there is ample evidence for creatine, leucine and nandrolone decanoate to enhance muscle mass gains in combination with or without exercise. However, far less is known about the capacity of these compounds to attenuate muscle atrophy. To induce muscle atrophy, we used a 7-day single-leg immobilization model in healthy young men in order to assess the effects of three different strategies to preserve muscle mass: two nutritional strategies, creatine supplementation prior to and during disuse and leucine supplementation during disuse, and one pharmacological strategy involving nandrolone decanoate, administered once at the beginning of the disuse period. None of the compounds attenuated the loss of muscle mass during 7 days of single-leg immobilization in healthy, young men.
Creatine monohydrate

Creatine supplementation has been considered as one of the most promising nutritional strategies to preserve muscle mass during disuse $(44,45)$. Previous speculation is based on the fact that creatine supplementation can enhance muscle mass and strength gains in the presence as well as in the absence of resistance-type exercise training (46-49). The increase in lean mass following creatine supplementation has, at least partly, been attributed to water retention in muscle tissue $(50,51)$. The greater osmotic pressure following the increase in intramuscular creatine content has been suggested to result in muscle cell swelling, which is considered to be a key stimulus for cell growth $(50,52)$. In addition, previous work showed that creatine supplementation can directly activate myogenic regulatory factors (MRFs), IGF-1 or other myogenic cofactors, which are known to initiate muscle fiber hypertrophy or attenuate muscle protein breakdown (53-55). One study in particular assessed muscle protein synthesis and whole body protein breakdown after a 5day creatine loading phase $(20 \mathrm{~g} / \mathrm{d})(56)$. In this study, creatine loading did not increase whole body or muscle protein synthesis rates (56). Creatine loading did, however, reduce whole body protein breakdown by $7.5 \%$ compared to a placebo group, suggesting anticatabolic effects of creatine (56). Creatine supplementation has also been shown to stimulate satellite cell proliferation and upregulate genes that promote protein synthesis, thereby possibly enhancing muscle mass gains over a prolonged supplementation period (55, 57-61)

Despite the biological plausibility, creatine supplementation did not prevent nor attenuate the decline in muscle mass or strength during short term disuse in our study (chapter 4) Our findings are in line with a previous study by Hespel et al., showing that creatine supplementation during a 14-day immobilization period did not preserve muscle mass (placebo: -850 vs creatine: $-1020 \mathrm{~mm}^{2}$ CSA of the quadriceps muscle) (53). However, this study did not include a creatine loading phase to increase total muscle creatine content before the start of the disuse period. In our study, the 5-day creatine loading phase $(20 \mathrm{~g} / \mathrm{d})$ allowed the total muscle creatine content to increase from $90 \pm 9$ to $107 \pm 4 \mathrm{mmol}$ per $\mathrm{kg}$ dry muscle prior to disuse. Still, the increased muscle creatine content before the start of the disuse period did not attenuate the loss of muscle mass. The only previous study that showed that creatine supplementation attenuates the loss of lean mass applied a 7-day period of upper arm immobilization (-3.7 vs $+0.9 \%$ for the placebo and creatine group) (62) However, this study assessed muscle mass using DEXA scans, which includes total body water content in the assessment of lean tissue mass (63). Therefore, the observed preservation of lean body mass in the creatine group might be attributed to the increase in body water content resulting from creatine supplementation.

Although the anabolic effects of creatine supplementation in active young men are well established (46-48), our data demonstrates that creatine supplementation prior to and during disuse does not prevent the loss of muscle mass or strength. It is likely that creatine supplementation has a greater anabolic effect on muscle mass when combined with regula muscle contraction (46-49). Therefore, creatine supplementation might serve to enhance 
the regain of muscle mass after a period of disuse when applied in combination with a resistance-exercise program. This suggestion is supported by the study of Hespel et al., which showed that CSA of the quadriceps muscle increased to a greater extent with creatine loading (21\%) compared to a placebo (14\%) after 10 weeks of rehabilitation (53). Therefore, although creatine supplementation does not preserve muscle mass during disuse, it may still be useful during rehabilitation from injury.

\section{Leucine}

Leucine has been found to be the most potent amino acid to stimulate muscle protein synthesis and inhibit muscle protein degradation (64-67). Leucine increases muscle protein synthesis rates via the direct or indirect regulation of the mTOR pathway (68-72). In addition, leucine supplementation can decrease muscle protein breakdown by inhibiting the ubiquitin pathway, which involves MuRF, MAFbx and FOXO proteins (73). So far, 3 animal studies have assessed the muscle preserving effect of leucine in an atrophy mode of which 2 studies show a beneficial effect of leucine (74-76). A recent study from English et al. assessed the effects of leucine supplementation during 2 weeks of bed rest in young men (77). Interestingly, this study showed that leucine supplementation preserved lean body mass after 7 days of bed rest $(-1.5 \pm 0.3$ and $-0.8 \pm 0.3 \mathrm{~kg}$ in the control and leucine group, respectively), but this effect was no longer evident after 14 days of bed rest (respectively $1.5 \pm 0.3$ and $-1.0 \pm 0.3 \mathrm{~kg}$ ). In contrast, our data show no effect of leucine on the preservation of muscle mass following one week of limb immobilization (chapter 5). The apparent discrepancy between our data and those by English et al. could be attributed to the disuse model (limb immobilization vs bed rest) or the amount of leucine provided (7.5 vs $13.2 \mathrm{~g}$ per day). Whether leucine only exerts an effect during bed rest remains to be established, but we postulate that the difference is more likely attributed to the dosage of leucine. English et al. provided $13.2 \mathrm{~g}$ leucine per day, divided over 3 meals $(4.4 \mathrm{~g} / \mathrm{meal})$, with each meal containing more than $20 \mathrm{~g}$ protein. We chose to give $7.5 \mathrm{~g}$ leucine per day, divided over 3 times per day, thus $2.5 \mathrm{~g}$ leucine ingested with each meal. The ingestion of $2.5 \mathrm{~g}$ leucine in combination with a meal-like amount of protein $(20 \mathrm{~g})$ has been shown to increase muscle protein synthesis rates by $22 \%$ more than the protein bolus alone (78). However, this previous work is conducted in active, young males and the question remains what dosage is needed during disuse. During disuse, the anabolic response to food intake is diminished by $\sim 30-70 \%$ (79-81). Due to this reduced capacity to respond to anabolic stimuli, a higher dosage of leucine might be required to overcome this anabolic resistance and maximally stimulate muscle protein synthesis rates during disuse. Thus, despite the fact that $2.5 \mathrm{~g}$ leucine stimulates muscle protein synthesis rates in active young males, it is possible that this amount does not stimulate muscle protein synthesis rates (markedly) in a disuse model.

Moreover, the anabolic impact of leucine supplementation may be determined by habitual levels of protein intake $(66,82)$. More specifically, leucine can enhance muscle protein synthesis rates when protein intake is suboptimal ( $6 \mathrm{~g}$ protein) (66). Therefore, in individuals with a suboptimal protein intake, such as in older adults or during hospitalization (83), the addition of leucine could be effective in maximizing muscle protein synthesis rates without the need to ingest larger protein boluses. In our study, healthy subjects were fed in energy balance, with a dietary protein intake of $1.1 \pm 0.1 \mathrm{~g} / \mathrm{kg} / \mathrm{d}$, which is well above the Recommended Daily Allowance (RDA) of $0.8 \mathrm{~g} / \mathrm{kg} / \mathrm{d}$ (84). In this regard, our findings may not necessarily represent the impact of leucine supplementation on preserving skeletal muscle mass during disuse under malnourished conditions.

\section{Nandrolone decanoate}

Besides creatine and leucine supplementation, we also tested the effect of the anabolic steroid, nandrolone decanoate, on muscle mass preservation during disuse. In resistancetrained subjects, anabolic steroid administration has been shown to increase lean mass by $2-5 \mathrm{~kg}(85,86)$ and is therefore a more potent stimulus for muscle mass gains than what has been reported in most nutritional interventions $(\sim 1-3 \mathrm{~kg})(87,88)$. Nandrolone decanoate or 19-nortestosterone, is a synthetic anabolic steroid that has a chemical structure similar to testosterone, although it does not show the same androgenic (masculinization) effects (89). Anabolic steroid administration, such as nandrolone decanoate, has been shown to increase fat free mass, muscle cross-sectional area and/or muscle strength in healthy subjects and in several patient groups (86, 90-92). In agreement, administration of nandrolone decanoate and testosterone has been shown to increase protein synthesis twofold (via IGF-1 and Akt/mTORC1 signalling) and decrease proteolysis (expression of FOXO transcriptional genes) (93-95). Based on these findings, we hypothesized that nandrolone decanoate administration may represent an effective pharmaceutical strategy to prevent or attenuate muscle disuse atrophy. However, as presented in chapter 6, nandrolone decanoate did not attenuate muscle disuse atrophy during 7 days of leg immobilization in healthy adults. Our study is the first to assess the effects of nandrolone decanoate administration prior to a period of disuse in vivo in humans. Based on our findings, we can speculate that the absence of any effect of nandrolone decanoate in our study is due to the rate of muscle loss and/or the duration of the study protocol. Firstly, although nandrolone has been shown to prevent the loss of muscle mass in several patient groups (96-98), these patients were not completely inactive, as was the case in our disuse model. The rate of muscle loss in our study was also much more rapid ( $0.8 \%$ per day) compared to what has been described in these patient groups (96-98). Thus, it could be speculated that the complete absence of muscle contraction, and the accompanied rapid rate of muscle loss, overpowers the anabolic effect of nandrolone administration. Secondly, to our knowledge, all previous studies administered repeated injections of (50-600 mg) nandrolone over a period of 1-6 months (86, 90-92, 96-99), whereas we administered only one single injection of $200 \mathrm{mg}$ nandrolone. Although serum nandrolone and total testosterone concentrations in our study were still elevated after 7 days of immobilization, the period might be too short for nandrolone to attenuate the loss of muscle mass. Our study protocol was designed to represent a practical and clinically relevant strategy for 
patients being hospitalized following both acute injury as well as scheduled surgery However, it appears that a single dose of nandrolone is not effective in preventing or attenuating muscle loss over 7 days of complete muscle disuse. We suggest that muscle is lost at such a rapid rate $(0.8 \%$ per day) during the first days of muscle disuse that even a pharmacological intervention is not strong enough to counteract this loss of muscle mass.

\section{Protein}

The intake of dietary protein stimulates muscle protein synthesis and inhibits muscle protein breakdown rates, thereby allowing net muscle protein accretion (100). Therefore, simply increasing dietary protein intake could potentially alleviate the decline in basal $(81$ 101-106) and postprandial (79-81) rates of muscle protein synthesis that is observed during disuse. Although some studies show that supplementation of protein or essential amino acids can preserve muscle mass during disuse (107), not all studies confirm this finding (108, 109). It remains to be established whether the apparent discrepancy between these studies is attributed to the duration of disuse (ranging from 5 to 28 days), the disuse model (bed rest vs limb immobilization), the level of protein intake (0.8 vs $1.1 \mathrm{~g} / \mathrm{kg} / \mathrm{d}$ ) or the study population (old vs young, men vs women).

Similar to periods of muscle disuse, energy intake restriction lowers the anabolic response to protein ingestion (110-112), contributing to the loss of muscle mass. Consequently, it has been previously speculated that an increased protein intake can attenuate the loss of muscle mass during periods of weight loss $(113,114)$. In chapter 7 , we assessed the effects of an increased dietary protein intake (from $0.9 \mathrm{~g} / \mathrm{kg} / \mathrm{d}$ to $1.7 \mathrm{~g} / \mathrm{kg} / \mathrm{d}$ ) on the preservation of muscle mass during energy intake restriction in overweight, older adults. After 12 weeks of $25 \%$ energy intake restriction, we observed a $10 \%$ decrease in body weight. The reduction in body weight was accompanied by a $2 \mathrm{~kg}$ decline in lean body mass and as much as a $10 \%$ decline in leg strength. Increasing dietary protein intake did not preserve lean body mas nor did it prevent the decline in muscle strength associated with prolonged energy intake restriction. We therefore conclude that increasing protein intake does not attenuate the loss of muscle mass during energy intake restriction. Our findings are in line with some (115, $116)$, but not all previous studies $(110,117,118)$. Two major differences in study design between our study and previous work could explain these findings. Firstly, our study compared an increase in protein intake $(1.7 \mathrm{~g} / \mathrm{kg} / \mathrm{d})$ to a diet that maintained habitual protein intake levels $(0.9 \mathrm{~g} / \mathrm{kg} / \mathrm{d})$, while other studies compared a high protein diet to group that decreased their protein intake $(0.8 \mathrm{~g} / \mathrm{kg} / \mathrm{d}$ or lower) $(110,118-121)$. Whereas our high protein group demonstrated the same loss of lean body mass ( $20 \%$ of total weight lost) compared to other studies $(117,122)$, our normal protein group experienced a lower percentage of lean body mass loss ( $23 \%$ of total weight lost) compared with the results of the aforementioned studies $(35 \%)(117,123)$. Thus, increasing protein intake above habitua intake levels does not attenuate the loss of lean mass, but a decrease in protein intake during energy intake restriction could possibly enhance lean mass loss. Secondly, most of the previous studies that observed a muscle-preserving effect of a high-protein diet, combined a dietary intervention with resistance training $(124,125)$. These studies show that the combination of a dietary intervention with resistance-type exercise training can even completely prevent the loss of muscle mass $(124,125)$. Thus, based on our study and current literature, total preservation of muscle mass during a period of energy intake restriction appears to be possible when protein intake is maintained (or increased) and combined with resistance-type exercise training $(124,125)$. During energy intake restriction, maintenance of protein intake is only possible when the protein density of the diet is increased. The protein density of a diet can be enhanced with food products that are naturally high in protein such as dairy products, by using protein supplements and/or by using protein enriched food products. The benefit of using protein supplements is that the protein density of the diet can be easily increased while overall energy intake is restricted. For example, during energy intake restriction, an individual can lower overall energy (including the protein) from their existing diet, but simultaneously increase protein density of the diet through protein supplementation. Moreover, protein supplements are effective for easily distributing protein intake over the day. Recent studies have reported that most individuals ingest protein in a skewed fashion throughout the day, with a low protein intake at breakfast and higher intakes at dinner. However, an equal protein distribution has been shown to allow a greater stimulation of $24 \mathrm{~h}$ muscle net balance (126-128), which might prevent muscle mass loss over a longer period (129). Protein supplements represent a convenient way to increase protein intake at breakfast and lunch to balance protein intake over the day. However, when protein supplements are consumed for prolonged periods, the compliance generally declines because of the limited number of different flavors and textures $(130,131)$. Protein enriched food products, such as bread, soup or fruit juices, can increase protein intake without changing eating habits or increasing portion sizes. Indeed, recent studies show that including familiar protein enriched foods and drinks increase protein intake in institutionalized and community-dwelling older adults $(132,133)$.

\section{Methodological considerations}

Although the presented studies were diverse in nature, some generic methodological issues and considerations regarding the models for muscle atrophy, study population and investigated nutritional compounds need to be discussed.

Models of muscle atrophy

This thesis presents two models to induce muscle atrophy: single-leg immobilization and energy intake restriction. Both models induced a substantial loss of muscle mass, $6 \%$ during 7 days of leg immobilization and $2 \mathrm{~kg}$ lean mass (representing 3.5\%) during 12 weeks of energy intake restriction. Both models are applicable to real-life settings such as the recovery from injury, illness and/or during periods of weight loss. 
In chapter 4, 5 and 6, we chose for a short-period (7 days) of limb immobilization to mode the typical length of hospitalization or recovery from sports injuries, which ranges from 5-7 days (134-136). In this short period, the nutritional interventions tested were not strong enough to counteract the loss of muscle mass and strength. In the studies presented, we show that young, healthy men lose $~ 6 \%$ muscle mass during 7 days of leg immobilization. To put this into perspective, the same amount of muscle mass can be gained during 12 weeks of resistance type exercise training (137). Thus, it is likely that much more time and effort is required to regain the muscle mass that is lost during short periods of disuse. Confirming this, in the absence of a resistance training program, the young men in our study regained only $1.8 \%$ muscle mass after one week of recovery, representing $26 \%$ of the muscle mass lost (chapter 4). Older adults appear unable to fully regain the loss of muscle mass after a 4-wk rehabilitation program including resistance-type exercise 3 times per week (138). Due to the rapid loss of muscle mass during short periods of disuse and the difficulty to regain muscle mass, it has been previously hypothesized that successive short periods of disuse throughout the lifespan will enhance the development of sarcopenia (Figure 1 of general introduction). Therefore, there is a great need for effective strategies to prevent the loss of muscle mass during short periods of disuse.

In chapter 7, we conducted a fully controlled dietary intervention for 12 weeks to assess the effect of a high protein diet on the preservation of lean mass during energy intake restriction. We chose for an intervention period of 12 weeks since this is the period required to show any detectable effect on the preservation of lean body mass (139). The strictly controlled nature of the study enhanced compliance of the subjects and allowed us to assess the efficacy of the dietary intervention without the possible effects of an increased protein intake on satiety and thus energy intake. This is confirmed by the similar decline in body weight in both intervention groups (high protein group: $-8.9 \pm 2.9 \mathrm{~kg}$ vs normal protein group: $-9.1 \pm 3.4 \mathrm{~kg}$ ). However, we acknowledge that this level of control is not always possible in real-life.

\section{Study population}

In this thesis, many different populations have been studied. The first chapters (chapter 2 and 3) were performed in male and female athletes. We continued with studies in young, healthy males (chapter 4, 5 and 6), and the last chapter (chapter 7) was conducted in overweight, older men and women. Thus, most subjects included in our studies were healthy and young (18-35 y) except for the subjects in chapter 7 (55-70 y). We did not find a muscle-preserving effect of the nutritional compounds that we tested (chapter 4, 5, 6 and 7), which might be partly attributed to the characteristics of the study population chosen. We chose to include young healthy males in chapters 4 to 6 to study the effects of our nutritional interventions since they generally show a greater loss of muscle mass compared to older adults. However, they were not nutritionally compromised at baseline as indicated by a protein intake of $1.1 \pm 0.1 \mathrm{~g} / \mathrm{kg} / \mathrm{d}$, which is well above the RDA as currently set at only $0.8 \mathrm{~g} / \mathrm{kg} / \mathrm{d}(84)$. We conclude that neither additional leucine, nor additional protein beyond habitual intakes preserve muscle mass in the populations that we studied. However, we acknowledge that our findings cannot be directly translated to an older and/or clinically compromised population with a protein intake much lower than $1.1 \mathrm{~g} / \mathrm{kg} / \mathrm{d}(83)$ and a higher chance of being malnourished, possibly making them more responsive to an increased protein or leucine intake. Furthermore, muscle phosphocreatine levels are generally 5\% lower in the elderly population (140) than those found in younger adults. Given such lower muscle creatine content levels, which are suggested to contribute to the loss of muscle mass during aging (140), creatine loading may represent a more effective strategy for preserving muscle mass during disuse in the older population. However, whether the nutritional compounds that we tested in this thesis (creatine, leucine, protein) can indeed preserve muscle mass and strength during disuse in an older population remains to be established.

Nutritional compounds

When combined with resistance type exercise training, there is prior evidence for all of the compounds (creatine, leucine, nandrolone, protein) studied in this thesis to be effective in augmenting muscle mass and strength gains $(46,47,86,87,90-92)$. Furthermore, it is well established that protein and leucine stimulate muscle protein synthesis rates in an acute setting $(78,100,141)$. Therefore, it was surprising to find that none of these compounds prevented or attenuated muscle loss during disuse or energy intake restriction.

The dosages of the nutritional compounds that we provided were in line with current recommendations and best estimates based on current evidence $(78,142-144)$. However as dose-finding studies are lacking and considering the development of anabolic resistance during disuse, it is possible that a higher dosage of our nutritional compounds is required. Therefore, future nutritional studies on the preservation of muscle mass during disuse should include dose-dependent effects of these compounds.

These studies might involve other novel nutritional compounds such as ursolic acid, phosphatidic acid, omega-3 fatty acids and resveratrol which appear to affect anabolic mechanisms alternative to those affected by the compounds in this thesis. Although these lesser-studied compounds have only been tested in myocytes or animals models (145-148), they might be able to prevent muscle mass during disuse in humans. Furthermore, combinations of two or more nutritional compounds may have complimentary or synergistic effects in the preservation of muscle mass during disuse. Future research could focus on administering multiple nutritional compounds known to affect different mechanisms, for example stimulating muscle protein synthesis and lowering breakdown simultaneously, or reducing inflammation or insulin sensitivity. By modulating different mechanisms, a combination of nutritional compounds may have stronger effects on muscle mass preservation than a single compound has.

Also, the combination of nutrition with an exercise mimetic, such as neuromuscular electrical stimulation (NMES) may be more effective than a nutritional intervention only. Involuntary muscle contractions by NMES has been shown to prevent the loss of muscle mass (but not muscle strength) during 5 days of leg immobilization (149). The combination 
of NMES with a nutritional intervention (creatine or leucine) might be able to effectively attenuate or even prevent the decline in both muscle mass and strength.

Moreover, since the nutritional compounds that we tested are effective in combination with resistance type exercise training, they might contribute to the regain in muscle mass and strength after a period of muscle loss. As such, protein, creatine and leucine supplementation may be (more) effective during clinical rehabilitation as they likely augment the skeletal muscle adaptive response to rehabilitative training. However, it should be noted that muscle loss during disuse occurs at a rate that is several-fold greater than muscle (re)gain during resistance type exercise training. Therefore, it is imperative that we continue our endeavors to identify nutritional or pharmaceutical compounds that may help in preventing or attenuating disuse atrophy (150)

\section{Future research}

- Although the first studies show promising results, more studies are needed to establish the effects of vitamin D supplements on muscle mass and function in athletes.

- The effect of vitamin D supplementation on the preservation of disuse-induced atrophy remains to be established.

- More studies are needed to establish whether creatine or leucine can prevent or attenuate the loss of muscle mass and strength during disuse in an older population.

- The effect of nutritional interventions in combination with an exercise mimetic, such as NMES, on the preservation of muscle mass during a period of disuse remains to be established.

- The effects of nutritional compounds such as ursolic acid, phosphatidic acid, omega-3 fatty acids and resveratrol on muscle mass preservation during disuse remain to be assessed.

- It remains to be established if nutritional interventions can enhance the regain of muscle mass and strength following a period of disuse.

\section{References}

1. Stevens JE, Walter GA, Okereke E, Scarborough MT, Esterhai JL, George SZ, et al. Muscle adaptations with immobilization and rehabilitation after ankle fracture. Medicine and science in sports and exercise. 2004;36(10):1695-701.

2. Vandenborne K, muscle adaptations during immobilization and rehabilitation. Muscle Nerve. 1998;21(8):1006-12.

3. Richter EA, Kiens B, Mizuno M, Strange S. Insulin action in human thighs after one-legged immobilization. Journal of applied physiolog, Brethesda, Md: 198,

Stuart CA, Shangraw RE, Prince MJ, Peters EJ, Wolfe RR. Bed-rest-induced insulin resistance occurs primarily in muscle. Metabolism: clinical and experimental. 1988;37(8):802-6.

5. Gunther O, Frenzel R. [Effect of prolonged physical inactivity on carbohydrate tolerance]. Zeitschrift fur die gesamte innere Medizin und ihre Grenzgebiete. 1969;24(22):814-7.

Schaap LA, Koster A, Visser M. Adiposity, muscle mass, and muscle strength in relation to functiona decline in older persons. Epidemiologic reviews. 2013;35:51-65.

Trombetti A, Reid KF, Hars M, Herrmann FR, Pasha E, Phillips EM, et al. Age-associated declines in muscle mass, strength, power, and physical performance: impact on fear of falling and quality of life. Osteoporosis international : a journal established as result of cooperation between the European Foundation for Osteoporosis and the National Osteoporosis Foundation or the USA. 2016,27(2):463-71.

8. Newman AB, Kupelian V, Visser M, Simonsick EM, Goodpaster BH, Kritchevsky SB, et al. Strength, but not muscle mass, is associated with mortality in the health, aging and body composition study cohort. The journals of gerontology Series A, Biological sciences and medical sciences. 2006;61(1):72-7.

9. Phillips P. Grip strength, mental performance and nutritional status as indicators of mortality risk among female geriatric patients. Age and ageing. 1986;15(1):53-6.

10. Weaver CM, Alexander DD, Boushey CJ, Dawson-Hughes B, Lappe JM, LeBoff MS, et al. Calcium plus vitamin D supplementation and risk of fractures: an updated meta-analysis from the Nationa Osteoporosis Foundation. Osteoporosis international . a journal established as result of cooperation between the European Foundation for Osteoporosis and the National Osteoporosis Foundation of the USA. 2016;27(1):367-76.

11. Tieland M, Brouwer-Brolsma EM, Nienaber-Rousseau C, van Loon L, De Groot LC. Low vitamin D status is associated with reduced muscle mass and impaired physical performance in frail elderly people. Europea

journal of clinical nutrition. 2013;67(10):1050-5.
Bischoff-Ferrari HA, Dietrich T, Orav EJ, Hu FB, Zhang Y, Karlson EW, et al. Higher 25-hydroxyvitamin D concentrations are associated with better lower-extremity function in both active and inactive person aged $>$ or $=60 \mathrm{y}$. The American journal of clinical nutrition. 2004;80(3):752-8.

13. Mowe M, Haug E, Bohmer T. Low serum calcidiol concentration in older adults with reduced muscular function. Journal of the American Geriatrics Society. 1999;47(2):220-6.

14. Snijder MB, van Schoor NM, Pluijm SM, van Dam RM, Visser M, Lips P. Vitamin D status in relation to oneyear risk of recurrent falling in older men and women. The Journal of clinical endocrinology and metabolism. 2006;91(8):2980-5.

15. Visser M, Deeg DJ, Lips P. Low vitamin D and high parathyroid hormone levels as determinants of loss of muscle strength and muscle mass (sarcopenia): the Longitudinal Aging Study Amsterdam. The Journal of clinical endocrinology and metabolism. 2003;88(12):5766-72.

16. Liu G, Lu L, Sun Q, Ye X, Sun L, Liu X, et al. Poor vitamin D status is prospectively associated with greater muscle mass loss in middle-aged and elderly Chinese individuals. Journal of the Academy of Nutrition an Dietetics. 2014;114(10):1544-51.e2.

17. Rosendahl-Riise H, Spielau U, Ranhoff AH, Gudbrandsen OA, Dierkes J. Vitamin D supplementation and its influence on muscle strength and mobility in community-dwelling older persons: a systematic review and meta-analysis. Journal of human nutrition and dietetics : the official journal of the British Dietetic Association. 2016.

18. Anek A, Bunyaratavej N, Jittivilai T. Effects of Short-Term Vitamin D Supplementation on Musculoskeleta and Body Balance for Prevention of Falling in Postmenopausal Women Journal of the Medical Association of Thailand = Chotmaihet thangphaet. 2015;98 Suppl 8:S26-31.

19. Agergaard J, Trostrup J, Uth J, Iversen JV, Boesen A, Andersen JL, et al. Does vitamin-D intake durin resistance training improve the skeletal muscle hypertrophic and strength response in young and elderly men? - a randomized controlled trial. Nutrition \& metabolism. 2015;12:32 
20. Close GL, Russell J, Cobley JN, Owens DJ, Wilson G, Gregson W, et al. Assessment of vitamin D concentration in non-supplemented professional athletes and healthy adults during the winter months in the UK: implications for skeletal muscle function. Journal of sports sciences. 2013;31(4):344-53.

21. Wyon MA, Koutedakis $Y$, Wolman R, Nevill AM, Allen $N$. The influence of winter vitamin supplementation on muscle function and injury occurrence in elite ballet dancers: a controlled study. Jourt of science and medicine in sport / Sports Medicine Australia. 2014:17(1):8-12.

22. Owens DJ, Sharples AP, Polydorou I, Alwan N, Donovan T, Tang J, et al. A systems-based investigation into vitamin $D$ and sketet muscle repir, regnertion, and hypetrophy. American jounal of physiology Endocrinology and metabolism. 2015;309(12):E1019-31.

Close GL, Leckey J, Patterson M, Bradley W, Owens DJ, Fraser WD, et al. The effects of vitamin D(3) supplementation on serum total $25[\mathrm{OH}] \mathrm{D}$ concentration and physical performance: a randomised doseresponse study. British journal of sports medicine. 2013;47(11):692-6.

24. Dubnov-Raz G, Livne N, Raz R, Cohen AH, Constantini NW. Vitamin D Supplementation and Physica 2015;25(4):317-25.

25. Stockton KA, Mengersen K, Paratz JD, Kandiah D, Bennell KL. Effect of vitamin D supplementation on muscle strength: a systematic review and meta Bnalysis. Osteoporosis international a journatestablished as result of cooperation between the European Foundation for Osteoporosis and the Nationa as result of cooperation betwi 2011:22(3):859-71.

26. Beaudart C, Buckinx F, Rabenda V, Gillain S, Cavalier E, Slomian J, et al. The effects of vitamin D on skeleta muscle strength, muscle mass, and muscle power: a systematic review and meta-analysis of randomized controlled trials. The Journal of clinical endocrinology and metabolism. 2014;99(11):4336-45.

27. Ross AC, Manson JE, Abrams SA, Aloia JF, Brannon PM, Clinton SK, et al. The 2011 report on dietary reference intakes for calium and vitamin D from the Institute of Medicine: what clinicians need to know. The Journal of clinical endocrinology and metabolism. 2011;96(1):53-8.

28. Farrokhyar F, Tabasinejad R, Dao D, Peterson D, Ayeni OR, Hadioonzadeh R, et al. Prevalence of Vitamin D Inadequacy in Athletes: A Systematic-Review and Meta-Analysis. Sports medicine (Auckland, NZ) 2014

Dawson-Hughes B, Heaney RP, Holick MF, Lips P, Meunier PJ, Vieth R. Estimates of optimal vitamin D status. Osteoporosis international : a journal established as result of cooperation between the European Foundation for Osteoporosis and the National Osteoporosis Foundation of the USA. 2005;16(7):713-6.

30. Barker T, Schneider ED, Dixon BM, Henriksen VT, Weaver LK. Supplemental vitamin D enhances the
recovery in peak isometric force shortly after intense exercise. Nutrition \& metabolism. 2013;10(1):69.

31. Dahlquist DT, Dieter BP, Koehle MS. Plausible ergogenic effects of vitamin D on athletic performance and recovery. Journal of the International Society of Sports Nutrition. 2015;12:33.

32. Bischoff-Ferrari HA, Giovannucci E, Willett WC, Dietrich T, Dawson-Hughes B. Estimation of optimal serum concentrations of 25 -hydroxyvitamin $D$ for multiple health outcomes. The American journal of clinical nutrition. 2006;84(1):18-28.

33. Gezondheidsraad. Evaluatie van de voedingsnormen voor vitamine D. Den Haag: Gezondheidsraad, 2012 Contract No.: ISBN 978-90-5549-931-1

34. Holick MF, Binkley NC, Bischoff-Ferrari HA, Gordon CM, Hanley DA, Heaney RP, et al. Evaluation, treatment and prevention of vitamin D deficiency: an Endocrine Society clinical practice guideline. The Journal of clinical endocrinology and metabolism. 2011;96(7):1911-30.

35. Dawson-Hughes B, Mithal A, Bonjour JP, Boonen S, Burckhardt P, Fuleihan GE, et al. IOF position statement: vitamin $D$ recommendations for older adults. Osteoporosis international : a journal established as result of cooperation between the European Foundation for Osteoporosis and the Nationa Osteoporosis Foundation of the USA. 2010;21(7):1151-4

36. Bhat $\mathrm{M}$, Ismail $\mathrm{A}$. Vitamin $\mathrm{D}$ treatment protects against and reverses oxidative stress induced muscle proteolysis. The Journal of steroid biochemistry and molecular biology. 2015;152:171-9.

37. Hayakawa N, Fukumura J, Yasuno H, Fujimoto-Ouchi K, Kitamura H. 1alpha,25(OH)2D3 downregulates gene expression levels of muscle ubiquitin ligases MAFbx and MuRF1 in human myotubes. Biomedica research (Tokyo, Japan). 2015;36(2):71-80,

38. Bhat M, Kalam R, Qadri SS, Madabushi S, Ismail A. Vitamin D deficiency-induced muscle wasting occurs through the ubiquitin proteasome pathway and is partially corrected by calcium in male rats. Endocrinology. 2013;154(11):4018-29.

39. Domingues-Faria C, Chanet A, Salles J, Berry A, Giraudet C, Patrac V, et al. Vitamin D deficiency downregulates Notch pathway contributing to skeletal muscle atrophy in old wistar rats. Nutrition \& metabolism. 2014;11(1):1-13.
40. Stratos I, Li Z, Herlyn P, Rotter R, Behrendt AK, Mittlmeier T, et al. Vitamin D increases cellular turnove and functionally restores the skeletal muscle after crush injury in rats. The American journal of pathology. 2013;182(3):895-904.

41. Ceglia L, Niramitmahapanya S, da Silva Morais M, Rivas DA, Harris SS, Bischoff-Ferrari H, et al. A randomized study on the effect of vitamin $D(3)$ supplementation on skeletal muscle morphology and vitamin $\mathrm{D}$ receptor concentration in older women. The Journal of clinical endocrinology and metabolism. 2013;98(12):E1927-35:

42. Maniar RN, Patil AM, Maniar AR, Gangaraju B, Singh J. Effect of Preoperative Vitamin D Levels on Functional Performance after Total Knee Arthroplasty. Clinics in orthopedic surgery. 2016:8(2):153-6.

3. Kiebzak GM, Moore NL, Margolis S, Hollis B, Kevorkian CG. Vitamin D status of patients admitted to a hospital ra \& rehabilitation / Association of Academic Physiatrists. 2007;86(6):435-45.

44. Wall BT, Morton JP, van Loon $\sqcup$. Strategies to maintain skeletal muscle mass in the injured athete: nutritiona

Calvani R, Miccheli A, Landi F, Bossola M, Cesari M, Leeuwenburgh C, et al. Current nutrition A, Land $F$, Bossola $M$, Ces to manage sarcopenia. The Journal of frailty \& aging. 2013:2(1):38-53.

46. Mihic S, MacDonald JR, McKenzie S, Tarnopolsky MA. Acute creatine loading increases fat-free mass, but does not affect blood pressure, plasma creatinine, or CK activity in men and women. Medicine and science in sports and exercise. 2000;32(2):291-6.

47. van Loon L, Oosterlaar AM, Hartgens F, Hesselink MK, Snow RJ, Wagenmakers AJ. Effects of creatine loading and prolonged creatine supplementation on body composition, fuel selection, sprint and endurance performance in humans. Clin Sci (Lond). 2003;104(2):153-62.

48. Becque MD, Lochmann JD, Melrose DR. Effects of oral creatine supplementation on muscular strength and body composition. Medicine and science in sports and exercise. 2000;32(3):654-8.

49. EFSA Panel on Dietetic Products NaAN. Scientific opinion on creatine in combination with resistance training and improvements in muscle strength: evaluation of a health claim pursuant to Article 13(5) of Regulation (EC) No 1924/2006. EFSA Journal 2016;14(2):4400, 17 pp. . 2016.

50. Hultman E, Soderlund K, Timmons JA, Cederblad G, Greenhaff PL. Muscle creatine loading in men Journ of applied physiology (Bethesda, Md : 1985). 1996;81(1):232-7.

51. Deminice R, Rosa FT, Pfrimer K, Ferrioli E, Jordao AA, Freitas E. Creatine Supplementation Increases Tota . 2016;37(2):149-53.

52. Lang F, Busch GL, Ritter M, VolkI H, Waldegger S, Gulbins E, et al. Functional significance of cell volume regulatory mechanisms. Physiological reviews. 1998;78(1):247-306.

53. Hespel P, Op't Eijnde B, Van Leemputte M, Urso B, Greenhaff PL, Labarque V, et al. Oral creatine supplementation facilitates the rehabilitation of disuse atrophy and alters the expression of muscle myogenic factors in humans. The Journal of physiology. 2001;536(Pt 2):625-33.

54. Burke DG, Candow DG, Chilibeck PD, MacNeil LG, Roy BD, Tarnopolsky MA, et al. Effect of creatine supplementation and resistance-exercise training on muscle insulin-like growth factor in young adults. International journal of sport nutrition and exercise metabolism. 2008;18(4):389-98.

55. Deldicque L, Louis $M$, Theisen D, Nielens $\mathrm{H}$, Dehoux M, Thissen JP, et al. Increased IGF mRNA in human skeletal muscle after creatine supplementation. Medicine and science in sports and exercise. 2005;37(5):731-6.

56. Parise G, Mihic S, MacLennan D, Yarasheski KE, Tarnopolsky MA. Effects of acute creatine monohydrate supplementation on leucine kinetics and mixed-muscle protein synthesis. Journal of applied physiology (Bethesda, Md : 1985). 2001;91(3):1041-7.

57. Vierck JL, Icenoggle DL, Bucci L, Dodson MV. The effects of ergogenic compounds on myogenic satellite cells. Medicine and science in sports and exercise. 2003;35(5):769-76.

58. Dangott B, Schultz E, Mozdziak PE. Dietary creatine monohydrate supplementation increases satellite cell mitotic activity during compensatory hypertrophy. International journal of sports medicine. 2000;21(1):13-6

59. Olsen S, Aagaard P, Kadi F, Tufekovic G, Verney J, Olesen JL, et al. Creatine supplementation augments the increase in satellite cell and myonuclei number in human skeletal muscle induced by strength training. The Journal of physiology. 2006;573(Pt 2):525-34

60. Deldicque L, Atherton P, Patel R, Theisen D, Nielens H, Rennie MJ, et al. Effects of resistance exercise with and without creatine supplementation on gene expression and cell signaling in human skeletal muscle. Journal of applied physiology (Bethesda, Md : 1985). 2008;104(2):371-8. 
61. Safdar A, Yardley NJ, Snow R, Melov S, Tarnopolsky MA. Global and targeted gene expression and protein content in skeletal muscle of young men following short-term creatine monohydrate supplementation. content in skeletal muscle of young men fol
Physiological genomics. 2008;32(2):219-28.

62. Johnston AP, Burke DG, MacNeil LG, Candow DG. Effect of creatine supplementation during cast-induced immobilization on the preservation of muscle mass, strength, and endurance. Journal of strength and conditioning research/ National Strength \& Conditioning Association. 2009;23(1):116-20

63. St-Onge MP, Wang Z, Horlick M, Wang J, Heymsfield SB. Dual-energy X-ray absorptiometry lean soft tissue

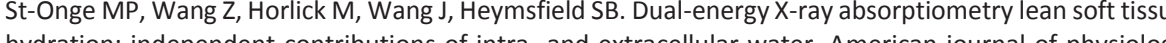
hydration: independent contributions of intra- and extracellular water. American journal of physiology
Endocrinology and metabolism. 2004;287(5):E842-7.

64. Nair KS, Schwartz RG, Welle S. Leucine as a regulator of whole body and skeletal muscle protein metabolism in humans. The American journal of physiology. 1992;263(5 Pt 1):E928-34.

65. Rieu I, Balage M, Sornet C, Giraudet C, Pujos E, Grizard J, et al. Leucine supplementation improves muscle

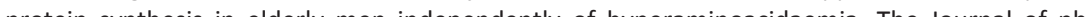
2006:575(Pt 1):305-15.

66. Churchward-Venne TA, Breen L, Di Donato DM, Hector AJ, Mitchell CJ, Moore DR, et al. Leucine supplementation of a low-protein mixed macronutrient beverage enhances myofibrillar protein synthesis in young men: a double blind, randomized trial. The Americanjouna of cinical nutrition. 2014,99(2):27686.

67. Nagasawa T, Kido T, Yoshizawa F, Ito Y, Nishizawa N. Rapid suppression of protein degradation in skeleta muscle after oral feeding of leucine in rats. The Journal of nutritional biochemistry. 2002;13(2):121-7.

68. Ham DJ, Caldow MK, Lynch GS, Koopman R. Leucine as a treatment for muscle wasting: a critical 7 . Clinical nutrition (Edinburgh, Scotland). 2014;33(6):937-45. Anthony IC, Anthony TG, Kimball SR, Vary TC, Jefferson IS. Orally administered leucine stimulates protein synthesis in skeletal muscle of postabsorptive rats in association with increased elF4F formation. The Journal of nutrition. 2000;130(2):139-45.

70. Anthony JC, Yoshizawa F, Anthony TG, Vary TC, Jefferson LS, Kimball SR. Leucine stimulates translation initiation in skeletal muscle of postabsorptive rats via a rapamycin-sensitive pathway. The Journal of nutrition. 2000;130(10):2413-9.

71. Kimball SR, Jefferson LS. Signaling pathways and molecular mechanisms through which branched-chain amino acids mediate translational control of protein synthesis. The Journal of nutrition. 2006;136 Suppl):227S-31S.

72. Abraham RT. Toward a Molecular Definition of Leucine-Dependent mTORC1 Activation. Cell metabolism. 2016;23(3):397-8.

73. Busquets S, Alvarez B, Llovera M, Agell N, Lopez-Soriano FJ, Argiles JM. Branched-chain amino acids inhibit proteolysis in rat skeletal muscle: mechanisms involved. Journal of cellular physiology. 2000:184(3):3804 proted

74. Baptista IL, Leal ML, Artioli GG, Aoki MS, Fiamoncini J, Turri AO, et al. Leucine attenuates skeletal muscle wasting via inhibition of ubiquitin ligases. Muscle Nerve. 2010;41(6):800-8.

75. Nicastro H, Zanchi NE, da Luz CR, de Moraes WM, Ramona P, de Siqueira Filho MA, et al. Effects of leucin supplementation and resistance exercise on dexamethasone-induced muscle atrophy and insulin resistance in rats. Nutrition (Burbank, Los Angeles County, Calif). 2012;28(4):465-71.

76. Ribeiro CB, Christofoletti DC, Pezolato VA, de Cassia Marqueti Durigan R, Prestes J, Tibana RA, et al. Leucine minimizes denervation-induced skeletal muscle atrophy of rats through akt/mtor signalin pathways. Frontiers in physiology. 2015;6:73.

77. English KL, Mettler JA, Ellison JB, Mamerow MM, Arentson-Lantz E, Pattarini JM, et al. Leucine partially protects muscle mass and function during bed rest in middle-aged adults. The American journal of clinica nutrition. 2016;103(2):465-73.

78. Wall BT, Hamer HM, de Lange A, Kiskini A, Groen BB, Senden JM, et al. Leucine co-ingestion improves post-prandial muscle protein accretion in elderly men. Clinical nutrition (Edinburgh, Scotland). 2013;32(3):412-9.

79. Glover El, Phillips SM, Oates BR, Tang JE, Tarnopolsky MA, Selby A, et al. Immobilization induces anabolic resistance in human myofibrillar protein synthesis with low and high dose amino acid infusion. The Journa of physiology. 2008;586(Pt 24):6049-61.

80. Wall BT, Snijders T, Senden JM, Ottenbros CL, Gijsen AP, Verdijk LB, et al. Disuse impairs the muscle protein synthetic response to protein ingestion in healthy men. The Journal of clinical endocrinology and metabolism. 2013;98(12):4872-81.

81. Drummond MJ, Dickinson JM, Fry CS, Walker DK, Gundermann DM, Reidy PT, et al. Bed rest impairs skeletal muscle amino acid transporter expression, mTORC1 signaling, and protein synthesis in response to essential amino acids in older adults. American journal of physiology Endocrinology and metabolism. 2012;302(9):E1113-22

82. Magne H, Savary-Auzeloux I, Migne C, Peyron MA, Combaret L, Remond D, et al. Contrarily to whey and high protein diets, dietary free leucine supplementation cannot reverse the lack of recovery of muscle mass after prolonged immobilization during ageing. The Journal of physiology. 2012;590(8):2035-49,

83. Tieland M, Borgonjen-Van den Berg KJ, van Loon $\mathrm{U}$, de Groot LC. Dietary protein intake in communitydwelling, frail, and institutionalized elderly people: scope for improvement. European journal of nutrition. 2012;51(2):173-9.

84. Panel EN. Scientific Opinion on Dietary Reference Values for protein. EFSA Journal. 2012;10(2):2557.

85. Hartgens F, Van Marken Lichtenbelt WD, Ebbing S, Vollaard N, Rietjens G, Kuipers H. Androgenic-anabolic steroid-induced body changes in stren th athletes. The Physician and sportsmedicine. 2001;20(1):49-65.

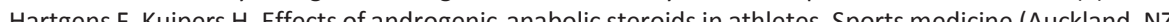
2004;34(8):513-54

87. Cermak NM, Res PT, de Groot LC, Saris WH, van Loon L. Protein supplementation augments the adaptive (1) clinical nutrition. 2012;96(6):1454-64.

Ormsbee MJ, Mandler WK, Thomas DD, Ward EG, Kinsey AW, Simonavice E, et al. The effects of six weeks of supplementation with multi-ingredient performance supplements and resistance training on anabolic hormones, body composition, strength, and power in resistance-trained men. Journal of the International Society of Sports Nutrition. 2012;9(1):49.

89. Kicman AT. Pharmacology of anabolic steroids. British journal of pharmacology. 2008;154(3):502-21.

90. Casaburi $R$, Bhasin $S$, Cosentino L, Porszasz J, Somfay A, Lewis ML et a. Effects of testosterone and resistance training in men with chronic obstructive pulmonary disease. American journal of respiratory and critical care medicine. 2004;170(8):870-8.

91. Bhasin S, Storer TW, Berman N, Callegari C, Clevenger B, Phillips t, et al The effects of supraphysiologic doses of testosterone on muscle size and strength in normal men. The New England journal of medicine. 1996;335(1):1-7.

92. Hartgens F, Van Marken Lichtenbelt WD, Ebbing S, Vollaard N, Rietjens G, Kuipers H. Body composition International journal of sports medicine. 2001:22(3):235-41.

93. Qin W, Pan J, Wu Y, Bauman WA, Cardozo C. Protection against dexamethasone-induced muscle atrophy is related to modulation by testosterone of FOXO1 and PGC-1alpha. Biochemical and biophysical research communications. 2010;403(3-4):473-8.

94. White JP, Gao S, Puppa MJ, Sato S, Welle SL, Carson JA. Testosterone regulation of Akt/mTORC1/FoxO3 signaling in skeletal muscle. Molecular and cellular endocrinology. 2013;365(2):174-86.

95. Ferrando AA, Tipton KD, Doyle D, Phillips SM, Cortiella J, Wolfe RR. Testosterone injection stimulates net protein synthesis but not tissue amino acid transport. The American journal of physiology. 1998;275(5 Pt 1):E864-71.

96. Storer TW, Woodhouse L, Sattler F, Singh AB, Schroeder ET, Beck K, et al. A randomized, placebocontrolled trial of nandrolone decanoate in human immunodeficiency virus-infected men with mild to Journal of clinical endocrinology and metabolism. 2005;90(8):4474-82.

97. Creutzberg EC, Wouters EF, Mostert R, Pluymers RJ, Schols AM. A role for anabolic steroids in the rehabilitation of patients with COPD? A double-blind, placebo-controlled, randomized trial. Chest. 2003;124(5):1733-42.

98. Schroeder ET, Terk M, Sattler FR. Androgen therapy improves muscle mass and strength but not muscle quality: results from two studies. American journal of physiology Endocrinology and metabolism. 2003;285(1):E16-24.

99. Johansen KL, Mulligan K, Schambelan M. Anabolic effects of nandrolone decanoate in patients receivin dialysis: a randomized controlled trial. JAMA : the journal of the American Medical Association. 1999;281(14):1275-81.

100. Rennie MJ, Edwards RH, Halliday D, Matthews DE, Wolman SL, Millward DJ. Muscle protein synthesis measured by stable isotope techniques in man: the effects of feeding and fasting. Clinical science (London, England : 1979). 1982;63(6):519-23.

101. Gibson JN, Halliday D, Morrison WL, Stoward PJ, Hornsby GA, Watt PW, et al. Decrease in human quadriceps muscle protein turnover consequent upon leg immobilization. Clin Sci (Lond). 1987;72(4):5039 . 
102. Glover El, Phillips SM, Oates BR, Tang JE, Tarnopolsky MA, Selby A, et al. Immobilization induces anabolic resistance in human myofibrillar protein synthesis with low and high dose amino acid infusion. The Journa resistance in human myofibrillar protein
of physiology. 2008;586(Pt 24):6049-61.

103. de Boer MD, Selby A, Atherton P, Smith K, Seynnes OR, Maganaris CN, et al. The temporal responses of protein synthesis, gene expression and cell signalling in human quadriceps muscle and patellar tendon to disuse. The Journal of physiology. 2007;585(Pt 1):241-51.

104. Ferrando AA, Lane HW, Stuart CA, Davis-Street J, Wolfe RR. Prolonged bed rest decreases skeletal muscle and whole body protein synthesis. The American journal of physiology. 1996;270(4 Pt 1):E627-33.

105. Symons TB, Sheffield-Moore M, Chinkes DL, Ferrando AA, Paddon-Jones D. Artificial gravity maintain skeletal muscle protein synthesis during 21 days of simulated microgravity. Journal of applied physiology. 2009;107(1):34-8.

106. Paddon-Jones D, Sheffield-Moore M, Cree MG, Hewlings SJ, Aarsland A, Wolfe RR, et al. Atrophy and imparin muscle protein synthesis endocrinology and metabolism. 2006;91(12):4836-41.

107. Paddon-Jones D, Sheffield-Moore M, Urban RJ, Sanford AP, Aarsland A, Wolfe RR, et al. Essential amino acid and carbohydrate supplementation ameliorates muscle protein loss in humans during 28 days bedrest. The Journal of clinical endocrinology and metabolism. 2004;89(9):4351-8.

108. Dirks ML, Wall BT, Nilwik R, Weerts DH, Verdijk LB, van Loon $L$. Skeletal muscle disuse atrophy is not Dattenuated by ditar protein supplementation in healthy older men. The dournat of nutrition.

109. Ferrando AA, Paddon-Jones D, Hays NP, Kortebein P, Ronsen O, Williams RH, et al. EAA supplementation to increase nitrogen intake improves muscle function during bed rest in the elderly. Clinical nutrition (Edinburgh, Scotland). 2010;29(1):18-23.

110. Pasiakos SM, Cao JJ, Margolis LM, Sauter ER, Whigham LD, McClung JP, et al. Effects of high-protein diets on fat-free mass and muscle protein synthesis following weight loss: a randomized controlled trial. FASEB journal : official publication of the Federation of American Societies for Experimental Biology. 2013;27(9):3837-47.

111. Areta JL, Burke LM, Camera DM, West DW, Crawshay S, Moore DR, et al. Reduced resting skeletal muscle protein synthesis is rescued by resistance exercise and protein ingestion following short-term energy deficit. American journal of physiology Endocrinology and metabolism. 2014;306(8):E989-97.

112. Murphy CH, Churchward-Venne TA, Mitchell CJ, Kolar NM, Kassis A, Karagounis LG, et al. Hypoenergetic diet-induced reductions in myofibrillar protein synthesis are restored with resistance training and diet-inced daily protein in metabolism. 2015;308(9):E734-43.

113. Murphy CH, Hector AJ, Phillips SM. Considerations for protein intake in managing weight loss in athletes. European journal of sport science. 2015;15(1):21-8.

114. Parr EB, Coffey VG, Hawley JA. 'Sarcobesity': a metabolic conundrum. Maturitas. 2013;74(2):109-13.

115. Parker B, Noakes M, Luscombe N, Clifton P. Effect of a high-protein, high-monounsaturated fat weight loss diet on glycemic control and lipid levels in type 2 diabetes. Diabetes care. 2002;25(3):425-30.

116. Mojtahedi MC, Thorpe MP, Karampinos DC, Johnson CL, Layman DK, Georgiadis JG, et al. The effects of a higher protein intake during energy restriction on changes in body composition and physical function in older women. The journals of gerontology Series A, Biological sciences and medical sciences. 2011;66(11):1218-25.

117. Leidy HJ, Carnell NS, Mattes RD, Campbell WW. Higher protein intake preserves lean mass and satiety with weight loss in pre-obese and obese women. Obesity (Silver Spring, Md). 2007;15(2):421-9.

118. Soenen S, Martens EA, Hochstenbach-Waelen A, Lemmens SG, Westerterp-Plantenga MS. Normal protein intake is required for body weight loss and weight maintenance, and elevated protein intake for additiona preservation of resting energy expenditure and fat free mass. The Journal of nutrition. 2013;143(5):5916.

119. Wycherley TP, Noakes M, Clifton PM, Cleanthous X, Keogh JB, Brinkworth GD. A high-protein diet with resistance exercise training improves weight loss and body composition in overweight and obese patients with type 2 diabetes. Diabetes care. 2010;33(5):969-76.

120. Evans EM, Mojtahedi MC, Thorpe MP, Valentine RJ, Kris-Etherton PM, Layman DK. Effects of protein intake and gender on body composition changes: a randomized clinical weight loss trial. Nutrition \& metabolism. 2012;9(1):55.

121. Noakes M, Keogh JB, Foster PR, Clifton PM. Effect of an energy-restricted, high-protein, low-fat diet relative to a conventional high-carbohydrate, low-fat diet on weight loss, body composition, nutritional status, and markers of cardiovascular health in obese women. The American journal of clinical nutrition. 2005;81(6):1298-306
122. Farnsworth E, Luscombe ND, Noakes M, Wittert G, Argyiou E, Clifton PM. Effect of a high-protein, energyrestricted diet on body composition, glycemic control, and lipid concentrations in overweight and obes hyperinsulinemic men and women. The American journal of clinical nutrition. 2003;78(1):31-9.

123. Layman DK, Evans E, Baum II, Seyler I, Erickson DJ, Boileau RA. Dietary protein and exercise have additive effects on body composition during weight loss in adult women. The Journal of nutrition. 2005;135(8):1903-10.

124. Longland TM, Oikawa SY, Mitchell CJ, Devries MC, Phillips SM. Higher compared with lower dietary protein during an energy deficit combined with intense exercise promotes greater lean mass gain and fat mass loss: a randomized trial. The American journal of clinical nutrition. 2016;103(3):738-46.

125. Verreijen AM, Verlaan S, Engberink MF, Swinkels S, de Vogel-van den Bosch J, Weijs PJ. A high whey protein-, leucine-, and vitamin D-enriched supplement preserves muscle mass during intentional weight loss in obese older adults: a double-blind randomized controlled trial. The American journal of clinica nutrition. 2015:101(2):279-86

126. Adechian S, Balage M, Remond D, Migne C, Quignard-Boulange A, Marset-Baglieri A, et al. Protein feeding pattern, casein feeding, or milk-soluble protein feeding did not change the evolution of body composition during a short-term weight loss program. American journal of physiology Endocrinology and metabolism. 2012;303(8):E973-82.

127. Mamerow MM, Mettler JA, English KL, Casperson SL, Arentson-Lantz E, Sheffield-Moore M, et al. Dietary protein distribution positively influnces 24-h muscle protein synthesis in healthy adults. The Journa nutrition. 2014;144(6):876-80.

128. Moore DR, Areta J, Coffey VG, Stellingwerff T, Phillips SM, Burke LM, et al. Daytime pattern of postmetabolism. 2012:9(1):91.

129. Loenneke JP, Loprinzi PD, Murphy CH, Phillips SM. Per meal dose and frequency of protein consumption is associated with lean mass and muscle performance. Clinical nutrition (Edinburgh, Scotland). 2016.

130. Bruce D, Laurance I, McGuiness M, Ridley M, Goldswain P. Nutritional supplements after hip fracture: poor compliance limits effectiveness. Clinical nutrition (Edinburgh, Scotland). 2003;22(5):497-500.

31. Methven L, Rahelu K, Economou N, Kinneavy L, Ladbrooke-Davis L, Kennedy OB, et al. The effect of consumption volume on profile and liking of oral nutritional supplements of varied sweetness: Sequential profiling and boredom tests. Food Quality and Preference. 2010;21(8):948-55.

132. Beelen J, De Roos NM, De Groot LCPGM. Protein enrichment of familiar foods as an innovative strateg to increase protein intake in institutionalized elderly. The journal of nutrition, health \& aging. 2016:1-7.

33. Ziylan C, Kremer S, Eerens J, Haveman-Nies A, de Groot LC. Effect of meal size reduction and protei enrichment on intake and satiety in vital community-dwelling older adults. Appetite. 2016;105:242-8.

34. Swain MS, Lystad RP, Henschke N, Maher CG, Kamper SJ. Match injuries in amateur Rugby Union: prospective cohort study - FICS Biennial Symposium Second Prize Research Award. Chiropractic \& manua therapies. 2016;24:17.

135. Tranaeus U, Heintz E, Johnson U, Forssblad M, Werner S. Injuries in Swedish floorball: a cost analysis. Scandinavian journal of medicine \& science in sports. 2016.

136. Fisher SR, Kuo YF, Graham JE, Ottenbacher KJ, Ostir GV. Early ambulation and length of stay in older adults hospitalized for acute illness. Archives of internal medicine. 2010;170(21):1942-3.

137. Snijders T, Res PT, Smeets JS, van Vliet S, van Kranenburg J, Maase K, et al. Protein Ingestion before Sleep Increases Muscle Mass and Strength Gains during Prolonged Resistance-Type Exercise Training in Health Young Men. The Journal of nutrition. 2015;145(6):1178-84

138. Suetta C, Hvid LG, Justesen L, Christensen U, Neergaard K, Simonsen L, et al. Effects of aging on human skeletal muscle after immobilization and retraining. Journal of applied physiology (Bethesda, Md : 1985). 2009;107(4):1172-80

139. Wycherley TP, Moran L, Clifton PM, Noakes M, Brinkworth GD. Effects of energy-restricted high-protein, ow-fat compared with standard-protein, low-fat diets: a meta-analysis of randomized controlled trials. The American journal of clinical nutrition. 2012;96(6):1281-98.

140. Moller P, Bergstrom J, Furst P, Hellstrom K. Effect of aging on energy-rich phosphagens in human skeleta muscles. Clin Sci (Lond). 1980;58(6):553-5.

141. Koopman R, Wagenmakers AJ, Manders RJ, Zorenc AH, Senden JM, Gorselink M, et al. Combined ingestion of protein and free leucine with carbohydrate increases postexercise muscle protein synthesis in vivo in male subjects. American journal of physiology Endocrinology and metabolism. 2005;288(4):E645-53.

142. Terjung RL, Clarkson P, Eichner ER, Greenhaff PL, Hespel PJ, Israel RG, et al. American College of Sports Medicine roundtable. The physiological and health effects of oral creatine supplementation. Med Sci Sports Exerc. 2000;32(3):706-17. 
143. Wall BT, Cermak NM, van Loon $L$. Dietary protein considerations to support active aging. Sports medicine (Auckland, NZ). 2014;44 Suppl 2:S185-94. Leenders M, Verdijk LB, van der Hoeven L, van Kranenburg J, Hartgens F, Wodzig WK, et al. Prolonged leucine supplementation does not augment muscle mass or affect glycemic control in elderly type 2 leucine supplementation does not augment muscle mass or affect glycemic control in elderly type 2
diabetic men. The Journal of nutrition. 2011;141(6):1070-6.

145. Kunkel SD, Suneja M, Ebert SM, Bongers KS, Fox DK, Malmberg SE, et al. mRNA expression signatures of human skeletal muscle atrophy identify a natural compound that increases muscle mass. Cell metabolism. 627-38.

146. Jaafar R, De Larichaudy J, Chanon S, Euthine V, Durand C, Naro F, et al. Phospholipase D regulates the size of skeletal muscle cells through the activation of mTOR signaling. Cell communication and signaling : CCS. of skeletal muscis

147. You JS, Park MN, Song W, Lee YS. Dietary fish oil alleviates soleus atrophy during immobilization in

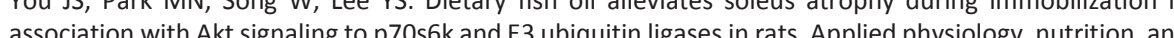
association with Akt signaling to p70s6k and E3 ubiquitin ligases in rats. Applied physiology, nutrition, an metabolism = Physiologie appliquee, nutrition et metabolisme. 2010;35(3):310-8.

148. Momken I, Stevens L, Bergouignan A, Desplanches D, Rudwill F, Chery I, et al. Resveratrol prevents the wasting disorders of mechanical unloading by acting as a physical exercise mimetic in the rat. FASEB journal : Official publication of the

149. Dirks ML, Wall BT, Snijders T, Ottenbros CL, Verdijk LB, van Loon L. Neuromuscular electrical stimulation prevents muscle disuse atrophy during leg immobilization in humans. Acta physiologica (Oxford, England). 2014;210(3):628-41.

150. Wall BT, van Loon $\mathrm{L}$. Nutritional strategies to attenuate muscle disuse atrophy. Nutrition reviews. 2013;71(4):195-208. 


\section{English summary}


Muscle mass is the main predictor for muscle strength and physical function. The amount of muscle mass can decline rapidly during periods of reduced physical activity or during periods of energy intake restriction. For athletes, it is important to maintain muscle mass, since the loss of muscle is associated with decreased muscle strength, decreased physical performance and a longer recovery period. In the older and more clinically compromised populations, the consequences of muscle loss can substantially impact metabolic health, physical functioning, quality of life and mortality rates. In this thesis, the effects of different nutritional interventions on the preservation of muscle mass are being evaluated.

Vitamin D deficiency (serum 25-hydroxyvitamin D or 25(OH)D) has been associated with increased muscle loss and reduced muscle strength. In chapter 2, we identified seasonal changes in $25(\mathrm{OH}) \mathrm{D}$ concentration in elite athletes. We observed that $25(\mathrm{OH}) \mathrm{D}$ concentrations were highest at the end of summer $(113 \pm 26 \mathrm{nmol} / \mathrm{L})$, and lowest at the end of winter $(78 \pm 30$ $\mathrm{nmol} / \mathrm{L})$. Athletes that had a sufficient $25(\mathrm{OH}) \mathrm{D}$ concentration $(>75 \mathrm{nmol} / \mathrm{L})$ at the start of the study, still had a high risk ( $20 \%$ ) of being deficient $(<50 \mathrm{nmol} / \mathrm{L})$ in late winter. Thus, a sufficient $25(\mathrm{OH}) \mathrm{D}$ concentration in summer does not guarantee a sufficient status in winter. In chapter 3, we assessed 25(OH)D concentrations in 128 highly-trained athletes and found that $70 \%$ had a deficient or insufficient $25(\mathrm{OH}) \mathrm{D}$ concentration at the end of the winter season. Supplementation with $2200 \mathrm{IU} / \mathrm{d}$ vitamin D resulted in a sufficient $25(\mathrm{OH}) \mathrm{D}$ concentration in $80 \%$ of the athletes after 12 months and was therefore a better dosage to improve $25(\mathrm{OH}) \mathrm{D}$ concentration than 400 or $1100 \mathrm{IU} / \mathrm{d}$.

In the following chapters, we assessed the effects of creatine supplementation (chapter 4), leucine supplementation (chapter 5) and nandrolone administration (chapter 6) on the preservation of muscle mass during a short period of muscle disuse. For all of these compounds there is prior evidence for their efficacy in augmenting muscle mass and strength gains in combination with resistance-type exercise training and all have been suggested to attenuate the loss of muscle mass during a period of muscle disuse. During 7 days of single-leg immobilization, muscle mass decreased by $\sim 6 \%$ and muscle strength decreased by $\sim 8 \%$. Surprisingly, none of the tested compounds attenuated the loss of muscle mass during 7 days of single-leg immobilization in healthy, young men.

In chapter 7, we performed a fully controlled dietary intervention to assess the impact of a high protein intake on the preservation of lean body mass during 12 weeks of energy intake restriction. Sixty-one overweight and obese men and women were randomly assigned to either a high protein diet $(1.7 \mathrm{~g} / \mathrm{kg} / \mathrm{d})$ or a normal protein diet $(0.9 \mathrm{~g} / \mathrm{kg} / \mathrm{d})$ during 12 weeks of $25 \%$ energy intake restriction. During the dietary intervention, subjects lost $9 \pm 3 \mathrm{~kg}$ body weight with a concomitant $2 \pm 2 \mathrm{~kg}$ decline in lean body mass with no differences between the two intervention groups. Thus, increasing protein intake above habitual intake levels $(0.9 \mathrm{~g} / \mathrm{kg} / \mathrm{d})$ did not preserve lean body mass during a period of energy intake restriction.

Finally, in chapter $\mathbf{8}$ we reflected on the main findings described in this thesis. In this chapter, we point out that the populations studied were all healthy and well-nourished. We conclude that in these populations, additional creatine, leucine and protein beyond habitual intakes did not preserve muscle mass. Older and/or malnourished individuals might be more responsive to these nutritional interventions. Future research could also focus on the combined effects of two or more nutritional compounds during disuse that are known to affect different mechanisms. Moreover, we speculate that the tested nutritional compounds could be effective in accelerating the regain of muscle mass and strength after a period of muscle loss. However, it should be noted that muscle loss during disuse occurs at a rate that is several-fold greater than muscle (re)gain during resistance type exercise training. Therefore, it is imperative that we continue our endeavors to identify nutritional or pharmaceutical compounds or exercise mimetics that may help to prevent or attenuate disuse atrophy. 
Nederlandse

samenvatting 
Spiermassa is de belangrijkste voorspeller van spierkracht en lichamelijk functioneren. De hoeveelheid spiermassa kan snel afnemen tijdens een periode van verminderde lichamelijke activiteit of verlaagde energie-inname. Voor sporters is het belangrijk om de hoeveelheid spiermassa te behouden omdat een afname van spiermassa geassocieerd is met een afname in spierkracht, verminderde sportprestaties en een langere herstelperiode na een blessure. In ouderen of kwetsbare populaties kan een afname van spiermassa leiden tot een verminderde metabole gezondheid, functionele capaciteit, kwaliteit van leven en levensverwachting. Het is dus belangrijk om spiermassa te behouden. In dit proefschrift is de invloed van verschillende voedingsinterventies getest op het behoud van de spiermassa. Een vitamine $D$ tekort (aangeduid als serum 25-hydroxyvitamine D of 25(OH)D concentratie) is geassocieerd met een verhoogd spiermassaverlies en een afname van de spierkracht. In hoofdstuk $\mathbf{2}$ hebben we de seizoensvariatie in $25(\mathrm{OH}) \mathrm{D}$ concentratie gemeten bij sporters. We zagen dat de $25(\mathrm{OH}) \mathrm{D}$ concentratie in het bloed het hoogst was aan het einde van de zomer $(113 \pm 26 \mathrm{nmol} / \mathrm{L})$ en het laagst aan het einde van de winter $(78 \pm 30 \mathrm{nmol} / \mathrm{L})$. Sporters met een voldoende $25(\mathrm{OH}) \mathrm{D}$ concentratie $(>75 \mathrm{nmol} / \mathrm{L}$ ) aan de start van de studie, hadden toch een hoog risico $(20 \%)$ op het ontwikkelen van een vitamine $D$ tekort $(<50 \mathrm{nmol} / \mathrm{L}$ ) aan het einde van de winter. Een voldoende vitamine D concentratie in de zomer garandeert dus geen voldoende vitamine $D$ concentratie in de winter. In hoofdstuk 3 hebben we de 25(OH)D concentratie bij 128 topsporters gemeten en we observeerden dat $70 \%$ van de sporters aan het eind van de winter een lage vitamine $D$ concentratie $(<75 \mathrm{nmol} / \mathrm{L})$ hadden. Vitamine D suppletie van $2200 \mathrm{IE} / \mathrm{d}$ resulteert in een voldoende $25(\mathrm{OH}) \mathrm{D}$ concentratie in $80 \%$ van de sporters na 12 maanden en was daardoor een betere dosis om de vitamine $D$ concentratie te verhogen dan 400 of $1100 \mathrm{IE} / \mathrm{d}$. In de hoofdstukken die daarop volgen hebben we de effecten van creatine supplementen (hoofdstuk 4), leucine supplementen (hoofdstuk 5) en het toedienen van nandrolon (hoofdstuk 6) onderzocht op het behoud van spiermassa tijdens een korte periode van inactiviteit. Voor al deze componenten is bewijs uit eerdere studies dat ze de toename in spiermassa en spierkracht kunnen vergroten als ze in combinatie met krachttraining worden gebruikt. Mede daardoor wordt er gespeculeerd dat deze componenten mogelijk ook spiermassaverlies kunnen tegengaan tijdens een periode van inactiviteit. Gedurende een periode van 7 dagen immobilisatie van één been zagen we een afname in spiermassa van $~ 6 \%$ en een afname in spierkracht van $\sim 8 \%$. Opvallend is dat geen van de onderzochte componenten (creatine, leucine en nandrolon) de afname van spiermassa konden tegengaan in jonge, gezonde mannen tijdens een 7-daagse gipsbehandeling van het been.

In hoofdstuk 7 staat beschreven dat we een volledig gecontroleerde voedingsinterventie hebben uitgevoerd om het effect te meten van een verhoogde eiwitinname op het behoud van spiermassa gedurende een 12-weekse periode van een verlaagde energie-inname ($25 \%)$. Eenenzestig mannen en vrouwen met overgewicht of obesitas zijn door middel van randomisatie toegewezen aan een hoog eiwit-dieet $(1.7 \mathrm{~g} / \mathrm{kg} / \mathrm{d})$ of aan een dieet met een normale eiwitinname $(0.9 \mathrm{~g} / \mathrm{kg} / \mathrm{d})$. Tijdens deze voedingsinterventie verloren de deelnemers gemiddeld $9 \pm 3 \mathrm{~kg}$ lichaamsgewicht, wat gepaard ging met een verlies van $2 \pm 2$ $\mathrm{kg}$ spiermassa. Omdat beide groepen evenveel spiermassa verloren, concluderen wij dat een verhoogde eiwitinname geen effect heeft op de afname van spiermassa tijdens een periode van een verlaagde energie-inname. Ten slotte hebben we in hoofdstuk 8 de belangrijkste bevindingen in dit proefschrift bediscussieerd. In dat hoofdstuk beschrijven we o.a. dat de bestudeerde populaties allemaal gezond zijn en niet ondervoed. We concluderen dat extra creatine, leucine en eiwit bovenop de dagelijkse inname in onze gezonde onderzoekspopulatie niet resulteert in een behoud van spiermassa tijdens een periode van immobilisatie van een ledemaat. Echter, het is mogelijk dat ouderen en ondervoede personen gevoeliger zijn voor voedingsinterventies. Toekomstig onderzoek zou zich ook kunnen richten op de combinatie van meerdere voedingscomponenten tegelijk op het behoud van spiermassa. We speculeren dat de onderzochte voedingsinterventies mogelijk wel een effect hebben op het herstel van spiermassa na een periode van spiermassaverlies. Echter, we benadrukken dat spierverlies veel sneller plaatsvindt dan het aanmaken van spiermassa. Het is daarom essentieel dat we blijven zoeken naar strategieën zoals voedings- en farmacologische componenten die spiermassaverlies kunnen tegengaan. 
Dankwoord |

Acknowledgements 
Voor je ligt het resultaat van 4 jaar werk, mijn proefschrift! Mijn naam staat dan wel op de voorkant, maar uiteraard moet ik veel personen bedanken voor hun bijdrage. In de afgelopen 4 jaar heb ik naast een leerzame, ook een leuke tijd gehad en dat was niet mogelijk geweest zonder de mensen om me heen.

Allereerst dank aan mijn promotoren. Lisette en Luc, jullie zijn uitersten, om jullie allebei als promotor te hebben is enorm waardevol. Ik heb veel van jullie geleerd en jullie hebben mij altijd het gevoel gegeven dat ik altijd bij jullie terechtkon. Het geduld en de open, scherpe blik van Lisette heeft mij geleerd om zelfstandig te werken en mijn eigen mening te vormen. Luc, jouw doorzettingsvermogen, passie en onvermoeibare inzet is bewonderingswaardig. Je hebt mij structuur en veel kennis bijgebracht. Ik heb mezelf kunnen overtreffen met behulp van jullie feedback.

Mike, vooral in het begin van mijn promotietraject was jij degene bij wie ik constant binnen kon lopen. Het praktisch uitvoeren van onderzoek heb ik voornamelijk van jou geleerd, mede daardoor is het gelukt om 4 grote experimenten op te zetten en uit te voeren. Daarnaast was er regelmatig tijd voor een praatje en drankje, ik hoop dat je met net zoveel plezier terugdenkt aan die tijd als ik!

Graag wil ik Prof. Wim Saris, dr. Jan Steijns, Prof. Renger Witkamp en dr. Nicole de Roos bedanken voor het plaatsnemen in mijn promotiecommissie. Alle co-auteurs van mijn artikelen, Kamiel, Arie, Cindy, Marco, Roland, Marie-Louise, Tim, Lex, Astrid, Gabriël, Janneau, Joey, Cas, Anniek, Douwe en John, bedankt voor jullie input!

Anouk, wat fijn dat je mijn paranimf wilt zijn. Tijdens de eerste 2 jaar van mijn PhD konden we vaak samen sparren, maar ook nadat ik naar Maastricht vertrok, konden we bij elkaar terecht om te overleggen. We zijn samen op PhD-tour geweest en op schijfweek, letterlijk een week in een huisje op de 'heideheuvel' waar ik het grootste gedeelte van mijn introductie en discussie heb geschreven.

Alle kamergenootjes die ik heb gehad in de afgelopen 4 jaar, en dat zijn er nogal wat: Margot, Dieuwertje, Roland, Bart, Tim, Jean, Sofie, Stefan, Tanya, Kristin en Cindy. Bedankt voor de gezelligheid, de discussies en de korte of langere pauzes! Alle collega's van Wageningen, bedankt voor alle gezellige lunches en theepauzes. Een PhD-student kan niet zonder! ledere keer dat ik in Wageningen ben, kom ik tijd tekort om met iedereen bij te praten. ledereen die mee is geweest op de PhD-tour in de VS, wat een ervaring! Bedankt! Alle collega's van Maastricht, bedankt voor jullie gezelligheid en kritische blik. Vooral van de etentjes en de stapavonden heb ik erg genoten, die houden we erin!

Lucy, bedankt voor de ontelbare bloedsamples die je hebt genomen voor het D-status onderzoek. Van het kleinste kamertje tot de meest luxe stadions, op de gekste plaatsen stond jij klaar. Zonder jouw ervaring en flexibiliteit was het D-status onderzoek niet mogelijk geweest. Anita, Jantien, Diana, en Henriëtte, voor mijn eerste onderzoeken zijn ruimten verbouwd en materialen aangeschaft. Bedankt dat jullie dit mogelijk hebben gemaakt. Karin, Pauline en alle andere diëtisten die bij Protect betrokken waren, wat een werk hebben jullie verzet! Bedankt! Adriënne en Karen, bedankt voor jullie support tijdens de afgelopen jaren. Joan, Janneau, Rachel, Joy, Antoine, Desiree en Cleo, wat is M3 zonder jullie? Bedankt voor het helpen bij de organisatie van de studies, de analyses en alle keren dat ik met vragen bij jullie terecht kon.

De studenten die mij hebben geholpen bij het praktisch werk; Wicher, Dominique, Wesselien, Carliene, Rinske, Manon, Nick, Mark, Cindy, Maaike, Gerjanne, Mariska, Nina en Charlotte. Ik hoop dat jullie een leuke en leerzame tijd hebben gehad. Bedankt voor al jullie werk!

Knotsbalteam 'de Voedingsmiepen', Annemarie, Marjolein, Margien, Ilse, Aafke, Liset, Natalie en Lien, ondanks dat we geen knotsbal-talenten waren, samen eten en stappen kunnen we als de beste! Jullie doorzettingsvermogen, ambitie en inzet werkt aanstekelijk. Bedankt dat jullie altijd voor me klaarstonden en de nodige afleiding boden

Uros-meiden, Laura, Laura, Esther, Esther, Marloes, Çarcia, Audrey en Eveline, bij jullie hoef ik geen blad voor de mond te houden. Wie weet kunnen alle discussies nog helpen tijdens mijn verdediging! Fijn dat ik altijd alle leuke en minder leuke dingen kon delen.

Af en toe is het prettig om van andere AIO's horen dat het bij hen ook niet vanzelf gaat, Eveline en Martin, bedankt voor de nuchtere blik en jullie hilarische verhalen. Aan Martin heb ik zelfs mijn nieuwe baan te danken, daar zullen we nog regelmatig op proosten!

Pap en mam, jullie pientje die promoveert, dat hadden jullie waarschijnlijk niet verwacht. Heel stellig was ik, na de middelbare school wilde ik niet gaan studeren. Pas toen jullie aangaven dat dat 'oké' was, kon ik op zoek naar wat ik echt wilde doen: de studie Bewegingswetenschappen. Tijdens mijn studie wilde ik zeker geen onderzoek gaan doen. Gelukkig kennen jullie mij beter dan ikzelf. Toen ik twijfelde over een PhD-positie, waren jullie wijze woorden dan ook dat ik het vooral niet voor jullie hoefde te doen. 'Doe wat je leuk vindt', en dat heb ik gelukkig altijd gedaan.

Annemiek en Rik, bedankt voor jullie interesse en luisterend oor. Jammer dat mijn logeerkamer nu wordt verbouwd, maar wat leuk dat er binnenkort nog een BackxKerremans in de familie komt! Miek, ik vind het ontzettend fijn dat je, zelfs hoogzwanger, samen met mij op het podium wilt staan tijdens mijn verdediging!

Andy, you made my time as a PhD-student so much better. Your unlimited support is invaluable. I respect and envy your talent for science. Our scientific discussions are useful, our holidays fun but just being with you is what makes me really happy. 


\section{About the author}

Curriculum Vitae

List of publications and presentations Overview of completed training activities 


\section{Curriculum Vitae}

Evelien Backx was born on January 7th, 1988 in Breda, the Netherlands. After completing secondary school at Onze Lyceum Vrouwelyceum in Breda in 2006, she started studying Health Sciences at Maastricht University with a major in Human Movement Sciences. During her BSc degree, Evelien went to the Helsinki University to complete 3 months of her courses abroad. For her BSC thesis, she studied the effect of leucine supplementation on muscle mass and glycemic control in elderly, type 2 diabetic men. Following her BSc degree, she moved to Wageningen to pursue her MSc degree in Nutrition and Health at Wageningen University. In 2012, Evelien completed her MSc thesis entitled: 'Effect of arginine-rich dietary protein on postprandial arterial stiffness'. After her MSc thesis, she did a 4-month internship on the topic of 'hydration and dehydration in military personnel and athletes' at the department of Training Medicine and Training Physiology of the Royal Dutch Army, Ministry of Defence in Utrecht. After working as a research assistant, Evelien started her own PhD-project. During her PhD, she conducted 4 large human intervention studies aimed at attenuating the loss of muscle mass during atrophic conditions. Most of her PhD-projects were in collaboration with food companies or the Netherlands Olympic Committee and Netherlands Sports Federation. Along with her PhD research, Evelien also taught at the BSc and MSc level and attended several (international) conferences and courses within the education program of the VLAG graduate school. In September 2016, Evelien started as a teacher at the Fontys University of Applied Sciences in Eindhoven. 


\section{Publications}

\section{Peer reviewed publications}

Backx EMP, Tieland M, Borgonjen-van den Berg KJ, Claessen P, van Loon LC, de Groot CPGM. Protein intake and lean body mass preservation during energy intake restriction in overweight older adults. International Journal of Obesity 2016 Feb; 40(2):299-304.

Dirks ML, Backx EMP, Wall BT, Verdijk LB, van Loon LC. May bed rest cause greater muscle loss than limb immobilization? Acta Physiologica 2016 Sep;218(1):10-2.

Backx EMP, Tieland M, Maase K, Kies AK, Mensink M, van Loon LC, de Groot CPGM. The impact of one year vitamin $D$ supplementation on vitamin $D$ status in athletes: a dose response study. European Journal of Clinical Nutrition 2016 Sep;70(9):1009-14.

Backx EMP, van der Avoort C, Tieland M, Maase K, Kies AK, van Loon LC, de Groot CPGM, Mensink M. Seasonal variation in Vitamin D status in elite athletes: a longitudinal study. International Journal of Sport Nutrition and Exercise Metabolism e-pub: 2016 Oct 6:1-15.

Submitted for publication

Backx EMP, Hangelbroek R, Snijders T, Verscheijden M, Verdijk LB, de Groot CPGM, van Loon LJC. Creatine loading does not preserve muscle mass or strength during leg immobilization in healthy, young males. Submitted.

\section{Abstracts and presentations}

Backx EMP, Hangelbroek R, Snijders T, Verscheijden M, Verdijk LB, de Groot CPGM, van Loon LJC. The effect of creatine loading on muscle disuse atrophy.

Oral presentation at the ECSS Annual Congress. Vienna, Austria, July 2016. Nominated for the Young Investigators Award

Backx EMP, Tieland M, Borgonjen-van den Berg KJ, Claessen P, van Loon LC, de Groo CPGM. Protein intake and lean body mass preservation during energy intake restriction in overweight older adults. Oral presentation at the Annual Conference TI Food and Nutrition, Wageningen, May 2016. Nominated for the TIFN publication prize.
Backx EMP, Tieland M, Borgonjen-van den Berg KJ, Claessen P, van Loon LC, de Groot CPGM. Protein intake and lean body mass preservation during energy intake restriction in overweight older adults. Poster presentation at the symposium: Breakthroughs in understanding central and peripheral pathways in obesity. Rockefeller University New York, United States, October 2015.

Backx EMP, Tieland M, Maase K, Kies AK, Mensink M, van Loon LC, de Groot CPGM. Yearlong vitamin $D$ supplementation on vitamin $D$ status in athletes - A dose response study. Oral presentation at the Johns Hopkins University, Baltimore, United States, October 2015.

Backx EMP, Tieland M, Maase K, Kies AK, Mensink M, van Loon LC, de Groot CPGM. Yearong vitamin D supplementation on vitamin D status in athletes - A dose response study. Oral presentation at the ECSS Annual Congress, Malmö, Sweden, July 2015.

Backx EMP, Tieland M, Maase K, Kies AK, Mensink M, van Loon LIC, de Groot CPGM. Impact of vitamin $D$ supplementation on vitamin $D$ status in athletes.

Poster presentation at the ACSM Annual Conference, San Diego, United States, May 2015.

Backx EMP, Tieland M, Borgonjen-van den Berg KJ, Claessen P, van Loon LJC, de Groot CPGM. Does a high protein diet preserve lean body mass during energy intake restriction in overweight older adults? Oral presentation at the Annual Conference TI Food and Nutrition, Unilever Vlaardingen, May 2015. Nominated for the TIFN poster prize.

Backx EMP, Tieland M, Borgonjen-van den Berg KJ, Claessen P, van Loon LC, de Groot CPGM. Increasing protein intake does not preserve lean mass during energy intake restriction.

Poster presentation at the NUTRIM Symposium, Maastricht, December 2014. Nominated for the NUTRIM poster prize

Backx EMP, Tieland M, Borgonjen-van den Berg KJ, Claessen P, van Loon LJ, de Groot CPGM. Does a high protein diet preserve lean body mass during energy intake restriction in overweight older adults? Oral presentation at the ECSS Annual Congress, Amsterdam, July 2014. Nominated for the Young Investigators Award.

Backx EMP, Tieland M, Borgonjen-van den Berg KJ, Claessen P, van Loon LJC, de Groot CPGM. Increasing protein intake does not preserve lean body mass during caloric restriction in overweight people.

Oral presentation at the Nutritional Science Days, Deurne, Oct 2013. 


\begin{tabular}{|c|c|c|}
\hline Discipline specific activities & Organizer and Location & Year \\
\hline \multicolumn{3}{|l|}{ Courses and workshops } \\
\hline Nutritional Science Days & NWO, Deurne & 2012 \\
\hline ECSS pre-conference & GSSI, Bruges & 2012 \\
\hline Nutritional Science Days & NWO, Deurne & 2013 \\
\hline Annual Conference & ECSS, Amsterdam & 2014 \\
\hline Annual Symposium & NUTRIM, Maastricht & 2014 \\
\hline Annual Conference & TIFN, Vlaardingen & 2015 \\
\hline Annual Conference & ACSM San Diego & 2015 \\
\hline Annual Congress & ECSS Malmö & 2015 \\
\hline Annual Symposium & NUTRIM, Maastricht & 2015 \\
\hline Annual Conference & ECSS, Vienna & 2016 \\
\hline \multicolumn{3}{|l|}{ General courses and workshops } \\
\hline $\begin{array}{l}\text { Wet regelgeving omtrent wetenschappelijk } \\
\text { onderzoek }\end{array}$ & ZGV, Ede & 2012 \\
\hline Mixed models course & WUR, Wageningen & 2013 \\
\hline MBTI Workshop & TIFN, Den Bosch & 2013 \\
\hline PhD week & VLAG, Wageningen & 2013 \\
\hline Data Management & WGS, Wageningen & 2013 \\
\hline Venapuncture & MUMC+, Maastricht & 2014 \\
\hline Good Clinical Practice (GCP) course & MUMC+, Maastricht & 2014 \\
\hline Project \& Time Management & WGS, Wageningen & 2014 \\
\hline PBL course (tutor course) & UM, Maastricht & 2014 \\
\hline \multicolumn{3}{|l|}{ Optional courses and activities } \\
\hline Expertmeetings Weight Management & TIFN, Wageningen & $2012-2015$ \\
\hline Staff seminars & Wageningen & $2013-2014$ \\
\hline Expertmeetings Muscle and Health & TIFN, Wageningen & $2013-2016$ \\
\hline Preparation PhD research proposal & WUR, Wageningen & 2013 \\
\hline 25 jaar ouderenonderzoek & WUR, Wageningen & 2013 \\
\hline We days Weight Management TIFN & TIFN, Wolfheze & 2014 \\
\hline Midterm review Muscle and Health & TIFN, Wageningen & 2014 \\
\hline Research communications & UM, Maastricht & $2015-2016$ \\
\hline Capita Selecta & NUTRIM, Maastricht & $2015-2016$ \\
\hline Journal Club meetings & UM, Maastricht & $2015-2016$ \\
\hline Information meeting cast room & UM, Maastricht & 2015 \\
\hline PhD Tour & HNE, USA & 2015 \\
\hline
\end{tabular}


The studies presented in this thesis were performed within the framework of TI Food and Nutrition (TIFN).

Financial support from Wageningen University, TIFN and Nutricia Research for printing this thesis is gratefully acknowledged.

\section{Cover design Remko Rinia}

Layout Evelien Backx

Printed by Digiforce, Proefschriftmaken.nl, Vianen NL.

Copyright@ $\quad$ Evelien Backx, 2016 
